\author{
Universidade de São Paulo \\ Instituto de Física
}

\title{
Dinâmica de Estados Excitados e Propriedades Espectroscópicas de Derivados de DNA/RNA Naturais e Sintéticos em Meio Solvente
}

\author{
Danillo Pires Valverde
}

Orientador: Prof. Dr. Sylvio Roberto Accioly Canuto

Tese de doutorado apresentada ao Instituto de Física da Universidade de São Paulo, como requisito parcial para a obtenção do título de Doutor em Ciências.

\footnotetext{
Banca Examinadora:

Prof. Dr. Sylvio Roberto Accioly Canuto (IFUSP) Sylvio Camito

Profa. Dra. Lucy Vitoria Credidio Assali (IFUSP)

Prof. Dr. Lucas Collucci Ducati (IQUSP)

Prof. Dr. Tertius Lima da Fonseca (IF/UFG)

Prof. Dr. André Luiz Barboza Formiga (IQ/UNICAMP)
} 
FICHA CATALOGRÁFICA

Preparada pelo Serviço de Biblioteca e Informação do Instituto de Física da Universidade de São Paulo

Valverde, Danilo Pires

Dinâmica de estados excitados e propriedades espectroscópicas de derivados de DNA/RNA naturais e sintéticos em meio solvente. São Paulo, 2020.

Tese (Doutorado) - Universidade de São Paulo. Instituto de Física. Depto. de Física Geral

Orientador: Prof. Dr. Sylvio Roberto Accioly Canuto

Área de Concentração: Física Atômica e Molecular.

Unitermos: 1. Fotoquímica; 2. Fotoluminescência; 3. Estrutura eletrônica; 4. Espectroscopia; 5. Solvatação.

USP/IF/SBI-083/2020 


\title{
University of São Paulo
}

Physics Institute

\section{Excited State Dynamics and Spectroscopic Proprieties of Natural and Synthetic DNA/RNA Derivatives in Solvent Environment}

\author{
Danillo Pires Valverde
}

Supervisor: Prof. Dr. Sylvio Roberto Accioly Canuto

Thesis submitted to the Physics Institute of the University of São Paulo in partial fulfillment of the requirements for the degree of Doctor of Science.

Examining Committee:

Prof. Dr. Sylvio Roberto Accioly Canuto (IFUSP)

Profa. Dra. Lucy Vitoria Credidio Assali (IFUSP)

Prof. Dr. Lucas Collucci Ducati (IQUSP)

Prof. Dr. Tertius Lima da Fonseca (IF/UFG)

Prof. Dr. André Luiz Barboza Formiga (IQ/UNICAMP) 

Dedico esse trabalho à minha esposa Sueny e aos meus familiares. 



\section{Agradecimentos}

A jornada para a obtenção do título de Doutor em Ciências foi bastante árdua e repleta de obstáculos. Esse sonho começou a dez anos atrás quando decidi cursar o bacharelado em Física (IF-UFG). Nunca foi o melhor da minha turma, mas sempre fui um dos mais esforçados, sendo essa uma das características que trago até hoje e que me fizeram persistir nessa caminhada. Vim fazer doutorado na Universidade de São Paulo, que é reconhecida como uma das melhores universidades da América Latina, no intuito de expandir os meus horizontes e em buscas de novos desafios. Sinto o gosto de dever cumprido e nessa trajetória do doutorado várias pessoas contribuíram diretamente ou indiretamente para a tese e merecem ser mencionadas.

Inicialmente, agradeço o incentivo e apoio da minha família. Em especial, gostaria de agradecer a minha mãe, que foi de fundamental importância durante todo a minha vida estudantil e permitiu que eu pudesse trilhar essa carreira. Outra pessoa que não poderia ficar de fora é a minha esposa Sueny, que sempre apoiou as minhas decisões e sempre esteve comigo nos momentos bons e ruins. Passamos por inúmeros problemas desde da nossa chegada em São Paulo. Sei que os seis meses que fiquei fora não foram fáceis para você e que não pude estar ao seu lado para te apoiar em um dos momentos mais difíceis da sua vida.

Agradeço ao Prof. Dr. Sylvio Canuto por ter me aceitado no seu grupo de pesquisa e ter me orientado nesses anos de doutorado. Mesmo repleto de compromissos, você sempre esteve presente e pronto para sanar as minhas dúvidas e questionamentos. Obrigado pela confiança depositada em mim e espero não tê-lo desapontado.

Agradeço ao Prof. Dr. Antonio Carlos Borin, que foi como um coorientador nessa tese. Infelizmente, o seu nome não pode estar na tese, mas fica os meus singelos agradecimentos. Você desempenhou um papel importante nesta tese e sempre me deu importantes conselhos, que vão além da vida acadêmica. Você me mostrou uma área de pesquisa formidável e me mostrou como é ser um cientista. Sempre tentei retribuir essa ajuda que você me deu e sinto que ainda estou em dívida com você.

Gostaria de agradecer aos amigos que fiz em Viena (Davide, Moritz, Julia, Sandra, Pedro, Nadja, Jin, entre outros). As discussões não somente sobre a vida acadêmica na hora do café foram bastante enriquecedoras. Os jogos e passeios depois do expediente nas quartas faziam o resto da semana bem mais animador. Foi uma estadia maravilhosa. Em especial, agradeço à Profa. Dra Leticia González por ter me aceitado no seu grupo de pesquisa, que é um dos mais renomados grupos no contexto de dinâmica de estados excitados. Essa experiência 
que tive no seu grupo, podendo aprender uma área de pesquisa formidável, vou levar para o restante da minha vida. Também agradeço ao Dr. Sebastian Mai que me ensinou as nuâncias do programa SHARC e sempre esteve disposto a explicar e ensinar, tentando passar o máximo de conhecimento. Você é uma inspiração para mim como pesquisador e espero em breve ter várias publicações com você.

Sou bastante grato aos amigos do Grupo de Física Molecular e Modelagem pelas discussões e sugestões. Agradeço aos profs. Dr. Marcio Varella e Dra Kaline Coutinho pelas dicas e sugestões nos seminários de grupo. Em especial, aos amigos que bandejaram comigo nesses últimos anos (Tárcius, Henrique, Ricardo, Arthur, Matheus, Júlio, entre outros). Além desses, agradeço ao Dr. Leandro Rezende pela sua amizade desde dos tempos de graduação. Suas sugestões e discussões ao decorrer do doutorado contribuíram bastante para a escrita da tese. Você estendeu inúmeras vezes a sua mão para ajudar eu e a Sueny. Se fosse escrever todas essas ajudas, não teria espaço para outros agradecimentos. Viemos para São Paulo com o mesmo ideal e também espero ter contribuído para a sua tese.

Agradeço ao membros do grupo de Fotofísica Computacional (Gustavo, Leonardo, Roiney, Eduardo, Yeny e Daniely) pela ótima convivência, discussões e conversas durante esses últimos anos. Também fico grato pelas amizades que fiz na química (Patrick, Natália, Ivana, entre outros). Sobretudo, agradeço ao Adalberto de Araújo pelas frutíferas colaborações. Publicamos três artigos juntos e foi muito proveitosa essa parceria. Aprendi bastante coisas com você, principalmente sobre insights químicos. Espero no futuro ter mais colaborações e artigos com você e em breve poder chamá-lo de Dr. Adalberto de Araújo.

Agradeço as membros da banca de Qualificação e de Doutorado pelas dicas e sugestões que enriquecerem ainda mais o trabalho.

Agradeço à Fundação de Amparo à Pesquisa do Estado de São Paulo (FAPESP) pela bolsa de doutorado no país desde 2017 (processo 2017/02612-4), que foi de fundamental importância para o desenvolvimento deste trabalho, além de fomentar o meu intercâmbio em 2019 para a Universidade de Viena (processo 2019/04413-4) em um dos melhores grupos de pesquisa no contexto de simulação de dinâmica de estados excitados. Também agradeço ao Conselho Nacional de Desenvolvimento Científico e Tecnológico (CNPq) por fomentar o meu primeiro ano de bolsa.

Agradeço ao centro de computação de computação HPC-USP (High Performance Computing of USP), sistema de computação petaflópica do SINAPAD (SDumont) e Vienna Scientific Cluster pelos recursos computacionais.

Finalmente, agradeço ao Instituto de Física da Universidade de São Paulo por proporcional um ambiente de agradável convivência. 
"A ciência nunca resolve um problema sem criar pelo menos outros dez" George Bernard Shaw 



\section{Resumo}

A fotofísica e a fotoquímica de sistemas moleculares representam uma ampla área da físicoquímica, que se preocupa com os efeitos da luz em moléculas. Nesse contexto, bases modificadas do DNA/RNA podem exibir caminhos de relaxação fotofísicos bastante distintos das suas análogas naturais, que são não fluorescentes e possuem um tempo de vida do estado excitado bastante curto. $\mathrm{O}$ objetivo dessa tese é a elucidação dos principais mecanismos de desativação após a absorção de luz de bases modificadas do DNA/RNA em fase gasosa. Os efeitos de solvente também são considerados, seja de maneira implícita (Modelo Contínuo Polarizável (PCM) e Solvent Model Density (SMD)) ou por meio explícito com as configurações geradas por Dinâmica Molecular Clássica ou amostragem de Monte Carlo. A abordagem estática e dinâmica não-adiabática são empregadas para explicar os caminhos fotofísicos mais viáveis.

O primeiro sistema estudado é um promissor alfabeto ribonucleosídeo fluorescente. Todos os compostos desse alfabeto fluorescem a partir da estrutura ${ }^{1}\left(\pi \pi^{*}\right)_{\min }$, porém a explicação para a fluorescência depende da molécula. No caso das moléculas purínicas, a fluorescência ocorre devido a um deslocamento para o vermelho no espectro de absorção, impedindo que a cônica com o estado fundamental $\left({ }^{1}\left(g s / \pi \pi^{*}\right)_{\mathrm{Cl}}\right)$ seja acessada. Por outro lado, a estrutura

${ }^{1}\left(g s / \pi \pi^{*}\right)_{\text {CI }}$ para as moléculas pirimidínicas é localizada em uma alta região energética.

Posteriormente, é estudado os efeitos de solvente nas propriedades dos estados excitados eletrônicos da 2-aminopurina (2AP), uma análoga bem conhecida da adenina. A aproximação ASEC-FEG, que combina a metodologia Sequential Quantum Mechanics/Molecular Mechanics e o gradiente de energia livre, descreve corretamente as propriedades espectroscópicas (absorção, emissão e fluorescência) dessa molécula em todos os solventes empregados. Em relação aos trabalhos teóricos anteriores, é obtido um melhor desvio solvatocrômico de 1,4-dioxano para água para o deslocamento Stokes. Além disso, é estimado a diferença de energia livre entre os dois tautômeros da $2 \mathrm{AP}$ nos estados fundamental e primeiro estado excitado ${ }^{1}\left(\pi \pi^{*}\right)$ em etanol e em solução aquosa.

Por fim, é estudado uma substituição simples da guanina que suprime a conversão interna para o estado fundamental e amplifica o cruzamento intersistemas com os estados tripletos. $O$ sistema inicialmente popula o estado singleto $S_{2}$ e rapidamente transfere a população para o estado $S_{1}$. Esse estado serve como uma porta de entrada para a população dos estados tripletos. O espectro de absorção transiente (TAS) foi simulado a fim de poder comparar com os dados experimentais disponíveis. Duas constantes de tempo associadas ao processo de cruzamento intersistemas (ISC) são extraídas, e ambas se encontram em bom acordo com o experimento. Uma explicação do motivo dessa molécula possuir um tempo de vida mais curto do estado tripleto em relação à sua análoga tiobase é também descrita em detalhes.

Palavras-chaves: Bases Canônicas Modificadas. Fotofísica e Fotoquímica. Efeitos de Solvente. Dinâmica de Estados Excitados. 



\section{Abstract}

Photophysics and Photochemistry of molecular systems represent a wide area of physical chemistry, which is concerned with the effects of light on molecules. In this context, modified nucleobases may exhibit photophysical relaxation paths quite distinct from those observed for their respective natural analogues, which are not fluorescent and have an ultrafast excited-state lifetime. The objective of this thesis is to elucidate the main deactivation pathways after the absorption of light of modified bases of DNA/RNA in gas phase. Solvent effects are also considered, either by implicit solvation (Polarizable Continuum Model (PCM) and Solvent Model Density (SMD)) or by explicit solvation extracting the configurations from Classical Molecular Dynamics Simulations and Monte Carlo Metropolis sampling. Static approach and non-adiabatic dynamics are performed in order to explain the feasible photophysical paths.

The first system studied consists of a promising fluorescent ribonucleoside alphabet. All compounds in this alphabet fluoresce from the structure ${ }^{1}\left(\pi \pi^{*}\right)_{\min }$, but the explanation why these molecules are fluorescent depends on the molecule. In the case of purine molecules, the fluorescence occurs due to a red shift in the electronic absorption spectrum, avoiding the accessibility to the conical intersection with the ground state $\left({ }^{1}\left(g s / \pi \pi^{*}\right) \mathrm{cl}\right)$. In turn, the ${ }^{1}\left(g s / \pi \pi^{*}\right)_{\text {Cl }}$ structure for the pyrimidine molecules is located in a high energy region.

Subsequently, it is studied the effects of solvent on the properties of the excited electronic states of 2-aminopurine (2AP), a well-known analogue of adenine. The ASEC-FEG approach, which combines the Sequential Quantum Mechanics/Molecular Mechanics methodology and the free energy gradient method, correctly describes the spectroscopic properties (absorption, emission and fluorescence) of this molecule in all solvents employed. In relation to previous theoretical works, a better solvatochromic shift from 1,4-dioxane to water was reached for the Stokes shift. Additionally, the difference in free energy between both tautomers of the 2AP in the ground and first excited states ${ }^{1}\left(\pi \pi^{*}\right)$ is estimated in ethanol and aqueous solution.

Finally, a simple substitution of guanine that suppresses the internal conversion to the ground state and amplifies the intersystem crossing with the triplet states is studied. The system initially populates the $S_{2}$ singlet state and quickly transfers the population to the $S_{1}$ state. This electronic state acts as a doorway for the population transfer into triplet states. The transient absorption spectrum (TAS) is simulated in order to compare with the available experimental data. Two time-constants are extracted from the simulated TAS spectrum, which are in agreement with experimentally estimated results. An explanation of why this molecule has a shorter lifetime of the triplet state in comparison with its thiobase analogue is also described in detail.

Keywords: Modified Nucleobases. Photophysics and Photochemistry. Solvent Effects. Excited State Dynamics. 



\section{Lista de figuras}

Figura 1.1 - (a) Ilustração do diagrama de Jabłoński, que exemplifica de uma maneira simples os principais mecanismos fotofísicos. No painel (b) é apresentado uma abordagem mais realística utilizando a ideia de superfície de energia potencial (PES) para descrever cada estado excitado eletrônico. . . . . . . 36

Figura 1.2 - Estrutura molecular dos compostos que constitui o DNA. No caso do RNA, a timina é substituída pela uracila. . . . . . . . . . . . . . . . . . . 37

Figura 1.3 - Ilustração do processo envolvido na PDT considerando a fotoreação tipo II. 39

Figura 2.1 - Exemplificação da divisão do espaço de orbitais no método CASSCF para um sistema arbitrário. (a) Os orbitais nesse espaço são inativos e sempre ocupados. (c) Os orbitais são sempre mantidos duplamente ocupados. (b) $\mathrm{O}$ espaço ativo possui dois elétrons ativos em dois orbitais ativos. A ocupação dos orbitais nesse espaço é entre zero e dois. . . . . . . . . . . . . . .

Figura 2.2 - Valores da diferença $I P_{p}-E A_{p}$ para todos os átomos da tabela periódica. A linha horizontal corresponde ao valor adotado para no IPEA $(\epsilon=0.25$ u.a). A figura foi adaptada da referência 81. . . . . . . . . . . . . . . . 55

Figura 3.1 - Ilustração esquemática da equação de movimento na dinâmica de Ehrenfest para um sistema com três estados eletrônicos. Nesse modelo, a trajetória é propagada em um superfície de energia potencial média, que é obtida pela soma sobre todos os estados eletrônicos ponderado pela respectiva população eletrônica. A seta em preto corresponde à trajetória para esse sistema fictício. A Figura foi adaptada da referência 103. . . . . . . . . . . 62

Figura 3.2 - llustração esquemática da equação de movimento na dinâmica ab initio multiple spawning para um sistema com dois estados eletrônicos. Nesse modelo, pacotes de onda gaussianos são propagados em trajetórias clássicas. Na região de acoplamento, existe uma divisão (spawning) do pacote de onda, que é dividido em duas subsequentes funções gaussianas. A Figura foi adaptada da referência 103. 
Figura 3.3 - Comparação entre o (a) pacote de onda quântico e (b) trajetórias SH. No painel (a), o pacote de onda está inicialmente no estado superior, movendose para a direita. Depois do cruzamento evitado, esse pacote de onda é dividido em duas partes. $O$ pacote de onda da parte inferior continua se movendo para a direita, enquanto o o outro é refletido. No painel (b), cinco trajetórias SH são inicialmente promovidas para o estado superior. No cruzamento, três trajetórias saltam (hop) para o estado inferior, a medida que duas trajetórias continuam no mesmo estado e são subsequentemente refletidas. . . . . . . . . . . . . . . . . . . . .

Figura 3.4 - Esboço explicando o problema da decoerência no método SH. A figura mostra uma única trajetória passando por um ponto de cruzamento duplo. Os números nos círculos correspondem à população no respectivo estado em cada etapa de tempo, com o círculo em negrito denotando o estado ativo. No painel (a) não há correção de decoerência, surgindo uma interferência artificial no próximo cruzamento. No painel (b) é aplicado uma correção de decoerência contornando o problema de interferência. . . . . . . . . . . . .

Figura 3.5 - Esboço explicando a técnica ant-eater. Nesse exemplo, o número randômico sorteado cai dentro do intervalo correspondente ao estado 2. Portanto, esse estado é o novo estado ativo, exceto se o hop for frustrado. . . . . . . . . .

Figura 3.6 - Esboço de vários cenários que podem ocorrer durante o ajuste da energia cinética. Nos painéis superiores são mostrados saltos em que a energia potencial do estado ativo (a) diminui durante o salto ou (b) aumenta. No painel (e) é ilustrado um hop frustrado, sendo que a energia total é menor do que a energia potencial do novo estado ativo. Quando um hop frustrado é identificado, o estado ativo não é alterado, mas a vetor velocidade pode ser inalterado (d) ou a componente ao longo do vetor NAC é refletida (e).

Figura 3.7 - Exemplos de curvas de energia potencial para as três representações mais comuns empregadas no método $\mathrm{SH}$. (a) Os estados $\mathrm{MCH}$ são tipicamente calculados em qualquer método de estrutura eletrônica. (b) Os estados diagonais são obtidos pela diagonalização do Hamiltoniano total e (c) os estados espectroscópicos consistem de uma base de estados que não alteram o seu caráter com respeito à coordenada. . . . . . . . . . . . . . . . . .

Figura 3.8 - Passos importantes para a geração das condições iniciais utilizados como ponto de partida para a dinâmica SH. Nos painéis (a) e (b) são exibidos duas maneiras de amostrar as coordenadas no espaço de fase $(\mathbf{R}, \mathbf{v})$. No painel (c) é apresentada como é feita a seleção do estado inicial. Essa etapa é subsequente e define os coeficientes eletrônicos iniciais (c) e o estado

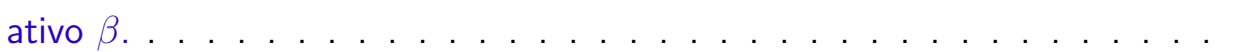


Figura 4.1 - Ilustração dos modelos de Onsager (lado esquerdo) e PCM (lado direito) para a molécula de formaldeído. Os símbolos + e - correspondem às cargas de polarização induzidas na superfície da cavidade. . . . . . . . . . . 76

Figura 4.2 - Ilustração da replicação da caixa de simulação em um sistema bidimensional. 78

Figura 4.3 - Ilustração das partes QM e MM nos modelos híbridos. Veja que nessa divisão existe uma ligação química na região de fronteira. . . . . . . . . . . . . . . 79

Figura 4.4 - Ilustração do modelo ASEC (visão frontal) considerando o meio aquoso. Os pontos vermelhos representam os átomos de oxigênio e os pontos brancos correspondem aos átomos de hidrogênio. Lembrando que cada sítio do solvente é tratado como carga pontual. As regiões de ligação de hidrogênio soluto-solvente são bastante nítidas, visto que é mantido a estrutura do líquido.

Figura 4.5 - Ilustração pictórica de uma superfície de energia potencial, contendo mínimos locais e globais, estados de transição. A linha em azul indica os possíveis caminhos de reação. . . . . . . . . . . . . . . . . . . . . 83

Figura 4.6 - Fluxograma da metodologia ASEC-FEG. . . . . . . . . . . . . . . . . . 85

Figura 4.7 - Ilustração de uma função de autocorrelação da energia com o respectivo ajuste biexponencial. . . . . . . . . . . . . . . . . . . . . 993

Figura 4.8 - Ilustração da estrutura de um líquido atômico através da $g(r)$. Adaptado da referência 180. . . . . . . . . . . . . . . . . . . . . . . . 999

Figura 5.1 - Ilustração do novo alfabeto ribonucleosídeo fluorescente obtido a partir da molécula isotizole[4,3-d]pirimidínica, sendo que a ribose foi substituída por um átomo de hidrogênio. O retângulo com linha azul se refere as moléculas tipo purínicas e com linha vermelha para as moléculas tipo pirimidínica. A numeração atômica será utilizada ao decorrer do texto. Representação atômica: nitrogênio $(\mathrm{N})=$ azul, oxigênio $(\mathrm{O})=$ vermelho e enxofre $(\mathrm{S})=$ amarelo. 96

Figura 5.2 - llustração do espaço ativo utilizado para a molécula ${ }^{\text {tz }} \mathbf{A}$. Nos cálculos de otimização de geometria (fundo amarelo) foi utilizado o espaço $\pi$ completo. Os orbitais $n_{\mathrm{N}}$ foram adicionados para os cálculos de energias de transição vertical (fundo azul). Um espaço ativo equivalente foi adotado para as demais moléculas. . . . . . . . . . . . . . . . . . . . . 98

Figura 5.3 - Ângulo de piramidalização (graus) durante o processo de otimização ASECFEG. O ponto inicial corresponde à geometria na região de Frank-Condon (FC) obtida em fase gasosa. Os pontos vazios correspondem aos valores obtidos na geometria otimizada pelo método PCM. . . . . . . . . . . . . . 100

Figura 5.4 - Função distribuição de pares de mínima distância $\left(G_{m d}(r)\right)$ para o novo alfabeto ribonucleosídeo fluorescente em (a) 1,4-dioxano e (b) água. No lado direito é apresentado uma ilustração da primeira de camada de solvatação para a molécula ${ }^{\mathrm{tz}} \mathbf{A}$. . . . . . . . . . . . . . . . . . . . . . 103 
Figura 5.5 - Ilustração dos critérios geométricos empregados para definição de ligações de hidrogênio, que compreende a distância entre os átomos eletronegativos $\left(R_{\mathrm{XY}}\right)$ e o ângulo formado entre os átomos $X, H$ e $Y\left(\theta_{\mathrm{XY}}\right) . . . .104$

Figura 5.6 - Distribuição de cargas (e) para as moléculas (a) ${ }^{\mathrm{tz}} \mathbf{A},(\mathrm{b}){ }^{\mathrm{tz}} \mathbf{C},(\mathrm{c}){ }^{\mathrm{tz}} \mathbf{G},(\mathrm{d})$ ${ }^{\mathrm{tz}} \mathbf{U}$ e $(\mathrm{e}){ }^{\mathrm{tz}} \mathbf{A}$ em fase gasosa, 1 ,4-dioxano e água. . . . . . . . . . . . 106

Figura 5.7 - Momento de dipolo (Debye) do novo alfabeto ribonucleosídeo fluorescente obtidos em fases gasosa e condensada (1,4-dioxano e água). O momento de dipolo para adenina, citosina [201], guanina [202] e uracila [203] em fase gasosa são obtidos por meio de dados experimentais (símbolos preenchidos). Em solução aquosa, os valores de momento de dipolo para as bases nucléicas são estimadas por simulações QM/MM on the fly (citosina e guanina [204]) e QM/MM sequencial (adenina [205] e uracila [206]) (símbolos preenchidos).107

Figura 5.8 - Transição eletrônica dominante na descrição do primeiro estado excitado (exceto para a molécula ${ }^{\text {tz }} \mathbf{A}$, veja o texto) obtido no nível $\operatorname{SA}(X)-\operatorname{CASSCF}(18,13) /$ ccpVDZ em fase gasosa utilizando a geometria de equilíbrio do estado fundamental. X corresponde ao número de estados excitados incluídos no procedimento state-averaged (veja metodologia). . . . . . . . . . . . 109

Figura 5.9 - Superposição das estruturas otimizadas dos estados fundamental (vermelho) $\mathrm{e}^{1}\left(\pi \pi^{*}\right)$ (azul) para o novo alfabeto ribonucleosídeo fluorescente. As geometrias no estado fundamental foram otimizadas no nível MP2/cc-pVDZ, enquanto o nível MS(2)-CASPT2/cc-pVDZ foi adotado para o estado excitado ${ }^{1}\left(\pi \pi^{*}\right) \ldots \ldots \ldots \ldots \ldots$. . . . . . . . . . . . . . . . . . . . . .

Figura 5.10-Momento de dipolo (Debye) do novo alfabeto ribonucleosídeo fluorescente obtidos em fases gasosa e condensada (1,4-dioxano e água) nos estados fundamental (símbolos preenchidos) e primeiro excitado ${ }^{1}\left(\pi \pi^{*}\right)$ (símbolos vazios). . . . . . . . . . . . . . . . . . . . . . . . . . 114

Figura 5.11-Caminho de menor energia (MEP) à partir da região de $\mathrm{FC}$ ao longo do primeiro estado excitado ${ }^{1}\left(\pi \pi^{*}\right)$ para as moléculas (a) ${ }^{\mathrm{tz}} \mathbf{A},(\mathrm{b}){ }^{\mathrm{tz}} \mathbf{C}$, (c) ${ }^{\mathrm{tz}} \mathbf{G}$, (d) ${ }^{\text {tz }} \mathbf{U}$ e (e) ${ }^{\text {tz }} \mathbf{I}$ calculado no nível SA(2)-CASSCF/cc-pVDZ em fase gasosa. Em cada ponto gerado pelo MEP é recomputado as energias de excitação verticais no nível SS(X)-CASPT2(18,13)/cc-pVDZ . . . . . . . . . . . . . . 118

Figura 5.12-Visão frontal e lateral correspondente à intersecção cônica entre os estados fundamental e primeiro excitado ${ }^{1}\left(\pi \pi^{*}\right)$ para o novo alfabeto ribonucleosídeo fluorescente. As cônicas foram otimizadas em fase gasosa no nível MS(2)CASPT2/cc-pVDZ. O espaço ativo empregado compreende todos os orbitais

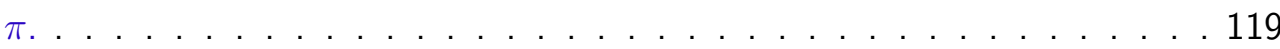


Figura 5.13-Interpolações lineares em coordenadas internas ligando as estruturas ${ }^{1}\left(\pi \pi^{*}\right)_{\min }$ $\mathrm{e}^{1}\left(g s / \pi \pi^{*}\right)$ cl para as moléculas (a) ${ }^{\mathrm{tz}} \mathbf{A}$, (b) ${ }^{\mathrm{tz}} \mathbf{C},(\mathrm{c}){ }^{\mathrm{tz}} \mathbf{G},(\mathrm{d}){ }^{\mathrm{tz}} \mathbf{U}$ e (e) ${ }^{\mathrm{tz}} \mathbf{I}$. Em cada geometria gerada através da técnica LIIC é calculado as energias de excitação verticais no nível SS(X)-CASPT2(18,13)/cc-pVDZ. . . . . . . . 122

Figura 5.14-Ilustração da fotofísica do novo alfabeto ribonucleosídeo fluorescente. . . 124

Figura 6.1 - Estrutura química da molécula 9H-2-aminopurina (9H-2AP) e seu respectivo

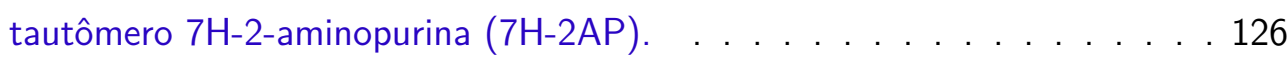

Figura 6.2 - Espaço ativo adotado para os cálculos das energias verticais da molécula $9 \mathrm{H}$ 2AP (fundo azul). O espaço contendo todos os orbitais $\pi$ (fundo amarelo) foi adotado para as otimizações de geometria do estado excitado mais baixo. Um espaço ativo similar para o tautômero $7 \mathrm{H}-2 \mathrm{AP}$ foi empregado. . . . . . 127

Figura 6.3 - Ciclo termodinâmico hipotético para obtenção da diferença de energia livre entre os dois tautômeros da molécula 2AP em solução. . . . . . . . . . . . 128

Figura 6.4 - Comprimentos de ligação $(\AA)$ para a molécula $9 \mathrm{H}$-aminopurina que foram mais susceptíveis a inclusão dos efeitos de solvente para o (a) estado fundamental e (b) primeiro estado excitado. A geometria no estado fundamental foi otimizada no nível MP2/ANO-L-VDZP, enquanto o método MS(2)CASPT2(12,10)/ANO-L-VDZP foi empregado na otimização do primeiro estado $^{1}\left(\pi \pi^{*}\right)$. . . . . . . . . . . . . . . . . . . . . . 131

Figura 6.5 - Função distribuição de mínima distância para os estados fundamental e ${ }^{1}\left(\pi \pi^{*}\right)_{\min }$ para a 2-aminopurina em diversos solventes. . . . . . . . . . . 132

Figura 7.1 - Estruturas esquemáticas e numeração para a guanina (lado esquerdo) e 6-selenoguanina (lado direito). . . . . . . . . . . . . . . . . . . . 142

Figura 7.2 - Espaços ativos adotados durante os cálculos MS-CASPT2/cc-pVDZ. Os orbitais moleculares com fundo amarelo são utilizados para as otimizações de geometria (CAS $(12,10))$ e com fundo azul para os cálculos de energias

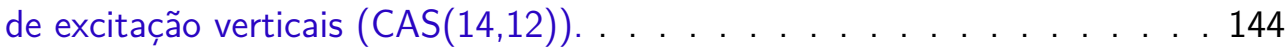

Figura 7.3 - Procedimento esquemático para geração das condições iniciais para a dinâmica de estados excitados. O primeiro passo consiste de uma dinâmica molecular clássica, na qual é salva um total de 500 snapshots no regime de produção. Em seguida, é realizado uma dinâmica QM/MM para os estados fundamental e excitado. Condições iniciais para a dinâmica de estados excitados são selecionadas considerando uma janela de excitação. . . . . . . 146

Figura 7.4 - Estruturas de mínimo e cruzamentos de energia mínima em fase gasosa para a molécula 6SeGua computada nos níveis ADC(2)/cc-pVDZ e MSCASPT2 $(12,10) /$ cc-pVDZ. As geometrias são agrupadas de acordo com os parâmetros de Cremer-Pople e Boyens. Os índices ADC2 e PT2 indicam que um ponto crítico otimizado é rotulado em uma classificação de Boyens distinta pela mudança no nível de mecânica quântica. . . . . . . . . . . . 150 
Figura 7.5 - Interpolações lineares em coordenadas internas conectando geometrias de mínimo e pontos de cruzamento de energia mínima computadas nos níveis (a) ADC(2)/cc-pVDZ e (b)MS-CASPT2(14,12)//MS-CASPT2(12,10)/ccpVDZ. Os caminhos de relaxação são indicados com círculos pretos abertos, mínimos com círculos pretos e pontos de cruzamento com X. As setas pretas mostram a excitação vertical a partir da região de FC para o segunto estado excitado singleto. SOCs entre pontos de cruzamentos relacionado ao ISC são exibidos em $\mathrm{cm}^{-1}$. . . . . . . . . . . . . . . . . . . . . . 153

Figura 7.6 - Espectro de absorção eletrônico da molécula 6SeGua embebida em água baseado na amostragem de 500 configurações advindas de uma dinâmica QM/MM no estado fundamental. Em cada snapshot, um total de 15 estados singletos são considerados no nível $\operatorname{ADC}(2) / c c-p V D Z$. A região em cinza denota a janela de excitação $(3.95$ - 4.05 eV; 345 - $359 \mathrm{~nm})$ para seleção das condições iniciais para os cálculos de dinâmica não-adiabática. . . . . . . 155

Figura 7.7 - (a) Evolução temporal da população dos estados de excitados para um ensemble compreendo 99 trajetórias. Os painéis (b) e (c) refletem o número de hops líquidos e o ajuste das constantes temporais, respectivamente . . . 156

Figura 7.8 - (a) Espectro de absorção transiente experimental [269], (b) espectro de absorção transiente simulado para específicos tempos, (c) evolução temporal do espectro de absorção transiente e (d) integração do espectro de aborção transiente juntamente com o respectivo ajuste exponencial. . . . . . . . . . 158

Figura 7.9 - População média de elétrons (buracos) deixando (chegando) no átomo de selênio oriunda de um ensemble de 99 trajetórias. As constantes temporais são ajustadas empregando um ajuste biexponencial. . . . . . . . . . . . . . 159

Figura 7.10-(a) Função de distribuição radial de pares $(g(r))$ entre $\mathrm{Se}_{\text {soluto }}-\mathrm{H}_{\text {solvente }}$ no estado fundamental (linha verde) e estado excitado (linha preta). Para o estado excitado, uma média sobre 99 trajetórias é considerado. (b) Evolução temporal da $g(r)$ levando em conta todas as trajetórias. A diferença na $g(r)$ $(\Delta g(r))$ é obtida usando como referência o valor médio da $g(r)$ no estado fundamental. Tempos negativos correspondem ao estado fundamental e tempos positivos para o estado excitado. . . . . . . . . . . . . . 160

Figura 7.11-Evolução temporal da (a) comprimento de ligação $C=S e$, ângulo de piramidalização (b) $p_{11,6,1,5}$ e (c) $p_{11,3,1,5}$ a partir de um ensemble de 99 trajetórias. Os painéis do lado esquerdo mostram a evolução temporal das mesmas coordenadas consideradas todas as 500 trajetórias propagadas no estado fundamental por meio de simulações de dinâmica QM/MM. . . . . . . . . 161 
Figura 7.12-Evolução temporal de alguns modos vibracionais da 6SeGua no estados fundamental (tempo negativo) e excitados (tempo positivo). A linha em preto representa a média sobre um ensemble de 99 trajetórias. O valor da frequência na região de FC é também reportada. . . . . . . . . . . . . . . 162

Figura 7.13-Interpolações lineares em coordenadas internas ligando as estruturas $\left(T_{1}\right)_{\min }$ e $\left(T_{1} / S_{0}\right)$ ISC para (a) 6-tioguanina e (b) 6-selenoguanina em fase gasosa e em água. O modelo PCM é introduzido para levar em conta os efeitos de solvente. Em cada estrutura gerada a partir da varredura LIIC é seguida por cálculos de energias de excitação vertical no nível MS-CASPT2(14,12)/ccpVDZ . . . . . . . . . . . . . . . . . . . . . 163

Figura 8.1 - llustração das partes QM e MM utilizadas na inserção da molécula 6selenoguanina no DNA. Duas regiões QM estão sendo consideradas. A primeira delas compreende apenas a $6 \mathrm{SeG}$ e a outra inclui o respectivo par de base (citosina) . . . . . . . . . . . . . . . . . . 166

Figura A.1 - Espaço ativo para a molécula ${ }^{\mathrm{tz}} \mathbf{G}$ com 3 orbitais $n$ e 10 orbitais $\pi$, contendo 18 elétrons calculado no nível SA(8)-CASSCF/cc-pVDZ. . . . . . . . . . . 191

Figura A.2 - Espaço ativo para a molécula ${ }^{\mathrm{tz}} \mathbf{G}$ com 3 orbitais $n$ e 10 orbitais $\pi$, contendo 18 elétrons calculado no nível SA(8)-CASSCF/cc-pVDZ. . . . . . . . . . . 192

Figura A.3 - Espaço ativo para a molécula ${ }^{\mathrm{tz}} \mathbf{U}$ com 3 orbitais $n$ e 10 orbitais $\pi$, contendo 18 elétrons calculado no nível SA(8)-CASSCF/cc-pVDZ. . . . . . . . . . . 192

Figura A.4-Espaço ativo para a molécula ${ }^{\mathrm{tz}} \mathbf{I}$ com 3 orbitais $n$ e 10 orbitais $\pi$, contendo 18 elétrons calculado no nível SA(8)-CASSCF/cc-pVDZ. . . . . . . . . . . 193

Figura C.1 - Caminho de menor energia (MEP) a partir da região de $\mathrm{FC}$ em direção à estrutura ${ }^{1}\left(\pi_{\mathrm{Se}} \pi_{8}^{*}\right)_{\min }$ para a 6 SeGua calculada no nível SA(4)-CASSCF $(12,10) /$ ccpVDZ. Em cada estrutura gerada do MEP foi seguida por um cálculo vertical no nível MS(4,3)-CASPT2(14,12)/cc-pVDZ. 



\section{Lista de tabelas}

Tabela 5.1 - Comprimentos de ligação $(\AA)$ das bases modificadas do RNA otimizadas em fase gasosa, 1,4-dioxano e água. As geometrias otimizadas em meio solvente foram obtidas com as aproximações PCM e ASEC-FEG no nível MP2/ccpVDZ. Valores experimentais também foram incluídos para comparação. . 101

Tabela 5.2 - Estatística percentual de ligações de hidrogênio soluto-solvente para as bases modificadas do RNA em 1,4-dioxano e água. . . . . . . . . . . . . . 104

Tabela 5.3 - Número médio de ligação de hidrogênio em cada sítio que é susceptível a fazer ligação de hidrogênio em solvente para o alfabeto ribonucleosídeo fluorescente. . . . . . . . . . . . . . . . . . . 105

Tabela 5.4 - Comparação entre experimento (Exp.[183]) e cálculos de energias de excitação verticais $(\Delta E, \mathrm{eV})$ para o novo alfabeto ribonuclesídeo fluorescente em fase gasosa, 1,4-dioxano e água. A força de oscilador $(f)$ para cada transição também é reportada. . . . . . . . . . . . . . . . . . . . 110

Tabela 5.5 - Comprimentos de ligação $(\AA)$ e ângulo de piramidalização $\left(^{\circ}\right)$ para o primeiro estado excitado singleto ${ }^{1}\left(\pi \pi^{*}\right)$ das bases modificadas do RNA otimizadas em fase gasosa e em solvente(1,4-dioxano e água). As geometrias foram otimizadas no nível de cálculo MS(2)-CASPT2/cc-pVDZ . . . . . . . . . . 113

Tabela 5.6 - Energias de emissão eletrônica teóricas calculadas no nível SS(X)-CASPT2(18,13)/ccpVDZ, juntamente com os respectivos dados experimentais (eV) [183] para o novo alfabeto ribonucleosídeo fluorescente em 1,4-dioxano e água. A força de oscilador respectiva a cada transição também é reportada. . . . . . . . . 115

Tabela 5.7 - Deslocamento Stokes teórico (eV) em fase gasosa, 1,4-dioxano e água. Resultados experimentais são reportados para comparação [183]. Desvio solvatocrômico (eV) no deslocamento Stokes de 1,4-dioxano para água é também reportado. 
Tabela 5.8 - Parâmetros de Cremer-Pople e Boyens para análise de conformação de anéis de seis membros da cônica ${ }^{1}\left(g s / \pi \pi^{*}\right)_{\mathrm{Cl}}$ obtidos para o novo alfabeto ribonucleosídeo fluorescente e suas respectivas análogas nucléicas. Esses parâmetros também foram empregados para a cônica obtida anteriormente para a molécula ${ }^{\mathrm{tz}}$ A. . . . . . . . . . . . . . . . . . . . . . . . . . 120

Tabela 5.9 - Barreiras energéticas (eV) computadas como a diferença de energia entre a geometria de mínimo do estado ${ }^{1}\left(\pi \pi^{*}\right)_{\min }$ e a estrutura correspondente ao máximo do LIIC (Barreira (LIIC)) e como a diferença de energia entre o estado de transição otimizado e o mínimo ${ }^{1}\left(\pi \pi^{*}\right)_{\min }$ (Barreira (TS)). A diferença de energia entre o mínimo e a interseção cônica $\left(E_{\min }-E_{C I}\right)$ para as fases gasosa e condensada (1,4-dioxano e água) também são reportadas. As energias de excitação vertical são computadas no nível SS(X)-CASPT2(18,13)/cc-pVDZ . . . . . . . . . . . . . . . . . . 123

Tabela 6.1 - Estatística de ligação de hidrogênio por sítio e número médio total de ligações hidrogênio $(\langle L H\rangle)$ para os estados fundamental e ${ }^{1}\left(\pi \pi^{*}\right)$ em cinco solventes. . . . . . . . . . . . . . . . . . . . . 133

Tabela 6.2 - Propriedades espectroscópicas (eV) calculadas em fase gasosa e em diversos meios solventes no nível de teoria MS(5)-CASPT2(18,13)/ANO-L-VDZP. As geometrias em solvente são as obtidas pelo procedimento de otimização de geometria ASEC-FEG. Dados experimentais [232] são incluídos para comparação. . . . . . . . . . . . . . . . . . . 135

Tabela 6.3 - Momento de Dipolo (Debye) dos dois tautômeros mais estáveis da 2AP obtido em diversos solventes para os dois primeiros estados eletrônicos. . . 138

Tabela 6.4 - Energias livre se solvatação $(\mathrm{kcal} / \mathrm{mol})$ no estado fundamental para os dois tautômeros da 2-aminopurina embebida em soluções de etanol e água usando a técnica FEP-MC. Entre parêntesis corresponde ao cálculo QM com $\mathrm{HF} / 6-31+\mathrm{G}(\mathrm{d}) / \mathrm{PCM}-\mathrm{UAHF}$ e em colchetes ao valor obtido empregando o modelo contínuo SMD no nível HF/6-31G*. . . . . . . . . . . . . . . . . 139

Tabela 6.5 - Energias livre de solvatação $(\mathrm{kcal} / \mathrm{mol})$ computada empregando simulações FEP-MC para o primeiro estado excitado dos dois tautômeros da molécula 2-aminopurina em etanol e em água. . . . . . . . . . . . . . . . 139

Tabela 7.1 - Energias de excitação vertical (eV) para a molécula 6SeGua calculadas nos métodos de química quântica MS(4,3)-CASPT2(12,10)/cc-pVDZ, MS(4,3)CASPT2(14,12)/cc-pVDZ, and ADC(2)/cc-pVDZ. Em parênteses é reportado a força de oscilador correspondente à transição eletrônica. . . . . . . . 148

Tabela 7.2 - Energias relativas (eV) à estrutura do estado fundamental, comprimentos de ligações $(\AA)$, ângulo $\left(^{\circ}\right)$, parâmetros de Cremer-Pople [220] e classificação de Boyens [221] para os mínimos otimizados da molécula 6SeGua nos níveis MS-CASPT2(12,10)/cc-pVDZ and ADC(2)/cc-pVDZ. . . . . . . . . . . 150 
Tabela 7.3 - Energias relativas (eV) à estrutura do estado fundamental, comprimentos de ligações $(\AA)$, ângulo $\left(^{\circ}\right)$, parâmetros de Cremer-Pople [220] e classificação de Boyens [221] para os pontos de cruzamento de energia mínima da molécula 6SeGua nos níveis MS-CASPT2(12,10)/cc-pVDZ and ADC(2)/cc-pVDZ. . 151

Tabela B.1 - Comprimentos de ligação $(\AA)$ para o estado fundamental em fase gasosa computada no nível MP2 empregando duas bases diferentes. Os efeitos relativísticos via formalismo de Douglas-Kroll-Hess são incluídos no cálculo com a base ANO-RCC-VDZP. . . . . . . . . . . . . . . . . . . . 195

Tabela B.2-Energias de excitação vertical da 6-selenoguanina computada no nível MS $(4,3)-C A S P T 2(14,10)$ utilizando duas bases atômicas diferentes. Os efeitos relativísticos via formalismo de Douglas-Kroll-Hess são incluídos no cálculo com a base ANO-RCC-VDZP. Esses cálculos foram realizados utilizando a estrutura do estado fundamental otimizada no nível MP2/ANORCC-VDZP. . . . . . . . . . . . . . . . . . . . . . . . 195 



\title{
Lista de abreviaturas e siglas
}

\author{
ACN Acetonitrila \\ ADC(2) Akgebraic Diagrammatic Construnction scheme for the polarization to the \\ second order \\ ASEC Average Solvent Electrostatic Configuration \\ ASEP Average Solvent Electrostatic Potential \\ AIMS $\quad$ Ab Initio Multiple Spawning \\ ASC Cargas Superficiais Aparentes \\ BAR Raio de Aceitação de Bennet \\ BFGS Broyden-Fletcher-Goldfarb-Shanno \\ BOA Aproximação de Born-Oppenheimer \\ CASSCF Complete Active Sace Self-Consistent Field \\ CASPT2 Second-Order Perturbation Theory with a CASSCF Reference Function \\ CC Coupled Cluster \\ cc-pVDZ correlation consistent polarized valence double- $\zeta$ \\ CHELPG CHarges from Electrostatic Potential \\ Cl Intersecção Cônica \\ CIS Interação de Configurações incluindo apenas Excitações Simples \\ CISD Interação de Configurações incluindo Excitações Simples e Duplas \\ CSF Configuration State Function \\ DFT Teoria do Funcional da Densidade
}




\begin{tabular}{|c|c|}
\hline DOF & Degree of Freedom \\
\hline DIO & 1,4-dioxano \\
\hline DNA & Ácido Desoxirribonucleico \\
\hline ETH & Etanol \\
\hline ESPF & Ajuste do Potencial Eletrostático \\
\hline $\mathrm{FCl}$ & Full $\mathrm{Cl}$ \\
\hline FEG & Método do Gradiente de Energia Livre \\
\hline FEP & Free Energy Perturbation \\
\hline FMS & Full Multiple Spawning \\
\hline GASSCF & Generalized Active Space SCF \\
\hline HF & Hartree-Fock \\
\hline HOMO & Orbital Molecular Ocupado mais Alto \\
\hline IC & Conversão Interna \\
\hline ISC & Cruzamento Intersistemas \\
\hline IPEA & Ionization Potencial and Electron Affinity correction \\
\hline LCAO & Linear Combination of Atomic Orbitals \\
\hline LJ & Lennard-Jonnes \\
\hline $\mathrm{LH}$ & Ligação de Hidrogênio \\
\hline LIIC & Interpolação Linear em Coordenadas Internas \\
\hline LS-CASPT2 & Level Shift CASPT2 \\
\hline LUMO & Orbital Molecular não Ocupado mais Baixo \\
\hline MBPT & Teoria de Perturbação de Muitos Corpos \\
\hline MC & Monte Carlo \\
\hline $\mathrm{MCH}$ & Molecular Coulomb Hamiltonian \\
\hline MCSCF & Método SCF Multiconfiguracional \\
\hline MCTDH & Método Hartree Multiconfiguracional Dependente do Tempo \\
\hline
\end{tabular}




\begin{tabular}{|c|c|}
\hline MD & Dinâmica Molecular \\
\hline MECP & Minimum-Energy Crossing Point \\
\hline MET & Metanol \\
\hline MM & Mecânica Molecular \\
\hline MP2 & Teoria de Pertubação de Muitos Corpos Møller-Plesset em Segunda Ordem \\
\hline MS-CASPT2 & Multi-State CASPT2 \\
\hline NAC & Acoplamento Não-Adiabático \\
\hline NEVPT2 & N-Electron Valence State Perturbation Theory \\
\hline NPT & ensemble isotérmico-isobárico \\
\hline NR & Newton-Raphson \\
\hline NVE & ensemble microcânonico \\
\hline NVT & ensemble canônico \\
\hline OPLS & Optimized Potential Liquid Simulations \\
\hline PCM & Modelo Contínuo Polarizável \\
\hline PDT & Terapia Fotodinâmica \\
\hline PES & Superfície de Energia Potencial \\
\hline PMCAS & Perturbation Modified CAS \\
\hline QDPT & Quasi-Degenerate Perturbation Theory \\
\hline QM & Mecânica Quântica \\
\hline RASSCF & Restricted Active Space SCF \\
\hline RNA & Ácido Ribonucleico \\
\hline RESP & Restrained Electrostatic Potential \\
\hline SA-CASSCF & State-Averaged CASSCF \\
\hline SCF & Self-Consistent Field \\
\hline SCRF & Campo de Reação Autoconsistente \\
\hline $\mathrm{SH}$ & Surface Hopping \\
\hline
\end{tabular}




$\begin{array}{ll}\text { SHARC } & \text { Surface Hopping including ARbitrary Couplings } \\ \text { SMD } & \text { Solvent Model Density } \\ \text { SOC } & \text { Acoplamento Spin-Orbíta } \\ \text { s-QM/MM } & \text { Sequential Quantum Mechanics/Molecular Mechanics } \\ \text { TAS } & \text { Espectro de Absorção Transiente } \\ \text { TBF } & \text { Trajectory Basis Function } \\ \text { TSH } & \text { Trajectory Surface Hopping } \\ \text { UAHF } & \text { United Atom for Hartree-Fock } \\ \text { UV-VIS } & \text { Ultra Violeta Visível } \\ \text { WAT } & \text { Água } \\ \text { XMS-CASPT2 } & \text { Extended Multi-State CASPT2 } \\ \text { 2AP } & \text { 2-aminopurina } \\ \text { 2SeUra } & \text { 2-selenouracila } \\ \text { 6SeGua } & \text { 6-selenoguanina } \\ \text { 6tGua } & \text { 6-tioguanina }\end{array}$




\section{Sumário}

INTRODUÇÃO . . . . . . . . . . . . . . . 35

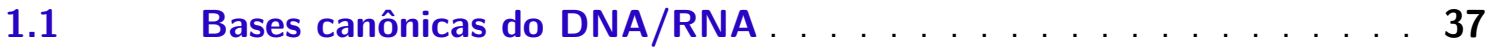

$1.2 \quad$ Análogos modificados do DNA/RNA . . . . . . . . . . . . 38

1.3 Objetivos e organização do texto . . . . . . . . . . . . . . . . 39

2 MÉTOdOS MULTICONFIGURACIONAIS . . . . . . . . . 41

2.1 Aproximação de Born-Oppenheimer . . . . . . . . . . . . . 41

2.2 Métodos Hartree-Fock e pós Hartree-Fock . . . . . . . . . . . . . . . 43

$2.3 \quad$ Método CASSCF . . . . . . . . . . . . . . . . . . 46

$2.4 \quad$ Teoria de Pertubação Multiconfiguracional de Segunda Ordem . . . 50

2.5 Método Multi-State CASPT2 . . . . . . . . . . . . . 55

2.6 Escolha do espaço ativo . . . . . . . . . . . . 57

3 DINÂMICAS NÃO-ADIABÁTICAS . . . . . . . . . . . 59

3.1 Dinâmicas quânticas . . . . . . . . . . . . . . . 59

3.2 Dinâmicas semiclássicas . . . . . . . . . . . . . . . . . . 61

3.2.1 Dinâmica de Ehrenfest . . . . . . . . . . . . . . . . . . . 61

3.2.2 Método Multiple Spawning . . . . . . . . . . . . . . . . 62

3.2.3 Dinâmica Surface Hopping . . . . . . . . . . . . . . . . . . . . 63

3.3 Ingredientes da dinâmica Surface Hopping . . . . . . . . . . . . . . 65

3.3.1 Movimento Nuclear . . . . . . . . . . . . . . . . 66

3.3.2 Propagação da função de onda . . . . . . . . . . . . . . . 66

3.3.3 Decoerência . . . . . . . . . . . . . . . . . . . 67

3.3.4 Ensemble de trajetórias . . . . . . . . . . . . . . . 68

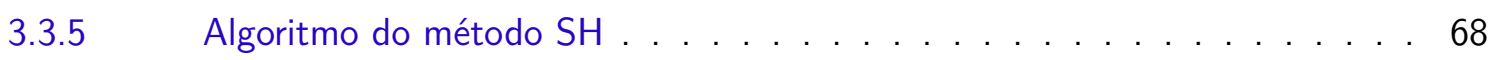

3.3.6 Ajuste da energia cinética e hops frustrados . . . . . . . . . . . . . . 69

3.3.7 Termos de acoplamentos e representações . . . . . . . . . . . . . . . 71

3.3.8 Condições iniciais . . . . . . . . . . . . . . . . . . . . . . . . . 73

4 MODELAGEM DO AMBIENTE MOLECULAR . . . . . . . . 75

4.1 Modelos contínuos . . . . . . . . . . . . . . . 75

4.2 Modelos Discretos . . . . . . . . . . . . . . . 77

$4.3 \quad$ Modelos híbridos . . . . . . . . . . . . . . . 79 
4.3.1 Polarização do soluto e o modelo ASEC . . . . . . . . . . . . . . . . . . 81

4.3.2 Método do Gradiente de Energia Livre . . . . . . . . . . . . . . . . . . 82

$4.4 \quad$ Simulação clássica . . . . . . . . . . . . . . . . . 85

4.4.1 Método de Monte Carlo e o algoritmo de Metropolis . . . . . . . . . . . 86

4.4.2 Dinâmica Molecular . . . . . . . . . . . . . . . . . . . . . . . . . . . . 89

$4.4 .3 \quad$ Potencial de interação . . . . . . . . . . . . . . . . 90

4.4.4 Função de autocorrelação da energia . . . . . . . . . . . . . . . . . 92

$4.5 \quad$ Função distribuição radial de pares . . . . . . . . . . . 93

5 ESTRUTURA ELETRÔNICA E PROPRIEDADES ESPECTROSCÓPICAS DE ANÁLOGOS NUCLEOSÍDEOS FLUORESCENTES . 95

$5.1 \quad$ Introdução e motivação . . . . . . . . . . . . . . 95

$5.2 \quad$ Detalhes computacionais . . . . . . . . . . . . . . . 97

5.2.1 Cálculos de estrutura eletrônica . . . . . . . . . . . . . . . . . . . . . . . 97

5.2.2 Efeitos do Solvente . . . . . . . . . . . . . . . . . . . . . . . 98

$5.3 \quad$ Geometria de equilíbrio do estado fundamental . . . . . . . . . . . 100

5.4 Estrutura do solvente e ligações de hidrogênio no estado fundamental102

5.5 Momento de dipolo e distribuição de cargas no estado fundamental 106

$5.6 \quad$ Espectro de Absorção Eletrônico . . . . . . . . . . . . . . . . 108

5.7 Geometria de equilíbrio e momento de dipolo do primeiro estado excitado . . . . . . . . . . . . . . . . . . . 111

$5.8 \quad$ Espectro de emissão eletrônico . . . . . . . . . . . . . . . . . . . 114

5.9 Deslocamento Stokes e desvio solvatocrômico . . . . . . . . . . 116

5.10 Caminhos de desativação fotofísicos . . . . . . . . . . . . 117

6 PROPRIEDADES ESPECTROSCÓPICAS DA 2-AMINOPURINA . 125

6.1 Introdução e motivação . . . . . . . . . . . . 125

6.2 Detalhes computacionais . . . . . . . . . . . . 126

6.2.1 Ciclo termodinâmico . . . . . . . . . . . . . . . . . . . 127

$6.2 .2 \quad$ Energias livre de solvatação . . . . . . . . . . . . . . 128

6.3 Estrutura de mínimo dos estados fundamental e primeiro estado

excitado . . . . . . . . . . . . . . . . . . . . 130

6.4 Estruturação do solvente e ligações de hidrogênios . . . . . . . . . 132

$6.5 \quad$ Propriedades espectroscópicas . . . . . . . . . . . . . . . . . . . 134

6.6 Energia livre de solvatação . . . . . . . . . . . . . 136

$6.7 \quad$ Estabilidade energética . . . . . . . . . . . . . . 140

7 DESVENDANDO A FOTOFÍSICA DA 6-SELENOGUANINA . . . 141

7.1 Introdução e Motivação . . . . . . . . . . . . . 141

7.2 Metodologia . . . . . . . . . . . . . . 143 
7.2.1 Métodos de estrutura eletrônica e cálculos estáticos . . . . . . . . . . . . . 143

7.2.2 Efeitos de solvente . . . . . . . . . . . . . . . . . 145

7.3 Dinâmica não-adiabática . . . . . . . . . . . . . 146

$7.4 \quad$ Energias de excitação vertical . . . . . . . . . . . . . . . . . 147

7.5 Estruturas de mínimo e pontos de cruzamentos . . . . . . . . . 149

7.6 Caminhos de desativação fotofísicos . . . . . . . . . . . . . 152

7.7 Simulação do espectro de absorção eletrônico . . . . . . . . . . . . . 154

7.8 Dinâmica não-adiabática . . . . . . . . . . . . . . 155

7.9 Evolução temporal dos parâmetros estruturais e modos vibracionais 160

7.10 Tempo de vida do estado tripleto . . . . . . . . . . . . 162

8 CONSIDERAÇÕES FINAIS E PERSPECTIVAS . . . . . . . 165

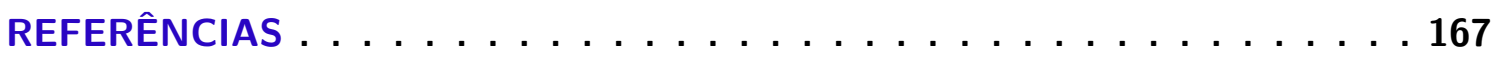

$\begin{array}{lr}\text { APÊNDICES } & 189\end{array}$

A - ESPAÇO ATIVO UTILIZADO NO MÉTODO CASSCF E CASPT2 PARA O ALFABETO RIBONUCLEOSÍDEO FLUORESCENTE . . . 191

B - COMPARAÇÃO ENTRE AS BASES ATÔMICAS CC-PVDZ E ANORCC-VDZP PARA A MOLÉCULA 6-SELENOGUANINA . . . . . 195

C - CAMINHO DE MENOR ENERGIA PARA A 6-SELENOGUANINA 197

ANEXOS 199

A - PUBlicaÇÕES EM QUE O TEXTO FOI BASEAdO . . . . . . 201

B - OUTRAS PUBlicAÇÕES DURANTE O DOUTORADO . . . . . 203

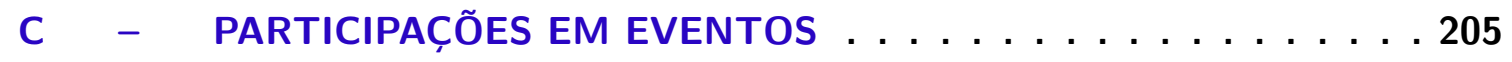





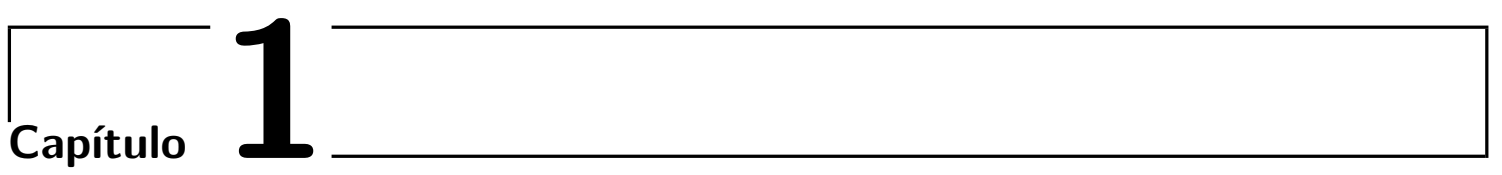

\section{Introdução}

Depois que uma dada molécula absorve radiação eletromagnética, existe o processo da excitação eletrônica a partir do estado fundamental para algum dos seus estados excitados eletrônicos. Depois desse evento, diversos mecanismos de desexcitação podem acontecer. De maneira geral, podemos classificar em dois distintos processos. O primeiro deles é chamado radiativo (fluorescência e fosforescência) e se baseia na liberação espontânea de fótons. O outro mecanismo não envolve radiação e está associado aos processos de conversão interna (IC) e cruzamento intersistemas (ISC), sendo que a energia extra é perdida através de movimentos vibracionais (calor). O processo de IC abrange a transferência de população eletrônica de estados de mesma multiplicidade de spin (por exemplo, $S_{0}$ e $S_{1}$ ), enquanto que o ISC contempla estados eletrônicos de diferentes multiplicidades (por exemplo, $S_{1}$ e $T_{1}$ ). O diagrama de Jabłoński é um simples e útil esquema para exemplificar tais processos [1], como pode ser visto na Figura 1.1(a). Nesse esquema pictórico, um sistema é excitado para o estado eletrônico singleto $S_{2}$, sofrendo subsequentemente um processo de IC para o estado singleto $S_{1}$, seguido por um ISC para o estado tripleto $T_{1}$. De acordo com esse diagrama ilustrativo, o sistema obedece a regra de Kasha [2], que postula que a emissão ou a transferência de população para outro estado eletrônico de diferente multiplicidade acontece apenas do estado excitado mais baixo daquela multiplicidade.

O conceito de superfícies de energia potencial (PESs) deve ser incluído para uma melhor compreensão dos caminhos de relaxação fotofísicos. Uma PES é uma função da energia potencial, que por sua vez depende do arranjo molecular. Para cada estado eletrônico é atribuído uma PES e uma versão mais precisa do diagrama de Jabłoński é mostrada na Figura 1.1(b), que compreende regiões de cruzamento (Cl e ISC) e de estados eletrônicos quase-degenerados.

Do ponto de vista teórico, o processo de IC ocorre quando a interação não-adiabática entre dois estados eletrônicos é muito forte e a aproximação de Born-Oppenheimer não é mais válida, isto é, os dois estados eletrônicos envolvidos são degenerados [3]. A geometria molecular que corresponde a essa região é comumente rotulada de intersecção cônica $(\mathrm{Cl})$. Por outro 
lado, o processo de ISC é fundamentado em um efeito puramente relativístico, chamado de acoplamento spin-órbita ( $\mathrm{SOC}$ ), que de maneira simples pode ser entendido como a interação do momento angular magnético orbital do elétron com o seu momento angular de spin. $O$ ISC tende a ser mais comum em moléculas contendo átomos mais pesados, dado que nesses sistemas o SOC será mais elevado. Essa última sentença pode ser reformulada no contexto da regra de El-Sayed, que diz que a taxa de população de estados tripletos está diretamente relacionado ao SOC envolvendo os dois estados eletrônicos [4]. Estados eletrônicos de caráter distinto (por exemplo, $\left.{ }^{1}\left(\pi \pi^{*}\right) \mathrm{e}^{3}\left(n \pi^{*}\right)\right)$ tendem a ter um SOC maior. Quando a molécula retorna para o estado fundamental, a geometria molecular pode ser a mesma (reagente) ou não (fotoproduto).

Nos dias atuais existem duas estratégias computacionais bem estabelecidas na literatura que visam a exploração das PESs [5,6]. A primeira delas, chamada de aproximação estática, utiliza técnicas de otimização para identificar as geometrias mais relevantes (mínimos, estados de transição, pontos de cruzamentos), sendo que essas geometrias podem ser conectadas para obter os caminhos de relaxação. Entre as suas desvantagens está o fato de não prever escalas de tempos e rendimentos quânticos, além de não conseguir discernir qual é o caminho fotofísico mais provável. A outra abordagem é chamada de aproximação dinâmica e leva em conta a evolução temporal dos núcleos e dos elétrons. Dentro dessa aproximação é possível determinar diferentes caminhos de desativação, constantes temporais, evolução do movimento nuclear, etc. Devido ao seu alto custo computacional, não podemos propagar longas dinâmicas, que tipicamente é da ordem de poucos picosegundos.

(a) Esquema de Jabłoński
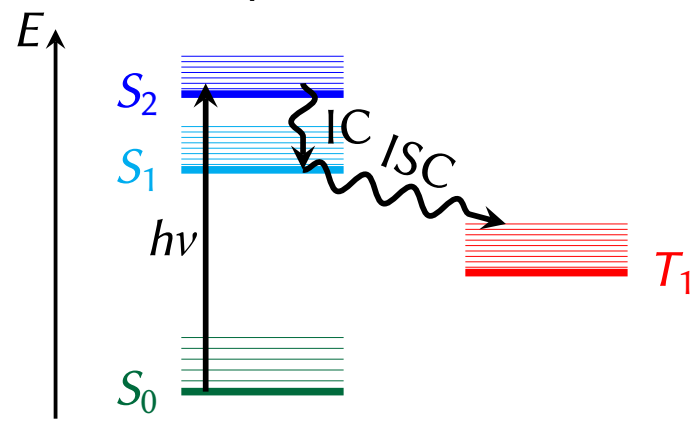

(b) Superfície de energia potencial (PESs)

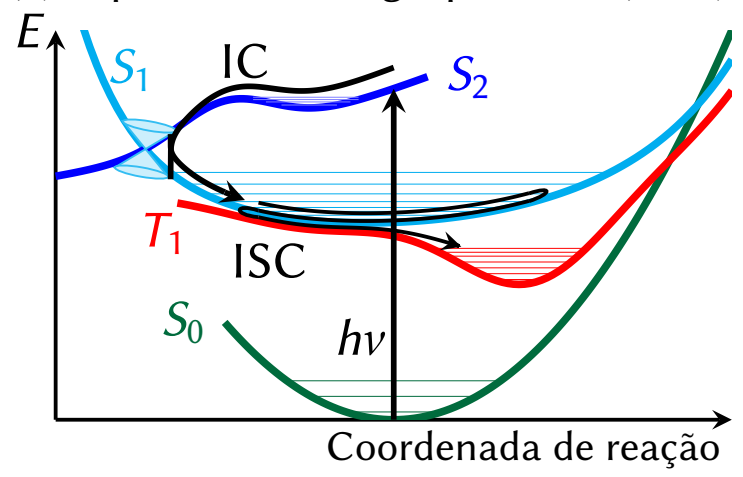

Figura 1.1 - (a) Ilustração do diagrama de Jabłoński, que exemplifica de uma maneira simples os principais mecanismos fotofísicos. No painel (b) é apresentado uma abordagem mais realística utilizando a ideia de superfície de energia potencial (PES) para descrever cada estado excitado eletrônico. 


\subsection{Bases canônicas do DNA/RNA}

A origem da vida na Terra é um assunto que ainda não é completamente explicado até hoje, mas a escolha das bases canônicas como constituintes do nosso código genético não parece ter sido ao acaso. No período prebiotico, não existia uma camada de ozônio para proteger o nosso planeta dos efeitos prejudiciais da radiação ultravioleta (UV) provida pelo Sol, resultando em um atmosfera hostil capaz de causar diversos danos ao DNA (ácido desoxirribonucleico) [7]. Todas as bases canônicas possuem uma ampla faixa de absorção no UV entre $4-6 \mathrm{eV}$ [8], podendo ser alvo dessa radiação. Dentre os efeitos nocivos dessa radiação, existe a possibilidade da ruptura de ligações do DNA durante a replicação, levando o código genético a não poder ser lido nesse ponto. A irradiação também pode promover outros tipos de lesões mutagênicas do DNA, como por exemplo, a formação de dímeros de pirimidina ciclobutano [9] e fotoprodutos (6-4)pirimidina-pirimidona [10], que levam à distorção da estrutura de dupla-hélice, evitando a replicação, recombinação e transcrição do material genético [11]. Entretanto, as nucleobases canônicas possuem um mecanismo de auto-proteção inerente contra essa radiação, dissipando a energia ganha devido à absorção da luz em forma de calor, evitando a quebra das ligações químicas que mantém a fita do DNA unida. Esse mecanismo de desativação sem radiação para o estado fundamental ocorre em uma escala de tempo ultra-rápida ( $\sim 1$ ps) e eficiente $[12,13]$. $\mathrm{Na}$ literatura existe o consenso que as Cl's são a chave para explicar esse processo, sendo que essas estruturas atuam como uma espécie de funil que transfere a população eletrônica eficientemente e não-radioativamente para o estado fundamental $[14,15]$.<smiles>Nc1ncnc2[nH]cnc12</smiles>

Adenina<smiles>Nc1nc2[nH]cnc2c(=O)[nH]1</smiles>

Guanina<smiles>Nc1cc[nH]c(=O)n1</smiles>

Citosina<smiles>Cc1c[nH]c(=O)[nH]c1=O</smiles>

Timina<smiles>O=c1cc[nH]c(=O)[nH]1</smiles>

Uracila

Figura 1.2 - Estrutura molecular dos compostos que constitui o DNA. No caso do RNA, a timina é substituída pela uracila.

Em 1869 foi dado um grande passo para um entendimento completo do DNA, quando Johann Friedrich Miescher determinou a composição bioquímica de linfócitos [16], chamando essa estrutura de "nucleina". Hoje em dia, é bem estabelecido que os blocos de construção do DNA são essencialmente compostos por bases nucleicas purínicas (adenina e guanina) e pirimidínicas (citosina e timina). Uma representação molecular dessas moléculas é apresentado na Figura 1.2. O arranjo molecular mais comum do DNA é o $\beta$-DNA, onde duas bases canônicas são pareadas via o pareamento de base Watson-Crick (adenina-timina e guaninacitosina) formando uma estrutura de dupla-hélice [17]. Contudo, sobre certas condições ( $\mathrm{pH}$, 
temperatura, etc), o DNA pode assumir outros tipos de configurações, tal como as estruturas i-motif [18] e G-quadruplex [19]. No RNA (ácido ribonucleico), que também desempenha funções biológicas importantes, como a codificação genética, não existe a formação de uma dupla-hélice, mas nessa estrutura há a troca da timina pela uracila.

\subsection{Análogos modificados do DNA/RNA}

$\mathrm{Na}$ literatura é bem conhecido que as bases canônicas naturais são bem sensíveis às mudanças químicas, ou seja, a substituição de um átomo ou grupo da molécula pode conduzir para um novo composto natural ou sintético com uma característica que não é observada em seu análoga natural. Dentre essas novas classes de bases canônicas modificadas, existem aquelas que são propensas à fluorescer. Esse tipo de molécula pode ser usada como sonda fluorescente, empregando, por exemplo, a técnica de espectroscopia de fluorescência [20,21] para investigação estrutural do DNA e a interação com outras biomoléculas [22,23]. Como esses análogos fluorescentes são bastante similares às bases canônicas naturais, a inserção no DNA/RNA causa perturbações mínimas [24]. Além disso, novos pareamentos de bases podem emergir, expandindo a biodiversidade genética [25]. Diversos compostos têm sido aplicados como análogos nucleicos fluorescente ao longo do tempo, tal como a 2-aminopurina $[26,27]$ e compostos obtidos pela adição de grupos em posições específicas, como as 8-vinilpurinas [28,29]. Mais recentemente, foi sintetizada a molécula 4-cianoindol [30], que tem sido considerada uma sonda universal para estudos do DNA e possui um rendimento quântico de fluorescência bem maior do que a 2-aminopurina.

De acordo com o trabalho de Sinkeldam et al. [23], que investigou as propriedades fluorescentes de mais de 100 bases modificadas emissivas, podemos agrupar os análogos fluorescentes em cinco grupos: (i) análogos de base cromófora, (ii) pteridinas, bases canônicas (iii) expandidas, (iv) estendidas e (v) isomórficas. No geral, algumas propriedades são desejadas para análogos fluorescentes como: (i) deslocamento para o vermelho no espectro de absorção em relação à absorção das bases naturais e (ii) aumento do rendimento quântico de fluorescência.

Em outra vertente, temos as modificações nas bases nucleicas que conduzem à supressão da conversão interna para o estado fundamental e permite um eficiente cruzamento intersistemas para o estado tripleto mais baixo, com um alto rendimento de estados tripletos. Esse tipo de molécula poderia ser utilizada no campo da terapia fotodinâmica (PDT), atuando como fotosensibilizador (PS).

A PDT é um tratamento medicinal que combina a ação de um PS, luz e uma adequada concentração de oxigênio molecular a fim de causar a morte de tecidos cancerígenos [31]. Entretanto, a PDT pode ser aplicada em outros contextos [32-37]. Essa técnica medicinal possui diversas vantagens em relação à radioterapia e cirurgia (não-invasiva, pode ser aplicada 
mais vezes, etc). O processo fotoquímico envolvido na PDT começa com a excitação do PS a partir do estado fundamental para o estado espectroscópico mais baixo. Depois disso, a população eletrônica é transferida para o estado tripleto via ISC. Durante o retorno para o estado fundamental, a energia liberada do PS é usada para excitar o oxigênio molecular a partir do seu estado fundamental tripleto ${ }^{3} \sum_{g}^{-}$para o estado excitado singleto ${ }^{1} \Delta_{g}$ [38], que possui um efeito citotóxico. Como o estado fundamental do oxigênio molecular possui simetria ${ }^{3} \sum_{g}^{-}$, o PS deve ter um alto rendimento de população de estados tripletos, caso contrário uma pequena quantidade de ${ }^{1} \mathrm{O}_{2}$ será produzida, reduzindo a efetividade da PDT [39]. Essa fotoreação é chamada na literatura de tipo Il e é a mais comum de acontecer [40]. No outro tipo de fotoreação (tipo I), o estado ${ }^{3} \mathrm{PS}$ transfere um elétron ou hidrogênio para uma biomolécula, produzindo radicais $\left(\mathrm{O}_{2}^{-}, \mathrm{OH}^{-}, \mathrm{H}_{2} \mathrm{O}_{2}\right.$, etc). Um esquema do processo fotoquímico da PDT é ilustrado na Figura 1.3.

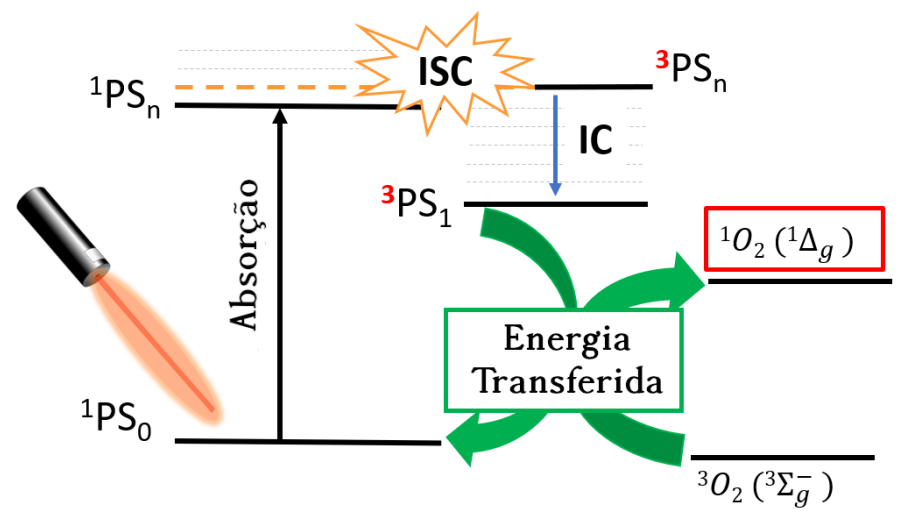

Figura 1.3 - Ilustração do processo envolvido na PDT considerando a fotoreação tipo II.

As tiobases, que se diferem das bases naturais pela substituição de átomos de oxigênio por enxofre, são boas candidatas para serem utilizadas como PS. Por exemplo, têm sido mostrado teoricamente e experimentalmente, que a molécula 6-tioguanina (6tGua) possui um rendimento quântico de ISC por volta de $21 \%[41,42]$. Outras tiobases também têm sido consideradas como potenciais PS, tal como as moléculas 2,4-ditiotimina [43], 6-tio-2-desoxiguanina [44] e 2,6-ditiopurina [45].

\subsection{Objetivos e organização do texto}

Como descrito acima, as bases canônicas modificadas podem desempenhar um papel importante em diversas áreas. $\mathrm{O}$ entendimento das propriedades dessas moléculas do ponto de vista físico-químico é de suma importante. Isso contempla a compreensão de suas propriedades espectroscópicas e estruturais. O principal objetivo desse trabalho foi descrever de forma precisa os mecanismos de relaxação fotofísicos de bases canônicas modificadas do DNA/RNA 
tanto em fase gasosa quanto em meio solvente. Os efeitos do ambiente foram inseridos de maneira implícita e/ou utilizando metodologias multiescala que combinam métodos de mecânica quântica e mecânica molecular (Quantum Mechanics/Molecular Mechanics - QM/MM). Para desvendar os principais caminhos fotofísicos, foram adotadas a abordagem estática e dinâmica de estados excitados no âmbito do algoritmo Trajectory Surface Hopping.

O texto está organizado da seguinte forma: introduzidos os métodos de química quântica que surgem depois da aproximação de Bohr-Oppenheimer no capítulo 2, com o foco nos métodos multiconfiguracionais CASSCF e CASPT2. O capítulo 3 elucida a parte teórica das principais técnicas de dinâmica de estados excitados, discutindo em detalhes o algoritmo Surface Hopping. O capitulo 4 é sobre a modelagem do ambiente molecular e técnicas de simulação computacional. O primeiro sistema estudado consiste de um promissor alfabeto ribonucleosídeo fluorescente do RNA, que foi estudado em 1,4-dioxano e água (capítulo 5). O segundo sistema investigado foi a molécula 2-aminopurina, sendo estudada isoladamente e em cinco distintos solventes: 1,4-dioxano, acetonitrila, etanol, metanol e água (capítulo 6). O último trabalho está relacionado à uma molécula modificada da guanina que possui um alto rendimento de estados tripletos. Em cada capítulo de resultados é sumarizado uma breve motivação para a escolha do sistema em questão. Por fim, uma conclusão é feita sintetizando os principais resultados obtidos nesses estudos. 


\section{Métodos Multiconfiguracionais}

A química quântica, como é conhecida nos dias atuais, teve o seu início quando Erwin Schödinger propôs a sua célebre equação em 1925. De lá para cá, diversas propostas de resolução dessa equação foram amplamente disseminadas na literatura. Dentre esses métodos, um dos mais simples de todos é o Hartree-Fock (HF), que é também empregado como ponto de partida de métodos mais robustos. Outras abordagens menos custosas, baseados na densidade eletrônica ou simplificações e parametrizações das integrais de dois elétrons (métodos semiempíricos) também foram propostas ao longo do tempo. Nesse capítulo serão apresentados de maneira breve os métodos HF e pós-HF. O foco desse capítulo é em dois refinados métodos de estrutura eletrônica: o Complete Active Space Self-Consistent Field (CASSCF) e o Second-Order Perturbation Theory with a CASSCF Reference Function (CASPT2)

\subsection{Aproximação de Born-Oppenheimer}

Nos métodos de primeiros princípios, no regime não relativístico, as informações sobre as propriedades moleculares podem ser extraídas da equação de Schrödinger independente do tempo. Todavia, é possível resolver essa equação analiticamente a rigor apenas para átomos hidrogenóides $^{\dagger}$. Para sistemas moleculares existem boas razões para separação dos movimentos nuclear e eletrônico. A primeira justificativa, e mais óbvia, é de que a complexidade do problema será reduzida. Outro ponto é a introdução do conceito de superfície de energia potencial. Como a massa do próton é cerca de 1836 vezes maior do que a massa do elétron, é seguro assumir que os elétrons têm bastante tempo para reorganizar seu movimento sempre que os núcleos mudam de posição. Em outras palavras, negligenciamos o acoplamento entre os núcleos e os elétrons.

Nessa aproximação é possível resolver a parte eletrônica com as coordenadas nucleares

\footnotetext{
† Átomos hidrogenóides são sistemas que possuem um único elétron.
} 
como parâmetro, assumindo que a função de onda total $\Psi(\mathbf{r}, \mathbf{R})$ é um produto de uma função que depende exclusivamente das coordenadas nucleares $\Psi^{\text {nuc }}(\mathbf{R})$ e de uma outra função que depende das coordenadas dos elétrons e parametricamente das coordenadas nucleares $\Psi^{\text {ele }}(\mathbf{r} ; \mathbf{R})$, ou seja:

$$
\Psi(\mathbf{r}, \mathbf{R})=\sum_{\alpha} \Psi_{\alpha}^{\mathrm{ele}}(\mathbf{r} ; \mathbf{R}) \Psi_{\alpha}^{\mathrm{nuc}}(\mathbf{R})
$$

sendo, $\mathbf{r}$ um índice coletivo que representa as coordenadas dos elétrons, $\mathbf{R}$ é um índice coletivo que representa as coordenadas dos núcleos e $\alpha$ corre sobre todos os autoestados eletrônicos.

Dessa forma, a equação de movimento dos núcleos pode ser escrita como [46]:

$$
\left(\mathcal{T}^{\mathrm{nuc}}+E_{\alpha}^{\mathrm{ele}}\right) \Psi_{\alpha}^{\mathrm{nuc}}(\mathbf{R})+\sum_{\alpha} \mathcal{T}_{\beta \alpha}^{\mathrm{NAC}} \Psi_{\beta}^{\mathrm{nuc}}(\mathbf{R})=E \Psi_{\alpha}^{\mathrm{nuc}}(\mathbf{R})
$$

sendo, $E_{\beta}^{\text {ele }}$ a energia eletrônica, $\mathcal{T}^{\text {nuc }}$ é o operador de energia cinética dos núcleos e $\mathcal{T}_{\beta \alpha}^{\mathrm{NAC}}$ é dado por:

$$
\mathcal{T}_{\beta \alpha}^{\mathrm{NAC}}=-\sum_{I} \frac{1}{2 m_{A}}\left[\left\langle\Psi_{\alpha}^{\mathrm{ele}}\left|\nabla_{A}^{2}\right| \Psi_{\beta}^{\mathrm{ele}}\right\rangle+\left\langle\Psi_{\alpha}^{\mathrm{ele}}\left|\nabla_{A}\right| \Psi_{\beta}^{\mathrm{ele}}\right\rangle\right]
$$

O primeiro termo da equação (2.3) é conhecido como o acoplamento diagonal e o segundo termo é chamado de acoplamento não-adiabático, que pode variar drasticamente em regiões na qual a função de onda eletrônica muda rapidamente com as coordenadas nucleares.

Dentro da aproximação de Born-Oppenheimer (BOA), conhecida também como aproximação adiabática, é desprezado os termos envolvendo os acoplamentos entre os estados eletrônicos da equação (2.2). Isso é feito assumindo que o operador de energia cinética dos núcleos atua apenas na função de onda nuclear. Dessa forma, a função de onda eletrônica varia lentamente com as coordenadas nucleares. A consequência dessa aproximação é a separação da equação de Schrödinger em uma equação para o movimento eletrônico e uma equação para o movimento dos núcleos, isto é:

$$
\begin{aligned}
\mathcal{H}_{\text {ele }}(\mathbf{r}) \Psi_{\text {ele }}(\mathbf{r} ; \mathbf{R}) & =E_{\text {ele }} \Psi_{\text {ele }}(\mathbf{r} ; \mathbf{R}) \\
\mathcal{H}_{\text {nucl }}(\mathbf{R}) \Psi_{\text {nucl }}(\mathbf{R}) & =E \Psi_{\text {nucl }}(\mathbf{R})
\end{aligned}
$$

Primeiramente é necessário resolver a equação eletrônica e em seguida a nuclear, pois a energia total $(E)$, que possui uma contribuição da energia eletrônica, é uma espécie de energia potencial para o movimento nuclear. A resolução da equação nuclear leva a descrição dos modos normais de rotação e vibração da molécula.

Os termos não-adiabáticos são tomados como nulos e se relacionam com o acoplamento de diferentes estados eletrônicos. Logo, a aproximação de Born-Oppenheimer é válida somente quando não existe um acoplamento significativo entre diferentes estados eletrônicos. Cruzamento entre curvas de energia potencial (intersecções cônicas e cruzamento intersistemas) é um exemplo típico onde essa aproximação falha. Para casos como esse, é preciso ir além da aproximação de Born-Oppenheimer e existem alguns métodos que incluem os efeitos nãoadiabiáticos a posteriori, como detalhado nas referências 47-48. 


\subsection{Métodos Hartree-Fock e pós Hartree-Fock}

Mesmo com a aproximação de Born-Oppenheimer, ainda não somos capazes de resolver o movimento eletrônico. O principal problema é devido ao termo de repulsão elétron-elétron, que correlaciona o movimento dos elétrons na molécula. A primeira tentativa foi considerar a função de onda eletrônica como um produto de funções de onda de um único elétron, denominado produto de Hartree. Contudo, o produto de Hartree não satisfaz o princípio de antissimetria, isto é, a função de onda deve ser antissimétrica com respeito a troca de quaisquer duas coordenadas. A solução empregada é a utilização de determinantes de Slater como função de onda eletrônica.

A aproximação de Hartree-Fock (HF) foi uma maneira simples de determinar a função de onda e a energia do estado fundamental de sistemas multieletrônicos usando um único determinante de Slater:

$$
\Psi_{0}\left(\mathbf{x}_{1}, \cdots, \mathbf{x}_{N}\right)=\frac{1}{\sqrt{N !}}\left|\begin{array}{cccc}
\chi_{1}\left(\mathbf{x}_{\mathbf{1}}\right) & \chi_{2}\left(\mathbf{x}_{\mathbf{1}}\right) & \cdots & \chi_{N}\left(\mathbf{x}_{\mathbf{1}}\right) \\
\chi_{1}\left(\mathbf{x}_{\mathbf{2}}\right) & \chi_{2}\left(\mathbf{x}_{\mathbf{2}}\right) & \cdots & \chi_{N}\left(\mathbf{x}_{\mathbf{2}}\right) \\
\vdots & \vdots & \ddots & \vdots \\
\chi_{1}\left(\mathbf{x}_{\mathbf{N}}\right) & \chi_{2}\left(\mathbf{x}_{\mathbf{N}}\right) & \cdots & \chi_{N}\left(\mathbf{x}_{\mathbf{N}}\right)
\end{array}\right|
$$

sendo que, $\chi$ representa o spin-orbital, que nada mais é do que a multiplicação de um orbital espacial por uma função de spin (up ou down).

Em outros termos, esse método permite obter os melhores coeficientes para esse único determinante de Slater e, consequentemente, a melhor energia possível para o estado fundamental. A ideia proposta é a minimização da energia do estado fundamental utilizando multiplicadores de Lagrange, com a restrição de que os spin-orbitais devem ser ortonormais. Esse procedimento variacional conduz para equações para os spin-orbitais, que devem ser resolvidas de maneira autoconsistente (SCF: Self-Consistent Field). Na sua forma canônica, a equação de Hartree-Fock é expressa por [49]:

$$
f \chi_{a}=\varepsilon_{a} \chi_{a}
$$

sendo que, $f$ é um operador de um elétron efetivo, chamado de operador de Fock e $\varepsilon_{a}$ é a energia orbital do spin-orbital $\chi_{a}$.

As equações de HF podem ser interpretadas como uma teoria de campo médio, em que trocamos um problema complicado de repulsão elétron-elétron, por outro de um elétron sentido um potencial efetivo médio devido aos demais. Porém, as equações de HF em sua essência são resolvidas de forma numérica e são inviáveis para um número grande de elétrons. Roothaan propôs expandir os orbitais moleculares em um conhecido conjunto de funções espaciais (formalismo de Hartree-Fock-Roothaan) [50], denominado funções base. Dessa forma, as equações de HF puderam ser escritas de uma maneira matricial, contribuindo para a popularização do método, devido à fácil implementação em códigos de computador. Uma 
tentativa natural de conjunto de funções base são os orbitais atômicos, levando a conhecida aproximação LCAO (Linear Combination of Atomic Orbitals) [51].

A solução via método Hartree-Fock leva a obtenção de até $99 \%$ da energia total não relativística [47]. Não obstante, outras propriedades físico-químicas não são bem descritas. Isso se deve ao método HF perder a informação sobre as interações sobre cada par de elétrons. Essa parcela que falta para reproduzir a energia total foi chamada por Löwdin de energia de correlação $\left(E_{\text {corr }}\right)$ [52], ou seja:

$$
E_{\text {corr }}=E_{\text {exata }}-E_{\mathrm{HF}}
$$

Métodos mais sofisticados, que usam o HF como ponto de partida, buscam capturar essa pequena contribuição e, consequentemente, a uma representação mais correta de outros processos físico-químicos. Esses métodos são chamados de métodos pós Hartree-Fock e destacamos aqui a Teoria de Pertubação de Muitos Corpos (MBPT), Interação de Configuração (CI) e o Coupled Cluster (CC).

O primeiro deles é baseado na teoria de perturbação de Rayleigh-Schrödinger, que está amplamente discutida na referência 53. A ideia central é a quebra do Hamiltoniano em uma parcela na qual as autofunções são conhecidas, chamado de Hamiltoniano não-perturbado, e o termo remanescente é chamado de perturbação. Essa perturbação deve ser pequena, no intuito de que a solução exata distingua pouco da solução não-perturbada. Além disso, essa imposição é importante para que as principais correções venham nas contribuições de ordem mais baixa. $A$ teoria de perturbação de muitos corpos (MBPT) usa essa conceito, seguindo o particionamento do Hamiltoniano proposto por Møller e Plesset [54], sendo que o Hamiltoniano não perturbado é definido como uma soma de operadores de Fock. A energia corrigida até primeira ordem conduz para a energia HF, portanto, é necessário corrigir pelo menos até segunda ordem. Vale salientar que a MBPT é extensiva em todas as ordens de perturbação (size-consistent) [55], isto é, a energia escala linearmente com o número de elétrons. Ademais, existe uma formulação diagramática usando as ideias de Brandow [56] e Goldstone [57].

Um ponto a ser destacado é de que a MBPT não é uma teoria variacional, significando que a energia obtida por esse método pode estar abaixo ou acima da energia exata. No entanto, na maioria das vezes, estamos interessados em propriedades que não são variacionais e que dependem exclusivamente da diferença dos níveis energéticos. Contudo, existem casos conhecidos em que a série perturbativa exibe um comportamento divergente [58].

Em outra vertente, o método $\mathrm{Cl}$ foi proposto para corrigir uma falha do método $\mathrm{HF}$. Como mostrado anteriormente, a função de onda eletrônica é escrita em termos de um único determinante de Slater. Os resultados são mais realísticos à medida que esse único determinante é dominante. Entretanto, há situações, como por exemplo dissociação, que é necessário incluir correções. Nesse intuito, o método $\mathrm{Cl}$ corrige essa limitação do HF, expressando a função de 
onda eletrônica como uma soma de determinantes de Slater:

$$
\Psi_{C I}=c_{0} \Psi_{0}+\sum_{a, r} c_{a}^{r} \Psi_{a}^{r}+\sum_{a, b, r, s} c_{a b}^{r s} \Psi_{a b}^{r s}+\cdots
$$

sendo que, $\Psi_{a}^{r}$ significa a promoção de um elétron do orbital ocupado a para um orbital virtual $r$. Os determinantes duplamente excitados $\Psi_{a b}^{r s}$ correspondem a troca de dois elétrons dos orbitais ocupados $a$ e $b$ pelos orbitais virtuais $r$ e $s$, e assim por diante. Aplicando o princípio variacional para a energia, com o vínculo de que a função de onda $\mathrm{Cl}$ seja normalizada, chegamos na seguinte equação matricial:

$$
\mathbf{H C}=\lambda \mathbf{C}
$$

sendo, $\mathbf{H}$ a representação matricial do Hamiltoniano e $\mathbf{C}$ é a matriz dos coeficientes.

Dessa forma, a expressão (2.9) é uma equação de autovalores para a matriz H. Logo, o problema consiste em diagonalizar a representação matricial do Hamiltoniano. Os coeficientes são determinados por meio dos autovetores e os autovalores correspondem as energias dos estados excitados. Muitos elementos de matriz serão nulos e isso é evidenciado empregando as regras de Condon-Slater e o teorema de Brillouin [49]. Se todos os termos da expansão da equação (2.8) são incluídos, temos o que é conhecido como full $\mathrm{Cl}(\mathrm{FCl})$ e constitui a melhor solução possível dentro da aproximação de Born-Oppenheimer. Essa solução tornaria exata quando o conjunto de funções base é infinito e completo. Infelizmente, nos dias atuais, esse cálculo ainda não é factível, salvo para sistemas pequenos com poucos elétrons e com um conjunto de funções base limitado. Isso se deve ao fato do número de configurações crescer rapidamente com o número de elétrons que podem ser excitados e com a quantidade de orbitais virtuais (fórmula de Weyl). Desse modo, a função de onda $\mathrm{Cl}$ deve ser truncada, dando origem aos métodos que incluem apenas excitações simples (CIS) e excitações simples e duplas (CISD). O método CIS é extensivo e é o nível mais simples de teoria para estudar estados excitados, sendo considerado um análogo da teoria do estado fundamental HF devido a não incluir correlação eletrônica. Um aprimoramento é alcançado incluindo excitações duplas por meio de correções perturbativas, dando origem ao método CIS(D) [59]. Já para o método CISD, a correção de Davidson é normalmente adotada para tornar essa aproximação extensiva por tamanho, sendo que a energia final corrigida se assemelha à obtida inserido até excitações quádruplas (CISDTQ).

Por fim, o método CC é um dos métodos pós-HF mais refinados para obtenção da função de onda de muitos elétrons para o estado fundamental. Inicialmente foi desenvolvida no contexto de física nuclear [60], mas Paldus e colegas aplicaram no âmbito da correlação eletrônica [61]. Esse método dá resultados bem precisos, mesmo quando o HF não é um bom ponto de partida. A ideia por trás do CC é considerar agrupamentos de pequenos elétrons, denominados clusters. Dessa forma, as interações entre os elétrons do mesmo cluster e com diferentes aglomerados podem ser calculadas. Nesse formalismo, a função de onda CC é escrita como:

$$
\Psi_{\mathrm{CC}}=e^{T} \Psi_{0}
$$


sendo que, $\Psi_{0}$ é a função de onda HF e $T$ é o operador de cluster e é expresso em termos de uma soma de todas as excitações simples, duplas, triplas e assim por diante.

Pode-se mostrar expandindo o operador de cluster em série de Taylor, que a função de onda CC nada mais é do que a expansão $\mathrm{FCl}$ escrita na linguagem de segunda quantização [62]. Os coeficientes que definem as excitações, chamadas de amplitudes de cluster, são obtidas impondo que a função de onda CC seja solução da equação de Schrödinger e, em seguida, projetando os determinantes substituídos nessa expressão. O grande problema é que uma amplitude de cluster depende de todas as outras, sendo inviável computacionalmente. Dessa forma, é necessário fazer truncamentos no operador de cluster, dando origem aos métodos CCD, CC2 [63], CC3 [64], CCSD [65] e CSDT (ou incluindo as excitações triplas indiretamente $\operatorname{CCSD}(\mathrm{T})[66])$. Vale mencionar, que mesmo com truncamentos no operador de cluster, o método CC continua sendo consistente de tamanho.

\subsection{Método CASSCF}

Como visto anteriormente, o modelo $\mathrm{Cl}$ tenta corrigir a limitação do $\mathrm{HF}$, escrevendo a função de onda como uma expansão de determinantes de Slater. Um exemplo típico na qual um único determinante não descreve corretamente o sistema é a dissociação da molécula de $\mathrm{H}_{2}$. A descrição correta do sistema é alcançada somente quando a função de onda é expressa em termos de dois determinantes (um ligante e outro anti-ligante). Dessa forma, o método $\mathrm{Cl}$ é consistente de tamanho, ou seja, a energia obtida para dois fragmentos separados por uma distância suficientemente grande será igual à soma das energias dos fragmentos calculados separadamente. Além do mais, do ponto de vista teórico, essa formulação é exata dentro da aproximação de Bohr-Oppenheimer. A pergunta que fica é: será que existe uma maneira sistemática de selecionar as configurações mais relevantes?

Nesse sentido, surgiu o método SCF multiconfiguracional (MCSCF) [67]. Em resumo, esse método é uma espécie de $\mathrm{Cl}$, na qual além dos coeficientes dos determinantes, os orbitais moleculares utilizados para construção dos determinantes também são otimizados, obtendo uma função de onda multiconfiguracional autoconsistente. Se apenas um determinante for considerado, teremos o método HF. Essa função de onda multiconfiguracional é expandida em termos de configurações adaptadas de spin (CSF - Configuration State Function), que são combinações lineares de determinantes de Slater e são autofunções dos operadores de spin $\hat{S}^{2}$ e $\hat{S}_{z}$. Outro ponto a ser salientado é de que a CSF's pertencem à mesma representação irredutível do grupo de simetria do Hamiltoniano.

Através do formalismo MCSCF, diversos tipos de função de onda puderam ser construídas. Dentre elas, destacamos a função de onda do tipo CASSCF (Complete Active Space SCF) [68]. O método CASSCF foi proposto originalmente por Björn Roos e a sua grande vantagem e de 
não se preocupar com a configuração em si. A ideia sugerida por Roos é escolher um conjunto de orbitais que seja mais relevante para o sistema em questão e, a partir disso, a função de onda multiconfiguracional pode ser determinada construindo um full $\mathrm{Cl}$ nesse espaço seleto, denominado espaço ativo. A escolha desse espaço ativo requer uma visão aprofundada sobre estrutura eletrônica, que muitas vezes é bastante óbvia. Entretanto, existem muitas situações na qual a escolha do espaço ativo não é totalmente clara e requer diversos testes a fim de encontrar os melhores orbitais para descrição do problema em questão. A escolha do espaço ativo será mais aprofundada na seção 2.6.

Na prática, o método é baseado no particionamento do espaço de orbitais (ocupados e virtuais) em três subconjuntos: inativo, ativo e externo. No espaço inativo, os orbitais são mantidos duplamente ocupados em todas as configurações que são usadas para construir a função de onda CASSCF. Em contrapartida, os orbitais que constituem o espaço externo são sempre vazios. Por fim, os orbitais do espaço ativo terão o número de ocupação fracionado, variando entre zero e dois. Na Figura 2.1 é exemplificado essa divisão do espaço de orbitais no método CASSCF. Uma vez escolhido quais orbitais integrarão cada espaço, a função de onda multiconfiguracional CASSCF é obtida a partir de uma combinação linear de todas as configurações adaptadas de spin, distribuindo os elétrons no espaço ativo de todas as formas possíveis. Em seguida, são otimizados os coeficientes da combinação linear e dos orbitais ativo e duplamente ocupado (exceto os que não forem considerados orbitais de caroço).

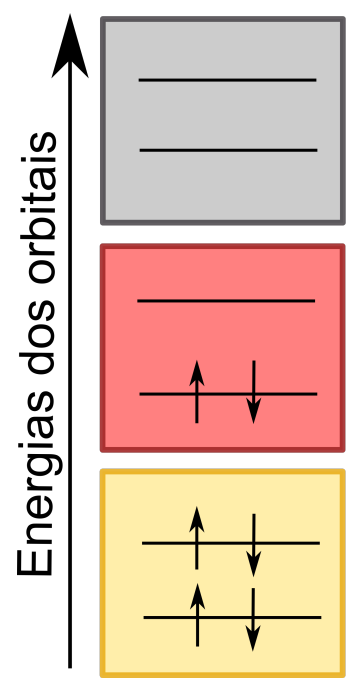

(a) Espaço inativo (vazio)

(b) Espaço ativo (ocupação: 0-2)

(c) Espaço inativo (duplamente ocupado)

Figura 2.1 - Exemplificação da divisão do espaço de orbitais no método CASSCF para um sistema arbitrário. (a) Os orbitais nesse espaço são inativos e sempre ocupados. (c) Os orbitais são sempre mantidos duplamente ocupados. (b) $O$ espaço ativo possui dois elétrons ativos em dois orbitais ativos. A ocupação dos orbitais nesse espaço é entre zero e dois.

A expressão da energia para uma função de onda $\mathrm{Cl}$ geral pode ser escrita na forma [69]:

$$
E=\sum_{p q} h_{p q} D_{p q}+\sum_{p q r s}(p q \mid r s) P_{p q r s}
$$


em que, $h_{p q}$ e ( $\left.p q \mid r s\right)$ são as integrais de um e dois elétrons, respectivamente. Essas integrais contém a informação sobre os orbitais moleculares. $D_{p q}$ e $P_{p q r s}$ são as matrizes reduzidas de um e dois corpos, que são construídas a partir da função de onda $\mathrm{Cl}$ :

$$
D_{p q}=\sum_{\mu \nu} c_{\mu}^{*} A_{p q}^{\mu \nu} c_{\nu} \quad \text { e } \quad P_{p q r s}=\sum_{\mu \nu} c_{\mu}^{*} A_{p q r s}^{\mu \nu} c_{\nu}
$$

sendo, $A_{p q}^{\mu \nu}$ e $A_{p q r s}^{\mu \nu}$ constantes estruturais que são independentes dos parâmetros que determinam a função de onda. Esses elementos de matriz dependem exclusivamente de como é gerada a função de onda $\mathrm{Cl}$ (determinantes de Slater ou configurações adaptadas de spin). $\mathrm{O}$ programa MOLCAS usa CSF na construção e análise da função de onda, mas transforma para determinantes na seção $\mathrm{Cl}$ do programa [70].

A otimização dos coeficientes de expansão e dos orbitais moleculares devem ser conduzidos simultaneamente. A condição para que os parâmetros estejam otimizados, é de que o gradiente da energia com respeito a variação dos parâmetros variacionais seja nulo, isto é:

$$
\frac{\delta E}{\delta p_{i}}=0
$$

sendo que, $p_{i}$ são os parâmetros variacionais. Comumente, são empregadas duas técnicas de otimização:

1. A primeira técnica de otimização é um processo iterativo baseado na expansão da energia em série de Taylor até segunda ordem, chamado de método Newton-Raphson (NR) [71]. A expressão para a energia até segunda ordem será dada por:

$$
E(\mathbf{p})=E(0)+\mathbf{p}^{\dagger} \mathbf{g}+\mathbf{p}^{\dagger} \mathbf{H} \mathbf{p}
$$

sendo, $\mathbf{p}$ o vetor dos parâmetros variacionais, $\mathrm{g}$ o gradiente de energia e $\mathbf{H}$ a matriz hessiana, que é expressa em termos das derivadas segundas da energia. Derivando a equação (2.14) em relação ao parâmetro $\mathbf{p}$ e admitindo um ponto estacionário, chegamos na seguinte expressão:

$$
\mathbf{p}=-\mathbf{H}^{-1} \mathrm{~g}
$$

A solução da equação (2.15) permite computar uma nova energia e, consequentemente, novas matrizes $\mathbf{g}$ e $\mathbf{H}$. Esse processo iterativo é finalizado quando um padrão preestabelecido é alcançado.

2. A segunda técnica para otimização dos parâmetros variacionais é empregando a abordagem super- $\mathrm{Cl}$ [72]. Nesse método, usado um conjunto de orbitais atuais, é realizado uma otimização dos coeficientes da expansão $\mathrm{Cl}$. Posteriormente, os orbitais são otimizados utilizando a função de onda super-Cl:

$$
\Phi=\Psi+\sum_{a r} c_{a}^{r} \Psi_{a}^{r}
$$


sendo que, $\Psi_{a}^{r}$ são as configurações advindas de excitações simples a partir da função de onda multiconfiguracional. Os novos orbitais são otimizados usando uma formula de contração [73]. Novamente, como na técnica anterior o processo é iterativo e acaba quando um patamar de convergência é alcançado.

Vale a ressalva, que o método Super- $\mathrm{Cl}$ conduz sempre para um ponto de mínimo, porém, é computacionalmente mais custoso. O método NR é relativamente mais barato, entretanto, dependendo do ponto de partida, não conduzirá para o mínimo, como por exemplo em pontos de sela (gradiente é nulo e, por conseguinte, o passo de otimização também será nulo). Levando isso em consideração, o método NR é mais indicado quando temos um bom ponto inicial. Indicamos aos leitores a referência 74 , que mostra em detalhes um comparativo entre ambos os métodos.

O programa Molcas utiliza as vantagens e desvantagens de ambos os métodos. A fim de evitar problemas de convergência, primeiramente, a otimização dos coeficientes começa com o método Super- $\mathrm{Cl}$ e após a convergências de alguns critérios é empregado o método NR [75].

Os métodos multiconfiguracionais são largamente aplicados no estudo de processos fotoquímicos, fotofísicos e espectroscopia. Logo, é necessário fazer o estudo dos estados excitados do sistema em questão. Contudo, cálculos envolvendo estados excitados são frequentemente mais complicados do que para o estado fundamental e podem levar a problemas de convergência. Cada estado excitado deveria ser tratado separadamente, produzindo o seu próprio conjunto de orbitais otimizados. O problema de se fazer esse procedimento acima é a não-ortogonalidade das funções de ondas dos estados excitados. Dessa forma, não é garantido que a integral de superposição seja pequena, podendo variar drasticamente dependendo da região da hipersuperfície de energia potencial. Outro agravante, seria a dificuldade de encontrar intersecções cônicas e cruzamento intersistemas, pois a otimização para essas regiões depende, no mínimo, de dois estados excitados. Além do mais, pode acontecer o problema de inversão de raiz (root flipping), que é a mudança de raízes ao longo do procedimento de otimização CASSCF. Além de todos esses problemas envolvendo o estudo de estados excitados separadamente, existem outras questões que podem inviabilizar o cálculo, como por exemplo, o espectro de energia ser bastante denso, ou seja, existem vários estados excitados com a energia bem próxima. Dessa forma, é impraticável a otimização dos orbitais de cada estado.

Para contornar os problemas reportados acima, podemos utilizar um mesmo conjunto de orbitais moleculares para descrever um conjunto de estados eletrônicos de mesma simetria e spin. Esse procedimento é denominado de state-averaged CASSCF (SA-CASSCF) [76]. Dessa maneira, os orbitais moleculares são otimizados para a energia média dos estados eletrônicos selecionados:

$$
\langle E\rangle=\sum_{I} \omega_{I} E_{I}
$$


sendo que, $\omega_{I}$ são os pesos associados as energias de cada estado $I$ incluídos no procedimento de state-averaged.

Via de regra, o peso atribuído a cada estado eletrônico é o mesmo. Entretanto, outras escolhas são possíveis, visto que em algumas circunstâncias estamos interessados em um estado eletrônico específico. A energia média terá uma fórmula similar a equação (2.11), porém, as matrizes densidades são substituídas por valores médios. No programa MOLCAS/OPENMOLCAS está disponível essa opção e em nossos cálculos utilizados esse procedimento empregando sempre o mesmo peso para cada estado eletrônico.

Dentre as principais vantagens do procedimento SA-CASSCF está a possibilidade de inclusão de um número considerável de estados eletrônico em um mesmo cálculo e as funções de onda dos estados eletrônicos são ortogonais entre si, simplificando o cálculo de momento de transição, força de oscilador, etc. A principal desvantagem é devido aos orbitais moleculares não serem otimizados para cada estado eletrônico, conduzindo, usualmente, para energias de excitação verticais bem maiores do que previstas experimentalmente. Todavia, um cálculo posterior incluindo a correlação dinâmica, como por exemplo o método CASPT2, pode corrigir essas energias e se aproximar mais dos dados experimentais.

\subsection{Teoria de Pertubação Multiconfiguracional de Segunda Ordem}

O método CASSCF é uma proposta bastante interessante para gerar uma função de onda multiconfiguracional. No coração do método está a escolha do espaço ativo. Porém, mesmo com um espaço ativo adequado, conseguimos capturar apenas uma parte da correlação eletrônica. Essa parcela é chamada na literatura de correlação estática, devido a não estar associado ao movimento dos elétrons. Para resultados mais precisos, é necessário a inclusão da correlação dinâmica. Existem diversos casos na literatura em que a ordem correta dos estados eletrônicos é alcançada apenas levando em conta essa correção. Uma maneira de incluir tais efeitos é por meio do método CASPT2 (Multiconfigurational Second-Order Perturbation Theory) [77, 78]. Esse método é baseado na teoria de perturbação de segunda ordem, empregando a função de onda CASSCF como referência.

O Hamiltoniano de ordem-zero (não-perturbado) é construído de tal forma que a teoria de Møller-Plesset é obtida no caso de um único determinante de Slater, em um sistema de camada fechada. Ademais, a expansão perturbativa deve convergir rapidamente e que seja possível fazer uma eficiente implementação computacional do método. Nesse sentido, um Hamiltoniano geral que cumpre todos esses requisitos é da forma [78]:

$$
H_{0}=P_{0} F P_{0}+P_{k} F P_{k}+P_{S D} F P_{S D}+P_{X} F P_{X}
$$

sendo que, $P_{0}$ é o operador de projeção no espaço de referência, $P_{k}$ é o operador de projeção no espaço ortogonal ao espaço de referência, $P_{S D}$ é a projeção no espaço de excitações simples 
e duplas (também chamado de espaço interagente de $1^{a}$ ordem) geradas pela função de onda referência e que não estão incluídas em $P_{0}$ e $P_{k}$. Finalmente, $P_{X}$ é o operador de projeção no espaço de excitações de ordem mais altas (excitações triplas, quádruplas, etc) e que não estão nos outros operadores de projeção.

O Hamiltoniano é constituído de operadores de um e dois corpos, logo, o espaço interagente de $1^{\mathrm{a}}$ ordem será empregado para calcular a contribuição da energia de correlação. Um ponto a ser destacado é que as excitações simples não precisam ser tratadas explicitamente [79]. O espaço interagente de $1^{\text {a }}$ ordem pode ser dividido em oito subespaços, de acordo com a natureza da configuração excitada. As funções correspondentes são geradas aplicando o produto de operadores de excitação, $E_{p q}$ e $E_{r s}$, na função de onda de ordem-zero. Esses subespaços podem incluir excitações que envolvem apenas os orbitais dos espaços inativo e ativo (excitações internas), promoção de um elétron para o estado virtual (excitações semi-internas) e a excitação de dois elétrons para o estado virtual (excitações externas).

A correção em primeira ordem da função de onda é expandida na base das funções $|j\rangle$ pertencente ao espaço interagente de $1^{\text {a }}$ ordem:

$$
\left|\Psi_{1}\right\rangle=\sum_{j=1}^{M} C_{j}|j\rangle
$$

sendo que, $\mathrm{M}$ é a dimensão do espaço interagente de $1^{\mathrm{a}}$ ordem e os coeficientes da expansão $\left(C_{j}\right)$ são determinados a partir do sistema de equações lineares:

$$
\sum_{j=1}^{M} C_{j}\left\langle i\left|F-E_{0}\right| j\right\rangle=-\left\langle i|H| \Psi_{0}\right\rangle \quad i=1, \ldots, M
$$

A função de onda normalizada corrigida até $1^{a}$ ordem pode ser escrita como:

$$
|\Psi\rangle=C_{0}\left|\Psi_{0}\right\rangle+C_{1}\left|\Psi_{1}\right\rangle
$$

onde, $C_{0}^{2}+C_{1}^{2}=1$. O peso associado à função de onda CASSCF pode ser usado como um critério de qualidade para o tratamento perturbativo. Caso esse termo seja pequeno, é necessário aumentar o espaço ativo, incluindo as configurações mais relevantes.

A correção da energia em segunda ordem é dada pela usual fórmula da teoria de perturbação de Moller-Plesset (MP2):

$$
E_{2}=\sum_{i, j, a, b} \frac{\left\langle\Psi_{0}|H| \Psi_{i j}^{a b}\right\rangle}{\varepsilon_{a}+\varepsilon_{b}-\varepsilon_{i}-\varepsilon_{j}}
$$

sendo que, $\varepsilon$ são as energias orbitais. Os índices $i$ e $j$ se referem aos orbitais ocupados e $a$ e $b$ aos orbitais virtuais.

A expressão (2.22) funciona corretamente quando a diferença de energia entre os orbitais $\mathrm{HOMO}^{*}$ e LUMO ${ }^{\dagger}$ é significativa, pois o denominador apresentará um valor grande e positivo.

* Último orbital ocupado de acordo com o método HF.

† Primeiro orbital virtual de acordo com o método HF. 
Entretanto, isso nem sempre é verdade para os cálculos CASPT2. Os orbitais ativos com número de ocupação perto de dois podem exibir uma energia perto dos valores dos orbitais inativos. Por outro lado, os orbitais ativos com número de ocupação perto de zero podem exibir energias próximas dos orbitais externos. Dessa forma, temos o problema de estados intrusos, visto que o denominador na equação (2.22) será pequeno ou até mesmo negativo, conduzindo para contribuições altas e artificiais. Em suma, temos três distintos casos de estados intrusos:

- Possui uma interação nula ou muita pequena com a função de onda referência CASSCF. Consequentemente, a sua contribuição na correção da energia em segunda ordem será desprezível, a mesmo que o denominador seja próximo de zero.

- A interação é grande com a função de onda referência CASSCF. Nesse caso, a solução mais indicada é adicionar esse orbital ao espaço ativo.

- A interação com a função de onda referência CASSCF possui uma intensidade intermediária. Nesse caso, o estado intruso pode ser removido pela técnica level shift, mas se possível sempre é recomendado aumentar o espaço ativo.

Um caminho para remoção dos estados intrusos, como mencionado acima, é adicionar um level shift $\varepsilon$ ao Hamiltoniano de ordem zero (LS-CASPT2) [80], de tal maneira que a equação em primeira ordem da teoria de Rayleigh-Schrodinger será:

$$
\begin{aligned}
\left(H_{0}-E_{0}+\varepsilon\right) \tilde{\Psi}_{1} & =-\left(H_{1}-E_{1}\right) \tilde{\Psi}_{0} \\
H_{0} \Phi_{\mu} & =\epsilon \Phi_{0} \\
\tilde{\Psi}_{1} & =\sum_{\mu} \tilde{C}_{\mu} \Phi_{\mu}
\end{aligned}
$$

sendo que, o til denota as quantidades obtidas com o level shift. Fazendo o desenvolvimento matemático apropriado, os novos coeficientes e a nova energia serão dados por:

$$
\begin{aligned}
& \tilde{C}_{\mu}=-\frac{\left\langle\Phi_{\mu}\left|H_{1}\right| \Psi_{0}\right\rangle}{\epsilon_{\mu}-E_{0}+\varepsilon} \\
& \tilde{E}_{2}=-\sum_{\mu} \frac{\left|\left\langle\Phi_{\mu}\left|H_{1}\right| \Psi_{0}\right\rangle\right|^{2}}{\epsilon_{\mu}-E_{0}+\varepsilon}
\end{aligned}
$$

Como podemos ver na expressão (2.24), o level shift removerá o estado intruso, mas existe uma dependência com o valor dele. Para contornar esse problema, podemos reescrever a energia em segunda como:

$$
\tilde{E}_{2}=E_{2}+\varepsilon \sum_{\mu=1}^{M}\left|\tilde{C}_{\mu}\right|^{2}\left(1+\frac{\varepsilon}{\epsilon_{\mu}-E_{0}}\right)
$$

sendo, $E_{2}$ a correção da energia em segunda sem o level shift. 
Se assumirmos que os denominadores da expressão acima são grandes $\left(\epsilon_{\mu}-E_{0} \gg \epsilon\right)$, podemos aproximar $E_{2}$ por:

$$
E_{2}=\tilde{E}_{2}-\varepsilon\left(\frac{1}{\tilde{\omega}}-1\right) \equiv E_{2}^{L S}
$$

sendo que, $\tilde{\omega}$ representa o peso da função de onda referência CASSCF no cálculo com a inclusão do level shift.

A escolha do level shift não deve ser maior do que 0.3 u.a, sendo que a melhor escolha para $\varepsilon$ é o menor valor possível capaz de remover os estados intrusos. Na ausência de estados intrusos, o valor de $E_{2}^{L S}$ deverá variar lentamente em relação ao parâmetro $\varepsilon$. Detalhes adicionais e uma discussão mais ampla, consulte as referências 81-82.

Uma outra opção mais eficiente foi proposta por Forsberg e Malmqvist [83]. Esse método é uma simples modificação do método LS-CASPT2 empregando um deslocamento imaginário (imaginary level shift), que remove completamente os estados intrusos com uma pequena distorção na função de energia potencial. Além disso, os efeitos da escolha do imaginary level shift nas propriedades do sistema são pequenas. Ambas as possibilidades de remoção dos estados intrusos estão disponíveis no programa MOLCAS. Em nossos cálculos sempre utilizamos a técnica de imaginary level shift, utilizando o valor apropriado para remoção dos estados intrusos.

Na expressão (2.23), o operador de um életron $F$ corresponde à generalização do operador de Fock, que não possui uma única representação [84]. Dentre essas formulações, a mais utilizada e que foi empregada no CASPT2, é definir o operador de Fock generalizado como:

$$
F=\sum_{p q} f_{p q} E_{p q}
$$

sendo que,

$$
f_{p q}=h_{p q}+\sum_{r s} D_{r s}\left[(p q \mid r s)-\frac{1}{2}(p r \mid q s)\right]
$$

Esse operador de Fock generalizado possui a propriedade que $f_{p p}=-I P_{p}$ (potencial de ionização) quando o orbital $p$ é duplamente ocupado e $f_{p p}=-E A_{p}$ (afinidade eletrônica) quando o orbital $p$ está vazio. Logo, o valor de $f_{p q}$ estará entre esses dois extremos para os orbitais ativos. Dessa forma, essa escolha do operador de Fock generalizado faz com que a formulação seja um pouco desbalanceada e favoreça sistemas de camada aberta, conduzindo para energias de ligação baixas.

A fim de corrigir essa falha sistemática da definição do Hamiltoniano não-perturbado, foi desenvolvido uma modificação no Hamiltoniano de ordem-zero, chamado de IPEA (Ionization Potencial and Electron Affinity correction) shift [85]. O elemento da diagonal do operador de Fock generalizado $f_{p p}$ pode ser rescrito em termos do potencial de ionização e da afinidade eletrônica:

$$
f_{p p}=-\frac{1}{2}\left[D_{p p} I P_{p}+\left(2-D_{p p}\right) E A_{p}\right]
$$


sendo que, $D_{p p}$ assume os valores 0 e 2 nos casos limites. Para o caso de camada fechada $\left(D_{p p}=1\right)$ obtemos:

$$
f_{p p}=-\frac{1}{2}\left(I P_{p}+E A_{p}\right)
$$

A energia de um orbital excitado deveria estar perto do IP desse orbital, porém esse valor é muito mais alto. Por sua vez, a energia de um orbital que está sendo excitado deveria estar perto da EA, mas o valor é bem mais baixo. Esses resultados levam para energias baixas para estados de camada aberta, ocasionando baixas energias de excitação e dissociação. Então, Roos e colaboradores propuseram introduzir uma correção na equação (2.29) a fim de que a interpretação do potencial de ionização e da afinidade eletrônica seja recuperada. Essa correção é dada por:

$$
\sigma_{p}^{E A}=\frac{1}{2} D_{p p}\left(I P_{p}-E A_{p}\right)
$$

quando se excita para um orbital ativo e

$$
\sigma_{p}^{I P}=\frac{1}{2}\left(2-D_{p p}\right)\left(I P_{p}-E A_{p}\right)
$$

quando se excita a partir de um orbital ativo.

O problema dessa correção é que a afinidade eletrônica e o potencial de ionização são grandezas difíceis de serem calculadas. Para solucionar esse problema, Roos e colaboradores sugeriram usar uma parametrização simples, substituindo a diferença $I P_{p}-E A_{p}$ por um parâmetro de deslocamento $\epsilon$, que foi determinado como 0.25 u.a. Esse valor foi escolhido baseado nos resultados obtidos para todos os átomos da tabela periódica e para 49 moléculas diatômicas. Como pode ser visto na Figura 2.2, boa parte dos átomos da tabela periódica possuem valor de $\epsilon$ na faixa de 0.2 até 0.3 u.a.. Os efeitos em outras propriedades moleculares foram negligenciáveis. Contudo, estudos posteriores mostraram que esse escolha não é universalmente bem-sucedida e que um valor maior é indicado para algumas sistemas de metal de transição $[86,87]$. O IPEA shift está disponível por padrão no programa MOLCAS, mas seguindo uma sugestão recente [88], optamos sempre por desprezar essa correção.

Outros métodos perturbativos existem, como por exemplo, o método NEVPT2 ( $N$-Electron Valence State Perturbation Theory) proposto por Angeli e colaboradores [89] e o método multireferência QDPT (Quasi-Degenerate Perturbation Theory) [90]. O grande trunfo do método NEVPT2 é de que não existe problemas com estados intrusos, porém a sua aplicabilidade nos dias atuais é apenas para cálculos de energias de excitação verticais, não possibilitando o estudo da fofofísica e fotoquímica de moléculas. Um comparativo envolvendo esses métodos e outros multireferências aplicado nas bases canônicas pode ser consultado na referência 91 . 


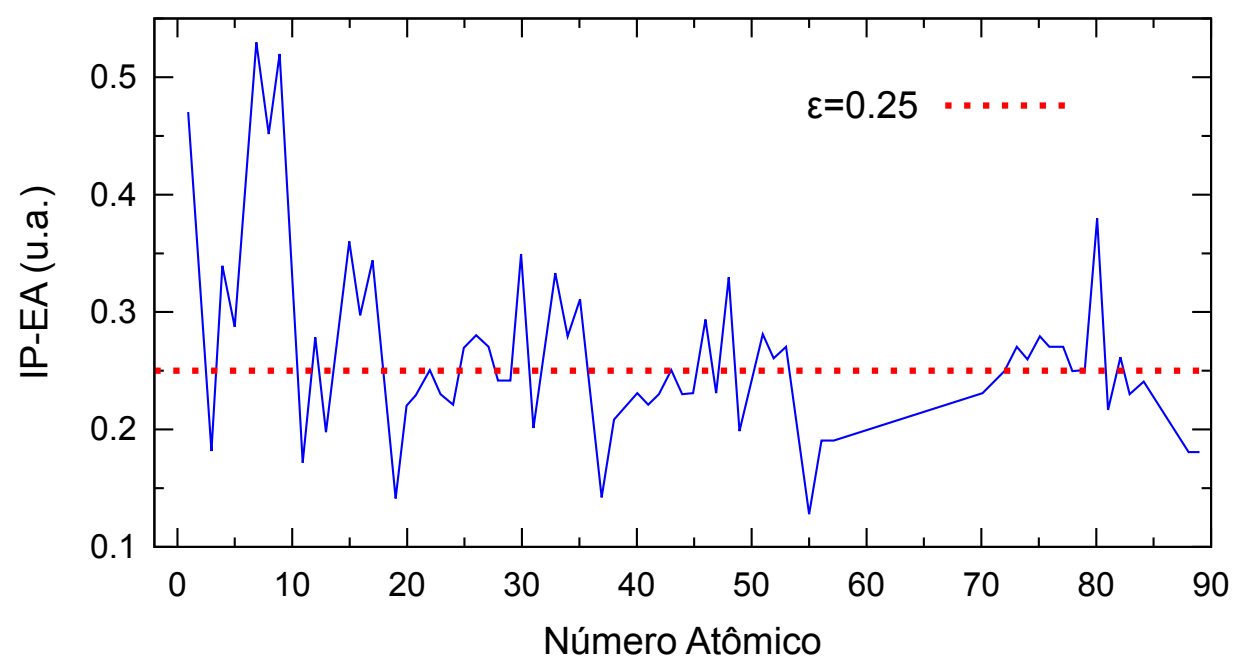

Figura 2.2 - Valores da diferença $I P_{p}-E A_{p}$ para todos os átomos da tabela periódica. A linha horizontal corresponde ao valor adotado para no IPEA ( $\epsilon=0.25$ u.a). A figura foi adaptada da referência 81.

\subsection{Método Multi-State CASPT2}

Em um cálculo de teoria de perturbação de estado único single-state CASPT2 (SS-CASPT2), as funções de onda geradas com o procedimento SA-CASSCF são usadas como estado de referência para a expansão perturbativa de cada estado separadamente. Nesse procedimento, não ocorre a relaxação da função de onda de ordem zero, ou seja, os coeficientes são mantidos constantes. Esse método não é adequado para descrever cruzamentos evitados e estados de Rydberg e valência quase-degenerados.

Para lidar com esses problemas citados acima, foi desenvolvido uma variante, chamado de método multi-state CASPT2 [92]. Nessa aproximação, uma matriz Hamiltoniana efetiva é construída, sendo que os elementos da diagonal correspondem às energias CASPT2 e os elementos fora da diagonal são os acoplamentos até segunda ordem na energia de correlação dinâmica.

Assumimos que $N$ estados eletrônicos são computados no procedimento state-averaged CASSCF, gerando as funções de onda de ordem-zero $\left(\Phi_{i}, i=1, \cdots, N\right)$ e as respectivas correções de $1^{a}$ ordem na função de onda $\left(\chi_{i}, i=1, \cdots, N\right)$ (depois do tratamento perturbativo). As funções de onda corrigidas até $1^{\text {a }}$ ordem podem ser escritas por: $\Psi_{i}=\Phi_{i}+\chi_{i}$. Essas funções não são ortonormais, visto que a integral de superposição é dada por:

$$
S_{i j}=\left\langle\Psi_{i} \mid \Psi_{j}\right\rangle=\left\langle\Phi_{i}|H| \Phi_{j}\right\rangle+\left\langle\Phi_{i}|H| \chi_{j}\right\rangle+\left\langle\chi_{i}|H| \Phi_{j}\right\rangle+\left\langle\mu_{i}|H| \mu_{j}\right\rangle=\delta_{i j}+s_{i j}
$$

sendo que, $s_{i j}=\left\langle\chi_{i} \mid \chi_{j}\right\rangle,\left\langle\Phi_{i} \mid \Phi_{j}\right\rangle=\delta_{i j}$ e $\left\langle\Phi_{i} \mid \chi_{j}\right\rangle=0$. 
Os elementos de matriz do Hamiltoniano serão dados por:

$$
H_{i j}=\left\langle\Phi_{i}+\chi_{i}|H| \Phi_{j}+\chi_{j}\right\rangle=\delta_{i j} E_{i}+\epsilon_{i j}+\epsilon_{j i}+\left\langle\chi_{i}|H| \chi_{j}\right\rangle
$$

sendo que, $E_{i}$ é a energia CASSCF para o estado $i$ e os elementos diagonais $\epsilon_{i i}=\left\langle\Phi_{i}|H| \chi_{i}\right\rangle$ são as energias de correlação CASPT2.

Como pode ser visto na equação (2.34), os elementos da diagonal do Hamiltoniano $\left(H_{i j}\right)$ são as energias CASPT2 e os elementos fora da diagonal representam o acoplamento até $2^{\mathrm{a}}$ ordem da energia de correlação dinâmica. Para resolver o último termo da equação (2.34), podemos expressar o Hamiltoniano como a soma da contribuição de ordem-zero e os efeitos remanescentes:

$$
H=H_{i}^{0}+H_{i}^{\prime}
$$

Logo,

$$
\left\langle\chi_{i}|H| \chi_{j}\right\rangle=\left\langle\chi_{i}\left|H_{i}^{0}\right| \chi_{j}\right\rangle+\left\langle\chi_{i}\left|H_{i}^{\prime}\right| \chi_{j}\right\rangle
$$

No entanto, o último termo é negligenciado, pois corresponde à uma contribuição de $3^{a}$ ordem na energia. Além disso, é requerido que a matriz seja hermitiana, significando que a matriz Hamiltoniana efetiva assimétrica deve ter elementos fora da diagonal similares e pequenos. Levando isso em consideração, podemos escrever em termos de um valor médio:

$$
\left\langle\chi_{i}|H| \chi_{j}\right\rangle \approx\left\langle\chi_{i}\left|H_{i}^{0}\right| \chi_{j}\right\rangle=\frac{1}{2}\left(\left\langle\chi_{i}\left|H_{i}^{0}\right| \chi_{j}\right\rangle+\left\langle\chi_{j}\left|H_{j}^{0}\right| \chi_{j}\right\rangle\right)
$$

Caso a equação (2.37) não seja válida, levando para uma matriz não simétrica, a única solução é aumentar o espaço ativo. Mesmo se essa tática não for suficiente, o método MSCASPT2 não poderá ser aplicado, conduzindo para resultados não-físicos. A alternativa é empregar o procedimento de estado único CASPT2.

Os elementos de matriz da equação (2.37) podem ser computados facilmente utilizando a expressão (2.20). Fazendo esse procedimento e substituindo a equação (2.37) em (2.34), podemos finalmente reescrever os elementos de matriz do Hamiltoniano como:

$$
H_{i j}=\delta_{i j} E_{i}+\epsilon_{i j}+\frac{1}{2}\left(E_{i}^{0}+E_{j}^{0}\right) s_{i j}+\frac{1}{2}\left(\epsilon_{i j}+\epsilon_{j i}\right)
$$

Dessa forma, devemos resolver a seguinte equação secular:

$$
(\mathbf{H}-E \mathbf{S}) \mathbf{C}=0
$$

Resolvendo a equação (2.39), obtemos as energias MS-CASPT2 e a função de onda de cada estado pode ser escrita como:

$$
\Psi_{i}=\sum_{j} C_{i j} \Phi_{j}+\chi_{i}=\Phi_{i}^{\prime}+\chi_{i}
$$


A função de onda MS-CASPT2 nada mais é do que uma combinação linear das funções de onda CASSCF, com seus respectivos pesos, acrescido da correção perturbativa em $1^{\text {a }}$ ordem. $\mathrm{Na}$ expressão acima, podemos ver que a função $\Phi_{i}^{\prime}$, chamada de perturbation modified CAS (PMCAS) [92], é uma espécie de nova função de onda referência para o estado $i$.

Cuidados adicionais devem ser tomados quando empregado o método MS-CASPT2 para estudos de intersecções cônicas. Merchán e Serrano-Andrés têm sugerido o uso do método XMS-CASPT2 (extended multi-state CASPT2) para regiões de cruzamentos [69]. Sua principal diferença com o método MS-CASPT2 é a adição de termos não-diagonais no operador de Fock generalizado [93]. Ambas as implementações (MS-CASPT2 e XMS-CASPT2) estão disponíveis no programa MoLCAS.

\subsection{Escolha do espaço ativo}

Na essência do método multiconfiguracional CASSCF está a escolha dos orbitais que integrarão o espaço ativo. Uma boa descrição das propriedades de interesse dependerá dessa seleção. De maneira geral, os orbitais que devem compor o espaço ativo devem ser os mais relevantes para descrever o processo em questão. Entretanto, nem sempre isso é uma tarefa simples e um demasiado número de testes devem ser efetuados. Abaixo listamos algumas regras sugeridas por Roos e colaboradores, que de certa forma ajudam a clarear quais são os orbitais mais importantes para cada tipo de sistema [94].

No caso de pequenas moléculas, com um número de até 4 átomos (exceto hidrogênios), uma boa escolha é incluir todos os orbitais de valência. Para os átomos $\mathrm{Li}, \mathrm{B}$ e $\mathrm{C}$, que pertencem ao $2^{\circ}$ período da tabela periódica, devemos adicionar os orbitais $2 s$ e $2 p$. O orbital $2 s$ pode ser removido do espaço ativo para os elementos mais pesados dessa linha ( $N, O$ e F). Para átomos do $3^{\circ}$ período, é preciso acrescentar os orbitais $3 s$ e $3 p$, mas a medida que o número de elétrons de valência é maior do que 3 , podemos excluir o orbital $3 s$ do espaço ativo.

Para metais de transição, é aconselhado a inclusão dos orbitais $4 s, 3 d$ e $4 p$. Caso o átomo faça parte da $1^{a}$ linha de metais de transição e a camada $3 d$ esteja mais da metade preenchida, talvez seja necessário inserir uma camada $3 d$ extra no espaço ativo. Isso às vezes é necessário devido aos fortes efeitos da correlação dinâmica, sendo chamado de efeito de dupla camada (double-shell effect). Os efeitos de dupla camada são menos severos para a $2^{a}$ e $3^{a}$ linha, logo, o preenchimento de uma segunda camada de orbitais $3 d, 4 d$ ou $5 d$ não é necessária. Para complexos de metal de transição, a situação é mais difícil, pois devemos adicionar também os orbitais dos ligantes. Metais em altos graus de oxidação formam ligações covalentes e isso requer mais orbitais dos ligantes no espaço ativo.

No caso dos lantanídeos, devemos incluir os orbitais $4 f, 6 s, 6 p$ e $5 d$ e para os actinídeos é preciso a inclusão dos orbitais $5 f, 7 s, 7 p$ e $6 d$. Um similar efeito de dupla camada pode 
ocorrer, consequentemente, a inserção de uma dupla camada nos orbitais $f$ pode ser solicitada.

Para descrição de estados excitados de moléculas orgânicas, comumente, é necessário a inclusão de todos os orbitais $\pi$ (ocupados e virtuais) e os orbitais associados aos pares de elétrons isolados, descrevendo as excitações do tipo $n \rightarrow \pi^{*}$. Em alguns casos, é preciso adicionar os orbitais de Rydberg. No caso de dissociação de um determinado grupo da molécula, devemos incluir o orbital molecular ligante $\sigma$ e o seu respectivo anti-ligante $\sigma^{*}$.

Mesmo com essas regras, nem sempre é possível adicionar todos os orbitais relevantes no espaço ativo. Isso se deve à quantidade de CSF crescer drasticamente com o aumento do espaço ativo. O número de CSF de uma dada simetria de spin $\mathrm{S}$ para $\mathrm{N}$ elétrons e $\mathrm{n}$ orbitais pode ser estimada por meio da fórmula de Weyl:

$$
K(n, N, S)=\frac{2 S+1}{n+1}\left(\begin{array}{c}
n+1 \\
\frac{N}{2}-S
\end{array}\right)\left(\begin{array}{c}
n+1 \\
\frac{N}{2}+S+1
\end{array}\right)
$$

Uma possibilidade para selecionar o espaço ativo adequado é através do método RASSCF (Restricted Active Space SCF) [95]. Esse método é uma extensão da aproximação CASSCF, sendo que o espaço ativo é divido em três subespaços. Em dois deles são feitas restrições no número de excitações. Dessa forma, o custo computacional é reduzido, permitindo a utilização de espaços ativos maiores. A grande desvantagem é a dificuldade de convergência do espaço ativo em alguns casos. Uma maior flexibilidade na escolha do espaço ativo pode ser alcançada empregando o método GASSCF (Generalized Active Space SCF). No método GASSCF [96], um número arbitrário de particionamentos do espaço ativo pode ser adotado e em cada um desses subespaços são feitas restrições no número de excitações.

Outra tática para se determinar um espaço ativo adequado é por meio do número de ocupação dos orbitais naturais, que são os autovalores da matriz densidade. Esse número de ocupação varia entre zero e dois. Se o orbital possui número de ocupação perto de dois, significa que há poucas excitações a partir desse orbital. Por outro lado, se o orbital possui número de ocupação quase nula, significa que raramente acontece uma transição para esse orbital. Logo, os orbitais que estão fora desses dois regimes devem ser incluídos no espaço ativo. 


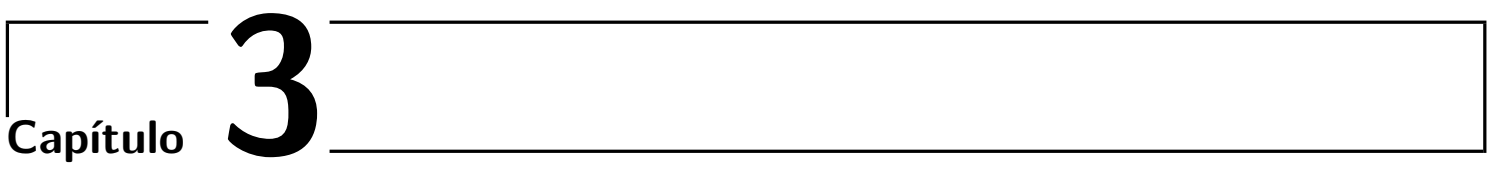

\section{Dinâmicas Não-Adiabáticas}

Nesse capítulo são discutidos algumas técnicas computacionais que visam a evolução temporal dos núcleos e dos elétrons incluindo os acoplamentos não-adiabáticos. As dinâmicas quânticas são as técnicas mais refinadas para esse estudo, mas demanda um alto custo computacional e na maioria das vez é infactível, mesmo nos dias atuais. Dinâmicas semiclássicas vêm para torna esse estudo mais viável. Dentre esses métodos focaremos no algoritmo Surface Hopping (SH). Algumas ingredientes essenciais que devem ser levados em conta na dinâmica SH são elucidados a fim de mostrar a importância de uma boa escolha de cada parâmetro.

\subsection{Dinâmicas quânticas}

Como visto no capítulo de métodos multiconfiguracionais, a evolução temporal no regime não-relativístico de uma molécula é governada pela equação de Schrödinger dependente do tempo. Dentro da aproximação BOA, os acoplamentos são neglicenciados e, como resultado, os núcleos se movem em um potencial correspondente a um único estado eletrônico. A partir daqui levaremos em conta esses acoplamentos não-adiabáticos, com o propósito de ver a evolução temporal dos núcleos além da aproximação BOA.

A solução numérica da equação de Schrödinger dependente do tempo é possível para um pequeno número de graus de liberdade nucleares. Essa tipo de propagação na literatura é conhecido como dinâmica quântica completa ou dinâmica de pacote de onda. A estratégia para solução dessa equação consiste em discretizar as amplitudes nucleares (função de onda nuclear), e também os diferentes operadores, em um grid numérico antes da realização da propagação da função de onda nuclear. A discretização pode ser feita por meio de um conjunto de pontos para cada grau de liberdade considerado.

Uma aproximação mais geral das dinâmicas quânticas (QD) é o uso de um conjunto de funções base independentes do tempo $\left(\phi_{k}\left(R_{k}\right)\right)$ para descrever cada grau de liberdade nuclear. 
Considerando que cada um dos $f$ graus de liberdade é expresso por $N$ funções bases, o custo computacional escala com $N^{f}$. Isso restringe a aplicação de simulações de dinâmica quântica numéricas para sistemas com no máximo 10 graus de liberdade. Logo, uma seleção cuidadosa dos modos nucleares essenciais é necessária para estudar a dinâmica não-adiabática de uma dada molécula. Outro ponto crítico é o pré-calculo de todas as informações necessárias de estrutura eletrônica. Por fim, há o grande desafio de integrar a equação de Schrödinger dependente do tempo. Diferentes integradores são disponíveis para essa tarefa, como por exemplo, o operador de divisão (split operator) [97].

Existem diversas propostas na literatura para tornar viável o uso de dinâmicas quânticas para sistemas maiores, incluindo um número maior de graus de liberdade nucleares. Destacamos aqui, o método Hartree multiconfiguracional dependente do tempo (MCTDH) [98]. As primícias desse método ainda estão fundadas na solução da equação de Schrödinger nuclear, porém é introduzido uma aproximação na função de onda. Nesse método a função de onda nuclear é expressa como:

$$
\Psi^{\text {nuc }}(\mathbf{R}, t)=\sum_{i=1}^{N_{1}} \cdots \sum_{f=1}^{N_{f}} c_{i \ldots j}(t) \prod_{k=1}^{f} \phi_{k}\left(R_{k}\right)
$$

A equação de movimento MCTDH deve ser resolvida para os coeficientes da função de onda $\left(c_{i \ldots j}(t)\right)$ e para as funções bases $\left(\phi_{k}\left(R_{k}\right)\right)$. Assim, a expansão das funções bases pode ser reduzida em comparação com as dinâmicas quânticas completas, reduzindo o custo computacional. Entretanto, o método MCTDH ainda escala exponencialmente com respeito ao número de graus de liberdade nuclear. Estratégias adicionais permitem reduzir o custo computacional desse método, baseado, por exemplo, em combinação de modos (dinâmicas com até 30 modos) ou múltiplas camadas MCTDH (dinâmicas com > 100 modos) [99].

Outra possível estrategia é por meio da representação das funções de onda nucleares em termos de combinações lineares de trajectories basis function (TBF), que são funções gaussianas multidimensionais. Usando essa representação para as amplitudes nucleares, é possível chegar em um conjunto de equações para os coeficientes de expansão que acoplam todos as TBF's. No limite de um número infinito de TBF'S, converge para a reprodução da solução da dinâmica quântica completa.

No mesmo espírito do método MCTDH, é empregado um número reduzido de TBF's. O desafio é definir um conjunto razoável de equações de movimento para as TBF's que descreva fielmente a função de onda nuclear, mas com o menor custo computacional viável. Dentre essas estratégias, podemos citar o método variacional multiconfiguracional gaussiano [100], que garante que a solução das equações das TBF's conduzem para uma boa função de onda nuclear durante toda a propagação da dinâmica. Existem outras propostas na literatura, como por exemplo, os métodos Ehrenfest multiconfiguracional [101] e o Full Multiple Spawning.

Para um review completo de diversos métodos de dinâmicas quânticas, sugerimos que o leitor consulte a referência 102. 


\subsection{Dinâmicas semiclássicas}

Na seção anterior discorremos brevemente a proposta das dinâmicas quânticas, que compreende uma preservação, na medida do possível, da natureza quântica dos graus de liberdade nucleares. Essa descrição puramente quântica incluem efeitos quânticos inerentes, tais como, tunelamento, coerência, interferência, etc. Todavia, ainda nos dias atuais, uma simulação de dinâmica quântica de sistemas grandes demanda um alto custo computacional, mesmo com a redução da dimensionalidade da função de onda nuclear.

Uma abordagem menos custosa é obtida pelo detalhamento dos núcleos do ponto de vista clássico. Os núcleos são propagados no tempo seguindo uma trajetória clássica ditada pela leis de Newton. Essa combinação de descrições clássicas e quânticas é chamada de dinâmica semiclássica ou dinâmica clássica-quântica mista (mixed quantum-classical dynamics). Existem várias propostas na literatura e exemplificaremos três tipos de aproximação. Para mais detalhes sobre outros tipos de dinâmicas semiclássicas, assim como, os recentes avanços e perspectivas, veja a referência 103.

\subsubsection{Dinâmica de Ehrenfest}

As dinâmicas semiclássicas baseadas somente nas equações de Newton não são capazes de descrever estados excitados, visto que os núcleos clássicos estão presos a uma única superfície de energia potencial.

A dinâmica de Ehrenfest é uma extensão da dinâmica molecular clássica incluindo a possibilidade de descrição de estados excitados. Esse método também é chamado de dinâmica de campo médio. Pressupondo que a mecânica quântica é uma teoria universal da matéria, a situação clássica é alcançada em um caso particular do formalismo quântico. Essa conexão é obtida pelo teorema de Ehrenfest. Utilizando esse teorema, podemos definir uma segunda lei de Newton para o movimento nuclear por meio de um potencial efetivo médio. Assim, a força que atua no núcleo A será dada por:

$$
\mathbf{F}_{A}(\overline{\mathbf{R}})=-\nabla_{A}\left\langle\Psi^{\text {ele }}(\mathbf{r}, t)\left|\mathcal{H}_{\text {ele }}(\mathbf{r} ; \overline{\mathbf{R}})\right| \Psi^{\text {ele }}(\mathbf{r}, t)\right\rangle
$$

Dentro da dinâmica Ehrenfest, a função de onda eletrônica é escrita como uma combinação linear de diversos estados eletrônicos:

$$
\Psi^{\mathrm{ele}}(\mathbf{r}, t ; \overline{\mathbf{R}})=\sum_{\alpha} c_{\alpha}(t) \Psi_{\alpha}(\mathbf{r} ; \overline{\mathbf{R}})
$$

sendo que, $\Psi_{\alpha}$ é a função eletrônica associada ao estado $\alpha$.

Uma ilustração esquemática da equação de movimento na dinâmica de Ehrenfest é mostrada na Figura 3.1. O método Ehrenfest fornece bons resultados se as superfícies de energia potencial 
dos vários estados eletrônicos são similares em topologia e em energia. Contudo, como é empregado um potencial efetivo médio, algumas trajetórias podem seguir estados mistos não físicos depois de passar por uma região de alto acoplamento não-adiabático. Além disso, o princípio do balanço detalhado não é satisfeito, significando que no equilíbrio o processo em uma direção não é balanceado pelo seu processo reverso. Uma extensão, chamado de método Ehrenfest multiconfiguracional [101], soluciona as principais desvantagens dessa dinâmica de campo médio.

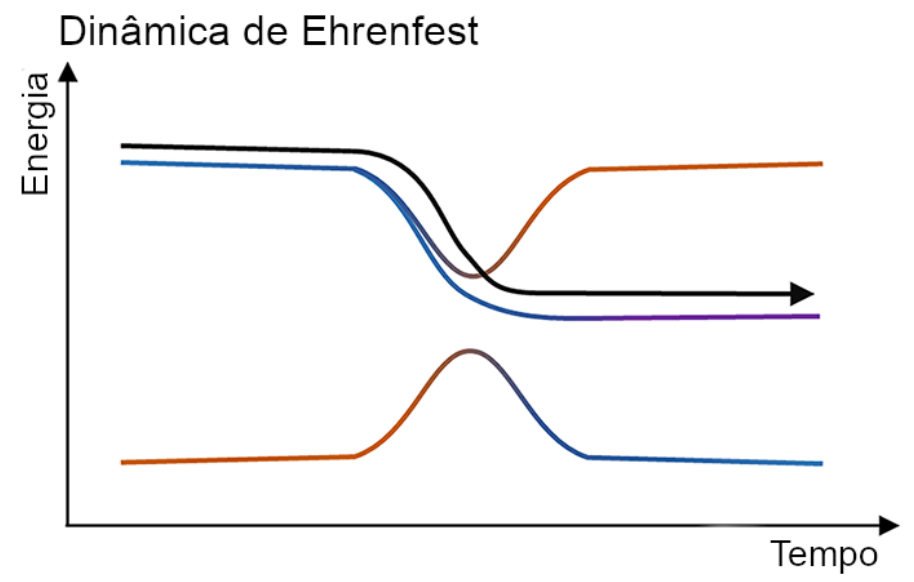

Figura 3.1 - Ilustração esquemática da equação de movimento na dinâmica de Ehrenfest para um sistema com três estados eletrônicos. Nesse modelo, a trajetória é propagada em um superfície de energia potencial média, que é obtida pela soma sobre todos os estados eletrônicos ponderado pela respectiva população eletrônica. A seta em preto corresponde à trajetória para esse sistema fictício. A Figura foi adaptada da referência 103.

\subsubsection{Método Multiple Spawning}

A ideia do método multiple spawning (MS) é expandir a função de onda nuclear por intermédio de funções gaussianas congeladas, ou seja, que possuam uma largura fixa e são independentes do tempo. Esse pacote de onda, que consiste do produto de $3 N$ funções de onda congeladas, é chamado de TBF (do inglês - trajectory basis function).

Na formulação formal exata, o método MS é conhecido como full multiple spawning (FMS). Por outro lado, se o método MS é acoplado a algum método de estrutura eletrônica, é comumente chamado de ab initio multiple spawning (AIMS). No caso do método AIMS, o pacote de onda nuclear propaga em uma superfície de energia potencial eletrônica adiabática. Na região de cruzamento, o pacote de onda se divide (spawing) em dois pacotes de onda independentes. Uma ilustração pictórica dessa dinâmica é exibida na Figura 3.2.

Essas TBFs não possuem um número constante para um dado estado eletrônico $\alpha$, sendo 


\section{Multiple Spawning}

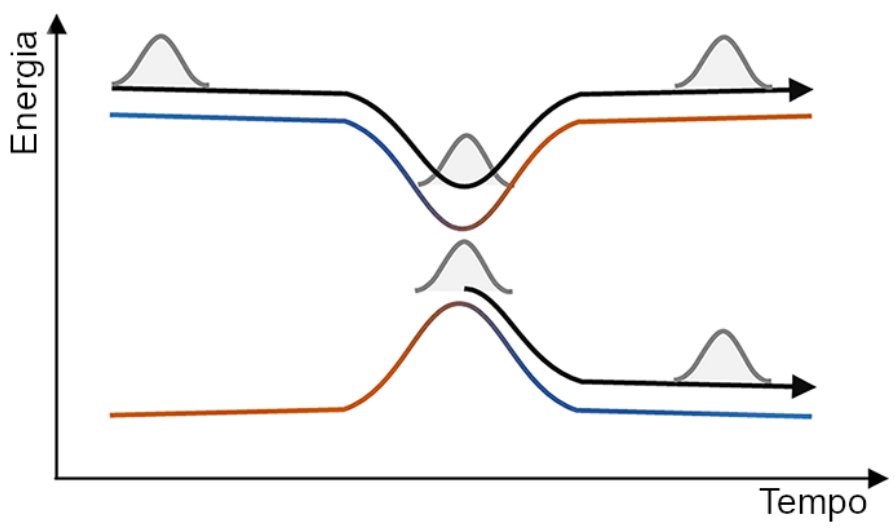

Figura 3.2 - Ilustração esquemática da equação de movimento na dinâmica ab initio multiple spawning para um sistema com dois estados eletrônicos. Nesse modelo, pacotes de onda gaussianos são propagados em trajetórias clássicas. Na região de acoplamento, existe uma divisão (spawning) do pacote de onda, que é dividido em duas subsequentes funções gaussianas. A Figura foi adaptada da referência 103.

que cada pacote de onda subsequente é capaz de posteriormente subdividir, e assim por diante.

\subsubsection{Dinâmica Surface Hopping}

O método Surface Hopping (SH) foi proposto por Tully e Preston no começo da década de 70 [104]. A hipótese básica é que durante a dinâmica não-adiabática, os núcleos movemse adiabaticamente boa parte do tempo e em períodos de tempo relativamente curtos sofre transições não-adiabáticas. A aproximação proposta é aproximar essas transições não-adiabáticas por saltos (hops) entre as superfícies de energia potencial adiabáticas. Na Figura 3.3 é ilustrada esse conceito, juntamente com uma comparação envolvendo a evolução temporal através de um pacote de onda quântico.

Originalmente, o método SH foi proposto como uma aproximação ad hoc para dinâmica não-adiabática, contudo, demonstrações mais rigorosas com mecânica quântica foram feitas ao decorrer do tempo $[105,106]$. Essas demonstrações se baseiam na equação de Liouville e assumem (i) trajetórias únicas, (ii) velocidades nucleares altas e que (iii) a decoerência eletrônica é proporcional a diferenças das forças de cada um das superfícies de energia potencial.

As vantagens desse método são fundadas na sua simplicidade, praticidade e escalabilidade. $\mathrm{O}$ método $\mathrm{SH}$ lida eficientemente com sistemas poliatômicos grandes e existe a possibilidade da propagação de diversas trajetórias independentes em paralelo. Além disso, é factível do ponto de vista computacional a inclusão de todos os graus de liberdades nucleares. Se a adição da decoerência for feita corretamente, escolhendo um adequado nível de teoria, esse método fornece resultados bastante precisos. Todas essas vantagens fazem como esse método seja um 
(a) Pacote de Onda Quântico

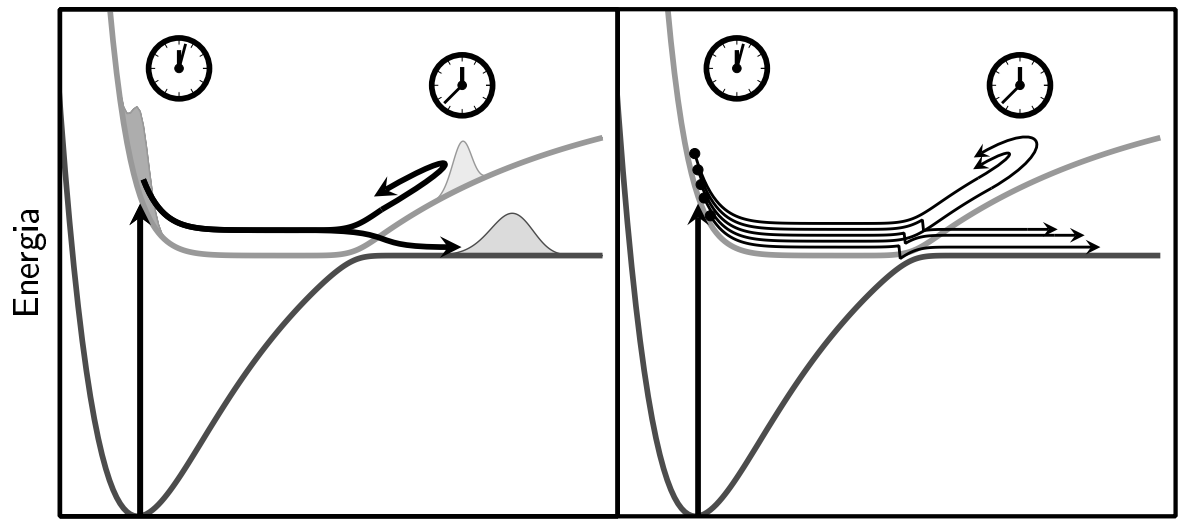

Coordenada (b) Trajetórias Surface Hopping

Coordenada

Figura 3.3 - Comparação entre o (a) pacote de onda quântico e (b) trajetórias SH. No painel (a), o pacote de onda está inicialmente no estado superior, movendo-se para a direita. Depois do cruzamento evitado, esse pacote de onda é dividido em duas partes. O pacote de onda da parte inferior continua se movendo para a direita, enquanto o o outro é refletido. No painel (b), cinco trajetórias SH são inicialmente promovidas para o estado superior. No cruzamento, três trajetórias saltam (hop) para o estado inferior, a medida que duas trajetórias continuam no mesmo estado e são subsequentemente refletidas.

dos mais extensivamente utilizados quando se trata de simulações de dinâmica não-adiabática.

Entretanto, como todo método, possui as suas limitações. Dentre elas, destacamos a perda de efeitos quânticos, tal como uma correta descrição da energia de ponto-zero, tunelamento e interferências nucleares.

Dentro da aproximação SH, os núcleos seguem uma equação de movimento newtoniana:

$$
M_{A} \frac{\partial^{2} \mathbf{R}_{A}}{\partial t^{2}}=-\frac{\partial E_{\text {ele }}}{\partial \mathbf{R}_{A}}
$$

sendo, $E_{\text {ele }}$ a energia eletrônica e $M_{A}$ e $R_{A}$ são, respectivamente, a massa e a posição do núcleo $A$. A evolução temporal das posições de todos os núcleos $\mathbf{R}(t)$ é denominada de trajetória.

Além dos núcleos, no método SH é considerado uma função de onda para os elétrons. Essa função de onda é expressa como uma combinação linear de estados bases:

$$
\left|\Psi_{\text {ele }}\right\rangle=\sum_{\alpha} c_{\alpha}(t)\left|\Psi_{\alpha}(t)\right\rangle
$$

sendo que, $\alpha$ corre sobre as bases de estados, $c_{\alpha}(t)$ são os coeficientes da expansão e $\left|\Psi_{\alpha}(t)\right\rangle$ são as bases de estado.

A evolução temporal da função de onda segue a equação de Schrödinger dependente do tempo, e que por sua vez, é afetada pelas coordenadas nucleares $\mathbf{R}(t)$ devido à dependência paramétrica do Hamiltoniano eletrônico com essa coordenadas. Por outro lado, a evolução de 
$\mathbf{R}(t)$ depende do gradiente da energia eletrônica. Dessa maneira, fica claro que a evolução temporal dos núcleos e dos elétrons está acoplada.

Ao contrário do pacote de onda quântico, os núcleos clássicos podem seguir apenas uma força particular em cada instante de tempo. Dentro do algoritmo $\mathrm{SH}$, essa força é dada pelo gradiente do estado eletrônico ativo (denotado pelo símbolo $\beta$ ). Em ordem de determinar o estado ativo, a composição da função de onda eletrônica é monitorada por meio da população em cada estado eletrônico. Quando a população do estado ativo atual diminui, são computadas probabilidades para trocar o estado ativo atual. Se a mudança é aceita, dizemos que houve um surface hop, daí o nome do método. Como a superfície de energia potencial do novo estado ativo difere do antigo, é necessário ajustar a energia cinética para manter a conservação da energia total. Existem várias maneiras de se fazer esse ajuste, como por exemplo, reescalonando o vetor velocidade total $\mathbf{v}$ ou simplesmente uma das componentes desse vetor.

Em um roteiro simplista, o algoritmo SH para um passo de tempo é composto das seguintes etapas:

1. Calcular as novas posições dos núcleos;

2. Computar as quantidades eletrônicas: energia, gradiente e acoplamentos

3. Calcular os novos coeficientes eletrônicos;

4. Escolher um novo estado ativo e obter as forças correspondentes;

5. Retornar para o passo 1.

Historicamente, antes de uma simulação SH ser realizada, a forma completa das superfícies de energia potencial eram definidas, comumente por meio de funções parametrizadas. Todas as propriedades eletrônicas eram computadas diretamente a partir dessas funções. Hoje em dia, a maioria das simulações SH são feitas on the fly, significando que todas as quantidades são calculadas no atual passo de tempo, empregando métodos de estrutura eletrônica ab initio, baseados na densidade eletrônica, semi-empírico, etc.

\subsection{Ingredientes da dinâmica Surface Hopping}

A motivação desse capítulo é embasada na descrição dos principais métodos de dinâmicas não-adiabáticas, focando no método SH. Como mostrado na seção anterior, a ideia básica do método SH é bastante simples. Contudo, nas últimas décadas, várias variantes foram implementadas. Essas novas implementações mudam alguma parte do algoritmo do $\mathrm{SH}$, como por exemplo, a equação empregada para calcular as probabilidades de hop ou outra maneira de 
deixar a energia conservada durante o hop. Nessa seção, detalharemos os principais fatores que devem ser levados em consideração na dinâmica SH.

\subsubsection{Movimento Nuclear}

No método $\mathrm{SH}$, um dos melhores algoritmos para solucionar as equações de Newton é empregando o algoritmo velocity-Verlet [107]. Nesse algoritmo, as posições nucleares são atualizadas com a seguinte expressão:

$$
\mathbf{R}_{A}(t+\Delta t)=\mathbf{R}_{A}(t)+\mathbf{v}_{A}(t) \Delta t+\frac{1}{2} \frac{\nabla_{A} E_{\beta}}{M_{A}} \Delta t^{2}
$$

É importante notar que a equação do lado direto depende apenas das quantidades no instante de tempo $t$, significando que essa equação é a primeira a ser calculada na iteração. As velocidades no algoritmo velocity-Verlet são atualizados por:

$$
\mathbf{v}_{A}\left(t+\Delta_{t}\right)=\mathbf{v}_{A}+\frac{1}{2} \frac{\nabla_{A} E_{\beta}(t)+\nabla_{A} E_{\beta}(t+\Delta t)}{M_{A}} \Delta t
$$

$\mathrm{Na}$ equação (3.7) é requerido calcular a quantidade $\nabla_{A} E_{\beta}(t+\Delta t)$, logo, para conservação da energia, em ambas as equações (posição e velocidade) deve ser utilizado o mesmo espaço ativo. Dessa forma, a decisão de fazer o hop é tomada depois da atualização das velocidades.

\subsubsection{Propagação da função de onda}

A partir da equação de Schrödinger, podemos encontrar uma equação de movimento para os coeficientes da expansão da expressão (3.5), dada por:

$$
\frac{\partial}{\partial t} c_{\beta}=-\sum_{\alpha}\left[i H_{\beta \alpha}+K_{\beta \alpha}\right] c_{\alpha}
$$

sendo, $H_{\beta \alpha}=\left\langle\Psi_{a}|\hat{H}| \Psi_{\beta}\right\rangle$ e $K_{\alpha \beta}=\left\langle\Psi_{\alpha}|\partial / \partial t| \Psi_{\beta}\right\rangle=\mathbf{v} \cdot\left\langle\Psi_{\alpha}|\nabla| \Psi_{\beta}\right\rangle$.

A equação (3.8) pode ser integrada numericamente, empregando, por exemplo, o método de Runge-Kutta. Entretanto, essa equação é difícil de ser integrada, principalmente devido ao termo $\mathbf{K}(t)$ mudar localmente extremamente rápido. Além disso, $\mathbf{K}(t)$ é usualmente calculado a partir de vetores de acoplamento adiabáticos $\left(\left\langle\Psi_{\alpha}|\nabla| \Psi_{\beta}\right\rangle\right)$, que são difíceis de serem obtidos em implementaç̃oses de diversos métodos de estrutura eletrônicas (métodos single-reference). Assim, muitas implementações de $\mathrm{SH}$ estimam o valor de $\mathbf{K}(t)$ aproximadamente a partir de diferenciações numéricas dos elementos da matrix de superposição [108], isto é:

$$
K_{\alpha \beta}(t+\Delta t / 2) \sim \frac{1}{2 \Delta t}\left[S_{\alpha \beta}(t, t+\Delta t)-S_{\alpha \beta}(t+\Delta t, t)\right]
$$


com o overlap $S_{\alpha \beta}$ definido como:

$$
S_{\alpha \beta}(t, t+\Delta t)=\left\langle\Psi_{\alpha}(t) \mid \Psi_{\beta}(t+\Delta t)\right\rangle
$$

A vantagem dessa abordagem é que os elementos $S_{\alpha \beta}$ podem ser sempre obtidos se uma representação dos estados eletrônicos é conhecida [109]. Um método mais sofisticado é o chamado local diabatization scheme [110], que tem se mostrado ser numericamente mais estável do que esquemas normais de integração da quantidade $\mathbf{K}$ [111]. Essa estabilidade é alcançada evitando a combinação de diferenciações numéricas de $\mathbf{S}(t, t+\Delta t)$ para obter $\mathbf{K}$ e a subsequente integração. Dentro dessa proposta, $\mathbf{K}$ não é nunca calculado explicitamente. Ao invés disso, a matriz de superposição $\mathbf{S}$ é diretamente inserida na propagação temporal dos coeficientes $c_{\beta}$.

\subsubsection{Decoerência}

Um grande problema da formulação original do algoritmo SH é devido as populações eletrônicas serem propagadas como muito mais coerência [112]. Um exemplo desse problema é ilustrado na Figura 3.4a, quando uma trajetória passa através de um cruzamento envolvendo duas superfícies de energia potencial. Inicialmente, a trajetória está no estado superior, com $100 \%$ das amplitudes eletrônicas correspondente a esse estado. Depois do cruzamento, $60 \%$ da amplitude é transferida para o estado mais baixo, induzindo um hop. A partir desse ponto, a trajetória segue o gradiente do estado mais baixo. O problema central é que as amplitudes no estado superior ( $40 \%$ ) também seguem o gradiente do estado mais baixo, embora deveria ser classicamente proibida. Uma vez que a trajetória se depara com um segundo cruzamento, existirá interferência eletrônica entre os estados inferior e superior. Todavia, nenhum tipo de interferência deveria existir, visto que o estado superior é proibido.

Uma maneira de resolver esse problema é por meio de um algoritmo de correção, que ao longo do tempo diminui as amplitudes dos estados inativos, de modo que após um certo tempo depois de atravessar um cruzamento, a trajetória recupera uma função de onda pura. Isso é ilustrado no painel (b) da Figura 3.4. Depois do hop para o estado mais baixo, a correção de decoerência destrói a população do estado superior, de tal forma que não há interferência no segundo cruzamento.

Existem diversos esquemas de decoerência propostos para o algoritmo $\mathrm{SH}$, mudando basicamente como é modelado as amplitudes dos estados inativos. Um esquema de decoerência bastante simples e popular é a utilização de um amortecimento exponencial no tempo, com a taxa de decaimento dependente da energia cinética [113]. Esquemas mais robustos introduzem trajetórias auxiliares para cada estado eletrônico, visando representar o quão rápido as amplitudes ativa e não-ativa se separam no espaço de fase $[114,115]$. A grande vantagem desses 


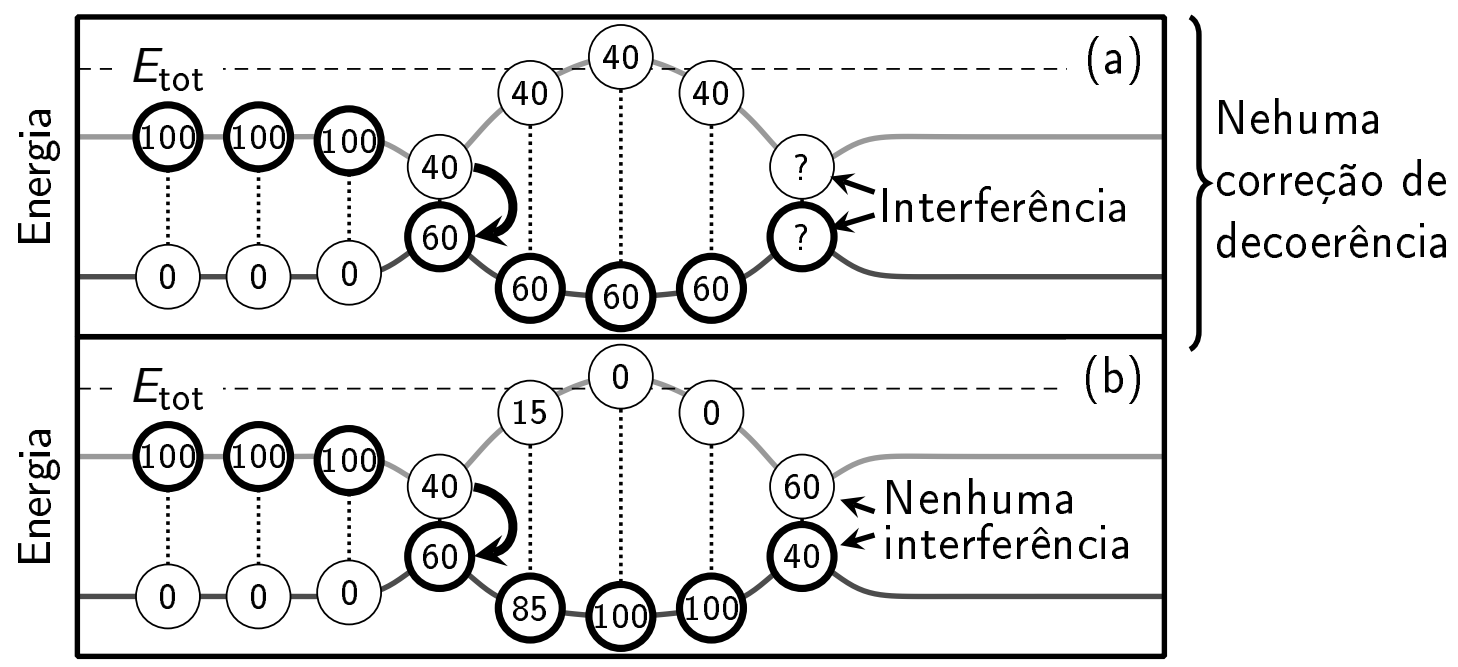

Figura 3.4 - Esboço explicando o problema da decoerência no método SH. A figura mostra uma única trajetória passando por um ponto de cruzamento duplo. Os números nos círculos correspondem à população no respectivo estado em cada etapa de tempo, com o círculo em negrito denotando o estado ativo. No painel (a) não há correção de decoerência, surgindo uma interferência artificial no próximo cruzamento. No painel (b) é aplicado uma correção de decoerência contornando o problema de interferência.

esquemas é a dependência com a diferença dos gradientes entre os diferentes estados, que é o comportamento esperado teoricamente [116].

\subsubsection{Ensemble de trajetórias}

Uma única trajetória não é capaz de representar um cruzamento entre duas superfícies de energia potencial, dado que a cada instante de tempo é seguido uma única superfície. Aliado a isso, o hop envolve um processo estocástico. Dessa forma, um ensemble de trajetórias é necessário para reproduzir tais efeitos. Esse ensemble deve ser o grande o suficiente para descrever corretamente o pacote de onda inicial e isso faz com que condições iniciais sejam distribuídas ao longo dos estados iniciais.

\subsubsection{Algoritmo do método SH}

Além da correção de decoerência, as trajetórias do método SH são bastante influenciadas pelo algoritmo que é usado para o procedimento do surface hop. Existem basicamente três aspectos que precisam ser considerados.

O primeiro deles está relacionado com a decisão de quando o hop vai acontecer. Uma 
aproximação é saltar apenas em pontos específicos ao longo da trajetória, sendo essas regiões definidas antes das simulações (por exemplo, pontos de cruzamentos otimizados) ou detectados durante a simulação (por exemplo, um gap de energia bem pequeno). Essa aproximação é historicamente a mais velha, mas ainda é empregada em alguns contextos [117]. Contudo, as principais implementações hoje em dia permitem o surface hop em qualquer instante de tempo da simulação $[118,119]$. Isso é vantajoso se a região que acontece os hops é suficientemente grande.

O segundo ponto é com respeito à equação que governa as probabilidades de saltar de uma superfície para outra. Um dos critérios mais utilizados na literatura é o fewest-switches, que tenta reduzir saltos excessivos entre as superfícies e faz com que as trajetórias se movam de acordo com a média de vários PESs. Portanto, desde que as populações eletrônicas não mudem, nenhum hop deveria ocorrer. O problema é que esse critério não fornece qualquer orientação de como a probabilidade total deve ser particionada sobre os possíveis estados alvos $\alpha$. Na formulação original de Tully é assumido um pequeno passo de tempo $\Delta t$, de tal forma que a probabilidade de sair de um estado $\beta$ para $\alpha$ será dada por [120]:

$$
h_{\beta \rightarrow \alpha} \sim-\frac{2 \Delta t}{\left|c_{\beta}(t)\right|^{2}} \Re\left(c_{\beta}^{*}(t) \frac{\partial c_{\beta}(t)}{\partial t}\right)=-\frac{2 \Delta t}{\left|c_{\beta}(t)\right|^{2}} \Re\left(c_{\beta}^{*}(t) \sum_{\alpha}\left[i H_{\beta \alpha}+K_{\beta \alpha}\right] c_{\alpha}(t)\right)
$$

O último aspecto se refere à amostragem estocástica realizada com base nas probabilidades computadas e a seleção de um novo estado ativo para o próximo passo temporal. A maioria das implementações SH usam a técnica "ant-eater", que consiste no sorteio de um número randômico $r$ entre 0 e 1 a cada passo de tempo [104]. Um hop a partir de $\beta$ para $\alpha$ será realizado se:

$$
\sum_{i=1}^{\alpha-1} h_{\beta \rightarrow i}<r \leq h_{\beta \rightarrow \alpha}+\sum_{i=1}^{\alpha-1} h_{\beta \rightarrow i}
$$

Esse esquema estocástico é exemplificado na Figura 3.5. O nome dessa técnica é uma analogia com o tamanduá (a trajetória) que tende a seguir o caminho onde a maioria das formigas (a população eletrônica) caminha. Existem outras alternativas, como por exemplo o algoritmo "army ants"[121]. Nesse esquema a decisão do hop é feita a partir de probabilidades uniformes, isto é, o hop para todos os estados é igualmente provável. Contudo, os valores de $h_{\beta \rightarrow \alpha}$ são armazenados no intuito de fazer o correto peso das trajetórias durante as análises finais. Esse técnica é principalmente indicada para amostragens de canais de reação raros.

\subsubsection{Ajuste da energia cinética e hops frustrados}

A estratégia mais comum para a conservação da energia total depois de um hop é o ajuste da energia cinética dos núcleos. Isso é necessário devido ao novo estado ativo possuir uma diferente energia potencial em relação ao estado ativo anterior. A energia cinética é ajustada 


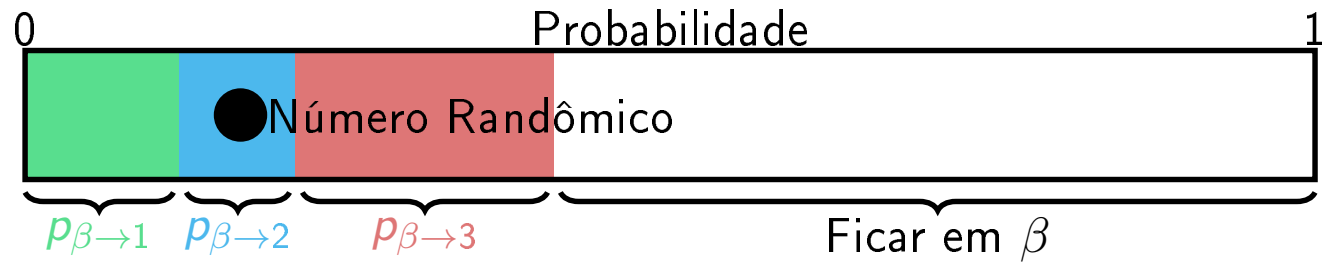

Figura 3.5 - Esboço explicando a técnica ant-eater. Nesse exemplo, o número randômico sorteado cai dentro do intervalo correspondente ao estado 2. Portanto, esse estado é o novo estado ativo, exceto se o hop for frustrado.

modificando o vetor velocidade total $\mathbf{v}$, que pode ser visto na ilustração dos painéis (a) e (b) da Figura 3.6 para os casos de aumento ou diminuição da energia cinética, respectivamente.

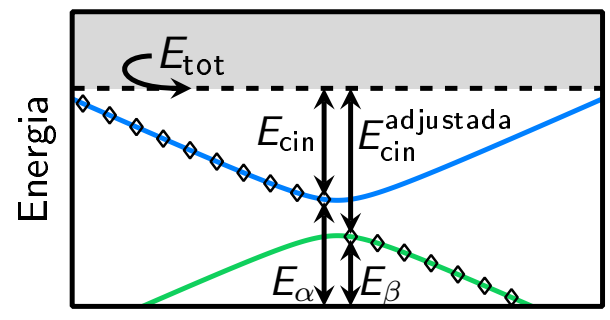

(a) Hop down

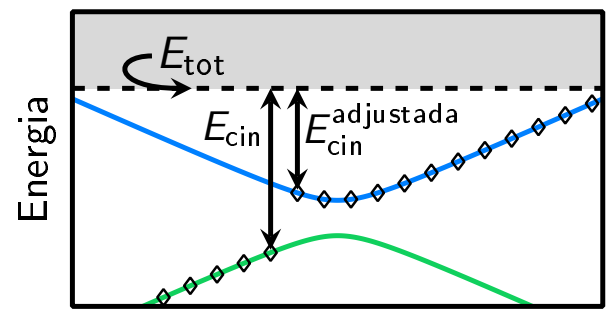

(b) Hop up

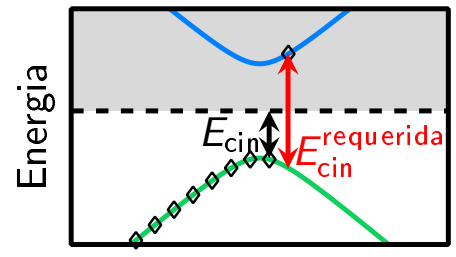

(c) Hop Frustrado

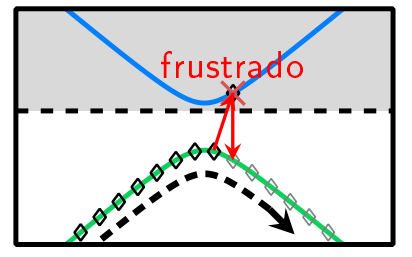

(d) Sem reflexão

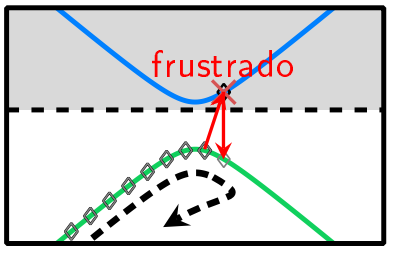

(e) Reflexão

Figura 3.6 - Esboço de vários cenários que podem ocorrer durante o ajuste da energia cinética. Nos painéis superiores são mostrados saltos em que a energia potencial do estado ativo (a) diminui durante o salto ou (b) aumenta. No painel (e) é ilustrado um hop frustrado, sendo que a energia total é menor do que a energia potencial do novo estado ativo. Quando um hop frustrado é identificado, o estado ativo não é alterado, mas a vetor velocidade pode ser inalterado (d) ou a componente ao longo do vetor NAC é refletida (e).

A ideia mais simples para ajustar a energia cinética é o reescalonamento do vetor velocidade total v:

$$
\mathbf{v}^{\text {ajustado }}=\sqrt{\frac{E_{\text {total }}-E_{\beta}}{E_{\text {total }}-E_{\alpha}}} \mathbf{v}
$$

sendo que, $E_{\alpha}$ é a energia potencial do estado ativo antigo, $E_{\beta}$ é a energia potencial do novo estado ativo e $E_{\text {total }}$ é a energia total.

Como podemos ver na equação (3.13), nenhuma outra quantidade física (como por exemplo o vetor NAC) é precisa para determinar $\mathbf{v}^{\text {ajustado }}$. Portanto, essa estratégia é regularmente 
empregada [122, 123], mas o algoritmo SH não é auto-consistente. Para exemplificar esse problema, imaginemos duas simulações $\mathrm{SH}$. A primeira delas consiste de uma molécula $\mathrm{A}$ e a segunda contém a mesma molécula $A$ mais outra molécula $B$, sendo que ambas as moléculas estão suficientemente distantes para que a interação entre elas seja nula. Em algum passo temporal, no sistema A é decidido fazer o hop para um estado como uma energia que é maior do que a energia total da molécula $A$. Dessa forma, no primeiro sistema o hop não é permitido (hop frustrado). Por sua vez, no segundo sistema $(A+B)$, a energia total do sistema é grande o suficiente para permitir o hop. Nessa situação, o reescalonamento do vetor velocidade total fica inconsistente. Isso não ocorre apenas como sistemas separados por uma distância infinita, mas também para sistemas finitamente separados contendo subsistemas com fraca interação.

A modificação instantânea do vetor velocidade por ser atribuída como a aplicação de uma força infinitamente grande nos núcleos. Pode ser mostrado pelo método de força quântica efetiva proposto por Pechukas [124], que a direção desse vetor força é justamente na direção do vetor NAC que conecta os dois estados ativos (velho e o novo). Essa aproximação é rigorosa e auto-consistente [125]. A sua principal desvantagem é a necessidade do cálculo do vetor NAC entre esses estados, que pode ser computacional caro e/ou não estar disponível em todos os programas de estrutura eletrônica.

Se a energia disponível é menor do que a diferença de energia entre o estado ativo velho e o designado a ser o novo estado ativo, o hop não poderá ser executado. Isso na literatura é chamado de hop frustado (Figura 3.6c), significando que esse hop é rejeitado no algoritmo $\mathrm{SH}$ e a trajetória continua no estado ativo velho. Alguns autores sugerem que depois de um hop ser proibido, a componente da velocidade $\mathbf{v}$ na direção do vetor NAC relevante deve ser invertida (reflexão). Um esboço dessas duas situações é exemplificada na Figura 3.6.

\subsubsection{Termos de acoplamentos e representações}

O Hamiltoniano eletrônico mais simples é aquele que leva em conta apenas as interações de Coulomb entre os núcleos e os elétrons ( $\mathrm{MCH}$ - do inglês Molecular Coulomb Hamiltonian). Esse Hamiltoniano está disponível na maioria dos cálculos de química quântica.

Com esse Hamiltoniano é possível descrever a dinâmica de conversão interna e de estados adiabáticos para moléculas em geral. Entretanto, esse Hamiltoniano não considera campos externos e nenhum interação além da coulombiana. Para incorporar esses acoplamentos arbitrários dentro do algoritmo $\mathrm{SH}$, é preciso estender esse Hamiltoniano adicionando um termo extra, isto é:

$$
\mathcal{H}^{\text {full }}=\mathcal{H}^{\mathrm{MCH}}+\mathcal{H}^{\text {adicional }}
$$

Por exemplo, para descrever cruzamento intersistemas (ISC) devemos incluir o operador 
spin-órbita, como por exemplo, com o auxílio do operador de Breit-Pauli [126]:

$$
\mathcal{H}^{\mathrm{SO}}=\frac{\hbar e^{2}}{2 m_{e}^{2} c^{2}}\left[\sum_{i} \sum_{A} \frac{Z_{A}\left(\mathbf{r}_{i A} \times \mathbf{p}_{i}\right) \cdot \mathbf{s}_{i}}{r_{i A}^{3}}-\sum_{i \neq j} \frac{\left(\mathbf{r}_{i j} \times \mathbf{p}_{i}\right) \cdot \mathbf{s}_{i}+2\left(\mathbf{r}_{i j} \times \mathbf{p}_{i}\right) \cdot \mathbf{s}_{j}}{r_{i j}^{3}}\right]
$$

sendo, $c$ a velocidade da luz e s o spin.

Hoje em dia, é comumente empregado aproximações de um elétron para baratear os cálculos [127], visto que é consideravelmente caro calcular o operador de Breit-Pauli em sua totalidade. No caso das interação da luz com a matéria (excitação, emissão estimulado, efeito Shark, etc) é preciso incluir a interação entre o campo elétrico e a distribuição de cargas do sistema.

Como vimos anterior, a função de onda é expandida em termos de funções bases $\Psi_{\alpha}(t)$. Se o conjunto de funções base é completo, a escolha da representação não importa em cálculos de mecânica quântica. Entretanto, essa escolha é importante para dinâmicas SH, dado que a representação altera a forma da superfície de energia potencial. Logo, em uma representação pode existir uma barreira de reação que é classicamente proibida, mas que em outra seja acessível. A Figura 3.7 ilustra essas diferenças. Além disso, os acoplamentos eletrônicos podem ser localizados ou delocalizados dependendo da representação, que podem a princípio influenciar o número de hops ao decorrer da dinâmica.

\section{Estados MCH}

(autoestados de $\mathcal{H}^{\mathrm{MCH}}$ )

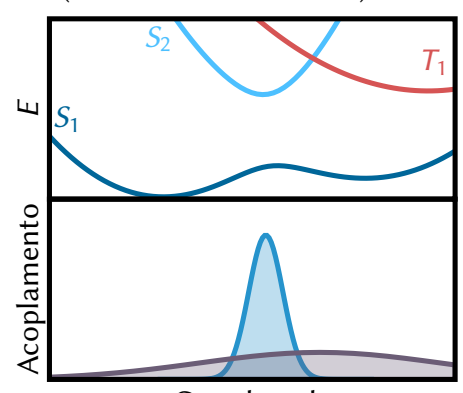

Coordenada

+ Padrão em química quântica

- Alguns acoplamentos delocalizados
Estados Diagonais (autoestados de $\mathcal{H}^{\text {total }}$ )

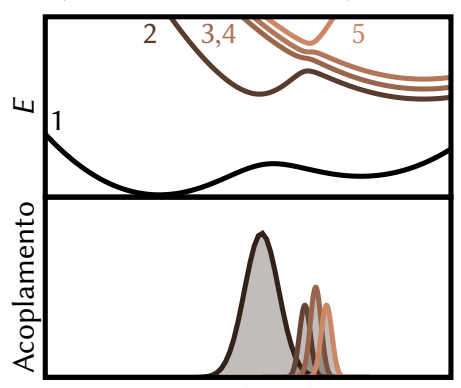

Coordenada

+ Todos os acoplados localizados

+ Correto tratamento dos multipletos

+ Energias mais precisas

- Nao e padrão em uímica quântica
Estados espectroscópicos (representação diabatica)

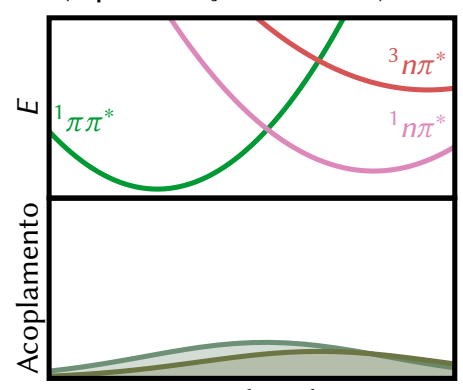

Coordenada

+ Fácil interpretação

- Acoplamentos sao delocalizados

- Necessita de muitos estados

Figura 3.7 - Exemplos de curvas de energia potencial para as três representações mais comuns empregadas no método $\mathrm{SH}$. (a) Os estados $\mathrm{MCH}$ são tipicamente calculados em qualquer método de estrutura eletrônica. (b) Os estados diagonais são obtidos pela diagonalização do Hamiltoniano total e (c) os estados espectroscópicos consistem de uma base de estados que não alteram o seu caráter com respeito à coordenada.

Devido a essas razões, a escolha da representação dentro do algoritmo SH é uma tópico amplamente discutido na literatura [128-130]. Geralmente, a melhor representação é aquela que diagonaliza o Hamiltoniano eletrônico total incluindo todos os acoplamentos adicionais, chamada de representação diagonal. Infelizmente, os programas de estrutura eletrônica atuais não 
calculam os autoestados desse Hamiltoniano. Contudo, alguns códigos de $\mathrm{SH}$, como por exemplo, o pacote SHARC (Surface Hopping including ARbitrary Couplings) [131-133], realizam essa diagonalização. No caso do SHARC, é possível encontrar autoestados aproximados do Hamiltoniano total por meio da teoria de perturbação quasi-degenerada [134]. Na prática, é escolhido um número de autoestados do Hamiltoniano eletrônico $\Psi^{\mathrm{MCH}}$, por exemplo, os estados mais baixos singletos e tripletos. Na base desses estados é possível diagonalizar esse Hamiltoniano por meio de uma transformação unitária, ou seja:

$$
\mathcal{H}^{\text {diag }}=\mathbf{U}^{\dagger} \mathcal{H}^{\mathrm{MCH}} \mathbf{U}
$$

e os autoestados desse Hamiltoniano serão dados por:

$$
\Psi_{\beta}^{\text {diag }}=\sum_{\alpha} \Psi_{\alpha}^{\mathrm{MCH}} U_{\alpha \beta}
$$

Outras representações podem ser empregadas para análises dos resultados ao fim da dinâmica. Um exemplo é a representação $M C H$, cujo a base de estados é formado por autoestados do Hamiltoniano molecular. Nessa representação não existe cruzamento entre estados eletrônicos de mesma multiplicidade $\left(S_{0}, S_{1}\right.$ e assim por diante) e os acoplamentos não-adiabáticos são localizados em cruzamentos de estados de diferentes multiplicidades (por exemplo, $S_{2}$ e $T_{1}$ ). Outra base de estados bastante utilizada é a representação diabática, visto que a função de onda de cada estado não se altera ao longo da coordenada nuclear. Uma característica dessa representação é a delocalização dos acoplamentos não-adiabáticos.

\subsubsection{Condições iniciais}

As principais quantidades nucleares e eletrônicas que são propagadas ao decorrer da dinâmica SH são: (i) posições nucleares $\mathbf{R}$, (ii) velocidades nucleares $\mathbf{v}$, (iii) coeficientes da função de onda c e (iV) o estado eletrônico ativo $\beta$. Dessa forma, é necessário definir essas constantes iniciais no tempo $t=0$.

A geração das condições iniciais comumente envolve primeiramente a amostragem de um conjunto grande de pares $(\mathbf{R}, \mathbf{v})$. Existem basicamente duas técnicas para a amostração de $\mathbf{R}$ e v, que são mostradas na Figura 3.8. A primeira delas é por meio da amostração de Wigner [135], na qual é calculado uma função de distribuição de probabilidade do espaço de fase que represente a densidade do estado vibracional do estado fundamental. Após isso, um processo estocástico extrai as amostras dessa distribuição. Dentre as vantagens dessa abordagem está o fato da inclusão de efeitos quânticos, como por exemplo, correção da energia de ponto-zero. Para moléculas poliatômicas, geralmente, a distribuição de Wigner decorre das soluções de um oscilador quântico harmônico em modos normais, que funciona bem para sistemas pequenos e rígidos. 
(a) Amostragem de Wigner

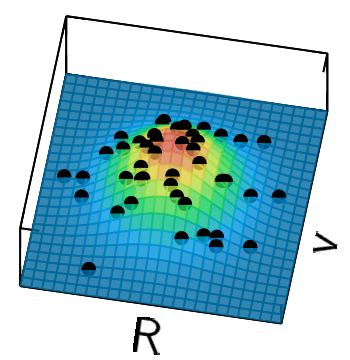

(b) Amostragem por Dinâmica Molecular

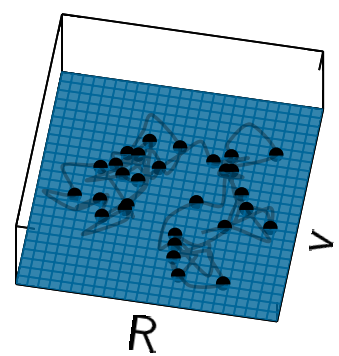

(c) Seleção do estado inicial

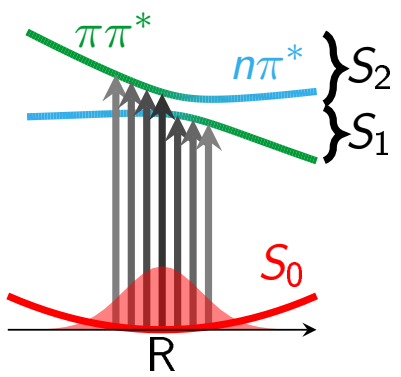

Figura 3.8 - Passos importantes para a geração das condições iniciais utilizados como ponto de partida para a dinâmica SH. Nos painéis (a) e (b) são exibidos duas maneiras de amostrar as coordenadas no espaço de fase (R, v). No painel (c) é apresentada como é feita a seleção do estado inicial. Essa etapa é subsequente e define os coeficientes eletrônicos iniciais (c) e o estado ativo $\beta$.

Outra vertente é por meio de uma simulação de dinâmica molecular clássica no estado fundamental, coletando randomicamente os pares $(\mathbf{R}, \mathbf{v})$ a partir dessa trajetória. Essa abordagem não leva em conta efeitos quânticos, mas funciona bem para sistemas poliatômicos que possuem modos anarmônicos consideráveis e com múltiplos mínimos locais na superfície de energia potencial do estado fundamental.

Uma vez amostrados e coletados os respectivos pares $(\mathbf{R}, \mathbf{v})$, podemos encontrar os valores iniciais de c e $\beta$. O caso mais simples é usar $c_{\alpha}(0)=\delta_{\alpha \beta}$, com $\beta$ sendo um dos estados excitados. Esse $\beta$ pode ser definido pelo usuário. Uma aproximação mais apropriada é a realização de um cálculo de energias de excitação verticais (Figura 3.8c) para cada geometria amostrada e computar a probabilidade de seleção baseado nas energias de excitação e força de oscilador de cada estado [136]:

$$
p_{\alpha}(\mathbf{R})=\frac{1}{p_{\text {norm }}} \frac{f_{\alpha}(\mathbf{R})}{\left|E_{\alpha}(\mathbf{R})-E_{\text {init }}(\mathbf{R})\right|^{2}}
$$

sendo que, $E_{\text {init }}$ é a energia do estado inicial, $f_{\alpha}$ é a força de oscilador do estado $\alpha$ e $p_{\text {norm }}$ é um fator de normalização. Com essas probabilidades, podemos estocasticamente selecionar os estados iniciais. Frequentemente algumas restrições no termo $\left|E_{\alpha}(\mathbf{R})-E_{\text {init }}(\mathbf{R})\right|$ são impostas, a fim de considerar apenas uma janela pequena de excitação. 
$\sqrt{c \text { contulu }} 4$

\section{Modelagem do ambiente molecular}

A modelagem de ambientes solvatados é uma tarefa bastante complexa, tanto do ponto de vista teórico quanto da limitação computacional. A principal dificuldade teórica é descrever o mais realístico possível a interação dos constituintes do sistema. Isso se deve ao fato de não podermos utilizar a periodicidade como acontece no estado sólido ou de interações fracas como ocorre no estado gasoso. Ademais, a limitação computacional impede uma realização de um cálculo mais refinado. Na literatura existem diversas propostas para modelar o solvente, podendo ser agrupadas em três grandes grupos: contínuo, discreto e híbrido. No final do capítulo são discutidos brevemente as principais técnicas de simulação computacional clássica de muitos corpos: Monte Carlo e Dinâmica Molecular.

\subsection{Modelos contínuos}

Nos modelos contínuos, o solvente é tratado como um dielétrico contínuo e infinito de constante dielétrica $\varepsilon$. O sistema de interesse é colocado no interior de uma cavidade contendo vácuo, cuja constante dielétrica é igual a um. A forma da cavidade não necessariamente precisa ser esférica, visto que a maioria das moléculas não apresentam tal simetria.

Nesses modelos, o solvente se polariza na presença de cargas eletrônicas e nucleares do soluto, induzindo cargas de polarização na superfície da cavidade, e que por sua vez, polarizam a distribuição de cargas do soluto. Essa distribuição de cargas na cavidade do dielétrico gera um potencial eletrostático, comumente chamado de campo de reação. Esse campo altera as cargas do soluto de uma forma autoconsistente e para cavidades esférias possui uma expressão analítica [137]. Outro ponto a ser salientado, é que esse campo de reação provoca o aumento da assimetria das cargas do sistema de interesse, pois a atuação desse campo é no mesmo sentido do dipolo do soluto. A principal diferença entre os vários modelos contínuos está na forma de gerar esse campo de reação, que podem ter implementações mais sofisticadas por 
meios de quadrupolos, octopolos e assim por diante [138].

Os modelos contínuo se baseiam na resolução da equação de Poisson:

$$
\nabla^{2} \varphi(\mathbf{r})=\frac{-4 \pi \rho(\mathbf{r})}{\varepsilon}
$$

sendo que, $\varphi$ é o potencial eletrostático e $\rho$ é a densidade eletrônica.

Dentre os métodos, podemos destacar o modelo contínuo polarizável (PCM), desenvolvido por Scrocco e colaboradores [139]. No modelo PCM a cavidade não é esférica, sendo que a cavidade é formada a partir da união de esferas nos átomos da molécula (Figura 4.1). Os raios de cada esfera são usualmente acrescidos em $20 \%$ do raio de van de Walls do respectivo átomo, gerando uma superfície que possui o formato da molécula. Na literatura existem outras propostas bastante empregadas, como por exemplo, o modelo COSMO [140], que trata o meio solvente como condutor ao invés de um dielétrico, e o modelo SMD elaborado por Truhlar e colaboradores [141], que é indicado para cálculos de energia livre de solvatação.
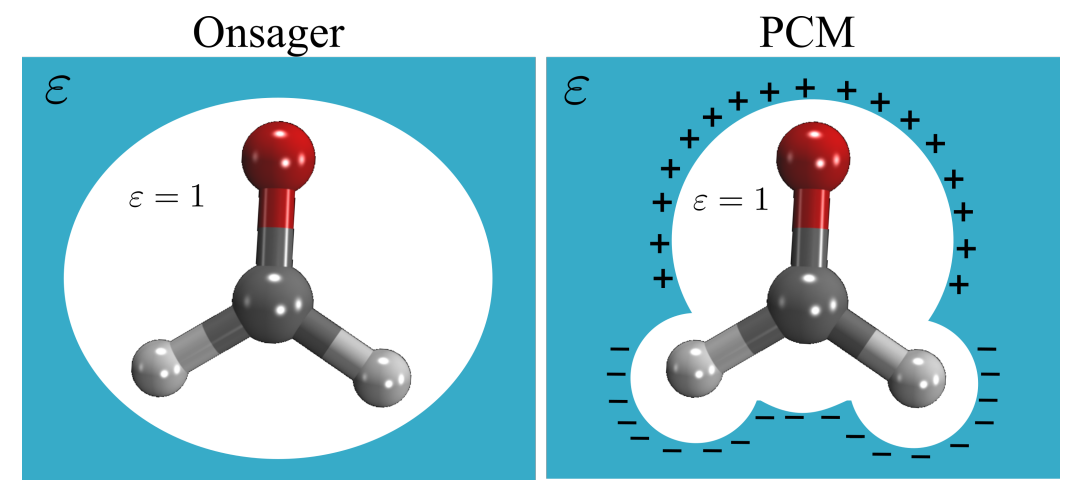

Figura 4.1 - llustração dos modelos de Onsager (lado esquerdo) e PCM (lado direito) para a molécula de formaldeído. Os símbolos + e - correspondem às cargas de polarização induzidas na superfície da cavidade.

No modelo PCM, as condições de contorno devem ser aplicadas na superfície da cavidade e no infinito, a fim de solucionar a equação (4.1) para ambos os meios (dentro e fora da cavidade). As cargas de polarização na superfície da cavidade são computadas por meio do método de Cargas Superficiais Aparentes (ASC) [142]. A interação vinda das cargas de polarização são adicionadas no Hamiltoniano do soluto como uma perturbação, que, por conseguinte, geram uma nova distribuição de cargas para o soluto. Esse procedimento de autoconsistência, chamado de Campo de Reação Autoconsistente (SCRF), foi implementado inicialmente por Tapia e Goscinski [143], McCreery et al. [144] e Rivail e Rinaldi [145], baseado nas ideias originais de Onsager [146] e Kirkwood [147].

Uma das grandes vantagens dos modelos contínuos é a interação soluto-solvente ser tratada de maneira puramente quântica. Além disso, a distribuição de carga contínua é uma boa aproximação para longas distâncias do soluto. O custo computacional baixo é um dos atrativos 
que fizeram crescer a popularização desse método, que na atual implementação utiliza o formalismo de equações integrais para aumentar a velocidades dos cálculos [148]. Todavia, essa aproximação falha para distâncias próximas do soluto, em virtude da densidade eletrônica ser discreta. Outras desvantagens estão relacionadas ao fato dos resultados variarem bastante com o tamanho da cavidade e a descrição ser boa somente para moléculas com alto momento de dipolo e o caráter do meio seja predominantemente eletrostático [146]. Dessa forma, os modelos contínuos não são indicados para meios que possuem interação específicas, como por exemplo, ligações de hidrogênio.

\subsection{Modelos Discretos}

Outra vertente para modelar o solvente é empregando os modelos discretos, cujos pilares se baseiam em tratar o ambiente molecular de uma forma totalmente atomística. A natureza estatística do líquido passa a ser importante e é preciso conhecer as posições de todos os átomos do sistema, como também as interações específicas que regem essa dinâmica. Dentre as abordagens nos dias atuais, podemos citar as dinâmicas quânticas (dinâmica molecular Car-Parrinello [149] e Bohr-Oppenheimer [150]) e as metodologias que parametrizam um potencial de interação para descrever as interações moleculares.

O primeiro grande empecilho dos modelos discretos é com respeito ao tamanho do sistema a ser considerado. As simulações computacionais tentam gerar um conjunto de configurações do líquido, em uma determinada condição termodinâmica. Logo, um número razoável de moléculas devem ser consideradas a fim de obter médias termodinâmicas condizentes com o experimento. Contudo, tratar agregados com milhares de moléculas do ponto de vista de mecânica quântica é atualmente impraticável.

Aliado a isso, temos o problema devido ao sistema ser finito e as moléculas da superfície da caixa de simulação sentirem um ambiente diferente daquelas que estão no interior. Esse problema é chamado de efeito de borda e ocasiona efeitos artificiais, comprometendo a simulação. Para contornar esse problema, uma alternativa é a utilização de um dielétrico contínuo fora da cavidade de simulação [151]. Entretanto, admitimos outra possibilidade, que envolve a replicação da caixa de simulação em todas as direções do espaço. Dessa forma, todas as moléculas sentirão o mesmo ambiente químico, com a condição de que as réplicas se movem de forma igual à original.

Em geral, um líquido não possui um padrão de simetria definido, consequentemente, não podemos adotar condições periódicas de contorno. Uma solução é a utilização de um artifício, chamado de convenção da mínima imagem. Nessa convenção, a interação de uma dada molécula com as demais ocorrerá somente com os primeiros vizinhos. Comumente, é atribuída uma aproximação adicional, introduzindo um raio de corte $r_{c}$, restringindo a interação 
até essa distância. Para caixas de simulação cúbicas, o maior raio de corte corresponde à metade da aresta. A grande vantagem dessa aproximação é uma redução drástica do número de interações de pares a serem computadas. O uso de outras caixas de simulação, como por exemplo, octaédrica truncada e dodecaédrica rômbica, possibilita um número maior de moléculas empregando o mesmo raio de corte [152]. Na Figura 4.2 é ilustrado um sistema bidimensional considerando uma caixa de simulação quadrada.

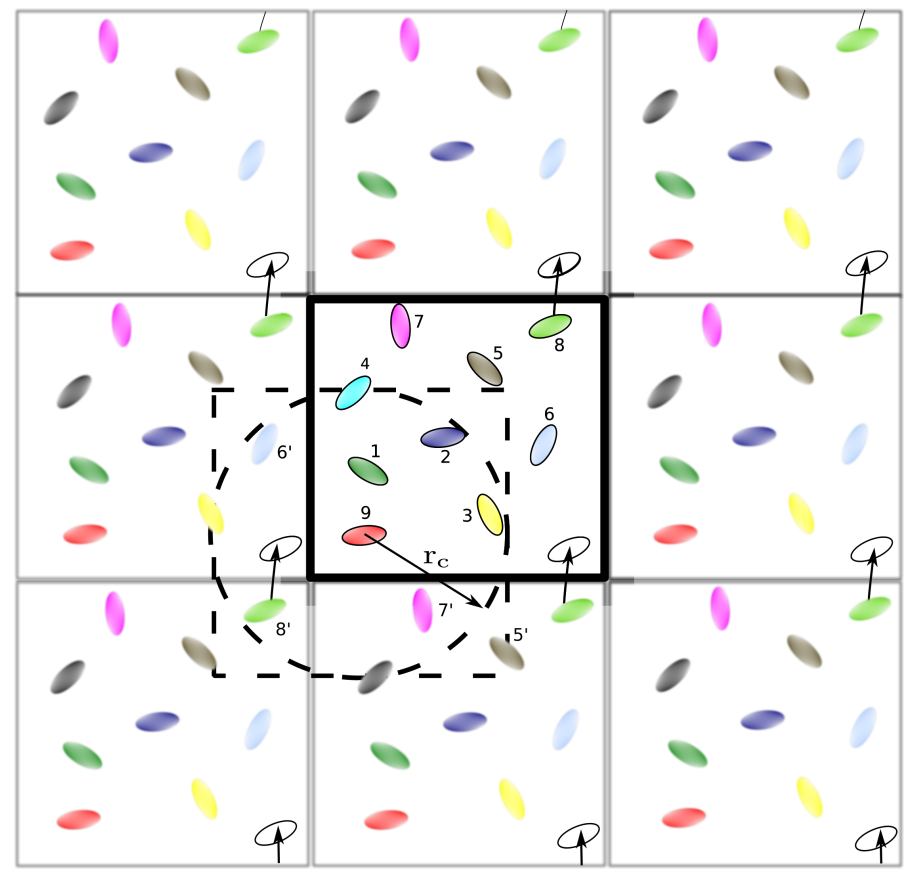

Figura 4.2 - Ilustração da replicação da caixa de simulação em um sistema bidimensional.

Como pode ser visto na Figura 4.2, na caixa de simulação central, a molécula 8 sai verticalmente da caixa, e por conseguinte, uma molécula imagem imediatamente entra na parte inferior. Ademais, a molécula 9 interage somente com as moléculas que estão dentro do quadrado tracejado, isto é, interage com as moléculas $1,2,3$ e 4 da caixa original e com as réplicas $5^{\prime}, 6^{\prime}, 7^{\prime}$ e $8^{\prime}$. Com a imposição do raio de corte, a molécula 9 não interage com a $5^{\prime}$ e provavelmente com a $6^{\prime}$.

A imposição de um raio de corte faz necessário uma correção de longo alcance para a energia dada por:

$$
U_{\mathrm{LA}}=2 \pi N \rho \int_{r_{c}}^{\infty} r^{2} U(r) d r
$$

Nas simulações clássica de líquidos, um potencial de interação bastante empregado é o potencial de Lennard-Jones (LJ) acrescido do potencial de Columb. Para esse caso, a correção de longo alcance é facilmente resolvida para a parte LJ. Todavia, existe uma divergência no termo coulombiano. A soma de Ewald e Campo de Reação são alternativas bem estabelecidas na literatura para lidar com a correção de longo alcance do termo eletrostático. Convidamos os leitores a consultar a referência 153 para um descrição mais aprofundada da teoria. 


\subsection{Modelos híbridos}

As limitações computacionais não permitem atacar todo o sistema com o uso de mecânica quântica. Diversos métodos foram propostos ao decorrer do tempo no intuito de reduzir o número de moléculas que são tratadas explicitamente, sem prejudicar substancialmente os resultados.

Uma metodologia que vem ganhando força nos últimos anos são os modelos híbridos, que combinam mecânica quântica (QM) e mecânica clássica ( $M M)$, corriqueiramente chamados de métodos $\mathrm{QM} / \mathrm{MM}$. Os primeiros trabalhos nessa linha foram desenvolvidos por Warshel e Levitt [154], Singh e Kollman [155] e Karplus et al. [156]. Os vencedores do prêmio Nobel de química em 2013 foram os pioneiros dessa área: A. Warshel, M. Levitt e M. Karplus.

Nesses métodos, o sistema é dividido em dois subsistemas. O primeiro subsistema (região QM) consiste de um número pequeno de átomos, podendo ser apenas o soluto ou até mesmo um aglomerado de moléculas contendo poucas moléculas de solvente. Essa região é onde queremos lidar com maior rigor, tratando os elétrons e os núcleos com métodos quânticos de primeiros princípios. A parte MM é o restante do sistema e serve como uma espécie de "ambiente" para a parte QM. Essa região contém um número muito maior de átomos do que na parte QM e são utilizados campos de força clássicos. Uma representação esquemática das regiões $\mathrm{QM}$ e $\mathrm{MM}$ nos métodos híbridos $\mathrm{QM} / \mathrm{MM}$ é ilustrada na Figura 4.3.

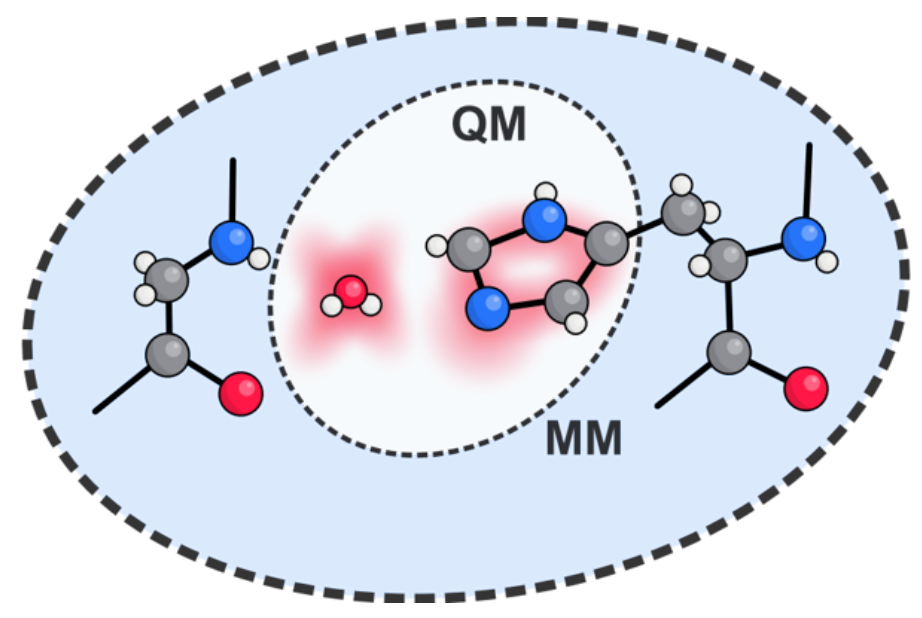

Figura 4.3 - Ilustração das partes QM e MM nos modelos híbridos. Veja que nessa divisão existe uma ligação química na região de fronteira.

Dentre as possibilidades de escolha da região QM, uma seleção difícil é quando lidamos com moléculas grandes, como por exemplo enzimas. Nesse casos, estamos interessados em descrever o sítio ativo ou um centro de reação. Entretanto, existem ligações químicas na divisão das regiões $\mathrm{QM}$ e MM. Dessa forma, surgem problemas relacionados com a separação entra as duas regiões e como será o tratamento na fronteira. A escolha da fronteira pode afetar 
drasticamente a precisão do cálculos $\mathrm{QM} / \mathrm{MM}$, tais como a distribuição de carga da parte QM e a energia do sistema [157]. Uma proposta bem difundida na literatura para lidar com regiões de fronteira que compartilham ligações químicas é por meio de átomos de ligação (link atoms). Essa abordagem tenta da melhor maneira possível reproduzir a densidade eletrônica ao longo da ligação QM-MM, saturando as ligações QM com átomos de hidrogênio (átomos de halogênio também podem ser empregados). Além disso, esses átomos ligados artificialmente na parte QM são invisíveis para a região MM. O acoplamento entre as partes clássica e quântica definem os diferentes tipos de $\mathrm{QM} / \mathrm{MM}$ e uma revisão de diversos tipos de métodos híbridos são detalhados na referência 158 .

A maneira mais comum de utilizar o método QM/MM é na forma convencional. Nessa abordagem, os cálculos das regiões quântica e clássica são realizados ao mesmo tempo. A energia de um sistema no método $\mathrm{QM} / \mathrm{MM}$ convencional é composta de um termo que representa a energia $\mathrm{QM}\left(E_{\mathrm{QM}}\right)$, um termo representando a energia $\mathrm{MM}\left(E_{\mathrm{MM}}\right)$ calculado a partir de um campo de força e, por fim, o termo que descreve o acoplamento entre as partes $\mathrm{QM}$ e $\mathrm{MM}\left(E_{\mathrm{QM} / \mathrm{MM}}\right)$. Dessa forma, podemos escrever a energia total como:

$$
E_{\mathrm{total}}=E_{\mathrm{QM}}+E_{\mathrm{MM}}+E_{\mathrm{QM} / \mathrm{MM}}
$$

O último termo da expressão (4.3) é usualmente escrito como a soma de três tipos de interação: interação eletrostática $E(\mathrm{QM} / \mathrm{MM})$, interação de van der Waals $E_{\mathrm{vdW}}(\mathrm{QM} / \mathrm{MM})$ e $E_{b}(\mathrm{QM} / \mathrm{MM})$, que é calculada somente se existirem ligações químicas entre as partes $\mathrm{QM}$ e MM.

Nesse tipo de abordagem, mesmo escolhendo uma região quântica pequena, pode culminar em um custo computacional elevado, já que em cada passo da simulação é preciso realizar um cálculo quântico. Logo, devemos saber balancear a região que será tratada quanticamente e qual nível de estrutura eletrônica a ser adotado.

Outra abordagem foi proposta por Coutinho e Canuto, denominado $Q M / M M$ sequencial (s-QM/MM) [159]. Nessa metodologia, existe o desacoplamento entre as partes quântica e clássica, realizando primeiramente uma simulação clássica MM e em sequência a parte QM. O objetivo é obter valores de propriedades convergidas estatisticamente. As principais vantagens dessa metodologia são o custo computacional reduzido, em virtude da redução dos cálculos QM, e o uso da mesma simulação clássica para diversos cálculos quânticos. Uma outra vantagem é a utilização de configurações que são estatisticamente descorrelacionadas, visto que configurações que se diferem pouco, não contribuem expressivamente para a média das propriedades de interesse. Como a região QM é escolhida a posteriori, evitamos o problema de fronteira, além de permitir uma maior liberdade de escolha. A principal desvantagem dessa metodologia é a supressão da polarização entre soluto e solvente. Contudo, estudos recentes têm sido desenvolvidos para corrigir essa falha, incluindo a polarização do soluto de forma média (veja próxima seção). 


\subsubsection{Polarização do soluto e o modelo ASEC}

A proposta da aproximação s-QM/MM é obter médias de propriedades convergidas estatisticamente. Entretanto, a polarização mútua entre soluto e solvente é perdida. Atualmente, existem duas maneiras de incluir a polarização do soluto. A primeira delas é obter a geometria e a distribuição de cargas utilizando algum modelo contínuo e empregar esses parâmetros posteriormente na simulação. A outra possibilidade é através de um procedimento iterativo, que converge a distribuição de cargas do soluto. $O$ procedimento consiste primeiramente em ajustar cargas parciais do soluto em fase gasosa ou no solvente desejado empregando algum modelo contínuo. Esse conjunto de cargas atômicas é um um ponto de partida para a distribuição de cargas iniciais do soluto em meio solvente. Através da simulação clássica, que pode ser feita via método Monte Carlo ou Dinâmica Molecular, extraímos um número razoável de configurações estatisticamente descorrelacionadas e ajustamos novas cargas atômicas para o soluto, tratando os sítios do solvente como carga pontual. Pela experiência em aplicar essa técnica, em média, são necessários 100 cálculos QM para a convergência de qualquer propriedade de interesse.

A distribuição de carga do soluto é atualizada e serve como ponto de partida para uma nova simulação clássica. Esse procedimento é realizado até a convergência das cargas parciais localizadas nos sítios atômicos do soluto. Essa convergência pode ser monitorada facilmente pelo momento de dipolo do soluto. Todavia, um número excessivo de cálculos $\mathrm{QM}$ devem ser efetuados, gerando um custo computacional elevado. Uma proposta para redução dos cálculos QM foi desenvolvida em nosso grupo de pesquisa, chamado ASEC (Average Solvent Electrostatic Configuration) [160] e é detalhado logo abaixo.

O modelo ASEC, que foi proposto por Coutinho e colaboradores, é uma variante do modelo ASEP (Average Solvent Electrostatic Potential) [161]. No modelo ASEP é separado um coleção ampla de configurações do sistema e um conjunto de cargas que reproduzem o potencial eletrostático médio do solvente é obtido por um similar procedimento de ajuste de cargas parciais. A interação do soluto com esse novo conjunto de cargas atômicas ajustadas constitui a interação soluto-solvente média proposta pelo modelo ASEP. Esse termo entra como uma perturbação no Hamiltoniano do soluto. Dessa forma, apenas um cálculo quântico é necessário, reduzindo drasticamente o tempo computacional.

Diferentemente do ASEP, o modelo ASEC é construído pela superposição das cargas atômicas nos sítios atômicos do solvente, extraídas a partir da simulação clássica. Cada carga atômica deve ser escalonada pelo número de configurações empregadas para produzir o modelo ASEC. Dessa maneira, é criado um sistema fictício que descreve a interação eletrostática soluto-solvente. Como no modelo ASEP, essa interação entra no Hamiltoniano do soluto como uma perturbação. Vale destacar que o valor obtido com o modelo ASEC se encontra dentro do erro estatístico, que seria obtido fazendo vários cálculos separadamente e em seguida a média. 


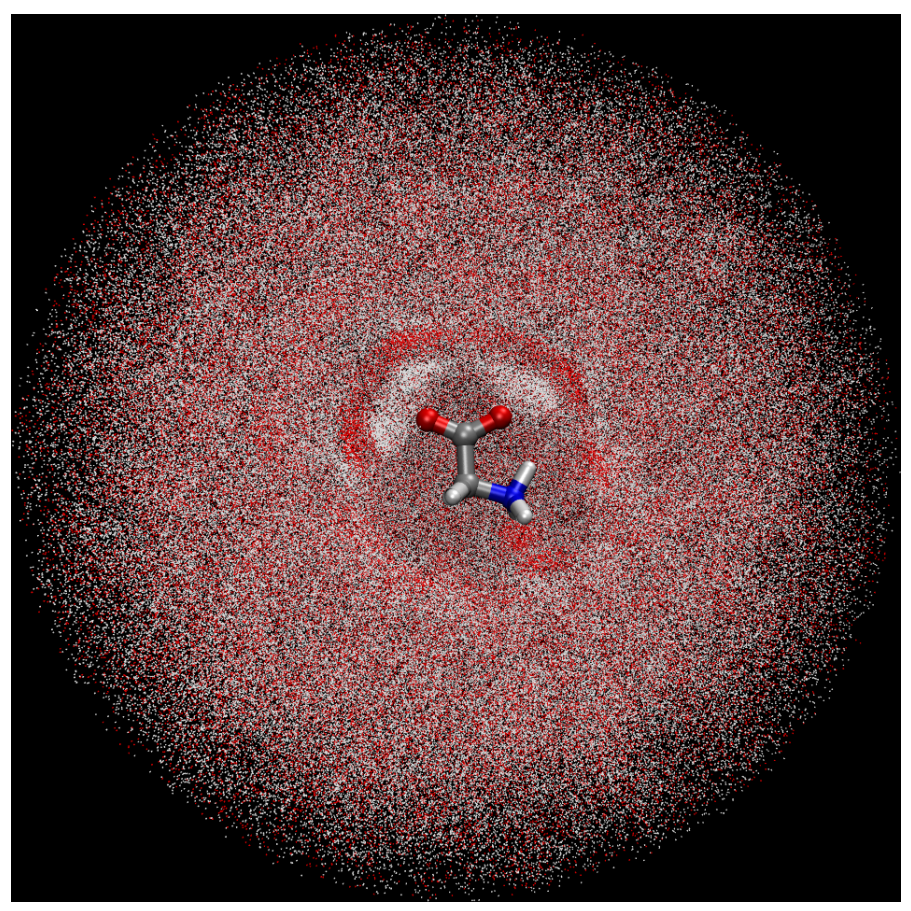

Figura 4.4 - Ilustração do modelo ASEC (visão frontal) considerando o meio aquoso. Os pontos vermelhos representam os átomos de oxigênio e os pontos brancos correspondem aos átomos de hidrogênio. Lembrando que cada sítio do solvente é tratado como carga pontual. As regiões de ligação de hidrogênio soluto-solvente são bastante nítidas, visto que é mantido a estrutura do líquido.

Uma característica importante do ASEC é a preservação da estrutura do líquido, como por exemplo, ligações de hidrogênio (veja Figura 4.4). Essa aproximação resulta em bons resultados se a contribuição eletrostática do solvente for dominante. Caso os efeitos de troca e dispersão sejam relevantes, um tratamento levando em conta algumas moléculas de solvente explicitamente pode ser necessário.

\subsubsection{Método do Gradiente de Energia Livre}

A aproximação de Born-Oppenheimer conduz para a existência de uma hipersuperfície de energia potencial. Cada ponto nessa hipersuperfície é associado a uma possível conformação do sistema com o mesmo número de núcleos e elétrons. Os vales de uma hipersuperfície de energia potencial representam reagentes ou produtos de uma reação. A diferença entre esses vales define a energia de reação. O caminho de menor energia entre esses vales é chamado de caminho de reação. A posição do mínimo em um vale representa uma estrutura de equilíbrio. Uma representação ilustrativa de uma hipersuperfície de energia arbitrária tridimensional é exibida na Figura 4.5.

O processo de encontrar mínimos na hipersuperfície de energia potencial para um dado 


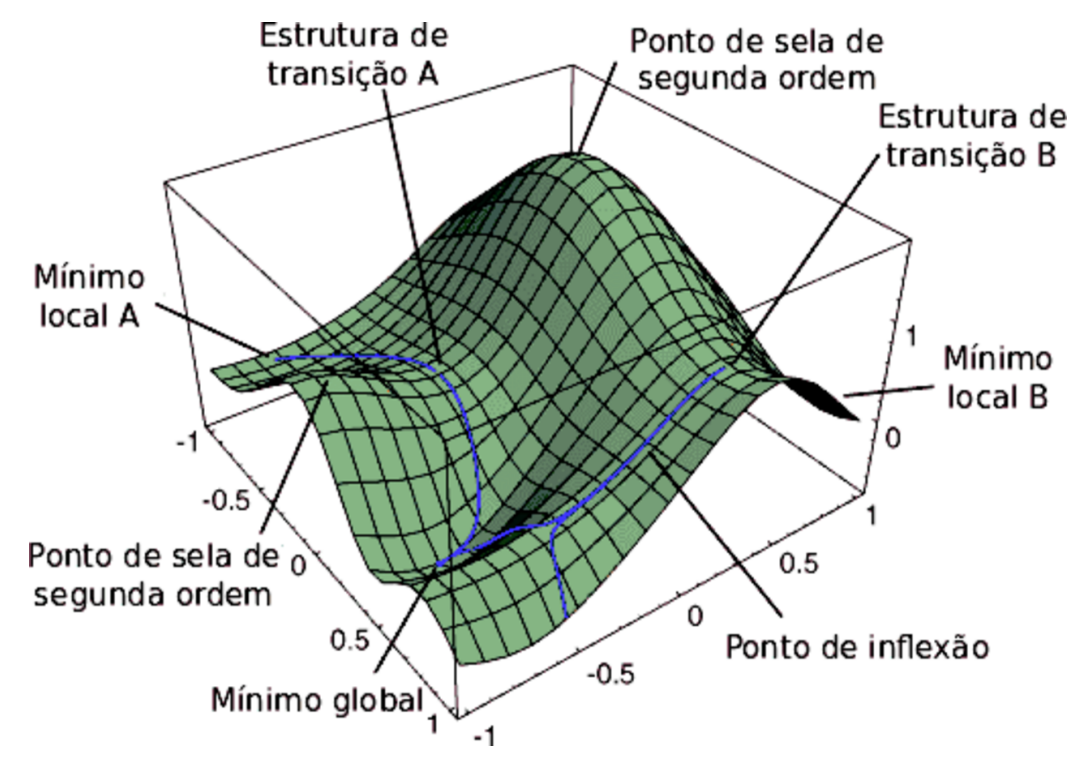

Figura 4.5 - Ilustração pictórica de uma superfície de energia potencial, contendo mínimos locais e globais, estados de transição. A linha em azul indica os possíveis caminhos de reação.

sistema é denominado de otimização de geometria. Na prática, as regiões de mínimo são encontradas buscando a direção que diminui a energia com respeito a todas as coordenadas, sendo essa direção oposta ao gradiente $\mathrm{g}$. Existem diversos métodos implementados atualmente que visam encontrar os pontos críticos de uma da função $f$. Um método bastante empregado para otimização é o método Newton-Raphson. Como visto anteriormente na seção 2.3, esse método consiste no truncamento da função na $2^{\mathrm{a}}$ ordem da série de Taylor. Admitindo um mínimo, encontramos uma maneira de caminhar na hipersuperfície em direção ao mínimo mais próximo, dada por:

$$
\mathbf{R}_{\text {new }}=\mathbf{R}_{\text {old }}-\mathbf{H}^{-1} \mathbf{g}
$$

No entanto, nem tudo é fácil como se parece, pois a cada passo, necessitamos construir a matriz Hessiana e depois achar a sua respectiva inversa. Para contornar esse problema, comumente são empregadas Hessianas aproximadas, mas com a condição de que todos os elementos da diagonal sejam positivos, no intuito de garantir que estejamos caminhando em direção ao mínimo. Uma técnica mais sofisticada e que é largamente adotada nos programas de otimização é o algoritmo BFGS (Broyden-Fletcher-Goldfarb-Shanno) [162], cuja ideia principal é a aproximar a Hessiana inicial da exata através de um processo iterativo.

Todo esse procedimento é feito em vácuo, considerando apenas uma molécula ou alguns aglomerados. A pergunta que fica é: Será possível fazer um procedimento análogo ao da fase gasosa levando em conta o fator atomístico do solvente?

O método do gradiente de energia livre (FEG) $[163,164]$ proposto por Nagaoka e colaboradores é a resposta para essa pergunta. Essa metodologia permite a relaxação da geometria do 
soluto devido à interação com o solvente, sendo possível obter uma estrutura de mínimo em solução.

A hipersuperfície de energia potencial é agora composta tanto pelo soluto quanto pelo solvente. No entanto, o interesse é somente sobre o soluto e na prática devemos projetar essa hipersuperfície em um subespaço de $3 N-6$, sendo $N$ o número de átomos do soluto. Essa projeção é feita de maneira estatística, integrando sobre todas as variáveis do solvente e mantendo fixas as coordenadas do soluto.

No ensemble NVT, o potencial termodinâmico associado é a energia livre de Helmholtz. Como mantemos as coordenadas do soluto fixa, adicionamos esse vínculo na energia livre:

$$
A=-K_{B} T \ln Z\left(N, V, T, \mathbf{q}_{0}\right)
$$

com,

$$
Z\left(N, V, T, \mathbf{q}_{0}\right)=\iint d \mathbf{P} d \mathbf{Q} e^{-\beta \mathcal{H}(\mathbf{R}, \mathbf{Q})} \delta\left(\mathbf{q}-\mathbf{q}_{0}\right)
$$

sendo que, $\mathbf{q}_{0}$ corresponde à uma configuração arbitrária fixa do soluto e q representa um índice coletivo que indica todas as coordenadas do soluto.

A força na hipersuperfície de energia livre será dada por:

$$
\mathbf{F}(\mathbf{q})=-\left(\frac{\partial A(\mathbf{q})}{\partial \mathbf{q}}\right)_{\mathbf{q} 0}=-\left\langle\frac{\partial U}{\partial \mathbf{q}}\right\rangle_{\mathbf{q} 0}
$$

sendo que, $U$ corresponde a soma das energias do soluto e da interação soluto-solvente.

Usualmente é aproximado o valor esperado da força pela força médias das configurações, ou seja:

$$
\mathbf{F}(\mathbf{q}) \approx-\frac{\partial\langle U(\mathbf{q})\rangle}{\partial \mathbf{q}}
$$

Derivando mais uma vez e após algumas manipulações matemáticas, os elementos de matriz da Hessiana podem ser escritos na forma:

$$
H_{i j}=\frac{\partial^{2} A}{\partial q_{i} \partial q_{j}}=\left\langle\frac{\partial^{2} U}{\partial q_{i} \partial q_{j}}\right\rangle-\beta\left[\left\langle\frac{\partial U}{\partial q_{i}} \frac{\partial U}{\partial q_{j}}\right\rangle-\left\langle\frac{\partial U}{\partial q_{i}}\right\rangle\left\langle\frac{\partial U}{\partial q_{j}}\right\rangle\right]
$$

cuja representação matricial é dada por:

$$
\mathbf{H}=\langle\nabla \nabla U\rangle-\beta \Delta \mathbf{F}
$$

sendo que, $\Delta \mathbf{F}=\left\langle\mathbf{F}^{2}\right\rangle-\langle\mathbf{F}\rangle^{2}$ corresponde à flutuação da força.

Uma aproximação adicional é desprezar o segundo termo da Hessiana, pois a flutuação na força é considerada ser pequena e é necessário apenas garantir que a geometria caminhará para um mínimo, ou seja, que a Hessiana seja positiva definida.

Com a força e a hessiana, podemos empregar o método NR para otimizações de geometrias de moléculas em meios solvatados. Essa metodologia do gradiente de energia livre foi acoplada 
na metodologia s-QM/MM usando o modelo ASEC para modelar a interação soluto-solvente no cálculo quântico, chamado de método ASEC-FEG $[165,166]$. Na Figura 4.6 é apresentado um esquema de como é o procedimento de otimização ASEC-FEG. Na prática, o procedimento consiste em gerar algumas centenas de configurações estatisticamente descorrelacionadas do líquido a partir de uma simulação clássica. A partir dessas configurações é possível criar o embedding eletrostático ASEC. Esse termo entra como uma perturbação no Hamiltoniano do soluto e o cálculo de gradiente e da Hessiana é realizado de uma maneira similar ao que é feito no vácuo. Com essa nova geometria embebida pelo mesmo ASEC, um novo conjunto de cargas atômicas do soluto pode ser ajustado. Esse conjunto de cargas atômicas e geometria do soluto podem ser utilizados em uma nova simulação clássica. Esse procedimento iterativo é repetido até que as alterações na geometria e do momento de dipolo do soluto flutuem em torno de um valor médio, dentro de um critério de convergência pré-estabelecido.

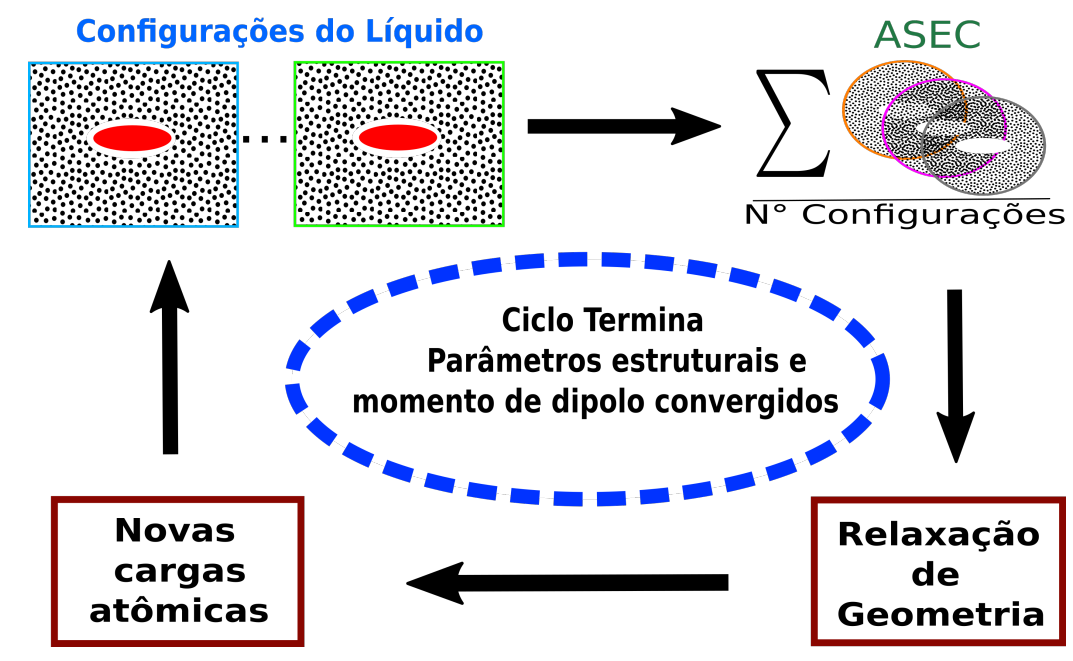

Figura 4.6 - Fluxograma da metodologia ASEC-FEG.

\subsection{Simulação clássica}

Até agora discutimos várias maneiras de modelar o solvente, que abrange desde de modelos mais simplistas até métodos que tentam descrever, na medida do possível, o sistema de uma forma totalmente quântica. A amostragem do líquido através de simulações clássicas é um modo de reduzir o custo computacional. Na literatura existem duas técnicas bastante difundidas: o método de Monte Carlo (MC) e a Dinâmica Molecular (MD). O primeiro envolve uma abordagem estocástica, que permite acessar apenas o espaço de configurações, não podendo obter propriedades temporais do sistema em questão. A outra técnica é um método determinístico, regido pelas equações de movimento newtoniana. Nessa seção apresentaremos os principais aspectos dessas duas técnicas bastantes utilizadas nos dias atuais. 


\subsubsection{Método de Monte Carlo e o algoritmo de Metropolis}

O método de Monte Carlo (MC) surgiu no meados do fim da Segunda Guerra Mundial por von Neuman, Ulam e Metropolis no laboratório de Los Alamos [167]. A principal motivação era a resolução de integrais multidimensionais, visto que o erro cometido com técnicas convencionais de integração numérica cresce drasticamente com o aumento da dimensão. Por outro lado, o erro envolvido no cálculo das integrais com MC é o mesmo, independente da dimensão.

Em 1953, o método de MC é introduzido no âmbito da mecânica estatística através do trabalho de Metropolis na tentativa de resolver as integrais de alta dimensionalidade que comumente aparecem nessa área da física. A ideia proposta foi aproximar as integrais termodinâmicas por uma soma que corre sobre $\mathrm{n}$ pontos escolhidos aleatoriamente no espaço de fase, isto é:

$$
\langle f\rangle=\frac{\sum_{i}^{n} f\left(\mathbf{r}_{i}\right) e^{-\beta U\left(\mathbf{r}_{i}\right)}}{\sum_{i}^{n} e^{-\beta U\left(\mathbf{r}_{i}\right)}}
$$

Contudo, a escrita da equação (4.11) não é conveniente, pois as configurações que contribuem pouco para a média terão igual probabilidade, levando a percorremos todo o espaço configuracional disponível e conduzindo para uma convergência bastante lenta. Uma maneira de evitar esse problema é a utilização da aproximação de amostragem por importância.

A amostragem por importância, como o nome diz, baseia em forçar a escolha de configurações que são mais relevantes para a média, ou seja, devemos amostrar regiões termodinamicamente mais prováveis. Isso é possível introduzindo uma função peso $P\left(\mathbf{r}_{i}\right)$ na equação $(4.11)$ da seguinte forma:

$$
\langle f\rangle=\frac{\sum_{i}^{n}\left[f\left(\mathbf{r}_{i}\right) e^{-\beta U\left(\mathbf{r}_{i}\right)} / P\left(\mathbf{r}_{i}\right)\right] P\left(\mathbf{r}_{i}\right)}{\sum_{i}^{n}\left[e^{-\beta U\left(\mathbf{r}_{i}\right)} / P\left(\mathbf{r}_{i}\right)\right] P\left(\mathbf{r}_{i}\right)}
$$

Metropolis propôs que para avaliar a média deveríamos adotar como função peso a própria probabilidade do ensemble [168]. Dessa forma, podemos reescrever a equação (4.12) como uma média aritmética simples:

$$
\langle f\rangle=\frac{1}{M} \sum_{i=1}^{M} f\left(\xi_{i}\right)
$$

sendo que, $\xi_{i}$ representa números aleatórios que satisfazem a distribuição de probabilidade do ensemble.

A pergunta é: Como gerar números aleatórios que satisfazem uma distribuição gerada

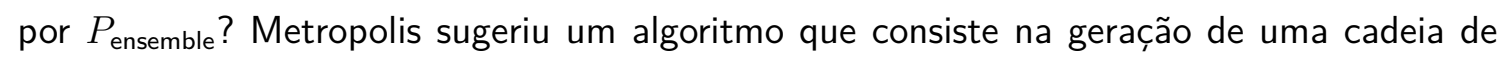
Markov* de sucessivos estados $\Gamma_{i}$ [168]. O novo estado é gerado a partir do antigo com uma probabilidade de transição $\pi\left(\Gamma_{i} \rightarrow \Gamma_{i+1}\right)$.

\footnotetext{
* Uma cadeia de Markov é um conjunto de configuração na qual a probabilidade de transição depende exclusivamente dos estados novo e atual. É comum dizer que as novas configurações geradas perdem a "memória" dos outros estados visitados.
} 
Um caminho para amostramos a distribuição de probabilidade do ensemble é no limite estacionário da equação mestra. Dessa equação, podemos extrair a taxa temporal da probabilidade devido as transições para o estado $i$ de todos os outros estados e da transição do estado $i$ para todos os outro, isto é:

$$
\frac{\partial P\left(\Gamma_{i}, t\right)}{\partial t}=\sum_{j}\left[\pi_{j i} P\left(\Gamma_{j}, t\right)-\pi_{i j} P\left(\Gamma_{i}, t\right)\right]
$$

Na situação de equilíbrio, a probabilidade $P\left(\Gamma_{i}, t\right)$ não deverá ter uma dependência explícita no tempo. Uma condição suficiente para o equilíbrio é dada pelo principio do balanço detalhado, muitas vezes chamado de principio de reversibilidade microscópica [169]:

$$
\pi_{j i} P_{j}=\pi_{i j} P_{i}
$$

Usualmente $\pi_{i j}$ é separado em dois elementos: a probabilidade de aceitar a mudança e a probabilidade de gerar $j$ a partir de $\mathrm{i}\left(\alpha_{i j}\right)$. Como temos em mente reproduzir a distribuição de probabilidade do ensemble, existem diversas maneiras de satisfazer o princípio do balanço detalhado, como proposto por Glauber [170]. Metropolis e colaboradores sugeriram o seguinte:

$$
\pi_{i j}=\left\{\begin{array}{lll}
1 & \text { se } & \Delta U_{i j} \leq 0 \\
P_{j} \alpha_{j i} / P_{i} \alpha_{i j} & \text { se } & \Delta U_{i j}>0 \\
1-\sum_{j \neq i} \pi_{i j} & \text { se } & i=j
\end{array}\right.
$$

$\mathrm{Na}$ amostragem de Metropolis, a matriz $\alpha$ é tomada como sendo a unidade, dado que esse fator entra no sorteio da escolha da molécula. No caso específico do ensemble NVT, temos que:

$$
\pi_{i j}=\left\{\begin{array}{lll}
1 & \text { se } & \Delta U_{i j} \leq 0 \\
\exp \left(-\beta \Delta U_{i j}\right) & \text { se } & \Delta U_{i j}>0
\end{array}\right.
$$

sendo que, $\Delta U=U\left(\Gamma_{j}\right)-U\left(\Gamma_{i}\right)$ é a diferença de energia potencial das duas configurações.

Até esse ponto, estamos lidando com um sistema composto de partículas. A ideia pode ser estendida para um sistema poliatômico. Considerando moléculas rígidas, devemos considerar além da translação, a rotação das moléculas do sistema. Essa rotação é mediada pelo sorteio de um dos ângulos de Euler de uma dada molécula do sistema. Existem outras propostas na literatura e que são discutidas na referência 153.

O método de $\mathrm{MC}$ com o algoritmo de Metropolis não pode ser empregado considerando moléculas flexíveis. O problema é encontrar coordenadas generalizadas para descrever as posições e momentos das moléculas. As expressões para a matriz de transição se tornam bastante complexas e de difícil manipulação, devido às expressões complexas vindas dos elementos jacobianos introduzidos pelo uso de sistema de coordenadas internas. Caso seja empregado coordenadas cartesianas, a energia intramolecular, que descreve o estiramento de 
ligações, dominará e qualquer movimento será aceito e, consequentemente, o ensemble não será amostrado corretamente. Um tratamento com moléculas flexíveis no contexto do programa DICE foi recentemente implementado em nosso grupo de pesquisa [171], baseado no método Configurational Bias MC [172].

A seguir mostramos os procedimentos para a geração das configurações de um sistema constituído de moléculas utilizando o algoritmo de Metropolis, como está implementado no programa DICE [171].

1. Geração de uma configuração inicial para o sistema, podendo ser ordenada ou aleatória. As dimensões da caixa inicial são geralmente calculadas para reproduzir a densidade experimental. A caixa de simulação é replicada em todas as direções, excluindo os efeitos de borda usando condições periódicas de contorno.

2. Uma nova configuração é obtida a partir da anterior selecionando sequencialmente uma molécula do sistema, transladando e rotacionando. Na proposta inicial de Metropolis, a nova configuração é obtida sorteando uma molécula do sistema, mas essa abordagem é equivalente. A translação é feita a partir do centro de massa e a rotação é promovida pelo sorteio de eixo com um ângulo entre $-15^{\circ}$ e $15^{\circ}$. Adicionalmente, no ensemble NPT há a mudança no volume, sorteando incrementos para os lados da caixa.

3. A energia da nova configuração é computada. Caso seja menor que a energia da configuração anterior, a configuração é aceita e faz parte da cadeia markoviana. Por outro lado, se a energia for maior, é sorteado um número aleatório entre 0 e 1 , sendo comparado com $\exp (-\beta \Delta U)$. Se o número aleatório for maior, a configuração é rejeitada, caso contrário, essa configuração é aceita e passa a ser a nova configuração.

4. Acumula a média das propriedades termodinâmicas de interesse, por exemplo, energia interna e calor específico. Retorna para a etapa 2 do processo.

Nos primeiro passos de $\mathrm{MC}$, as configurações geradas são arranjos não estacionários, que devem ser evitados nas médias das propriedades de interesse. Esse estágio é chamado de termalização. No intuito de acelerar esse estágio e chegar mais rápido ao equilíbrio, normalmente é empregado o que denominamos de cooling, isto é, ao invés de utilizarmos o teste de aceiterejeição de Metropolis, é adotado um procedimento que aceita a nova configuração apenas se a energia do sistema diminuir.

Para melhorar a eficiência computacional, um raio de overlap $\left(r_{0}\right)$ é comumente atribuído. Se a distância entre dois átomos estiver mais próxima do que $r_{0}$, a configuração é rejeitada de imediato, visto que haverá uma repulsão muito forte (energia bastante alta). 


\subsubsection{Dinâmica Molecular}

A dinâmica molecular é outra técnica de amostragem de sistemas moleculares, que está fundamentada no formalismo newtoniano. Dessa forma, para um sistema com $N$ partículas clássicas interagentes de massa $m_{i}$ submetidas a um potencial $U(\mathbf{r})$, que pode incluir também campos externos, a equação de movimento para cada partícula é ditada pela $2^{a}$ lei de Newton, ou seja:

$$
\frac{d^{2} \mathbf{r}_{i}}{d t^{2}}=-\frac{1}{m_{i}} \nabla_{i} U(\mathbf{r}), \quad i=1,2, \ldots, N
$$

Esse método é determinístico, uma vez que resolvendo a equação 4.18, podemos obter a velocidade $v_{i}$ e a posição $r_{i}$ de cada partícula para cada instante de tempo $\Delta t$. Ao longo do tempo foram desenvolvidos vários algoritmos de integração na literatura em ordem de resolver a equação 4.18, sendo os mais conhecidos os algoritmos de Verlet, Leapfrog, Predictor Corrector e Velocity Verlet.

O programa Amber utiliza como padrão a integração de leapfrog. Nesse algoritmo, as novas posições e velocidades são atualizadas pelas seguintes equações:

$$
\begin{aligned}
\mathbf{v}_{i}\left(t+\frac{1}{2} \Delta t\right) & =\mathbf{v}_{i}\left(t-\frac{1}{2} \Delta t\right)+\frac{\mathbf{F}(t)}{m_{i}} \Delta t \\
\mathbf{r}_{i}(t+\Delta t) & =\mathbf{r}_{i}(t)+\mathbf{v}_{i}\left(t+\frac{1}{2} \Delta t\right)
\end{aligned}
$$

A Dinâmica Molecular em sua formulação original propaga as quantidades temporais no ensemble microcanônico (NVE), ou seja, o número de partículas, volume e energia são mantidos constantes. Entretanto, esse tipo de ensemble, na maioria das vezes, não é o ideal para comparação com dados experimentais, dado que não condiz com as condições usuais dos experimentos. Para esses casos é indicado o uso de outros ensembles, como o canônico (NVT) e o isotérmico-isobárico (NPT).

Vários métodos foram propostos para tentar adaptar a dinâmica molecular ao ensemble canônico. O mais simples dele é o método isocinético, que fixa a energia cinética a cada passo da simulação por meio de um renormalização das velocidades. Sua desvantagem é a eliminação da flutuação da temperatura existente nesse ensemble. O termostato de Anderson corrige essa deficiência, visto que em certos intervalos de tempo, uma ou mais moléculas são escolhidas aleatoriamente para ganhar uma nova velocidade. Outros termostatos mais refinados foram também propostos, sendo os mais difundidos, os termostatos de Nosé-Hoover, Berendsen e o método velociy scale. Esse último método é uma correção do termostato de Berendsen, cuja a ideia é adicionar correções estocásticas por meio de um movimento Browniano a fim de se obter de uma melhor maneira as flutuações do ensemble canônico. Para maiores delalhes sobre cada um desses termostatos e outros, recomendamos a leitura da referência 173. 
Uma outra maneira de se obter o ensemble canônico é por meio do termostato de Langevin [153]. A proposta inicial era descrever o movimento browniano de partículas em um líquido. Basicamente são adicionados dois termos na equação de movimento, sendo o primeiro relacionado a uma "força aleatória", que seria o elemento estocástico do algoritmo e está ligado as colisões da partícula $i$ com as moléculas de solvente. O segundo termo consiste de uma "força de atrito", que é proporcional a velocidade. A equação de movimento a ser resolvida é dada pela equação (4.20).

$$
\frac{d^{2} \mathbf{r}_{i}}{d t^{2}}=-\frac{1}{m_{i}} \nabla_{i} U(r)-\gamma \frac{d \mathbf{r}_{i}}{d t}+\frac{\xi_{i}(t)}{m_{i}}
$$

sendo que, $\xi_{i}(t)$ é uma função aleatória do tempo e o coeficiente de fricção $\gamma$ é extraído pela lei de Stokes. Essa dinâmica é amplamente recomendada para descrever o solvente implicitamente

No caso do ensemble NPT, além de um termostato, é necessário a adição de um barostato. A ideia central é reescalonar as coordenadas das moléculas e o tamanho da caixa periodicamente a fim de manter a caixa em uma pressão constante. O método de acoplamento fraco de Berendsen é um dos mais empregados para essa finalidade. O conceito é o mesmo do termostato de Berendsen, ou seja, a pressão converge exponencialmente para a pressão alvo. Outro barostato bastante empregado é o de Parrinello-Rahman, sendo esse uma variação do barostato de Andersen, que permite a mudança de tamanho e formato da caixa de simulação.

\subsubsection{Potencial de interação}

No coração de qualquer simulação clássica, seja via MC ou MD, é necessário conhecer o potencial de interação $U(\mathbf{r})$ do sistema a cada arranjo molecular. No caso do algoritmo de Metropolis, esse potencial está diretamente relacionado à aceitação ou rejeição da nova configuração. Já para a Dinâmica Molecular, é preciso computar o gradiente desse potencial de interação molecular. O potencial de interação pode ser agrupado em termos de um corpo, dois corpos e assim por diante. No contexto de líquidos, é necessário levar em conta pelo menos até o termo de três corpos, dado que a contribuição de termos de ordem superior é muito pequena [137]. Correntemente, os termos de dois e três corpos são fundidos em um potencial efetivo de pares, sendo expresso por:

$$
U(\mathbf{r})=\sum_{i} u_{i}\left(\mathbf{r}_{i}\right)+\sum_{i} \sum_{j>i} u_{2}^{\mathrm{eff}}\left(\left|\mathbf{r}_{i j}\right|\right)
$$

O potencial efetivo de pares poderá ter uma dependência com parâmetros macroscópicos, devido a impormos que esse termo reproduza dados experimentais. Considerando que não exista nenhum campo externo agindo no sistema, o primeiro termo será nulo e o potencial de interação será expresso somente como uma contribuição do potencial efetivo.

Esse potencial efetivo é regularmente dividido em duas partes: intramolecular e intermolecular. A parcela intramolecular é referente as modificações estruturais do sistema e é modelada por 
termos que representam o estiramento de ligações químicas $\left(u_{b}\right)$, dobramentos de ângulos de ligação $\left(u_{a}\right)$ e torsionais $\left(u_{d}\right)$, ou seja:

$$
\begin{aligned}
u_{\text {intra }} & =\sum_{b} k_{r}\left(r_{i j}-r_{\mathrm{eq}}\right)^{2} \underset{\mathrm{r}}{\longrightarrow} \\
& +\sum_{a} k_{\theta}\left(\theta_{i j}-\theta_{\mathrm{eq}}\right)^{2} \\
& +\sum_{d} \frac{V_{n}}{2}\left[1+\cos \left(n \phi_{i j}-\delta\right)\right] \\
& +\sum_{i} \frac{V}{2}[1+\cos (2 \phi-\pi)]
\end{aligned}
$$

Os dois primeiros termos da equação (4.22) são potenciais harmônicos que descrevem a ligação química e o ângulo de abertura formado por três átomos, respectivamente. Os outros dois termos remanescentes descrevem ângulos torsonais e ângulos impróprios formados por quatro átomos, respectivamente.

O termo intermolecular está relacionado com as interações eletrostáticas e de van der Waals. Comumente, é expresso como uma soma dos potenciais de sítios que caracterizam uma molécula. A título de exemplo, para duas moléculas $A$ e $B$, o potencial intermolecular será expresso por:

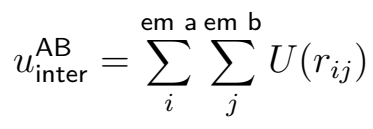

sendo que, o primeiro somatório é sobre os sítios da molécula $A$, o segundo somatório é sobre os sítios da molécula $\mathrm{B}$ e $r_{i j}$ é a distância entre os sítios $i$ e $j$.

Nem sempre, o número de sítios será igual ao número de átomos da molécula. Esse número pode ser menor quando tratamos um grupo funcional ou a molécula inteira com um único sítio. A vantagem dessa abordagem é o número reduzido de sítios a serem contabilizados, reduzindo o custo computacional. No campo de forção OPLS united atom (OPLS-UA) [174], os átomos de hidrogênios ligados aos átomos de carbonos não possuem sítios de interação, pois a contribuição deles já está incorporada na parametrização dos átomos de carbono. Também existem casos em que o número de sítios é maior do que o número de átomos da molécula. Os exemplos típicos são os modelos de água TIP4P [175] e TIP5P [176]. O principal ganho de mais sítios é uma descrição mais precisa da distribuição de carga da molécula ou o melhoramento na previsão de propriedades termodinâmicas.

Dentre os potencias intermoleculares empíricos já parametrizados na literatura, destacamos o potencial de Lennard-Jones (LJ) [177] acrescido do potencial de Coulomb:

$$
u_{\text {inter }}^{\text {LJC }}=4 \varepsilon_{i j}\left[\left(\frac{\sigma_{i j}}{r_{i j}}\right)^{12}-\left(\frac{\sigma_{i j}}{r_{i j}}\right)^{6}\right]+\frac{q_{i} q_{j}}{r_{i j}}
$$


sendo que, $\varepsilon_{i j}=\sqrt{\varepsilon_{i} \varepsilon_{j}}$ e $q_{i}$ é a carga do sítio i. Existem duas maneiras de escrever $\sigma_{i j}$; regra de Good-Hope $\left(\sigma_{i j}=\sqrt{\sigma_{i} \sigma_{j}}\right)$ [178] e a regra de Lorentz-Berthelot $\left(\sigma_{i j}=\left(\sigma_{i}+\sigma_{j}\right) / 2\right)$.

O potencial LJ possui um comportamento atrativo para longas distâncias $r^{-6}$ (termo de van der Waals) e um termo repulsivo para curtas distâncias $\left(r^{-12}\right)$. O termo atrativo possui uma origem quântica. Em contrapartida, o termo repulsivo não necessariamente precisaria ser parametrizado como $r^{-12}$. Lennard-Jones obteve resultados satisfatórios para diversas propriedades termodinâmicas utilizando o potencial de interação como na equação (4.24), além de ser uma função simples e elegante. $O$ parâmetro $\varepsilon$ se refere à profundidade do poço de potencial e o parâmetro $\sigma$ diz a distância para o qual o potencial é nulo.

Outro potencial bastante utilizado na literatura é o de Buckingham, sendo que a parte repulsiva do potencial LJ é substituída por uma forma exponencial $\left(A_{i j} \exp \left(-B_{i j} r_{i j}\right)\right)$. Em comparação com o potencial LJ, a sua parametrização é mais complexa.

\subsubsection{Função de autocorrelação da energia}

As configurações salvas a partir do método de MC são desejadas serem o mais descorrelacionadas possíveis. Isso na prática significa obter configurações que são bem distintas, mas que representem bem o sistema simulado. A metodologia s-QM/MM usa essa ideia para reduzir o número de cálculos quânticos e obter propriedades estatisticamente descorrelacionadas. Nesse contexto, uma quantidade importante, que diz a eficiência estatística da simulação e prediz um intervalo de passo de MC para descorrelacionar as configurações é a função de autocorrelação da energia. Essa função é matematicamente definida por:

$$
C(t)=\frac{\left\langle\delta U_{i} \delta U_{i+t}\right\rangle}{\left\langle\delta U^{2}\right\rangle}=\frac{\sum_{i}\left(U_{i}-\langle U\rangle\right)\left(U_{i+t}-\langle U\rangle\right)}{\sum_{i}\left(U_{i}-\langle U\rangle\right)^{2}}
$$

sendo que, $U_{i}$ é a energia da configuração $i$ e $U_{i+t}$ corresponde a energia da configuração após $t$ passos de $\mathrm{MC}$.

Na equação (4.25) é visível que um número de passos de $M C$ conduz para uma correlação bem próxima de 1 , significando que nenhuma informação estatística nova é adquirida. Em contrapartida, a correlação nula é alcançada apenas quando o número de passos de MC tende ao infinito. Em processos Markovianos, a função de autocorrelação da energia assume uma natureza exponencial [179]:

$$
C(t)=\sum_{i} c_{i} e^{-t / \tau_{i}}
$$

O intervalo de correlação é matematicamente definido por:

$$
\tau=\int_{0}^{\infty} C(t) d t
$$


O ajuste com duas exponencias para a função de autocorrelação da energia já é suficiente para simulação de líquidos moleculares, ou seja:

$$
C(t)=c_{1} e^{-t / \tau_{1}}+c_{2} e^{-t / \tau_{2}}
$$

Na Figura 4.7 é exibido um exemplo de função de autocorrelação da energia e, como pode ser visto, um decaimento biexponencial reproduz corretamente o comportamento da função. O intervalo de correlação utilizando duas exponencias como função será dado por $\tau=c_{1} \tau_{1}+c_{2} \tau_{2}$. Com o intervalo de correlação é possível estimar outra quantidade importante, que é a ineficiência estatística. Essa propriedade diz o intervalo de passos de $\mathrm{MC}$ necessários para descorrelacionar as configurações. Essa grandeza é dada por $s \sim 2 \tau$ e avaliando a correlação para $t=s$, em geral, resulta em uma correlação da ordem de $13 \%$.

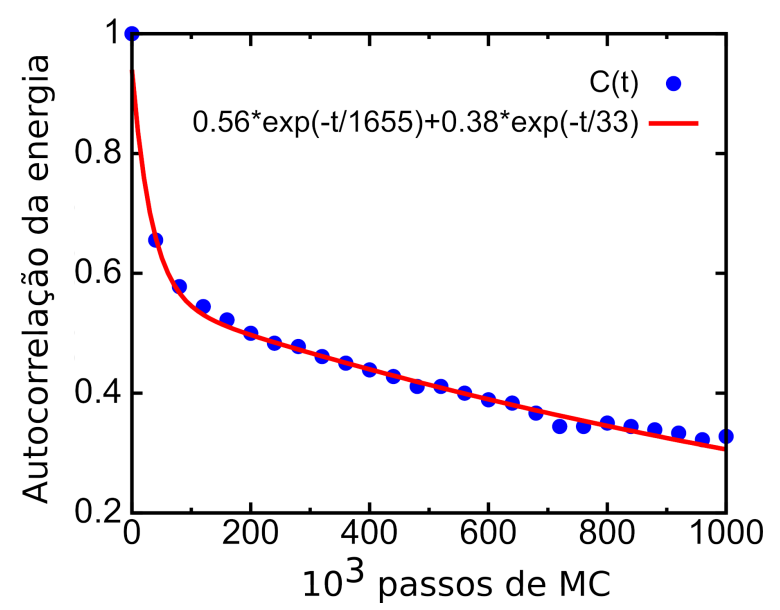

Figura 4.7 - Ilustração de uma função de autocorrelação da energia com o respectivo ajuste biexponencial.

\subsection{Função distribuição radial de pares}

No estudo da estrutura do líquido é correntemente empregado a função distribuição radial de pares $(g(r))$. Essa função diz qual é a probabilidade de encontrar um par de átomos a uma dada distância $r$ com respeito à probabilidade de uma gás ideial que possua distribuição totalmente aleatória. Essa função pode ser obtida indiretamente por experimentos de difração de raios-X ou de nêutrons por meio da transformada de Fourier do fator de estrutura.

Do ponto de vista teórico, a $g(r)$ é contabilizada integrando a função de distribuição do ensemble em todas as variáveis espaciais, salvo o par de átomos de interesse. No ensemble NVT, para um par de sítios $i$ e $j$, a função $g(r)$ será dada por:

$$
g\left(\mathbf{r}_{i}, \mathbf{r}_{j}\right)=\frac{N(N-1)}{\rho^{2} Z} \int d \mathbf{r}_{1} d \mathbf{r}_{2} \cdots d \mathbf{r}_{i} d \mathbf{r}_{i+1} \cdots d \mathbf{r}_{j} d \mathbf{r}_{j+1} \cdots d \mathbf{r}_{N} e^{-\beta U(\mathbf{r})}
$$


sendo, $N$ o número de moléculas, $\rho$ é a densidade e $Z$ é um fator de normalização.

Todavia, na simulação essa função é calculada através de um histograma dos sítios $i$ e $j$ usando a seguinte expressão:

$$
g_{i j}(r+d r / 2)=\frac{n_{i j}(r, r+d r)}{n^{i d e a l}(r, r+d r)}
$$

sendo que, $n_{i j}$ é o número de pares $i j$ que estão separados entre uma distância $r$ e $r+d r$, e $n^{\text {ideal }}$ é o número de pares para um gás ideal que é dado por:

$$
n^{\text {ideal }}(r, r+d r)=\frac{4 \pi \rho}{3}\left[(r+d r)^{3}-r^{3}\right]
$$

Ilustramos na Figura 4.8 o arranjo molecular de um líquido atômico e a sua respectiva estrutura dada pela $g(r)$. Os picos da $g(r)$ definem as camadas de solvatação e a integração sobre esses picos resulta no número de coordenação, que é a quantidade de moléculas de solvente que se distribuem nas camadas de solvatação ao redor do soluto. $O$ número de coordenação é computado matematicamente por:

$$
N=4 \pi \rho \int_{0}^{r} g(r) r^{2} d r
$$

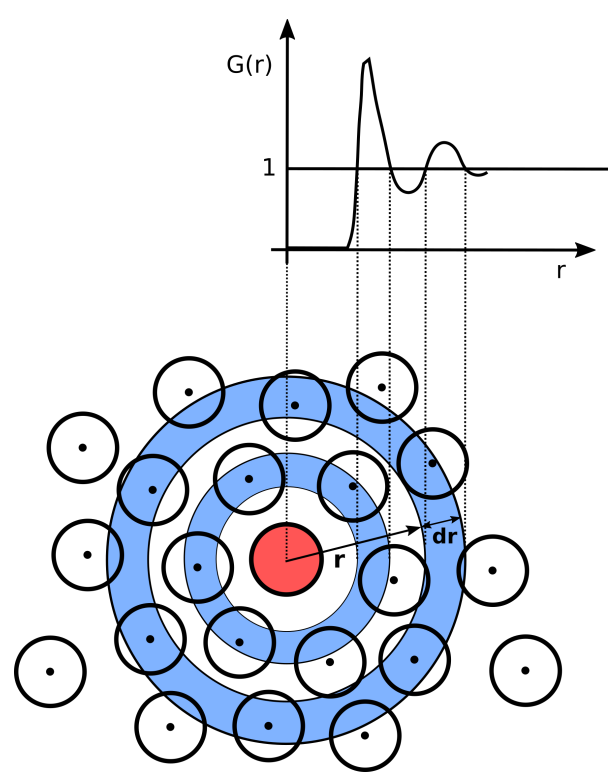

Figura 4.8 - Ilustração da estrutura de um líquido atômico através da $g(r)$. Adaptado da referência 180.

Uma maneira mais realística de avaliar o número de moléculas de solvente em torno do soluto é construindo uma $g(r)$ entre centros de massa. Essa $g(r)$ de centro de massa mostra como as moléculas do solvente estão estruturadas como um todo. Entretanto, não é conveniente usar esse tipo de abordagem para solutos que possuem um formato alongado, visto que o soluto não possui mais uma simetria radial. O nosso grupo de pesquisa propôs uma alternativa, considerando a menor distância entre qualquer par de moléculas, sendo chamada de função distribuição de mínima distância $\left(G_{\mathrm{MD}}\right)$ [181]. 
Capítulo 2

\section{Estrutura eletrônica e propriedades espectroscópicas de análogos nucleosídeos fluorescentes}

Nesse capítulo são apresentados os resultados de espectroscopia e fotofísica de um novo alfabeto de bases modificadas do RNA. Esse alfabeto foi estudado isoladamente e em meio solvente empregando as técnicas computacionais descritas nos capítulos anteriores. $O$ estudo desse sistema tem a colaboração do professor Antonio Carlos Borin do Instituto de Química da USP (IQUSP).

\subsection{Introdução e motivação}

A expansão do alfabeto genético oferece uma variedade de novas possibilidades de pareamento, além de aumentar a biodiversidade biológica. $O$ estudo das propriedades físico-químicas de análogos das convencionais bases nucléicas tem se tornado uma área de bastante interesse. Dentre esses compostos, a síntese química de novas moléculas vem sendo desenvolvida ao decorrer dos anos, sendo que destacamos aquelas que são propensas a fluorescência. Tais moléculas podem ser empregadas em interações biomoleculares e dinâmica de ácidos nucléicos via experimentos de fluorescência, com diversas vantagens sobre outras técnicas espectroscópicas [20,23]. Entre muitos estudos em andamento, vale mencionar aqueles relacionados à síntese de um alfabeto completo ribonucleosídeo isomórfico fluorescente. Em uma tentativa para obtenção de um alfabeto completo do RNA, Shin e colaboradores utilizaram a molécula tieno[3,4-d]-pirimidínica como modelo para sintetizar os nucleosídeos ${ }^{\text {th }} \mathbf{A}$ (adenina), ${ }^{\text {th }} \mathbf{C}$ (citosina), ${ }^{\text {th }} \mathbf{G}$ (guanina) e ${ }^{\text {th }} \mathbf{U}$ (uracila) [182]. Apesar de suas propriedades emissivas, esses novos compostos não eram completamente compatíveis com os nucleotídeos naturais do RNA. O principal motivo dessa incompatibilidade foi devido à ausência do átomo de nitrogênio na posição sete $\left(\mathrm{N}_{7}\right)$ do esqueleto purina, que é responsável por propriedades químicas importantes tais como: basicidade e coordenação. 
Esse empecilho foi resolvido por Rovira e colaboradores adotando como modelo a molécula isotiazole[4,3-d]pirimidínica [183]. Dessa forma, foi sintetizado um novo alfabeto ribonucleosídeo fluorescente, resultando nas espécies: ${ }^{\mathrm{tz}} \mathbf{A},{ }^{\mathrm{tz}} \mathbf{C},{ }^{\mathrm{tz}} \mathbf{G}$ e ${ }^{\mathrm{tz}} \mathbf{U}$ (Figura 5.1). Adicionalmente, uma outra molécula foi também sintetizada por meio da deaminação da molécula ${ }^{\text {tz }} \mathbf{A}$, sendo rotulada de ${ }^{\text {tz }} \mathbf{I}$ (inosina). Além disso, foi constatado experimentalmente que a deaminação para esse alfabeto era mais eficiente e rápido do que foi observado para o primeiro alfabeto.

Até o presente momento, alguns trabalhos teóricos já foram publicados na literatura. Samanta et al. [184] e Gedik et al. [185] estudaram a primeira geração, usando o método PCM e DFT (teoria do funcional da densidade). Mais recentemente, o segundo alfabeto foi investigado combinando DFT e C-PCM (versão alternativa do PCM, cujo o meio solvente é tratado como condutor ao invés de dielétrico) [140] por Chawla et al. [186]. Recentemente, novos alfabetos do RNA com tamanho expandido (inserindo um benzeno entre os anéis) e substituindo o átomo de enxofre por um átomo de selênio [187] têm sido propostos teoricamente. Ademais, novos compostos ( ${ }^{\mathrm{t} z} \mathbf{2}-\mathbf{A A},{ }^{\mathrm{tz}} \mathbf{i s o G}$ e ${ }^{\mathrm{tz}} \mathbf{X}$ ) foram sintetizados empregando o mesmo template [188], expandindo ainda mais esse alfabeto.

Como discorrido acima, nenhum desses trabalhos teóricos consideram o aspecto atomístico do solvente, além das propriedades obtidas via DFT serem bastante dependentes do funcional empregado. Logo, um melhor entendimento do papel dos efeitos de solvente nas propriedades eletrônicas nos estados fundamental e excitados é uma questão em aberto.

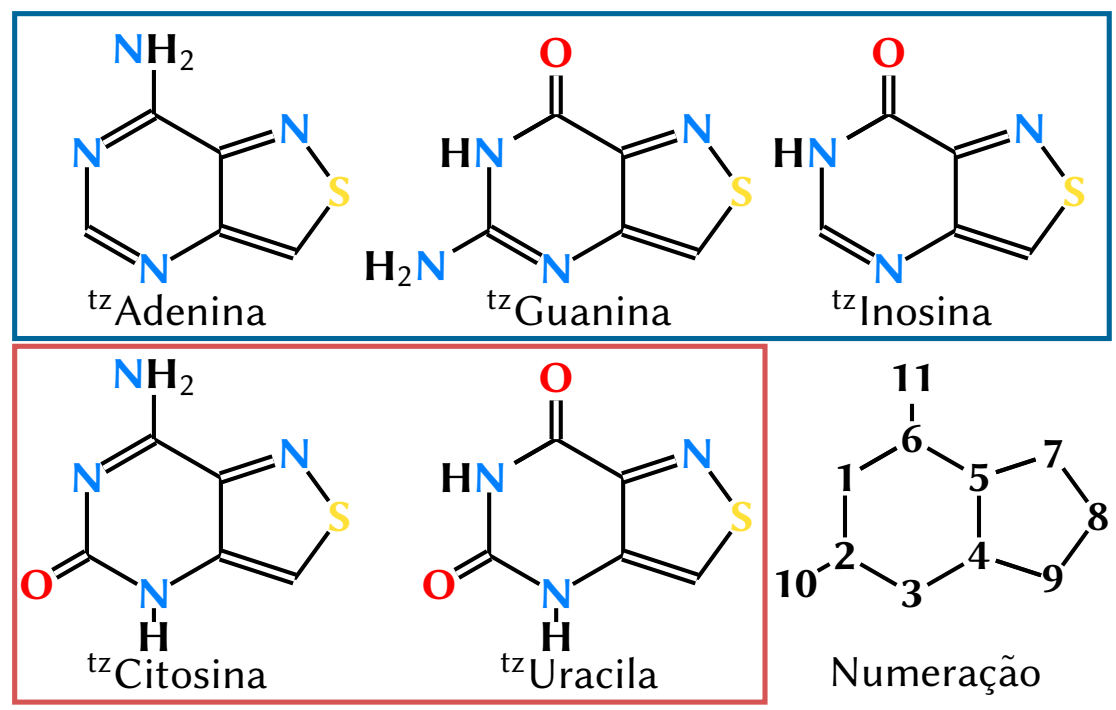

Figura 5.1 - Ilustração do novo alfabeto ribonucleosídeo fluorescente obtido a partir da molécula isotizole[4,3-d]pirimidínica, sendo que a ribose foi substituída por um átomo de hidrogênio. $O$ retângulo com linha azul se refere as moléculas tipo purínicas e com linha vermelha para as moléculas tipo pirimidínica. A numeração atômica será utilizada ao decorrer do texto. Representação atômica: nitrogênio $(N)=$ azul, oxigênio $(\mathrm{O})=$ vermelho e enxofre $(\mathrm{S})=$ amarelo. 


\subsection{Detalhes computacionais}

\subsubsection{Cálculos de estrutura eletrônica}

A geometria molecular do estado fundamental em fase gasosa, 1,4-dioxano e água de todas as moléculas é otimizada no nível de teoria MP2 (teoria de pertubação de muitos corpos Møller-Plesset em segunda ordem), seguido pela análise das frequências vibracionais harmônicas, que revelam nenhuma frequência imaginária. A geometria do primeiro estado excitado ${ }^{1}(\pi \pi)^{*}$ da molécula isolada é obtida por meio do método Multi-State CASPT2 [77, 78, 92] empregando três raízes no procedimento state-averaged, ou seja, um único conjunto de orbitais é otimizado com base na média dos três estados eletrônicos mais baixos. $O$ espaço ativo adotado para o procedimento de otimização de geometria compreende todos os orbitais $\pi$ e $\pi^{*}$. Em todos os cálculos (otimizações de geometria e espectro de absorção e fluorescência) são realizados usando o conjunto de funções bases atômicas cc-pVDZ (correlation consistent polarized valence double- $\zeta$ ) [189].

O espectro de absorção e emissão eletrônicos em fase gasosa e em solvente são computados no nível de teoria CASPT2. Os orbitais são retirados a partir de um cálculo $S A(X)$ CASSCF $(18,13)$, sendo que $X\left(6\right.$ para ${ }^{\mathrm{tz}} \mathbf{A},{ }^{\mathrm{tz}} \mathbf{G}$ e ${ }^{\mathrm{tz}} \mathbf{I}, 8$ para ${ }^{\mathrm{tz}} \mathbf{C}$ e 10 para $\left.{ }^{\mathrm{tz}} \mathbf{U}\right)$ representa o número de estados inseridos no procedimento state-averaged. O espaço ativo é composto de 10 orbitais $\pi$ e $\pi^{*}$, com os correspondentes 12 elétrons, adicionando mais os 3 orbitais não-ligados ( $\mathrm{n}$ ) e os seus respectivos 6 elétrons. O orbital $n$ associado ao átomo de enxofre não é incorporado no espaço ativo, visto que o número de ocupação médio desse orbital em todas as moléculas estudadas exibe um valor próximo de dois. Isso significa que as excitações a partir desse orbital se localizam em um intervalo de energia bem acima do que propomos estudar. Como exemplo, na Figura 5.2 é apresentado o espaço ativo adotado para a molécula ${ }^{\text {tz }} \mathbf{A}$ na otimização de geometria e nos cálculos de energias de excitação vertical. Para as demais moléculas, o espaço ativo pode ser consultado no Anexo A. Efeitos de correlação dinâmicas são levados em conta mediante o método SS(X)-CASPT2 (Single-State CASPT2). Na tentativa de evitar possíveis estados intrusos, um deslocamento de nível imaginário (Imaginary Level Shift) [83] de 0.2 a.u. é adotado. Nenhuma correção de deslocamento IPEA [85] é empregada, como sugerida recentemente [88]. Em nenhum desses cálculos são impostas restrições espaciais, isto é, todos os cálculos foram feitos sem a utilização de simetria.

Pontos de cruzamento de mínima energia (MECP) entre os estados fundamental e o mais baixo ${ }^{1}\left(\pi \pi^{*}\right)$ foram otimizados por meio da técnica de multiplicadores de Lagrange restrito [190], empregando o mesmo nível de teoria e espaço ativo dos procedimentos de otimizações mencionados acima. Caminho de menor energia (MEP) a partir da região FranckCondon, ao longo da hipersuperfície do estado mais baixo ${ }^{1}\left(\pi \pi^{*}\right)$ são computados no nível 


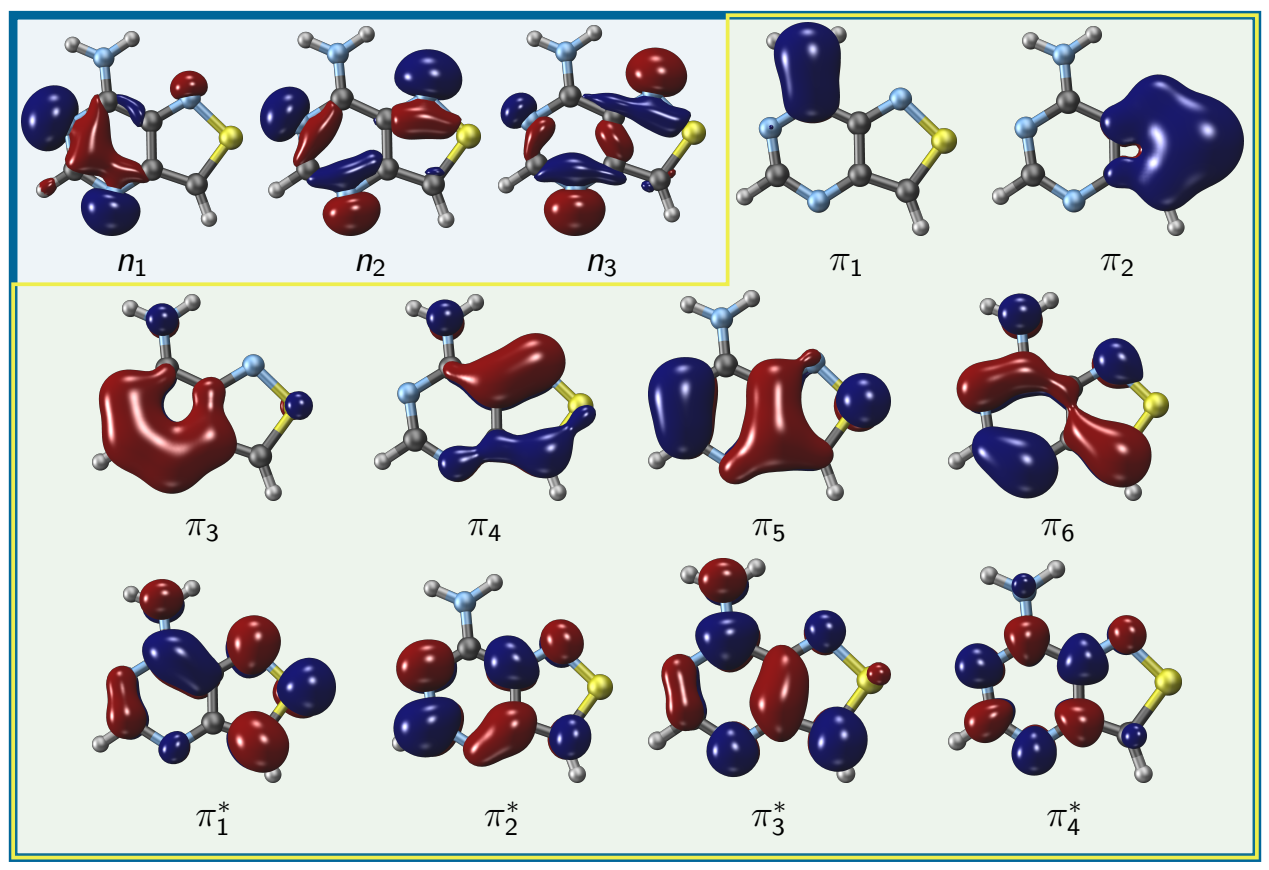

Figura 5.2 - Ilustração do espaço ativo utilizado para a molécula ${ }^{\mathrm{tz}} \mathbf{A}$. Nos cálculos de otimização de geometria (fundo amarelo) foi utilizado o espaço $\pi$ completo. Os orbitais $n_{\mathrm{N}}$ foram adicionados para os cálculos de energias de transição vertical (fundo azul). Um espaço ativo equivalente foi adotado para as demais moléculas.

SA(2)-CASSCF / cc-pVDZ com o espaço $\pi$ completo. Em cada ponto gerado pelo MEP, correlação dinâmica foi incluída recalculando as energias no nível SS(X)-CASPT2(18,13)/ccpVDZ, seguindo o chamado protocolo CASPT2//CASSCF. Sempre que os cálculos de MEP não são factíveis, o perfil energético entre os pontos críticos é conectado por intermédio da técnica de interpolações lineares em coordenadas internas (LIIC), computando as energias de transição vertical em cada ponto como descrito acima.

\subsubsection{Efeitos do Solvente}

Em meio solvente, as geometrias moleculares tanto do estado fundamental quanto do estado excitado ${ }^{1}\left(\pi \pi^{*}\right)$ são otimizadas assumindo duas distintas aproximações para o solvente. Em uma delas, as geometrias de todas as espécies são otimizadas empregando o modelo PCM [139], em sua versão dielétrica. A outra metodologia é baseada na aproximação ASECFEG $[165,166]$, que combina a metodologia QM/MM sequencial (s-QM/MM) com um embedding eletrostático médio para o solvente (ASEC) [160] e o gradiente de energia livre (FEG) $[163,164]$. Essa combinação permite o mapeamento da hipersuperfície de energia livre, incluindo mínimos e estados de transição. Os critérios de convergência adotados nesse trabalho foram: desvios padrões nos comprimentos de ligação e ângulos de $10^{-3} \AA$ e $1^{\circ}$, respectivamente. Esses critérios conduzem para forças máxima e quadrática média abaixo de 
$3 \times 10^{-3}$ Hartree/Bohr. O embedding eletrostático ASEC foi gerado pela superposição de 200 configurações estatisticamente descorrelacionadas.

As simulações clássicas são executadas empregando o método de Monte Carlo (MC), com o teste de aceite-rejeição dado pelo algoritmo de Metropolis [191]. Durante a simulação clássica, tanto o soluto quanto as moléculas de solvente foram mantidas rígidas. O potencial de LennardJonnes (LJ) acrescido do potencial de Coulomb são usados para modelar a interação molecular. Os parâmetros LJ do soluto foram extraídos dos potenciais otimizados para simulação de líquidos moleculares (OPLS-AA) [192], contudo, a carga para cada sítio atômico do soluto é obtida através de um ajuste de cargas parciais. Para o estado fundamental é empregado o ajuste CHELPG (CHarges from Electrostatic Potential) [193] no nível de cálculo MP2/cc-pVDZ, enquanto para o estado excitado é feito o ajuste do potencial eletrostático (ESPF) [194] no nível CASSCF [68] utilizando o procedimento state-averaged incluindo duas raízes (estados fundamental ${ }^{1}$ (gs) e ${ }^{1}\left(\pi \pi^{*}\right)$ ). No caso do solvente, os campos de forças empregados são o modelo SPC/E [195] para descrever as moléculas de água e os parâmetros propostos por Luhmer e colaboradores para a molécula de 1,4-dioxano [196]. As simulações são realizadas no ensemble NPT em condições normais (pressão de $1 \mathrm{~atm}$ e temperatura de $298 \mathrm{~K}$ ). A termalização foi dividida em dois estágios. Primeiramente é feita uma termalização NVT com cerca de $8 \times 10^{4}$ ciclos de MC, seguidos por uma termalização NPT com $12 \times 10^{4}$ ciclos de MC. Um total de $4 \times 10^{5}$ ciclos de MC foram realizados no regime de equilíbrio. As simulações clássicas de MC são feitas por intermédio do programa DICE [171].

As energias de excitação vertical em solvente são calculadas através de dois procedimentos: (i) A interação soluto-solvente é tratada apenas com o embedding eletrostático ASEC e (ii) algumas moléculas de solvente são consideradas explicitamente no cálculo e a remanescentes continuaram sendo descritas como cargas pontuais. Nesse segundo caso, devido ao custo computacional elevado, foram escolhidas apenas 5 configurações que serviram para a produção do ASEC. Para o meio aquoso, as espécies ${ }^{\mathrm{tz}} \mathbf{A}$ e ${ }^{\mathrm{tz}} \mathbf{I}$ são rodeadas por seis moléculas de água explicitamente, ao passo que para as moléculas ${ }^{\mathrm{tz}} \mathbf{C},{ }^{\mathrm{tz}} \mathbf{G}$ e ${ }^{\mathrm{tz}} \mathbf{U}$, esse número é estipulado como oito. Já no solvente 1,4-dioxano, meramente duas moléculas de solvente foram selecionadas baseado em critérios de ligação de hidrogênio, sendo essas escolhas elucidadas nas próximas seções.

Infelizmente, o programa MOLCAS não disponibiliza o solvente 1,4-dioxano em sua base de dados. O solvente benzeno é utilizado para contornar esse problema, dado que ambos os solventes possuem uma constante dielétrica próxima. 


\subsection{Geometria de equilíbrio do estado fundamental}

A geometria otimizada em fase gasosa para as moléculas ${ }^{\mathrm{tz}} \mathbf{U}$ e ${ }^{\mathrm{tz}} \mathbf{I}$ exibe uma estrutura planar (grupo pontual de simetria Cs), enquanto que as espécies ${ }^{\text {tz }} \mathbf{A},{ }^{\text {tz }} \mathbf{C}$ e ${ }^{\text {tz }} \mathbf{G}$ apresentam uma piramidalização do grupo amino $\left(-\mathrm{NH}_{2}\right)$.

Os efeitos de solvente nas geometrias otimizadas foram analisados observando as mudanças estruturais nos comprimentos de ligação e no ângulo de piramidalização $(\alpha)$. Esse ângulo está diretamente relacionado com a hibridização do átomo de nitrogênio. Uma hibridização do tipo $\left(s p^{2}\right)$ indica um valor de $\alpha$ próximo de zero, ao passo que uma hibridização do tipo $\left(s p^{3}\right)$ significa que o valor de $\alpha$ se encontra perto dos $60^{\circ}$. Além do mais, essa coordenada descreve o movimento de wagging dos átomos de hidrogênio do grupo amino. Como pode ser visto na Figura 5.1, três das cinco moléculas possuem em sua estrutura molecular um grupo $\mathrm{NH}_{2}\left({ }^{\mathrm{tz}} \mathbf{A},{ }^{\mathrm{tz}} \mathbf{C}\right.$ e $\left.{ }^{\mathrm{tz}} \mathbf{G}\right)$. Como uma ilustração de como funciona a convergências dos parâmetros estruturais dentro da aproximação ASEC-FEG, na Figura 5.3 é mostrada a coordenada $\alpha$ em função dos passos de otimização para os dois solventes empregados. Na Tabela 5.1 são exibidos os parâmetros geométricos para os quais os efeitos de solvente foram mais pronunciados, como obtido com os métodos PCM e ASEC-FEG (média sobre os três últimos passos). Dados experimentais são também apresentados para comparação.

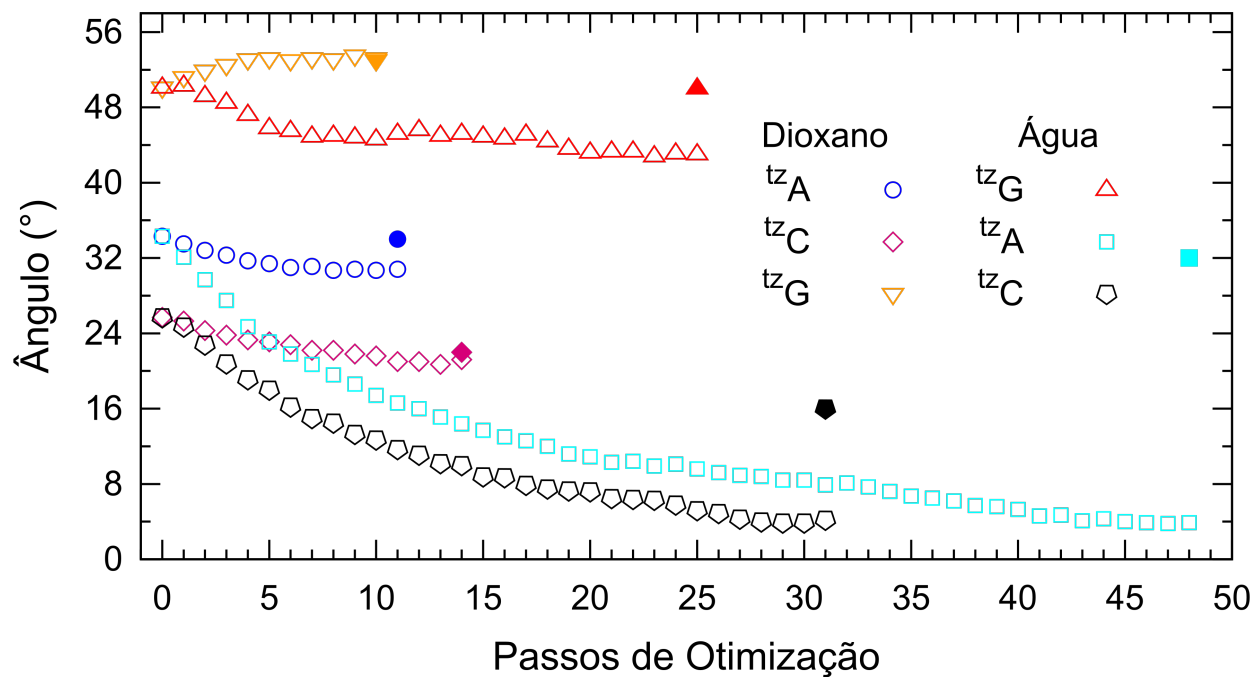

Figura 5.3 - Ângulo de piramidalização (graus) durante o processo de otimização ASEC-FEG. $O$ ponto inicial corresponde à geometria na região de Frank-Condon (FC) obtida em fase gasosa. Os pontos preenchidos correspondem aos valores obtidos na geometria otimizada pelo método PCM.

Em relação à fase gasosa, os métodos PCM e ASEC-FEG mostram uma diminuição do ângulo de piramidalização, mas com diferentes extensões. Em 1,4-dioxano foi observada uma ligeira diminuição dessa coordenada, com a maior redução de $5^{\circ}$ vista para a molécula ${ }^{\text {tz }} \mathbf{C}$. 
Tabela 5.1 - Comprimentos de ligação $(\AA)$ das bases modificadas do RNA otimizadas em fase gasosa, 1,4-dioxano e água. As geometrias otimizadas em meio solvente foram obtidas com as aproximações PCM e ASEC-FEG no nível MP2/cc-pVDZ. Valores experimentais também foram incluídos para comparação.

\begin{tabular}{|c|c|c|c|c|c|c|c|}
\hline \multirow[b]{2}{*}{ Molecule } & \multirow[b]{2}{*}{ Coordenadas } & \multirow[b]{2}{*}{ Gás } & \multicolumn{2}{|c|}{ 1,4-dioxano } & \multicolumn{2}{|c|}{ Água } & \multirow[b]{2}{*}{ Exp.[183] } \\
\hline & & & PCM & ASEC-FEG & $\mathrm{PCM}$ & ASEC-FEG & \\
\hline \multirow[t]{5}{*}{${ }^{\mathrm{tz}} \mathbf{A}$} & $\mathrm{N}_{3}-\mathrm{C}_{4}$ & 1.372 & 1.373 & 1.373 & 1.374 & 1.382 & 1.384 \\
\hline & $C_{5}-C_{6}$ & 1.436 & 1.437 & 1.441 & 1.437 & 1.450 & 1.440 \\
\hline & $\mathrm{N}_{1}-\mathrm{C}_{6}$ & 1.332 & 1.334 & 1.337 & 1.337 & 1.353 & 1.342 \\
\hline & $\mathrm{C}_{6}-\mathrm{N}_{11}$ & 1.362 & 1.360 & 1.357 & 1.356 & 1.342 & 1.325 \\
\hline & $\mathrm{N}_{11}-\mathrm{H}$ & 1.015 & 1.015 & 1.020 & 1.016 & 1.029 & 0.920 \\
\hline \multirow[t]{6}{*}{${ }^{\mathrm{tz}} \mathbf{C}$} & $\mathrm{C}_{2}-\mathrm{N}_{3}$ & 1.417 & 1.410 & 1.409 & 1.401 & 1.392 & 1.399 \\
\hline & $\mathrm{N}_{3}-\mathrm{C}_{4}$ & 1.373 & 1.374 & 1.374 & 1.375 & 1.384 & 1.394 \\
\hline & $\mathrm{N}_{1}-\mathrm{C}_{6}$ & 1.313 & 1.316 & 1.319 & 1.321 & 1.340 & 1.325 \\
\hline & $\mathrm{C}_{2}-\mathrm{O}_{10}$ & 1.220 & 1.224 & 1.227 & 1.23 & 1.249 & 1.226 \\
\hline & $\mathrm{C}_{6}-\mathrm{N}_{11}$ & 1.356 & 1.352 & 1.352 & 1.347 & 1.342 & 1.321 \\
\hline & $\mathrm{N}_{11}-\mathrm{H}$ & 1.014 & 1.014 & 1.016 & 1.014 & 1.023 & 0.926 \\
\hline \multirow[t]{7}{*}{${ }^{\mathrm{tz}} \mathbf{G}$} & $\mathrm{N}_{1}-\mathrm{C}_{2}$ & 1.385 & 1.386 & 1.389 & 1.388 & 1.400 & 1.391 \\
\hline & $\mathrm{C}_{2}-\mathrm{N}_{3}$ & 1.306 & 1.308 & 1.311 & 1.311 & 1.325 & 1.308 \\
\hline & $\mathrm{C}_{6}-\mathrm{N}_{1}$ & 1.412 & 1.407 & 1.405 & 1.399 & 1.396 & 1.378 \\
\hline & $\mathrm{C}_{6}-\mathrm{O}_{11}$ & 1.221 & 1.224 & 1.225 & 1.228 & 1.238 & 1.227 \\
\hline & $\mathrm{C}_{2}-\mathrm{N}_{10}$ & 1.391 & 1.386 & 1.383 & 1.379 & 1.366 & 1.344 \\
\hline & $\mathrm{N}_{10}-\mathrm{H}$ & 1.020 & 1.019 & 1.021 & 1.018 & 1.025 & 0.880 \\
\hline & $\mathrm{N}_{1}-\mathrm{H}$ & 1.019 & 1.020 & 1.026 & 1.020 & 1.042 & 0.879 \\
\hline \multirow[t]{6}{*}{${ }^{\mathrm{tz}} \mathbf{U}$} & $\mathrm{N}_{1}-\mathrm{C}_{2}$ & 1.401 & 1.401 & 1.404 & 1.402 & 1.412 & 1.388 \\
\hline & $\mathrm{C}_{2}-\mathrm{N}_{3}$ & 1.389 & 1.384 & 1.385 & 1.380 & 1.379 & 1.373 \\
\hline & $\mathrm{N}_{1}-\mathrm{C}_{6}$ & 1.405 & 1.402 & 1.400 & 1.397 & 1.395 & 1.388 \\
\hline & $\mathrm{C}_{6}-\mathrm{O}_{11}$ & 1.219 & 1.221 & 1.223 & 1.225 & 1.234 & 1.216 \\
\hline & $\mathrm{C}_{2}-\mathrm{O}_{10}$ & 1.219 & 1.221 & 1.222 & 1.223 & 1.234 & 1.224 \\
\hline & $\mathrm{N}_{1}-\mathrm{H}$ & 1.020 & 1.020 & 1.024 & 1.020 & 1.038 & 0.922 \\
\hline \multirow[t]{3}{*}{${ }^{\mathrm{tz}} \mathbf{I}$} & $C_{5}-C_{6}$ & 1.475 & 1.474 & 1.473 & 1.474 & 1.466 & - \\
\hline & $\mathrm{C}_{6}-\mathrm{N}_{1}$ & 1.412 & 1.412 & 1.407 & 1.412 & 1.395 & - \\
\hline & $\mathrm{C}_{6}-\mathrm{O}_{11}$ & 1.221 & 1.221 & 1.224 & 1.221 & 1.237 & - \\
\hline
\end{tabular}

Ambas as aproximações predizem valores similares entre si. A influência da água é mais pronunciada e depende do tipo de molécula e método utilizado. Empregando a aproximação ASEC-FEG, o ângulo de piramidalização é perto de zero para as moléculas ${ }^{\text {tz }} \mathbf{A} e^{\text {tz }} \mathbf{C}$, com uma redução de quase $30^{\circ}$ e $22^{\circ}$, respectivamente. A mesma tendência é verificada para a molécula ${ }^{\text {tz }} \mathbf{C}$, sendo que ocorre um decréscimo de $13^{\circ}$, porém ainda distante de uma planarização do grupo $\mathrm{NH}_{2}$. O modelo PCM prevê leves reduções dessa coordenada, contudo, com o mesmo sentido indicado a partir do método ASEC-FEG. Em todos os casos não foi observado uma rotação do grupo amino.

A posição do grupo amino no anel de seis membros pode ser considerada um forte indício 
para explicar a razão de uma maior influência na coordenada $\alpha$ para as moléculas ${ }^{\mathrm{tz}} \mathbf{A} \mathrm{e}^{\mathrm{tz}} \mathbf{C}$. Nessas moléculas o grupo amino é ligado ao átomo $C_{6}$ (veja a numeração atômica na Figura 5.1), uma região que facilita a formação de ligação de hidrogênio entre o grupo $\mathrm{NH}_{2}$ e os átomos $\mathrm{N}_{1}$ e $\mathrm{N}_{7}$. Portanto, formando duas ligações de hidrogênio e, consequentemente, favorecendo a sua planarização. Em contrapartida, o grupo amino na molécula ${ }^{\mathrm{tz}} \mathbf{G}$ é conectado ao átomo $C_{2}$. Nessa região é formada uma única ligação de hidrogênio envolvendo o átomo $N_{3}$. Em alguns de nossos testes com a molécula ${ }^{\mathrm{tz}} \mathbf{A}, 5$ moléculas explícitas de água foram consideradas no procedimento de otimização de geometria, sendo que a geometria convergida apresentou uma planarização do grupo amino. Zhang e colaboradores obtiveram a mesma tendência em água empregando o modelo PCM no nível B3LYP/6-311+G(d,p) [197], apesar de nenhuma justificativa teórica acerca da planarização ser discutida no artigo. O modelo de microsolvatação reportado no mesmo artigo também exibiu o mesmo comportamento.

Em suma, os resultados obtidos em fase gasosa para os comprimentos de ligação estão em bom acordo com os dados experimentais, embora sejam meios distintos. A influência do solvente 1,4-dioxano nos parâmetros do soluto foram concluídas serem bem pequenas. As maiores modificações ocorrem em água, principalmente com os comprimentos de ligação envolvendo os átomos eletronegativos e que são capazes de fazer ligações de hidrogênio com as moléculas de água. O modelo PCM não trata interações específicas, como por exemplo, ligações de hidrogênio, conduzindo para uma geometria muito próxima da obtida em fase gasosa.

Focando no método ASEC-FEG em água, a ligação $C_{1}-N_{6}$ aumenta por volta de $0.02-0.03$ $\AA ̊$ para as moléculas ${ }^{\text {tz }} \mathbf{A} \mathrm{e}^{\text {tz }} \mathbf{C}$. Por sua vez, para as outras moléculas ocorre um encurtamento entre $0.01-0.02 \AA$. O acréscimo ou decréscimo dessa ligação em ambiente aquoso pode ser atribuído aos diferentes grupos suspensos no átomo $C_{6}$ (veja Figura 5.1). Os comprimentos de ligação $\mathrm{C}=\mathrm{O}$ e $\mathrm{N}-\mathrm{H}$ em todos os casos mostraram um considerável aumento, com o estiramento máximo de até $0.03 \AA$. Na ligação $C_{2}-N_{3}$, mudanças relevantes em comparação com a fase gasosa foram vistas nas moléculas ${ }^{\mathrm{tz}} \mathbf{A},{ }^{\mathrm{tz}} \mathbf{G}$ e ${ }^{\mathrm{tz}} \mathbf{U}$. Uma plausível razão é de que diferentemente da molécula ${ }^{\mathrm{tz}} \mathbf{A}$, o grupo conectado ao átomo $C_{2}$ não é um átomo de hidrogênio. Todavia, essa ligação exibiu um alongamento quando ligado a um átomo de oxigênio $\left({ }^{\text {tz }} \mathbf{C}\right.$ e $\left.{ }^{\text {tz }} \mathbf{U}\right)$ e um redução quando conectado a um átomo de nitrogênio $\left({ }^{\mathrm{tz}} \mathbf{G}\right)$.

\subsection{Estrutura do solvente e ligações de hidrogênio no estado fun- damental}

As camadas de solvatação de água e 1,4-dioxano ao redor das bases modificadas do RNA foram analisadas por meio da função distribuição de pares de mínima distância $G_{m d}(r)$ [181] (Figura 5.4). Em 1,4-dioxano, exceto para a molécula ${ }^{\mathrm{tz}} \mathbf{I}$, a $G_{m d}(r)$ é bastante similar para 
todas as moléculas, com vales e mínimos coincidentes. Entretanto, todas essas funções exibem duas camadas de solvatação bem definidas. Na primeira camada de solvatação é notada uma estruturação em torno de $2 \AA \AA$ e certamente está relacionada com as ligações de hidrogênio entre soluto e solvente. $\mathrm{O}$ número efetivo de ligações de hidrogênio será melhor detalhado ainda nessa seção adicionando critérios angulares e energéticos. A primeira camada de solvatação, incluindo a estruturação, começa por volta de $1.4 \AA$ e termina em $4.2 \AA$. Essa camada contém ao todo 15 moléculas de 1,4-dioxano, exceto para a molécula ${ }^{\text {tz }} \mathbf{I}$, cuja $G_{m d}(r)$ apresenta 14 moléculas de solvente até o primeiro vale.

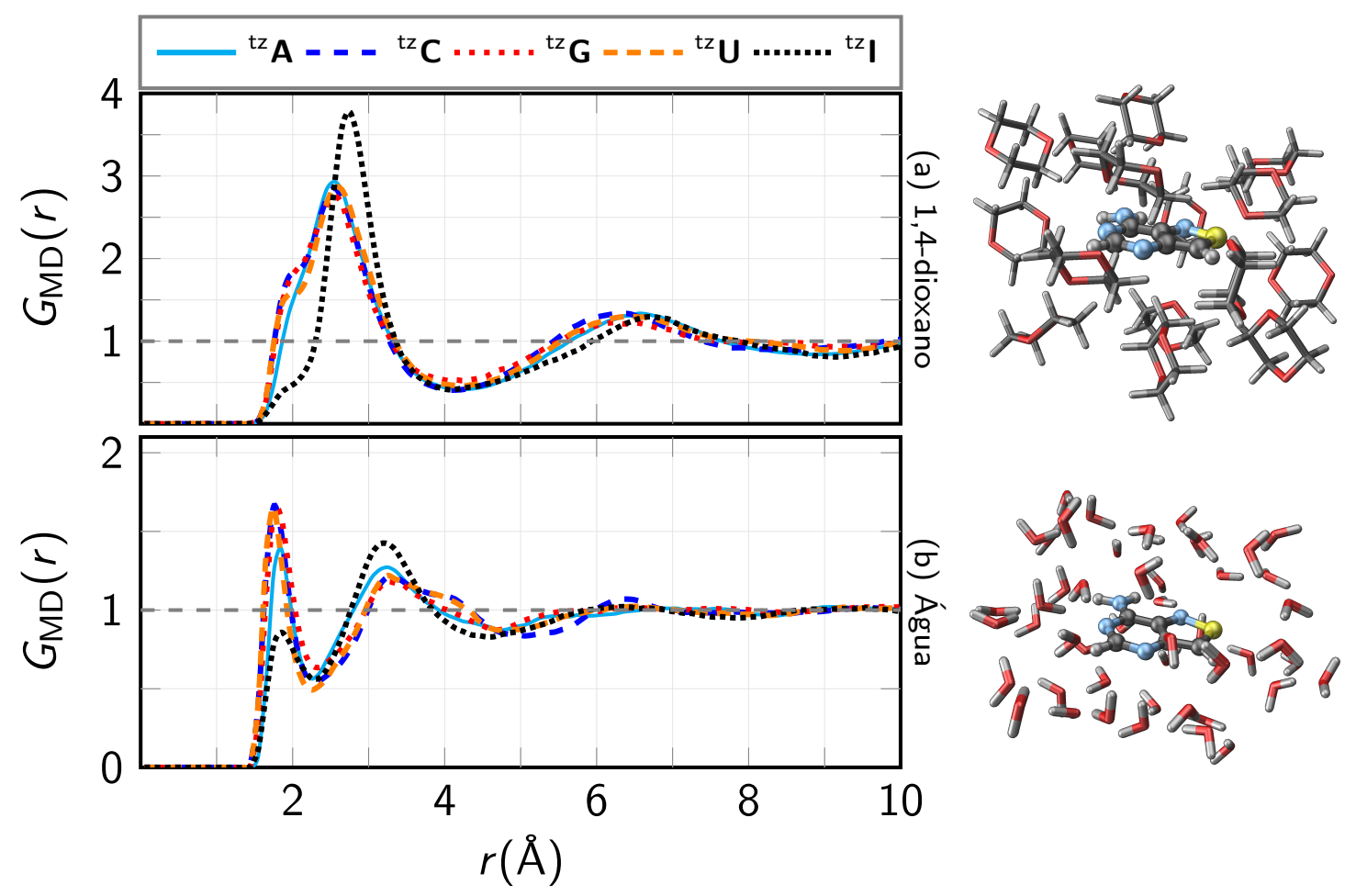

Figura 5.4 - Função distribuição de pares de mínima distância $\left(G_{m d}(r)\right)$ para o novo alfabeto ribonucleosídeo fluorescente em (a) 1,4-dioxano e (b) água. No lado direito é apresentado uma ilustração da primeira de camada de solvatação para a molécula ${ }^{\mathrm{tz}} \mathbf{A}$.

Em solução aquosa, a camada de microhidratação relacionada às ligações de hidrogênio é mais nítida do que em 1,4-dioxano e é assinalada por volta de $2.25 \AA$. A primeira camada de solvatação contempla 49 moléculas de água para as moléculas ${ }^{\mathrm{tz}} \mathbf{A},{ }^{\mathrm{tz}} \mathbf{G}$ e ${ }^{\mathrm{tz}} \mathbf{U}$. A molécula ${ }^{\text {tz }} \mathbf{C}$ abrange o maior número de moléculas de água nessa camada, totalizando 49 moléculas de solvente. Em contrapartida, a molécula ${ }^{\text {tz } I}$ é englobada por apenas 44 moléculas de água.

$\mathrm{O}$ número de ligações de hidrogênio soluto-solvente $(\mathrm{HB}) \mathrm{X} \cdots \mathrm{H}-\mathrm{Y}$ de uma dada configuração foi estimado empregando as seguintes condições [198-200]: (i) $R_{\mathrm{XY}}$, definido pelo primeiro mínimo da função distribuição radial de pares $g(r)$ entre os átomos eletronegativos $\mathrm{X}$ e Y; (ii) $\theta_{\mathrm{XY}}$ formado pelos átomos $X, H$ e $Y$; (iii) A energia de ligação $E_{\mathrm{HB}}$, obtida a partir 
da distribuição de energia de pares soluto-solvente. Uma ilustração dos critérios geométricos para definição de ligações de hidrogênio é mostrada na Figura 5.5. Na Tabela 5.2 é apresentada a ocorrência estatística das ligações de hidrogênio para um total de $2 \times 10^{4}$ configurações empregando os critérios mencionados acima.

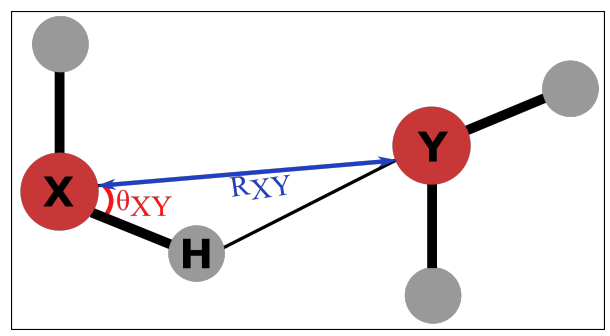

Figura 5.5 - Ilustração dos critérios geométricos empregados para definição de ligações de hidrogênio, que compreende a distância entre os átomos eletronegativos $\left(R_{\mathrm{XY}}\right) \mathrm{e}$ o ângulo formado entre os átomos $X, H$ e $Y\left(\theta_{\mathrm{XY}}\right)$.

Tabela 5.2 - Estatística percentual de ligações de hidrogênio soluto-solvente para as bases modificadas do RNA em 1,4-dioxano e água.

\begin{tabular}{ccccccc}
\hline Meio & $\mathrm{N}^{\circ}$ de $\mathrm{LHs}$ & ${ }^{\mathrm{tz}} \mathbf{A}$ & ${ }^{\mathrm{tz}} \mathbf{C}$ & ${ }^{\mathrm{tz}} \mathbf{G}$ & ${ }^{\mathrm{tz}} \mathbf{U}$ & ${ }^{\mathrm{tz}} \mathbf{I}$ \\
\hline 1,4-Dioxane & 0 & 3.5 & - & - & 0.1 & 97.1 \\
& 1 & 31.4 & 4.6 & 9.0 & 5.9 & 2.9 \\
& 2 & 64.1 & 38.4 & 37.5 & 90.8 & - \\
& 3 & 1.0 & 55.2 & 52.8 & 3.1 & - \\
Água & 4 & - & 1.7 & 0.7 & - & - \\
& $\langle\mathrm{LH}\rangle^{*}$ & 1.63 & 2.54 & 2.45 & 1.97 & 0.03 \\
& 2 & - & - & - & - & 2.3 \\
& 3 & 0.2 & - & - & - & 15.6 \\
& 5 & 3.8 & - & - & 0.5 & 40.4 \\
& 6 & 21.8 & 0.5 & 0.4 & 5.0 & 29.9 \\
& 7 & 26.1 & 27.9 & 18.0 & 39.7 & 1.8 \\
& 8 & 7.5 & 41.3 & 36.0 & 23.5 & 0.2 \\
& 9 & 0.9 & 21.2 & 29.5 & 6.2 & - \\
& 10 & 0.1 & 3.9 & 10.2 & 0.7 & - \\
& 11 & - & 0.4 & 1.7 & - & - \\
& 12 & - & - & 0.2 & - & - \\
& $\langle\mathrm{LH}\rangle$ & 6.14 & 7.91 & 8.26 & 7.02 & 4.35 \\
\hline
\end{tabular}

* $\langle\mathrm{LH}\rangle$ é o número médio de ligações de hidrogênio.

De acordo com os nossos resultados, o menor número de ligações de hidrogênio, em média, foi visto para a molécula ${ }^{\text {tz }} \mathbf{I}$, com o percentual de $0.03 \mathrm{em} \mathrm{1,4-dioxano} \mathrm{e} 4.35 \mathrm{em}$ água. Por sua vez, em 1,4-dioxano e em água as moléculas ${ }^{\mathrm{tz}} \mathbf{C}$ e ${ }^{\mathrm{tz}} \mathbf{G}$, respectivamente, são as moléculas que efetuam o maior número de ligação de hidrogênio, correspondendo em média para 2.54 e 8.26. 
Tabela 5.3 - Número médio de ligação de hidrogênio em cada sítio que é susceptível a fazer ligação de hidrogênio em solvente para o alfabeto ribonucleosídeo fluorescente.

\begin{tabular}{|c|c|c|c|c|c|c|c|}
\hline Molécul & & 1,4-Dioxano & Água & Molécula & & 1,4-Dioxano & Água \\
\hline \multirow{6}{*}{${ }^{\mathrm{tz}} \mathbf{A}$} & $\mathrm{N}_{10}-\mathrm{H} \cdots \mathrm{O}$ & 0.91 & 1.00 & \multirow{6}{*}{ tzI } & $\mathrm{N}_{1}-\mathrm{H} \cdots \mathrm{O}$ & 0.03 & 0.13 \\
\hline & $\mathrm{N}_{10} \cdots \mathrm{H}-\mathrm{O}$ & - & 0.02 & & $\mathrm{~N}_{1} \cdots \mathrm{H}-\mathrm{O}$ & - & 0.00 \\
\hline & $\mathrm{N}_{1} \cdots \mathrm{H}-\mathrm{O}$ & - & 1.69 & & $\mathrm{~N}_{3} \cdots \mathrm{H}-\mathrm{O}$ & - & 1.10 \\
\hline & $\mathrm{N}_{3} \cdots \mathrm{H}-\mathrm{O}$ & - & 1.88 & & $\mathrm{~N}_{7} \cdots \mathrm{H}-\mathrm{O}$ & - & 0.67 \\
\hline & $\mathrm{N}_{7} \cdots \mathrm{H}-\mathrm{O}$ & - & 0.54 & & $\mathrm{~S}_{8} \cdots \mathrm{H}-\mathrm{O}$ & - & 0.20 \\
\hline & $\mathrm{S}_{8} \cdots \mathrm{H}-\mathrm{O}$ & - & 0.02 & & $\mathrm{O}_{10} \cdots \mathrm{H}-\mathrm{O}$ & - & 2.25 \\
\hline \multirow{8}{*}{${ }^{\mathrm{tz}} \mathbf{C}$} & $\mathrm{N}_{10}-\mathrm{H} \cdots \mathrm{O}$ & 0.94 & 0.97 & \multirow{8}{*}{${ }^{\mathrm{tz}} \mathbf{U}$} & $\mathrm{N}_{1}-\mathrm{H} \cdots \mathrm{O}$ & 0.98 & 1.01 \\
\hline & $\mathrm{N}_{3}-\mathrm{H} \cdots \mathrm{O}$ & 0.97 & 1.01 & & $\mathrm{~N}_{3}-\mathrm{H} \cdots \mathrm{O}$ & 1.02 & 1.02 \\
\hline & $\mathrm{N}_{10} \cdots \mathrm{H}-\mathrm{O}$ & - & 0.02 & & $\mathrm{~N}_{1} \cdots \mathrm{H}-\mathrm{O}$ & - & 0.04 \\
\hline & $\mathrm{N}_{1} \cdots \mathrm{H}-\mathrm{O}$ & - & 1.98 & & $\mathrm{~N}_{3} \cdots \mathrm{H}-\mathrm{O}$ & - & 0.04 \\
\hline & $\mathrm{N}_{3} \cdots \mathrm{H}-\mathrm{O}$ & - & 0.11 & & $\mathrm{~N}_{7} \cdots \mathrm{H}-\mathrm{O}$ & - & 0.56 \\
\hline & $\mathrm{N}_{7} \cdots \mathrm{H}-\mathrm{O}$ & - & 0.46 & & $\mathrm{~S}_{8} \cdots \mathrm{H}-\mathrm{O}$ & - & 0.16 \\
\hline & $\mathrm{S}_{8} \cdots \mathrm{H}-\mathrm{O}$ & - & 0.03 & & $\mathrm{O}_{10} \cdots \mathrm{H}-\mathrm{O}$ & - & 2.07 \\
\hline & $\mathrm{O}_{11} \cdots \mathrm{H}-\mathrm{O}$ & - & 2.43 & & $\mathrm{O}_{11} \cdots \mathrm{H}-\mathrm{O}$ & - & 2.12 \\
\hline \multirow{8}{*}{${ }^{\mathrm{tz}} \mathbf{G}$} & $\mathrm{N}_{11}-\mathrm{H} 13 \cdots \mathrm{O}$ & 0.81 & 0.95 & & & & \\
\hline & $\mathrm{N}_{1}-\mathrm{H} \cdots \mathrm{O}$ & 0.97 & 1.01 & & & & \\
\hline & $\mathrm{N}_{11} \cdots \mathrm{H}-\mathrm{O}$ & - & 0.12 & & & & \\
\hline & $\mathrm{N}_{1} \cdots \mathrm{H}-\mathrm{O}$ & - & 0.01 & & & & \\
\hline & $\mathrm{N}_{3} \cdots \mathrm{H}-\mathrm{O}$ & - & 1.72 & & & & \\
\hline & $\mathrm{N}_{7} \cdots \mathrm{H}-\mathrm{O}$ & - & 0.80 & & & & \\
\hline & $\mathrm{S}_{8} \cdot \mathrm{H}-\mathrm{O}$ & - & 0.33 & & & & \\
\hline & $\mathrm{O}_{11} \cdots \mathrm{H}-\mathrm{O}$ & - & 2.27 & & & & \\
\hline
\end{tabular}

Em solução aquosa, as espécies ${ }^{\text {tz }} \mathbf{C}$ e ${ }^{\text {tz }} \mathbf{G}$, as maiores moléculas desse alfabeto, preferencialmente fazem $8 \mathrm{LHs}$, com percentual de $44 \%$ e $35 \%$, respectivamente. As moléculas ${ }^{\mathrm{tz}} \mathbf{C}$ e ${ }^{\text {tz }} \mathbf{A}$ vêm em seguida realizando em média 7 e 6 LHs com a água, respectivamente. Ademais, o número médio de ligações de hidrogênio possui em ambos os solventes uma clara tendência de crescimento: ${ }^{\text {tz }} \mathbf{I}{ }^{\text {tz }} \mathbf{A} \rightarrow{ }^{\text {tz }} \mathbf{C} \rightarrow{ }^{\text {tz }} \mathbf{G}$.

Ainda analisando os resultados em solução aquosa, foi computado também o número efetivo de ligações de hidrogênio por sítio atômico como mostrado na Tabela 5.3. Como pode ser visto, o número de ligações de hidrogênio no átomo de nitrogênio do grupo amino para as moléculas ${ }^{\mathrm{tz}} \mathbf{A}$ e ${ }^{\mathrm{tz}} \mathbf{C}$ é baixo. Isso provavelmente se deve ao fato do ângulo de piramidalização de ambas as moléculas ser próximo de zero que, consequentemente, conduz para uma maior rejeição de ligação de hidrogênio por critérios angulares. Uma outra observação é uma diminuição no número de LHs com os átomos de nitrogênio $\left(N_{1}, N_{3}\right.$ e $\left.N_{7}\right)$ quando há um átomo de hidrogênio conectado. Em termos do número efetivo de LHs por sítio atômico, exceto para a molécula ${ }^{\mathrm{tz}} \mathbf{A}$, o sítio mais propenso para ligação de hidrogênio é o átomo de oxigênio, sendo realizada mais de $2 \mathrm{LHs}$ em média. Para a molécula ${ }^{\mathrm{tz}} \mathbf{A}$, o átomo $\mathrm{N}_{3}$ é o sítio atômico que efetua mais ligações de hidrogênio (1.88 LHs em média). Como é sabido na literatura, o átomo de enxofre 
pode também fazer ligação de hidrogênio com o solvente, embora seja um número médio de LHs estritamente baixo, variando entre 0.02 e 0.33 LHs dependendo da molécula. Uma possível explicação pode ser atribuída à eletronegatividade do enxofre, que é bem menor comparada com a obtida para os átomos de oxigênio e nitrogênio.

\subsection{Momento de dipolo e distribuição de cargas no estado funda- mental}

A influência dos efeitos de solvente na distribuição de cargas atômicas de todas essas moléculas foi também investigada. Como esse alfabeto compartilha uma unidade heterocíclica em comum, a análise da distribuição de carga será dividida em quatro diferentes grupos: (i) anel de seis membros, (ii) grupos suspensos no anel de seis membros, (iii) comprimento de ligação $\mathrm{C}_{9}-\mathrm{H}$ e (iv) átomos $\mathrm{S}_{8}$ e $\mathrm{N}_{7}$. Na Figura 5.6 é apresentado os resultados para as fases gasosa e condensada (1,4-dioxano e água).

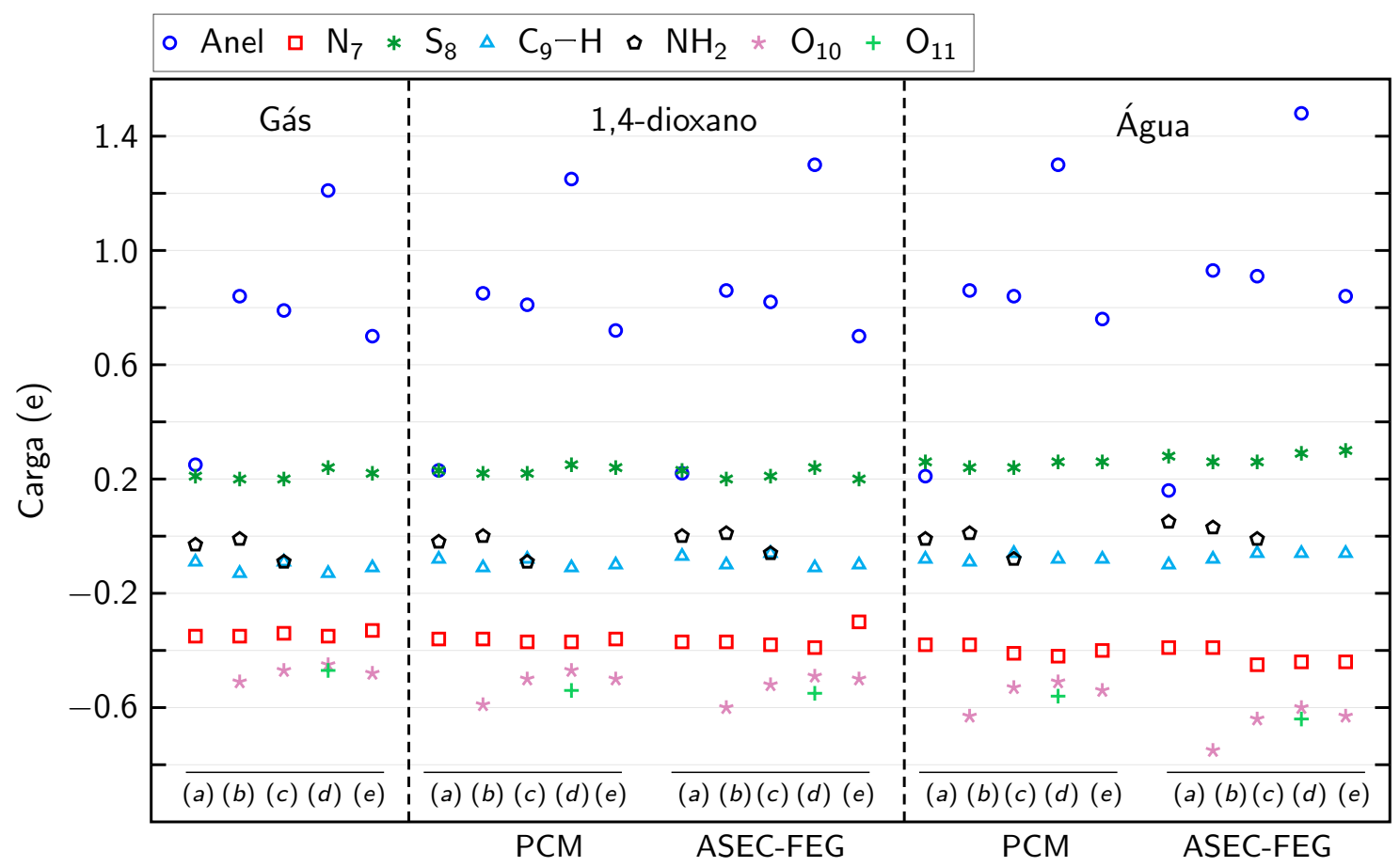

Figura 5.6 - Distribuição de cargas (e) para as moléculas (a) ${ }^{\mathrm{tz}} \mathbf{A}$, (b) ${ }^{\mathrm{tz}} \mathbf{C}$, (c) ${ }^{\mathrm{tz}} \mathbf{G},(\mathrm{d}){ }^{\mathrm{tz}} \mathbf{U}$ e (e) ${ }^{\text {tz }} \mathbf{A}$ em fase gasosa, 1,4-dioxano e água.

De modo geral, é observado que o aumento da polaridade do solvente conduz para um aumento das cargas atômicas do átomo $\mathrm{S}_{8}$ e do grupo amino. Em contrapartida, as cargas atômicas associadas aos átomos eletronegativos (nitrogênio e oxigênio) se tornaram ainda mais 
negativas. Além disso, a carga atômica sobre o anel apresenta apenas uma diminuição de carga para a molécula ${ }^{\text {tz }} \mathbf{A}$. Uma plausível explicação poderia ser designada por essa molécula ser a única desse alfabeto que não possui um átomo de oxigênio em sua composição química.

As cargas atômicas do soluto exibem uma leve mudança de fase gasosa para 1,4-dioxano, induzindo uma pequena variação do momento de dipolo do soluto. A maior mudança do momento de dipolo é vista para a molécula ${ }^{\text {tz }} \mathbf{G}$, rendendo um aumento de $37 \%$ utilizando a metodologia ASEC-FEG (saindo de 4.81 Debye em fase gasosa para 6.58 Debye) e $14 \%$ empregando o modelo PCM (saindo de 4.81 Debye em fase gasosa para 5.51 Debye) (Figura 5.7). Em meio aquoso ocorrem aumentos consideráveis do momento de dipolo de todos os compostos. Nesse ambiente, as mais drásticas mudanças são constatadas para as moléculas ${ }^{\mathrm{tz}} \mathbf{A}$ e ${ }^{\mathrm{tz}} \mathbf{C}$, com crescimento acima dos $100 \%$ em relação à fase gasosa. Em seguida temos incrementos no momento de dipolo de $68 \%$ e $63 \%$ para as moléculas ${ }^{\text {tz }} \mathbf{G}$ e ${ }^{\text {tz }} \mathbf{U}$, respectivamente. A molécula ${ }^{\text {tz }} \mathbf{l}$ exibe o menor crescimento do momento de dipolo nesse meio, com um aumento de aproximadamente $58 \%$ em comparação com a fase gasosa.

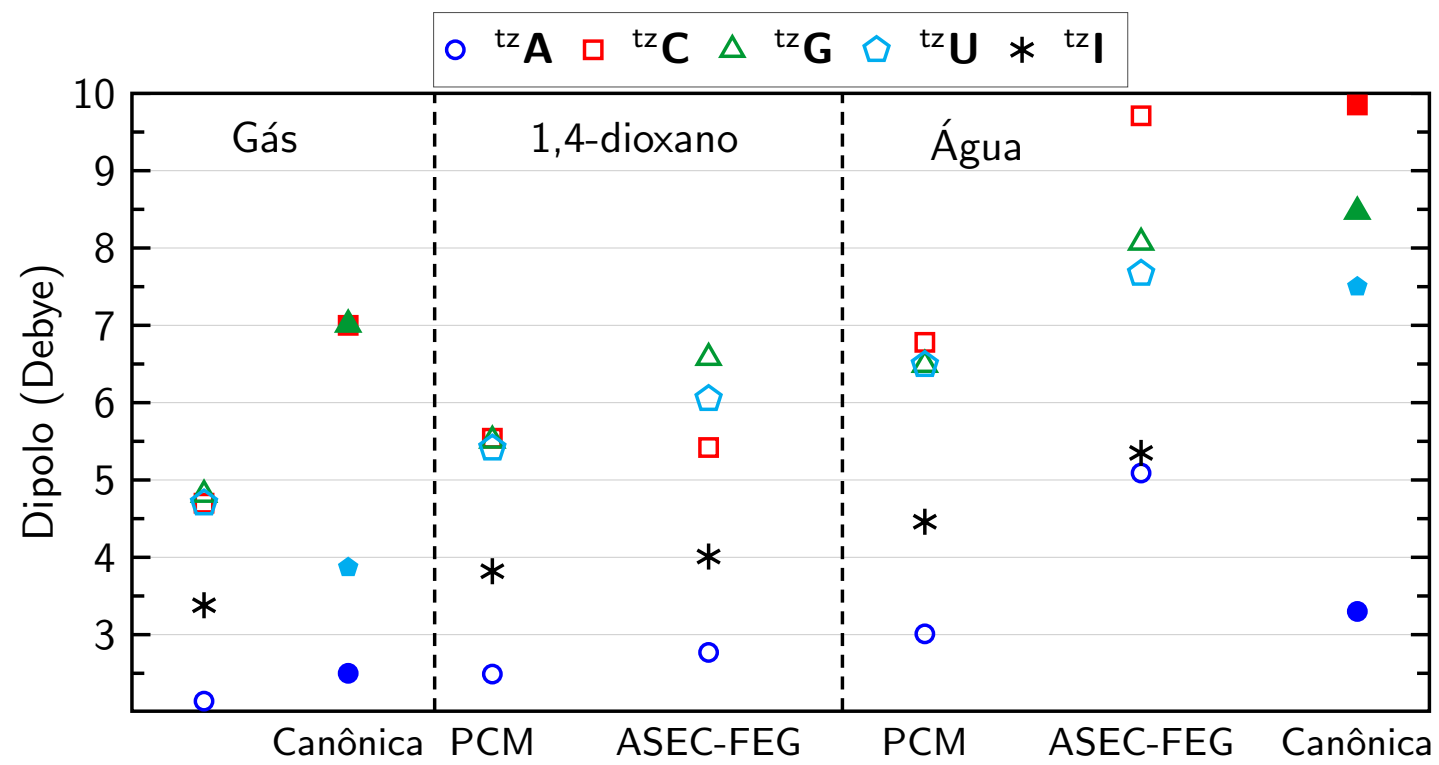

Figura 5.7 - Momento de dipolo (Debye) do novo alfabeto ribonucleosídeo fluorescente obtidos em fases gasosa e condensada (1,4-dioxano e água). O momento de dipolo para adenina, citosina [201], guanina [202] e uracila [203] em fase gasosa são obtidos por meio de dados experimentais (símbolos preenchidos). Em solução aquosa, os valores de momento de dipolo para as bases nucléicas são estimadas por simulações QM/MM on the fly (citosina e guanina [204]) e QM/MM sequencial (adenina [205] e uracila [206]) (símbolos preenchidos).

A performance dos métodos empregados para descrever a distribuição de cargas e momento de dipolo em 1,4-dioxano é bastante similar e é presumido ser devido ao fato de pequenas mudanças estruturais acarretadas pela inclusão desse solvente em ambos os métodos. Ademais, o modelo PCM normalmente descreve bem solventes considerados apolares, que é o caso 
do solvente 1,4-dioxano que possui uma pequena constante dielétrica $(\varepsilon=2.20)$. Em água, contudo, existe uma tendência geral com o momento de dipolo, sendo o valor convergido dessa propriedade com o modelo ASEC-FEG é maior do que os obtidos com o PCM. Como o método PCM não trata interações específicas, já é um indício para se esperar um momento de dipolo menor.

Finalmente, comparamos o valor do momento de dipolo com as bases canônicas naturais. O valor experimental medido para o momento de dipolo da uracila em fase gasosa é de $3.87 \mathrm{D}$ e os nossos resultados teóricos para a molécula ${ }^{\text {tz }} \mathbf{U}$ apontam um valor acima. Por sua vez, os valores experimentais para a adenina, citosina e guanina conduzem para um valor maior comparado com os seus homólogos. Já em água, foi encontrado apenas valores do momento de dipolo para as nucleobases preditos por simulações QM/MM. A principal conclusão é de que existe uma tendência de crescimento do momento de dipolo comparando ambas as moléculas considerando a aproximação ASEC-FEG, isto é, o crescimento segue a seguinte tendência: Adenina $\rightarrow$ Uracila $\rightarrow$ Guaninia $\rightarrow$ Citosina. Esse tendência não é claramente enxergada quando empregado o modelo PCM.

\subsection{Espectro de Absorção Eletrônico}

As energias de excitação verticais e forças de oscilador para as transições eletrônicas assinaladas no espectro de absorção experimental reportado por Rovira e colaboradores [183] são exibidas na Tabela 5.4. Exceto para a molécula ${ }^{\text {tz }} \mathbf{A}$, o primeiro estado excitado singleto é apontado como um estado claro, devido à sua alta força de oscilador. Esse estado excitado é derivado a partir do estado fundamental por uma única excitação do orbital HOMO $\pi$ para o orbital LUMO $\pi^{*}$ (os orbitais foram indexados de acordo com o método Hartree-Fock). Como pode ser visto na Figura 5.8, a transição eletrônica $\pi \rightarrow \pi^{*}$ para todas as espécies são delocalizadas sobre os dois anéis. Os orbitais HOMO podem ser agrupados em duas categorias; uma composta pelas moléculas ${ }^{\mathrm{tz}} \mathbf{A},{ }^{\mathrm{tz}} \mathbf{G}$ e ${ }^{\mathrm{tz}} \mathbf{I}$ descrevendo moléculas tipo purina e o outro grupo corresponde à classe tipo pirimidínica, que contempla as moléculas ${ }^{\mathrm{tz}} \mathbf{C} \mathrm{e}^{\mathrm{tz}} \mathbf{U}$. A principal diferença nos orbitais $H O M O$ é a contribuição a partir do orbital $3 p$ localizado no átomo $\mathrm{S}_{8}$, cuja contribuição não se mistura com o orbital $2 p$ do átomo $\mathrm{N}_{7}$ no caso das pirimidínicas. A estrutura dos orbitais $L U M O$ é basicamente a mesma para todas as moléculas, sendo delocalizando sobre os dois anéis e exibindo uma contribuição relevante nos orbitais localizados nos átomos $\mathrm{N}_{7}, \mathrm{~S}_{8}$ e $\mathrm{C}_{9}$.

Em comparação com os valores experimentais obtidos em 1,4-dioxano e água, as energias de excitação obtidas em fase gasosa exibem valores maiores em energia, com exceção da molécula ${ }^{\mathrm{tz}} \mathbf{C}$. A maior discrepância é observada para a molécula ${ }^{\mathrm{tz}} \mathbf{A}$, com uma energia de excitação $\sim 0.4 \mathrm{eV}$ acima do valor reportado experimentalmente em 1,4-dioxano $(\sim 0.3 \mathrm{eV}$ 


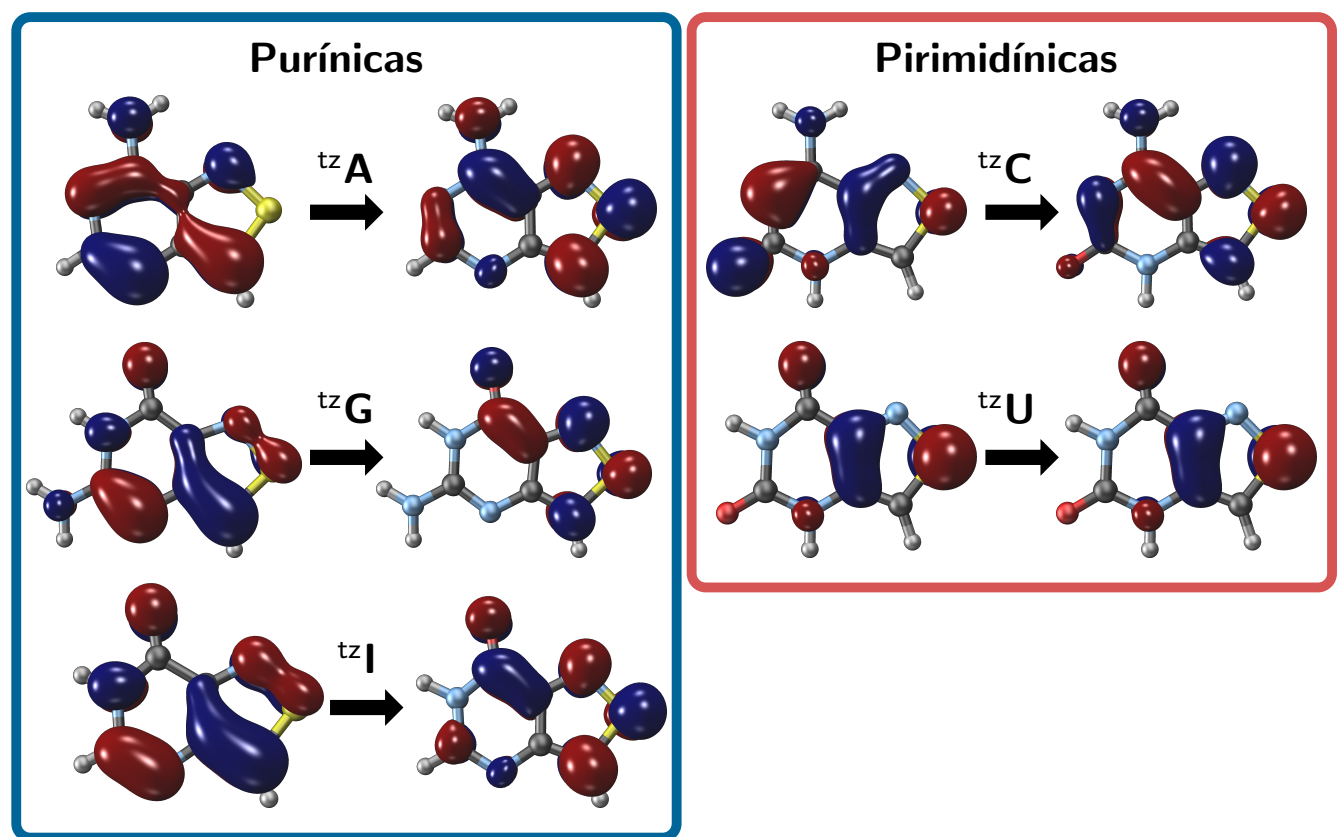

Figura 5.8 - Transição eletrônica dominante na descrição do primeiro estado excitado (exceto para a molécula ${ }^{\text {tz }} \mathbf{A}$, veja o texto) obtido no nível $\operatorname{SA}(X)-\operatorname{CASSCF}(18,13) /$ ccpVDZ em fase gasosa utilizando a geometria de equilíbrio do estado fundamental. $\mathrm{X}$ corresponde ao número de estados excitados incluídos no procedimento stateaveraged (veja metodologia).

em água). Também vale a pena mencionar que o estado excitado mais baixo na fase gasosa para a molécula ${ }^{\mathrm{tz}} \mathbf{A}$ é um estado escuro ${ }^{1}\left(n \pi^{*}\right)$, que é descrito por uma transição do orbital $n_{2}$ para o orbital $\pi_{1}^{*}$.

A inclusão do solvente 1,4-dioxano empregando ambas metodologias não indica em geral uma grande mudança nas energias de excitação verticais em relação à fase gasosa. Para a molécula ${ }^{\text {tz }} \mathbf{A}$, o estado excitado singleto mais baixo continuou sendo o estado escuro ${ }^{1}\left(n \pi^{*}\right)$, seguido por um estado claro ${ }^{1}\left(\pi \pi^{*}\right)$. Salvo a molécula ${ }^{\text {tz }} \mathbf{A}$, os resultados teóricos obtidos para as energias de excitação verticais empregando a metodologia ASEC-FEG estão em bom acordo com os dados experimentais. O modelo PCM descreve razoavelmente essa propriedade, embora com uma diferença em relação ao experimental maior do que o obtido com a outra abordagem.

Em solução aquosa, o estado escuro ${ }^{1}\left(n \pi^{*}\right)$ da molécula ${ }^{\text {tz }} \mathbf{A}$ se mantém como primeiro estado excitado singleto de acordo com o modelo PCM. Em oposição, a ordem esperada para os estados eletrônicos é alcançada com o procedimento ASEC-FEG, ou seja, o estado ${ }^{1}\left(\pi \pi^{*}\right)$ passa a ser o primeiro estado excitado singleto. Aliado a isso, os valores teóricos preditos para a energia de absorção ficam em muito bom acordo com o experimental, diferindo por menos do que $0.1 \mathrm{eV}$, dentro do erro esperado para os resultados obtidos no nível de teoria CASPT2 [207]. $O$ modelo PCM também resulta em bom acordo com o experimental, mas como enfatizado anteriormente, esse modelo não diz nenhuma informação sobre a estruturação do solvente, que 
Tabela 5.4 - Comparação entre experimento (Exp.[183]) e cálculos de energias de excitação verticais $(\Delta E, \mathrm{eV})$ para o novo alfabeto ribonuclesídeo fluorescente em fase gasosa, 1,4-dioxano e água. A força de oscilador $(f)$ para cada transição também é reportada.

\begin{tabular}{|c|c|c|c|c|c|c|c|c|c|c|c|c|c|c|}
\hline & \multirow{2}{*}{\multicolumn{2}{|c|}{ Gás }} & \multicolumn{6}{|c|}{ 1,4-dioxano } & \multicolumn{6}{|c|}{ Água } \\
\hline & & & \multicolumn{2}{|c|}{ ASEC-FEG } & \multicolumn{2}{|c|}{ PCM } & \multirow{2}{*}{$\begin{array}{l}\text { Expl. } \\
\Delta E\end{array}$} & \multirow{2}{*}{$\begin{array}{l}\text { Exp. } \\
\Delta E\end{array}$} & \multicolumn{2}{|c|}{ ASEC-FEG } & \multicolumn{2}{|c|}{ PCM } & \multirow{2}{*}{$\begin{array}{l}\text { Expl. } \\
\Delta E\end{array}$} & \multirow{2}{*}{$\begin{array}{l}\text { Exp. } \\
\Delta E\end{array}$} \\
\hline & $\Delta E$ & $f$ & $\Delta E$ & $f$ & $\Delta E$ & $f$ & & & $\Delta E$ & $f$ & $\Delta E$ & $f$ & & \\
\hline${ }^{\mathrm{tz}} \mathbf{A}$ & 4.00 & 0.115 & 3.96 & 0.084 & 4.01 & 0.079 & 3.78 & 3.63 & 3.77 & 0.142 & 3.83 & 0.054 & 3.65 & 3.67 \\
\hline${ }^{\mathrm{tz}} \mathbf{C}$ & 3.63 & 0.231 & 3.64 & 0.232 & 3.49 & 0.199 & 3.50 & 3.72 & 3.80 & 0.236 & 3.70 & 0.233 & 3.65 & 3.81 \\
\hline${ }^{\mathrm{tz}} \mathbf{G}$ & 3.87 & 0.095 & 3.76 & 0.116 & 3.82 & 0.113 & 3.63 & 3.66 & 3.63 & 0.125 & 3.75 & 0.121 & 3.47 & 3.72 \\
\hline${ }^{\mathrm{tz}} \mathbf{U}$ & 4.09 & 0.165 & 3.99 & 0.162 & 4.10 & 0.152 & 3.83 & 3.94 & 3.92 & 0.170 & 3.98 & 0.169 & 3.75 & 3.97 \\
\hline $\mathrm{tz}_{\mathbf{I}}$ & 4.03 & 0.104 & 3.99 & 0.108 & 4.01 & 0.109 & 4.00 & 3.94 & 3.99 & 0.121 & 4.01 & 0.108 & 3.89 & 3.92 \\
\hline
\end{tabular}

envolve o detalhamento das redes de ligações de hidrogênio soluto-solvente e solvente-solvente.

Em uma tentativa de melhorar ainda mais os nossos resultados, especificamente para a molécula ${ }^{\text {tz }} \mathbf{A}$ em 1,4-dioxano, algumas moléculas explícitas de solvente foram consideradas explicitamente no cálculo das energias de excitação verticais (veja metodologia). Os resultados obtidos com algumas moléculas de solvente explícitas em ambos os meios colocaram a ordem dos estados eletrônicos corretamente, isto é, o estado excitado de mais baixa energia é caracterizado pela transição ${ }^{1}\left(\pi \pi^{*}\right)$. Devido ao alto custo computacional, apenas duas moléculas de $1,4-$ dioxano foram selecionadas, porém, a presença das ligações de hidrogênio soluto-solvente tratadas explicitamente foi um fator importante para o melhoramento da energia de absorção vertical para a molécula ${ }^{\text {tz }} \mathbf{A}$, trazendo o valor teórico para dentro de um erro de apenas $0.2 \mathrm{eV}$ em comparação com o dado experimental. Para as demais moléculas, a inserção de ligações de hidrogênio soluto-solvente explicitamente foi menos impactante, conduzindo para um deslocamento para o vermelho no intervalo de $0.13-0.16 \mathrm{eV}$. Nossos resultados sugerem que em solvente apolares, tais como o solvente 1,4-dioxano, a inclusão de termos além da interação eletrostática (interações de troca, dispersão, etc) pode ser necessária para uma melhor descrição das propriedades espectroscópicas.

Dessa forma, o espaço ativo contendo 18 elétrons em 13 orbitais é mostrado ser uma boa escolha no detalhamento do espectro de absorção desse novo alfabeto modificado do RNA, com o orbital $n$ associado ao átomo de enxofre não sendo relevante na caracterização do espectro UV-VIS. Com esse espaço ativo, um bom compromisso entre tempo computacional e acordo com os valores experimentais é alcançado.

Um teste final foi verificar se a presença da ribose possui alguma influência nas energias de excitação. Para esse fim, a molécula ${ }^{\mathrm{tz}} \mathbf{A}$ foi embebida em ambos os solventes. Contudo, foi empregado uma versão mais antiga do método s-QM/MM, sendo que a geometria do soluto é mantida fixa e é convergido apenas o momento de dipolo do soluto [208]. Essa metodologia tem sido aplicado com sucesso em estudos anteriores de propriedades eletrônicas e estruturais 
de moléculas orgânicas no estado fundamental e excitados [209-211]. A geometria molecular e o conjunto de cargas atômicas iniciais foram calculadas previamente em fase gasosa no nível MP2/cc-pVDZ. Os nossos resultados empregando um espaço ativo equivalente indicam que o açúcar não interfere nos valores teóricos das energias de excitação verticais, em acordo com cálculos teóricos para moléculas semelhantes reportados por Kister e colaboradores [212].

\subsection{Geometria de equilíbrio e momento de dipolo do primeiro es- tado excitado}

A geometria do primeiro estado excitado ${ }^{1}\left(\pi \pi^{*}\right)$ de todas as moléculas foi otimizada em fase gasosa e em solvente (1,4-dioxano e água). O ponto de partida escolhido é a geometria de Frank-Condon (FC) otimizado em fase gasosa. A estrutura otimizada desse estado excitado para as moléculas ${ }^{\mathrm{tz}} \mathbf{A},{ }^{\mathrm{tz}} \mathbf{U}$ e ${ }^{\mathrm{tz}} \mathbf{I}$ exibe uma conformação completamente planar. De maneira oposta, os hidrogênios do grupo amino $\left(\mathrm{NH}_{2}\right)$ saem do plano do anel para o mínimo do primeiro estado ${ }^{1}\left(\pi \pi^{*}\right)$ das moléculas ${ }^{\text {tz }} \mathbf{C}$ e ${ }^{\text {tz }} \mathbf{G}$ por $38^{\circ}$ e $25^{\circ}$, respectivamente. Comparando essas geometrias com as obtidas no estado fundamental (nível MP2/cc-pVDZ), as principais diferenças são visualizadas nas distâncias de ligação e no ângulo de piramidalização do grupo amino, como pode ser visto na superposição dessas estruturas (Figura 5.9).

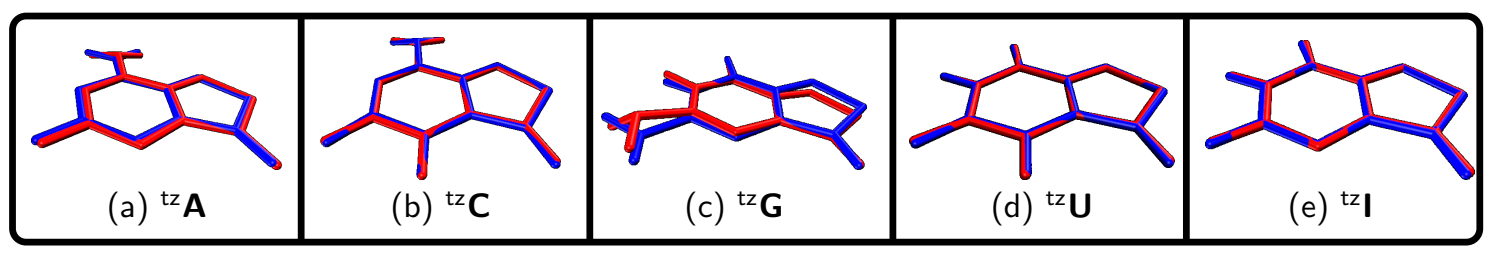

Figura 5.9 - Superposição das estruturas otimizadas dos estados fundamental (vermelho) e ${ }^{1}\left(\pi \pi^{*}\right)$ (azul) para o novo alfabeto ribonucleosídeo fluorescente. As geometrias no estado fundamental foram otimizadas no nível MP2/cc-pVDZ, enquanto o nível MS(2)-CASPT2/cc-pVDZ foi adotado para o estado excitado ${ }^{1}\left(\pi \pi^{*}\right)$.

Na Tabela 5.5 são apresentadas algumas coordenadas que sofreram mudanças consideráveis de fase gasosa para solvente. A geometria de mínimo em ambos os solventes é bastante distinta da estrutura de fase gasosa, embora a geometria do soluto obtida em 1,4-dioxano com o modelo PCM é bastante semelhante à de fase gasosa. Os efeitos de solvente empregando ambas as metodologias não influenciam no ângulo de piramidalização da molécula ${ }^{\text {tz }} \mathbf{A}$. Já para as moléculas ${ }^{\mathrm{tz}} \mathbf{C}$ e ${ }^{\mathrm{tz}} \mathbf{G}$, essa coordenada foi mais sensível ao ambiente. Para a molécula ${ }^{\mathrm{tz}} \mathbf{C}$ em 1,4-dioxano, o valor de $\alpha$ utilizando o método PCM conduz para um aumento de $12^{\circ} \mathrm{em}$ relação à fase gasosa, enquanto que o método ASEC-FEG prediz os mesmos $12^{\circ}$, porém em sentido contrário. Em água, o valor de $\alpha$ é exatamente o mesmo para ambas as metodologias. Curiosamente, para a molécula ${ }^{\text {tz }} \mathbf{G}$ acontece o oposto, com o valor de $\alpha$ semelhante em 
1,4-dioxano. Em água, ambos os métodos predizem um decréscimo dessa coordenada, mas com diferente extensões. O método ASEC-FEG conduz para uma leve diminuição de $5^{\circ}$ e o modelo PCM sugere uma geometria planar.

De modo geral, as coordenadas $\mathrm{C}=\mathrm{O}$ e $\mathrm{N}-\mathrm{H}$ em ambos os métodos apontam para uma elongação dessa distância de ligação em relação à fase gasosa seguindo o aumento de polaridade do meio, ou seja, gás $\rightarrow$ 1,4-dioxano $\rightarrow$ água. Essas ligações ficam mais estiradas em água empregando a aproximação ASEC-FEG, salvo para a molécula ${ }^{\mathrm{tz}} \mathbf{C}$. As ligações $\mathrm{N}-\mathrm{H}$ variam de $0.004-0.036 \AA$, enquanto que as ligações $C=0$ possuem mudanças no intervalo de $0.002-0.035 \AA$ em comparação com a fase gasosa. O modelo ASEC-FEG prediz uma elongação do comprimento de ligação $\mathrm{C}-\mathrm{NH}_{2}$ para as moléculas ${ }^{\mathrm{tz}} \mathbf{C}$ e ${ }^{\text {tz }} \mathbf{G}$ de acordo com a polaridade do meio. Para a molécula ${ }^{\text {tz }} \mathbf{A}$, o maior valor é obtido em 1,4-dioxano.

Analisando os comprimentos de ligação do anel de seis membros, a ligação $C_{2}-C_{3}$ encurta em comparação com a fase gasosa empregando a aproximação ASEC-FEG, exceto para a

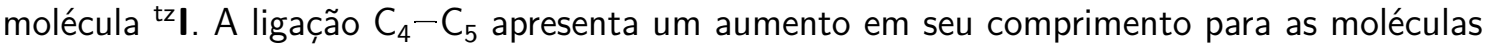
${ }^{\text {tz }} \mathbf{A} e^{\text {tz }} \mathbf{I}$. Em contrapartida, ocorre uma diminuição dessa coordenada em relação à fase gasosa para as moléculas ${ }^{\text {tz }} \mathbf{C}$ e ${ }^{\text {tz }} \mathbf{U}$. De modo geral, o modelo PCM prediz mudanças no sentido oposto aos previstos pelo modelo ASEC-FEG para os comprimentos de ligação do anel de seis membros.

Os comprimentos de ligação envolvendo o átomo de enxofre também exibem alterações relevantes. Para a molécula ${ }^{\mathrm{tz}} \boldsymbol{A}$, o comprimento de ligação $\mathrm{N}_{7}-\mathrm{S}_{8}$ mostra um aumento seguindo a polaridade do meio de acordo com o modelo ASEC-FEG, com um aumento de $0.04 \AA$ de gás para água. As demais moléculas exibem comportamento inverso, com a maior redução dessa coordenada obtida em 1,4-dioxano. As espécies ${ }^{\mathrm{tz}} \mathbf{A},{ }^{\mathrm{tz}} \mathbf{U}$ e ${ }^{\mathrm{tz}} \mathbf{A}$ contraem a ligação $\mathrm{S}_{8}-\mathrm{C}_{9}$ de fase gasosa para solvente, ao passo que um comportamento oposto é observado para a molécula ${ }^{\text {tz }} \mathbf{C}$. A molécula ${ }^{\text {tz }} \mathbf{G}$ praticamente não sofre mudança de gás para 1 ,4-dioxano, mas exibe um aumento de $0.011 \AA$ de gás para a água.

Os efeitos de solvente sobre o momento de dipolo também foram analisados. Na Figura 5.10 são mostrados os valores do momento de dipolo dos estados fundamental e excitados em fase gasosa e em solvente (1,4-dioxano e água) para o novo alfabeto ribonucleosídeo fluorescente. Como podemos ver na Figura 5.10, os efeitos de solvente no momento de dipolo para o estado excitado são bastante expressivos para todas as moléculas, principalmente em água. Para algumas moléculas $\left({ }^{\mathrm{tz}} \mathbf{A},{ }^{\mathrm{tz}} \mathbf{G}\right.$ e $\left.{ }^{\mathrm{tz}} \mathbf{U}\right)$ o crescimento do momento de dipolo exibe uma diferença percentual maior do que $100 \%$ de fase gasosa para água. Além de tudo, como ocorreu no estado fundamental, o momento de dipolo obtido em água é sempre maior com o modelo ASEC-FEG. Com exceção da molécula ${ }^{\text {tz }} \mathbf{A}$, em 1,4-dioxano é visto também a mesma tendência. Outro ponto que é comum ao observado no estado fundamental é de que o momento de dipolo cresce de acordo com o aumento da polaridade do meio. Comparando os dipolos do estado fundamental e excitado, vemos que os efeitos de solvente são mais pronunciados no estado 
Tabela 5.5 - Comprimentos de ligação $(\AA)$ e ângulo de piramidalização $\left(^{\circ}\right)$ para o primeiro estado excitado singleto ${ }^{1}\left(\pi \pi^{*}\right)$ das bases modificadas do RNA otimizadas em fase gasosa e em solvente(1,4-dioxano e água). As geometrias foram otimizadas no nível de cálculo MS(2)-CASPT2/cc-pVDZ.

\begin{tabular}{|c|c|c|c|c|c|c|}
\hline \multirow[b]{2}{*}{ Molecule } & \multirow[b]{2}{*}{ Coordenadas } & \multirow[b]{2}{*}{ Gás } & \multicolumn{2}{|c|}{ 1,4-dioxano } & \multicolumn{2}{|c|}{ Água } \\
\hline & & & PCM & ASEC-FEG & PCM & ASEC-FEG \\
\hline \multirow[t]{7}{*}{${ }^{\mathrm{tz}} \mathbf{A}$} & $\mathrm{C}_{2}-\mathrm{C}_{3}$ & 1.371 & 1.361 & 1.339 & 1.397 & 1.360 \\
\hline & $C_{4}-C_{5}$ & 1.439 & 1.429 & 1.481 & 1.449 & 1.477 \\
\hline & $\mathrm{S}_{8}-\mathrm{C}_{9}$ & 1.740 & 1.731 & 1.720 & 1.790 & 1.724 \\
\hline & $\mathrm{N}_{7}-\mathrm{S}_{8}$ & 1.697 & 1.706 & 1.711 & 1.700 & 1.727 \\
\hline & $\mathrm{C}_{6}-\mathrm{N}_{11}$ & 1.317 & 1.311 & 1.350 & 1.320 & 1.329 \\
\hline & $\mathrm{N}_{11}-\mathrm{H}$ & 1.017 & 1.024 & 1.018 & 1.030 & 1.042 \\
\hline & $\alpha$ & 0 & 0 & 3 & 1 & 1 \\
\hline \multirow[t]{7}{*}{${ }^{\mathrm{tz}} \mathbf{C}$} & $\mathrm{C}_{2}-\mathrm{C}_{3}$ & 1.494 & 1.463 & 1.407 & 1.450 & 1.434 \\
\hline & $\mathrm{C}_{4}-\mathrm{C}_{5}$ & 1.461 & 1.463 & 1.440 & 1.461 & 1.456 \\
\hline & $\mathrm{S}_{8}-\mathrm{C}_{9}$ & 1.731 & 1.716 & 1.751 & 1.713 & 1.740 \\
\hline & $\mathrm{C}_{6}-\mathrm{N}_{11}$ & 1.365 & 1.384 & 1.352 & 1.388 & 1.387 \\
\hline & $\mathrm{N}_{11}-\mathrm{H}$ & 1.016 & 1.022 & 1.032 & 1.027 & 1.052 \\
\hline & $\mathrm{C}_{2}-\mathrm{O}_{10}$ & 1.233 & 1.249 & 1.240 & 1.252 & 1.242 \\
\hline & $\alpha$ & 38 & 50 & 26 & 53 & 52 \\
\hline \multirow[t]{8}{*}{${ }^{\mathrm{tz}} \mathbf{G}$} & $\mathrm{C}_{2}-\mathrm{N}_{3}$ & 1.365 & 1.370 & 1.350 & 1.371 & 1.338 \\
\hline & $C_{4}-C_{5}$ & 1.482 & 1.476 & 1.490 & 1.468 & 1.449 \\
\hline & $\mathrm{S}_{8}-\mathrm{C}_{9}$ & 1.728 & 1.732 & 1.729 & 1.736 & 1.739 \\
\hline & $\mathrm{N}_{7}-\mathrm{S}_{8}$ & 1.759 & 1.753 & 1.700 & 1.750 & 1.727 \\
\hline & $\mathrm{C}_{2}-\mathrm{N}_{10}$ & 1.351 & 1.338 & 1.362 & 1.330 & 1.395 \\
\hline & $\mathrm{N}_{10}-\mathrm{H}$ & 1.014 & 1.023 & 1.021 & 1.028 & 1.055 \\
\hline & $\mathrm{C}_{6}-\mathrm{O}_{11}$ & 1.234 & 1.238 & 1.249 & 1.245 & 1.269 \\
\hline & $\alpha$ & 25 & 3 & 5 & 2 & 50 \\
\hline \multirow[t]{7}{*}{${ }^{\mathrm{tz}} \mathbf{U}$} & $\mathrm{C}_{2}-\mathrm{N}_{3}$ & 1.433 & 1.432 & 1.358 & 1.428 & 1.382 \\
\hline & $C_{4}-C_{5}$ & 1.474 & 1.479 & 1.456 & 1.475 & 1.458 \\
\hline & $\mathrm{S}_{8}-\mathrm{C}_{9}$ & 1.720 & 1.721 & 1.746 & 1.724 & 1.746 \\
\hline & $\mathrm{N}_{7}-\mathrm{S}_{8}$ & 1.773 & 1.780 & 1.623 & 1.772 & 1.665 \\
\hline & $\mathrm{C}_{6}-\mathrm{O}_{11}$ & 1.222 & 1.236 & 1.238 & 1.245 & 1.282 \\
\hline & $\mathrm{C}_{2}-\mathrm{O}_{10}$ & 1.222 & 1.223 & 1.252 & 1.226 & 1.244 \\
\hline & $\mathrm{N}_{1}-\mathrm{H}$ & 1.020 & 1.024 & 1.038 & 1.030 & 1.045 \\
\hline \multirow[t]{5}{*}{ tzI } & $\mathrm{C}_{2}-\mathrm{N}_{3}$ & 1.353 & 1.352 & 1.430 & 1.352 & 1.389 \\
\hline & $C_{4}-C_{5}$ & 1.488 & 1.481 & 1.492 & 1.471 & 1.505 \\
\hline & $\mathrm{S}_{8}-\mathrm{C}_{9}$ & 1.724 & 1.724 & 1.688 & 1.727 & 1.698 \\
\hline & $\mathrm{N}_{7}-\mathrm{S}_{8}$ & 1.758 & 1.758 & 1.697 & 1.750 & 1.688 \\
\hline & $\mathrm{C}_{6}-\mathrm{O}_{11}$ & 1.231 & 1.236 & 1.229 & 1.240 & 1.245 \\
\hline
\end{tabular}




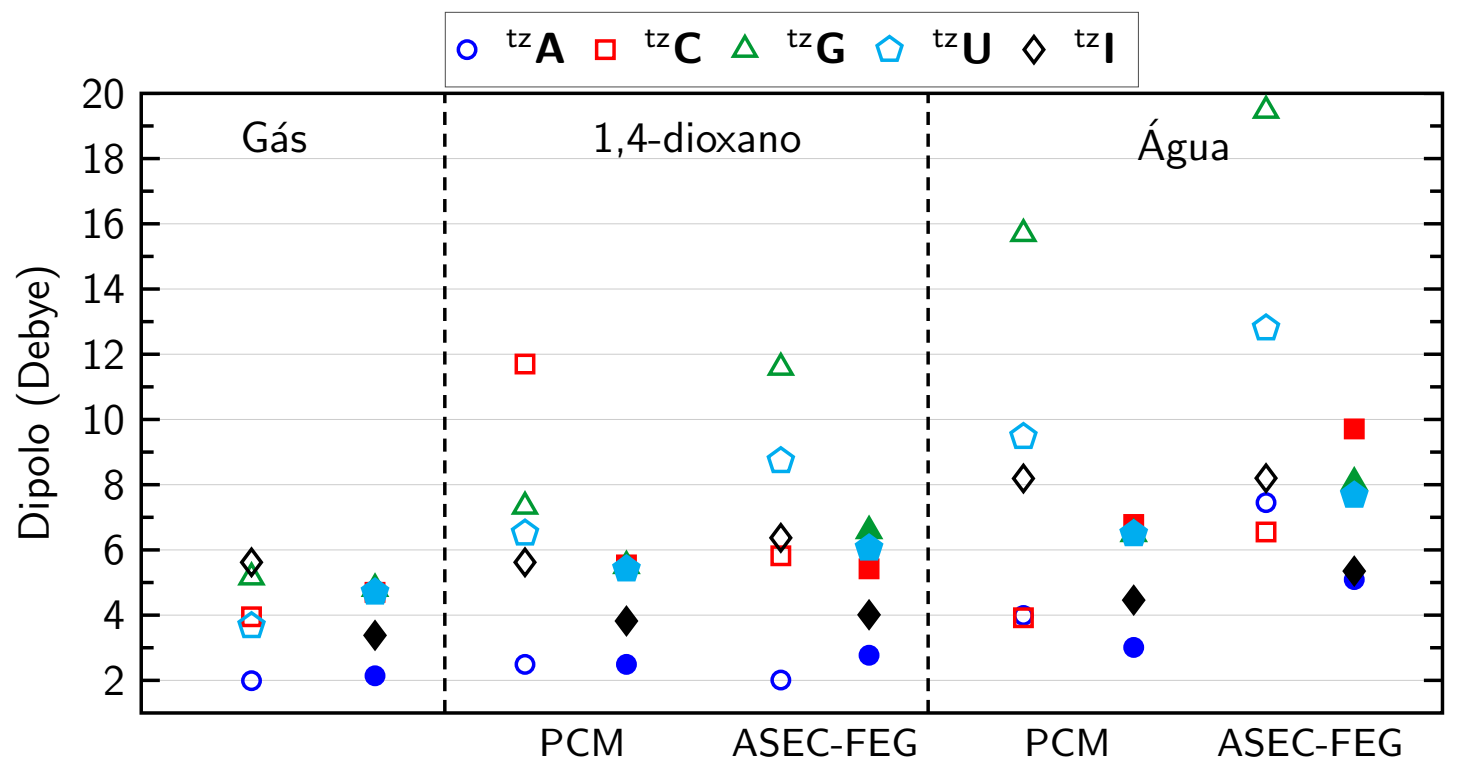

Figura 5.10 - Momento de dipolo (Debye) do novo alfabeto ribonucleosídeo fluorescente obtidos em fases gasosa e condensada (1,4-dioxano e água) nos estados fundamental (símbolos preenchidos) e primeiro excitado ${ }^{1}\left(\pi \pi^{*}\right)$ (símbolos vazios).

excitado ${ }^{1}\left(\pi \pi^{*}\right)$.

\subsection{Espectro de emissão eletrônico}

O espectro de emissão eletrônico do novo alfabeto fluorescente é calculado utilizando as geometrias dos estados excitados otimizadas em fase gasosa e em solução (1,4-dioxano e água). Quando computamos a emissão com a geometria otimizada em solução, estamos considerando que o tempo de vida do estado excitado é longo o suficiente para que o equilíbrio eletrostático entre soluto e solvente seja alcançado. Como foi visto na seção anterior, basicamente existe uma relaxação dos comprimentos de ligação e do ângulo de piramidalização $(\alpha)$ em relação à geometria FC. Desse modo, acreditamos que mesmo para um tempo de vida curto, todas as moléculas desse alfabeto conseguem relaxar sua geometria para o mínimo do estado claro. Infelizmente, até o presente momento, não há medidas experimentais do tempo de vida dos estados excitados desse alfabeto. Na Tabela 5.6 são exibidos os valores obtidos para a emissão eletrônica teórica para todas as moléculas desse alfabeto, juntamente com os dados experimentais.

Como pode ser visto na Tabela 5.6, o valor teórico para a energia de emissão para as moléculas ${ }^{\mathrm{tz}} \mathbf{A}$ e ${ }^{\mathrm{tz}} \mathbf{G}$ obtido em fase gasosa consegue reproduzir adequadamente os dados experimentais em 1,4-dioxano, com erros abaixo de $0.2 \mathrm{eV}$. Todavia, para as demais moléculas, o erro cometido entre o valor teórico e o experimental é da ordem de $0.3 \mathrm{eV}$. 
Tabela 5.6 - Energias de emissão eletrônica teóricas calculadas no nível SS(X)CASPT2 $(18,13) /$ cc-pVDZ, juntamente com os respectivos dados experimentais (eV) [183] para o novo alfabeto ribonucleosídeo fluorescente em 1,4-dioxano e água. A força de oscilador respectiva a cada transição também é reportada.

\begin{tabular}{|c|c|c|c|c|c|c|c|c|c|c|c|c|}
\hline & & & \multicolumn{5}{|c|}{ 1,4-dioxano } & \multicolumn{5}{|c|}{ Água } \\
\hline & \multicolumn{2}{|c|}{ Gás } & \multicolumn{2}{|c|}{ PCM } & \multicolumn{2}{|c|}{ ASEC-FEG } & \multirow{2}{*}{$\begin{array}{l}\text { Exp. } \\
\Delta E\end{array}$} & \multicolumn{2}{|c|}{ PCM } & \multicolumn{2}{|c|}{ ASEC-FEG } & \multirow{2}{*}{$\begin{array}{l}\text { Exp. } \\
\Delta E\end{array}$} \\
\hline & $\Delta E$ & $f$ & $\Delta E$ & $f$ & $\Delta E$ & $f$ & & $\Delta E$ & $f$ & $\Delta E$ & $f$ & \\
\hline${ }^{\mathrm{tz}} \mathbf{A}$ & 3.23 & 0.111 & 3.12 & 0.122 & 3.35 & 0.108 & 3.03 & 2.94 & 0.135 & 3.04 & 0.146 & 3.02 \\
\hline${ }^{\mathrm{tz}} \mathbf{C}$ & 2.70 & 0.158 & 2.88 & 0.288 & 3.00 & 0.140 & 2.96 & 2.50 & 0.126 & 2.82 & 0.140 & 3.01 \\
\hline${ }^{\mathrm{tz}} \mathbf{G}$ & 3.00 & 0.111 & 3.32 & 0.118 & 3.11 & 0.098 & 2.92 & 2.66 & 0.097 & 2.57 & 0.082 & 2.70 \\
\hline${ }^{\mathrm{tz}} \mathbf{U}$ & 3.63 & 0.167 & 3.44 & 0.162 & 3.57 & 0.145 & 3.29 & 3.48 & 0.164 & 3.02 & 0.116 & 3.16 \\
\hline${ }^{\mathrm{tz}} \mathbf{I}$ & 3.63 & 0.146 & 3.31 & 0.113 & 3.50 & 0.141 & 3.23 & 3.26 & 0.123 & 3.48 & 0.080 & 3.29 \\
\hline
\end{tabular}

Um bom acordo entre experimental e teórico é obtido em 1,4-dioxano quando empregado a metodologia ASEC-FEG, com exceção da molécula tz $\mathbf{A}$, que possui um erro acima de $0.3 \mathrm{eV}$. Como discorrido anteriormente na seção sobre o espectro de absorção eletrônico, a energia de absorção dessa espécie em 1,4-dioxano também apresenta um problema semelhante. Uma concordância mais acertada com o dado experimental foi alcançada incluindo a camada de ligações de hidrogênio explicitamente no cálculo de energias de excitação verticais. Dessa maneira, acreditamos que a inclusão de algumas moléculas de solvente tratadas explicitamente com mecânica quântica conduza para um melhor conformidade com o resultado experimental. No caso do espectro de absorção da molécula ${ }^{\mathrm{tz}} \mathbf{A}$, houve uma deslocamento para o vermelho de $0.18 \mathrm{eV}$ na energia de absorção quando duas moléculas de 1,4-dioxano foram descritas juntamente com cálculos de primeiros princípios. Imaginando que ocorra um deslocamento de mesma magnitude, o valor de emissão teórico ficaria dentro da acurácia prevista pelo método CASPT2. A energia de emissão em 1,4-dioxano alcançada com a aproximação ASEC-FEG em relação ao predito em fase gasosa possui um deslocamento para o vermelho de 0.06 e $0.13 \mathrm{eV}$ no caso das moléculas ${ }^{\text {tz }} \mathbf{U}$ e ${ }^{\text {tz }} \mathbf{I}$, respectivamente. Um deslocamento para o azul de $0.12,0.30$ e $0.11 \mathrm{eV}$ é observado para as moléculas ${ }^{\mathrm{tz}} \mathbf{A},{ }^{\mathrm{tz}} \mathbf{C}$ e ${ }^{\mathrm{tz}} \mathbf{G}$, respectivamente.

Em solução aquosa, o modelo ASEC-FEG reproduz corretamente a energia de emissão experimental para todas as moléculas, com o maior desvio de $0.19 \mathrm{eV}$. Como essa aproximação leva em conta apenas o embedding eletrostático médio do solvente no cálculo QM, os nossos melhores resultados deveriam ser obtidos em solventes cuja contribuição eletrostática seja dominante, que é a situação da água. A energia de emissão em água com respeito à fase gasosa possui um deslocamento para o vermelho de $0.19,0.43,0.61$ e $0.15 \mathrm{eV}$ para as moléculas ${ }^{\mathrm{tz}} \mathbf{A}$, ${ }^{\text {tz }} \mathbf{G},{ }^{\text {tz }} \mathbf{U}$ e ${ }^{\text {tz }} \mathbf{I}$, respectivamente. Apenas a molécula ${ }^{\text {tz }} \mathbf{C}$ exibe um deslocamento para o azul de $0.12 \mathrm{eV}$.

Analisando os valores obtidos com o modelo PCM, notamos que a descrição da energia de emissão para algumas molécula é condizente com o dado experimental. Os melhores resultados 
são obtidos em 1,4-dioxano, com um erro da ordem de $0.2 \mathrm{eV}$ (exceto para a molécula ${ }^{\text {tz }} \mathbf{C}$ $\sim 0.4 \mathrm{eV})$. Em água, por outro lado, é visto as maiores discrepâncias, com erros de até $0.5 \mathrm{eV}$ em comparação com experimental. Esses resultados sugerem que o modelo PCM não é um método indicado para cálculos de energias de emissão para solvente polares.

De modo geral, a intensidade da transição eletrônica desse estado excitado singleto é sempre maior com o modelo PCM, mas ambas aproximações predizem valores na mesma ordem de grandeza. Outro ponto a ser destacado é de que a intensidade de fase gasosa para solvente exibe leves alterações.

A tendência de crescimento da energia de emissão experimental entre as moléculas em ambos os solventes segue a seguinte tendência: ${ }^{\mathrm{tz}} \mathbf{G} \rightarrow{ }^{\mathrm{tz}} \mathbf{C} \rightarrow{ }^{\mathrm{tz}} \mathbf{A} \rightarrow{ }^{\mathrm{tz}} \mathbf{U} \rightarrow{ }^{\mathrm{tz}} \mathbf{I}$. A aproximação ASECFEG descreve essa tendência razoavelmente em água, invertendo as posições das moléculas ${ }^{\text {tz }} \mathbf{A}$ e ${ }^{\text {tz }} \mathbf{U}$. Em 1,4-dioxano, nenhum dos dois métodos conseguem capturar essa tendência, porém, vale mencionar, que em ambos os solventes as diferenças na energia de emissão de uma molécula para outra são relativamente pequenas.

\subsection{Deslocamento Stokes e desvio solvatocrômico}

O deslocamento Stokes, que é definido como sendo a diferença entre o pico da banda de absorção e o pico da banda de emissão, foi estimado para cada uma dessas moléculas. Dessa maneira, essa quantidade é bastante sensível, visto que ela depende da acurácia das energias de absorção e emissão. Os valores referentes a essa propriedade são mostrados na Tabela 5.7.

Tabela 5.7 - Deslocamento Stokes teórico (eV) em fase gasosa, 1,4-dioxano e água. Resultados experimentais são reportados para comparação [183]. Desvio solvatocrômico (eV) no deslocamento Stokes de 1,4-dioxano para água é também reportado.

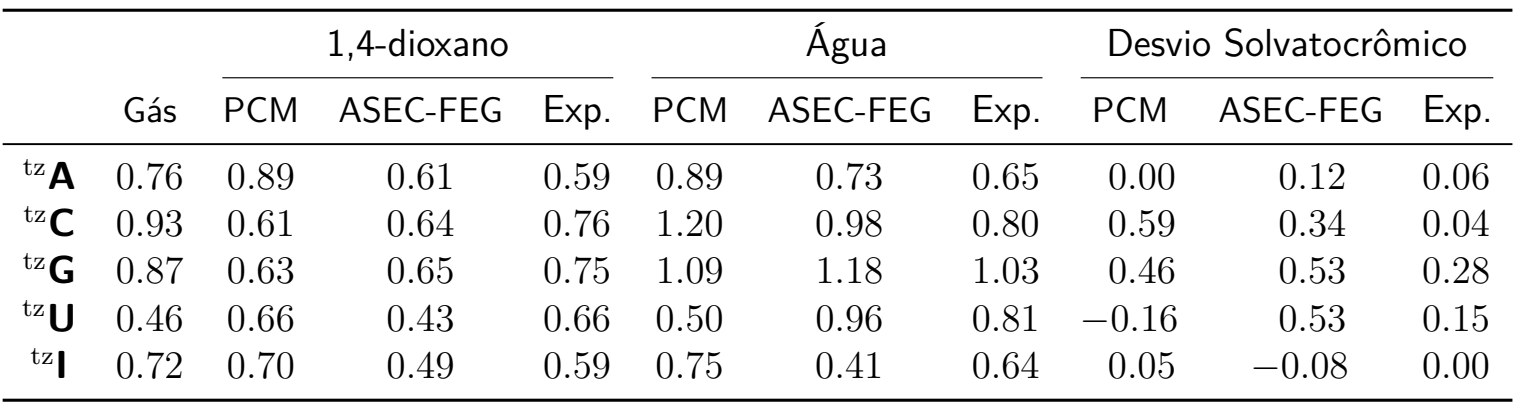

Os resultados obtidos para essa propriedade em fase gasosa são comparáveis com os dados experimentais em 1,4-dioxano, com o maior desvio de $0.2 \mathrm{eV}$ para a molécula ${ }^{\text {tz }} \mathbf{U}$. A inclusão dos efeitos de solvente via aproximação ASEC-FEG melhoram os nossos resultados em comparação com o dado experimental, sendo que há um deslocamento para o vermelho em todas as moléculas com relação à fase gasosa. O nosso pior resultado é para a molécula ${ }^{\text {tz }} \mathbf{U}$, cujo valor é da mesma ordem obtido em fase gasosa. Isso se deve ao fato da emissão eletrônica 
teórica ser um pouco acima do que é medido experimentalmente, mas certamente a inclusão de moléculas explícitas de solvente resolveria o problema. Salvo a molécula ${ }^{\text {tz }} \mathbf{A}$, o modelo PCM consegue mensurar bons valores para essa quantidade, sendo que em algumas circunstâncias o valor previsto é bem melhor do que o predito pela outra aproximação. O modelo PCM não reproduz adequadamente o deslocamento Stokes para a molécula ${ }^{\text {tz }} \mathbf{A}$, porque a emissão é muito bem assinalada, porém falha ao caracterizar a energia de absorção eletrônica (erro da ordem de $0.4 \mathrm{eV}$ em relação ao experimental).

Como ocorrido na emissão, bons valores são preditos para o deslocamento Stokes em água empregando o modelo ASEC-FEG. Em relação à fase gasosa, existe um deslocamento para o vermelho nas moléculas ${ }^{\mathrm{tz}} \mathbf{A}(0.03 \mathrm{eV})$ e ${ }^{\mathrm{tz}} \mathbf{I}(0.31 \mathrm{eV})$, enquanto é visto um deslocamento para o azul para as demais moléculas. Mais uma vez o modelo PCM não é apto em descrever essa propriedade, com diferenças de até $0.4 \mathrm{eV}$ em comparação com o dado experimental.

Por fim é examinado a influência do solvente no deslocamento Stokes, por meio do desvio solvatocrômico de 1,4-dioxano para água. A aproximação ASEC-FEG prediz um sentido correto, com exceção da molécula ${ }^{\mathrm{tz}} \mathbf{I}$. Todavia, esse desvio experimental para essa molécula é relativamente pequeno, menor do que $0.1 \mathrm{eV}$, que está dentro do erro esperado pelo CASPT2. $\mathrm{O}$ modelo PCM prediz um sentido oposto ao experimental para a molécula ${ }^{\text {tz }} \mathbf{U}$ e não distingue o deslocamento Stokes de 1,4-dioxano para água na molécula ${ }^{\text {tz }} \mathbf{A}$. Em termos nominais, ambos os métodos indicam valores mais altos em energia do que os estimados experimentalmente.

\subsection{Caminhos de desativação fotofísicos}

As propriedades espectroscópicas do novo alfabeto ribonucleosídeo fluorescente, que envolve a descrição dos espectros de absorção e emissão, foram minuciadamente detalhadas em fase gasosa e em solução. Contudo, uma importante pergunta ainda se encontra em aberto. Por quê esse alfabeto é fluorescente?

Para responder essa pergunta tentamos descrever os possíveis caminhos fotofísicos de cada uma dessas moléculas. O primeiro passo é monitorar a desativação à partir do estado claro ${ }^{1}\left(\pi \pi^{*}\right)$ depois da excitação eletrônica em fase gasosa. Para esse fim é comumente utilizado a técnica de caminho de menor energia (MEP), que a partir de otimizações de geometria restritas a um raio definido previamente, descreve o provável caminho de relaxação fotoquímico. Como mostrado na Figura 5.11, esse caminho de relaxação ao longo do primeiro estado claro ${ }^{1}\left(\pi \pi^{*}\right)$ para todas as moléculas desse alfabeto exibe uma evolução sem a presença de nenhuma barreira em direção ao mínimo desse estado excitado. Considerando o ponto inicial do MEP como referência, o mínimo do primeiro estado claro $\left({ }^{1}\left(\pi \pi^{*}\right)_{\min }\right)$ é colocado mais baixo energeticamente por $-0.38,-0.20,-0.25,0.30 \mathrm{e}-0.12 \mathrm{eV}$ para as moléculas ${ }^{\mathrm{tz}} \mathbf{A},{ }^{\mathrm{t} z} \mathbf{C},{ }^{\mathrm{tz}} \mathbf{G}$, ${ }^{\mathrm{tz}} \mathbf{U}$ e ${ }^{\mathrm{tz}} \mathbf{I}$, respectivamente. 

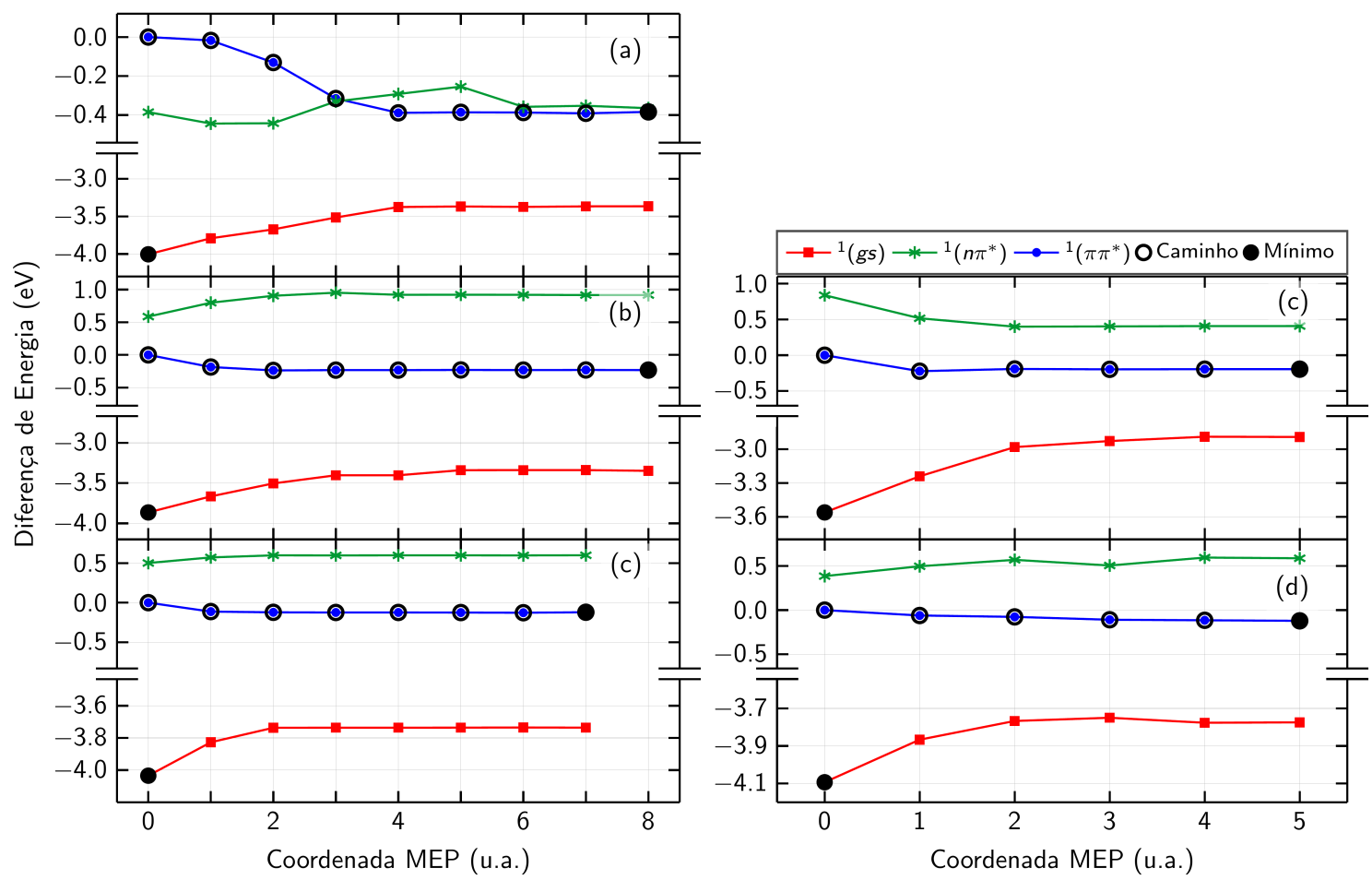

Figura 5.11 - Caminho de menor energia (MEP) à partir da região de $\mathrm{FC}$ ao longo do primeiro estado excitado ${ }^{1}\left(\pi \pi^{*}\right)$ para as moléculas (a) ${ }^{\mathrm{tz}} \mathbf{A}$, (b) ${ }^{\mathrm{tz}} \mathbf{C}$, (c) ${ }^{\mathrm{tz}} \mathbf{G},(\mathrm{d}){ }^{\mathrm{tz}} \mathbf{U} \mathrm{e}$

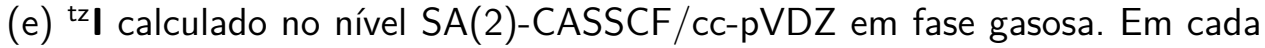
ponto gerado pelo MEP é recomputado as energias de excitação verticais no nível SS(X)-CASPT2 $(18,13) /$ cc-pVDZ.

Dentre as moléculas estudadas, apenas a molécula ${ }^{\mathrm{tz}} \mathrm{A}$ poderia transferir a população para o estado escuro ${ }^{1}\left(n \pi^{*}\right)$ por meio de um intersecção cônica, visto que esse cruzamento aparece no MEP. É conhecido na literatura que a $9 \mathrm{H}$-adenina, sua respectiva análoga nucléica, em fase gasosa possui o estado excitado excitado mais baixo descrito por um transição do tipo $n \rightarrow \pi^{*}[213,214]$. Entretanto, baseado no conhecimento sobre a adenina, achamos que esse caminho não é viável. Além do mais, os efeitos de solvente provocam uma inversão dos estados eletrônicos, situando a transição ${ }^{1}\left(\pi \pi^{*}\right)$ como o primeiro estado excitado. Apenas uma dinâmica de estados excitados, que envolve a propagação da função de onda eletrônica e das coordenadas nucleares no tempo, poderia responder de fato esse questionamento. Infelizmente não existe nenhum dado experimental para a fase gasosa.

Dessa forma, tentamos encontrar outra possibilidade além da fluorescência para que essas moléculas retornassem para o estado fundamental depois da absorção de luz. No caso das bases nucléicas canônicas, as interseções cônicas são a chave para descrever a volta da população para o estado fundamental em um processo ultra-rápido e eficiente. Baseado nesse conhecimento sobre as bases nucléicas naturais, o próximo passo é a busca pela intersecção cônica entre os estados fundamental e primeiro estado excitado ${ }^{1}\left(\pi \pi^{*}\right)$, cunhado como ${ }^{1}\left(g s / \pi \pi^{*}\right){ }_{\mathrm{Cl}}$. Como 
as moléculas desse alfabeto são análogas as bases nucléicas, é de se esperar que as cônicas encontradas possam ser estruturalmente semelhantes com as obtidas para as bases originais. Na Figura 5.12 é ilustrada as estruturas otimizadas que correspondem a essa interseção cônica em gás.

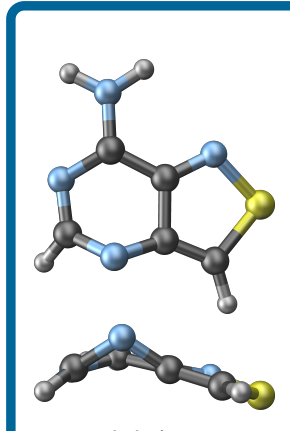

(a) ${ }^{\text {tz }} \mathbf{A}$

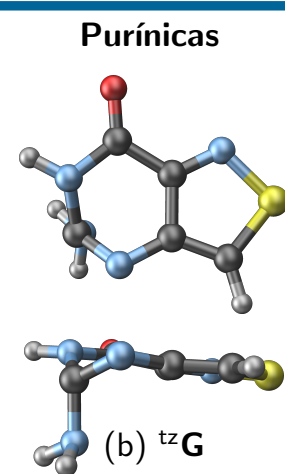

(b) ${ }^{\mathrm{tz}} \mathbf{G}$

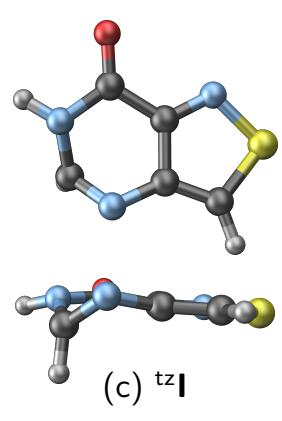

(c) ${ }^{\mathrm{t}} \mathbf{I}$

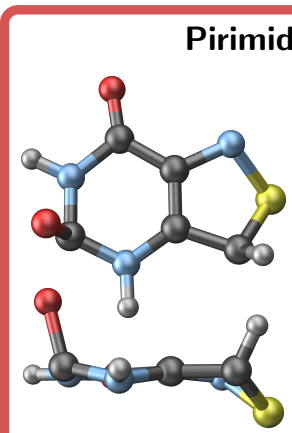

(d) ${ }^{\text {tz }} \mathbf{U}$

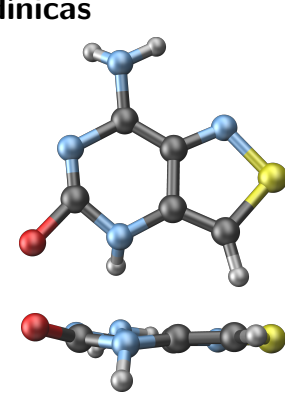

$\left(\mathrm{e}{ }^{\mathrm{tz}} \mathbf{C}\right.$

Figura 5.12 - Visão frontal e lateral correspondente à intersecção cônica entre os estados fundamental e primeiro excitado ${ }^{1}\left(\pi \pi^{*}\right)$ para o novo alfabeto ribonucleosídeo fluorescente. As cônicas foram otimizadas em fase gasosa no nível MS(2)CASPT2/cc-pVDZ. O espaço ativo empregado compreende todos os orbitais $\pi$.

Começando pela estrutura ${ }^{1}\left(g s / \pi \pi^{*}\right)_{\mathrm{Cl}}$ otimizada para as moléculas purínicas, todas elas exibem grande distorções no anel de seis membros, enquanto o anel de cinco membros permanece planar. Mudanças significativas são vistas na posição $C_{2}$ para as três moléculas, com o grupo ligado nessa posição perpendicular ao anel de seis membros para as moléculas ${ }^{\mathrm{tz}} \mathbf{G}$ e ${ }^{\mathrm{tz}} \mathbf{I}$. As posições $\mathrm{N}_{1}$ e $\mathrm{C}_{2}$ são distorcidas para a molécula ${ }^{\mathrm{tz}} \mathbf{A}$. Em comparação com as estruturas de mínimo ${ }^{1}\left(\pi \pi^{*}\right)_{\min }$, a ligação $C_{2}-N_{3}$ é enlogada em todas as situações. Por outro lado, há um encurtamento da ligação $N_{1}-C_{2}$ para a molécula ${ }^{\text {tz }} \mathbf{A}$ e um estiramento dessa ligação para as moléculas ${ }^{\mathrm{tz}} \mathbf{G}$ e ${ }^{\mathrm{tz}} \mathbf{I}$.

Em termos das moléculas pirimidínicas, a estrutura ${ }^{1}\left(g s / \pi \pi^{*}\right)$ Cl em relação ao mínimo ${ }^{1}\left(\pi \pi^{*}\right)_{\text {min }}$ para o composto ${ }^{\mathrm{tz}} \mathbf{C}$ exibe uma rotação do grupo $\mathrm{NH}_{2}$, um aumento da ligação $\mathrm{C}=\mathrm{O}$ e o hidrogênio ligado ao átomo $\mathrm{N}_{1}$ deixa o plano do anel de seis membros por volta de $60^{\circ}$. Já para a molécula ${ }^{\mathrm{tz}} \mathbf{U}$, a cônica correspondente é caracterizada por uma grande distorção do anel de cinco membros, com o átomo de enxofre deixando o plano desse anel. Além disso, os átomos $\mathrm{O}_{11}$ e hidrogênio da ligação $\mathrm{C}_{9}-\mathrm{H}$ se situam quase perpendiculares aos anéis.

Essas cônicas otimizadas em fase gasosa podem ser comparadas com as obtidas previamente para adenina [214], citosina [215,216], guanina [217], uracila [218] e inosina [219]. Para uma comparação mais detalhada é empregado os parâmetros de Cremer-Pople [220] e Boyens [221] ( $Q$ em $\AA$, $\phi$ e $\theta$ em graus), que analisa a conformação de anéis de seis membros. A comparação entre essas moléculas é exibida na Tabela 5.8. 
Tabela 5.8 - Parâmetros de Cremer-Pople e Boyens para análise de conformação de anéis de seis membros da cônica ${ }^{1}\left(\mathrm{gs} / \pi \pi^{*}\right)$ cl obtidos para o novo alfabeto ribonucleosídeo fluorescente e suas respectivas análogas nucléicas. Esses parâmetros também foram empregados para a cônica obtida anteriormente para a molécula ${ }^{\text {tz }} \mathbf{A}$.

\begin{tabular}{ccccc}
\hline & $Q / \AA$ & $\Phi /{ }^{\circ}$ & $\Theta /{ }^{\circ}$ & Boeyens [221] \\
\hline${ }^{\mathrm{tz}} \mathbf{A}$ (Esse trabalho) & 0.63 & 125 & 74 & ${ }^{3,6} \mathrm{~B}$ \\
${ }^{\mathrm{tz}} \mathbf{A}$ (Karsili et al.) [222] & 0.55 & 92 & 65 & ${ }^{3} \mathrm{~S}_{2}$ \\
Adenina [214] & 0.54 & 76 & 66 & ${ }^{3} S_{2}$ \\
\hline${ }^{\mathrm{tz}} \mathbf{G}$ & 0.47 & 68 & 57 & $E_{2}$ \\
Guanina [217] & 0.49 & 67 & 60 & $E_{2}$ \\
\hline${ }^{\mathrm{tz}} \mathbf{I n o s i n a ~ [ 2 1 9 ]}$ & 0.51 & 78 & 60 & ${ }^{3} \mathrm{~S}_{2}$ \\
\hline${ }^{\mathrm{tz}} \mathbf{C}$ & 0.51 & 65 & 62 & ${ }_{2}$ \\
\hline Citosina (Bond-inversion) [215] & 0.07 & 19 & 110 & ${ }^{6} \mathrm{C}_{3}$ \\
\hline${ }^{4} S_{5}$ \\
\hline${ }^{\mathrm{tz}} \mathbf{U}$ & 0.41 & 104 & 113 & ${ }^{3} \mathrm{H}_{2}$ \\
\hline Uracila [218] & 0.20 & 27 & 59 & ${ }^{4} E$ \\
\hline
\end{tabular}

Novamente começando pelas purínicas, é importante mencionar que as estruturas ${ }^{1}\left(g s / \pi \pi^{*}\right)_{\mathrm{Cl}}$ para as bases canônicas foram obtidas no nível CASSCF. Também comparamos a cônica da molécula ${ }^{\text {tz }} \mathbf{A}$ obtida anteriormente por Karsili e colegas no nível de cálculo $\operatorname{SA}(2)-\operatorname{CASSCF}(6,6) / 6$ $31 G(d)$ [222], que negligência os efeitos de correlação dinâmica durante o processo de otimização.

A análise de conformação de anéis revela que a cônica ${ }^{1}\left(g s / \pi \pi^{*}\right)$ cı para a molécula ${ }^{\text {tz }} \mathbf{A}$ possui uma conformação boat ${ }^{3,6} B$, com as posições $\mathrm{N}_{3}$ e $\mathrm{C}_{6}$ fora do plano. Essa estrutura difere a partir da adenina, visto que sua análoga é classificada como skew-boat ${ }^{3} S_{2}$. Recentemente, Karsili e colaboradores reportaram uma cônica ${ }^{1}\left(g s / \pi \pi^{*}\right)$ cı para a molécula ${ }^{\mathrm{tz}} \mathbf{A}$, sendo essa estrutura bastante semelhante à da adenina, pertencendo ao mesmo grupo de Boyens ${ }^{3} S_{2}$. Contudo, é importante mencionar que ambas as estruturas foram otimizadas no mesmo nível de teoria, sendo um possível motivo para que ambas as cônicas sejam indexadas no mesmo grupo de Boyens. Barbatti e Lischka reportaram, pela primeira vez, uma intersecção cônica para adenina com classificação de Boyens ${ }^{3,6} B$, computada no nível MR-CIS $(6,5) / / \mathrm{SA}(3)$ CAS $(12,10) / 6-31 G *$ [223]. Entretanto, essa cônica está relacionada a um caminho secundário.

A cônica para as moléculas ${ }^{\mathrm{tz}} \mathbf{G}$ e $9 \mathrm{H}$-guanina, sua análoga nucléica, são colocadas no mesmo grupo de Boyens. De acordo com essa classificação, ambas estruturas são caracterizadas por uma conformação envelope na posição $C_{2}\left(E_{2}\right)$. Vale lembrar que para a molécula $9 \mathrm{H}$-guanina em fase gasosa [217], o estado claro ${ }^{1}\left(\pi \pi^{*}\right)$ é sempre o estado excitado com mais baixa energia e a partir da região de FC é visto uma evolução sem barreiras em direção a cônica com o estado fundamental. 
No mesmo caminho, comparando a cônica das moléculas inosina e ${ }^{\mathrm{tz}} \mathbf{I}$, observamos parâmetros similares de $\mathrm{Q}(0.51 \AA$ para ambas as moléculas $), \phi\left(78^{\circ}\right.$ para ${ }^{\text {tz }} \mathbf{I}$ e $65^{\circ}$ para inosina $), \theta$ $\left(60^{\circ}\right.$ para ${ }^{\text {tz }} \mathbf{I}$ e $62^{\circ}$ para inosina). Contudo, essas estruturas são incluídas em grupos distintos,

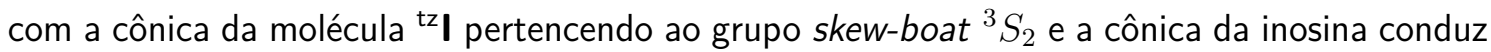
para um conformação envelope $E_{2}$.

Por fim, é analisado as cônicas para o caso das moléculas pirimidínicas. Existem distintas cônicas que estão relacionadas ao decaimento não-radioativo ultra-rápido da molécula citosina $[14,15,224]$, embora duas delas são consideradas mais relevantes. A primeira, chamada de intersecção cônica ethene-like, compreende uma elongação e rotação da ligação $C_{4}-C_{5}$. $A$ segunda cônica, cunhada como intersecção cônica bond-inversion, envolve uma mudança de caráter de ligação comparando a conformação do estado fundamental, juntamente com uma ligeira piramidalização do átomo $C_{4}$. Na molécula ${ }^{\text {tz }} \mathbf{C}$, as posições $C_{4}$ e $C_{5}$ são responsáveis pela junção dos dois anéis, consequentemente, deformações estruturais nesses sítios não são favoráveis. Além disso, a cônica obtida para a molécula ${ }^{\mathrm{tz}} \mathbf{C}$ se difere bastante das reportadas anteriormente para a citosina (veja Tabela 5.8).

Já para a uracila, a cônica mais significativa para explicar o seu decaimento não-radioativo é a ethene-like. Como discutido acima, as posições referentes a essa cônica para a molécula ${ }^{\text {tz }}$ são bloqueadas. Dessa forma, como mostrado na Figura 5.12, a estrutura ${ }^{1}\left(g s / \pi \pi^{*}\right)_{\mathrm{Cl}}$ para a molécula ${ }^{\mathrm{tz}} \mathbf{U}$ não exibe deformações estruturais características observadas para a cônica da uracila.

Em relação ao mínimo do primeiro estado excitado ${ }^{1}\left(\pi \pi^{*}\right)$, a cônica obtida para as moléculas pirimidínicas são posicionadas em um alta região energética $\left(1.25 \mathrm{eV}\right.$ para a molécula ${ }^{\mathrm{tz}} \mathbf{C}$ e 5.06 eV para a molécula $\left.{ }^{\text {tz }} \mathbf{U}\right)$. Portanto, a cônica ${ }^{1}\left(g s / \pi \pi^{*}\right)$ Cı não é acessível a partir da estrutura ${ }^{1}\left(\pi \pi^{*}\right)_{\min }$. No caso das purínicas, a cônica é ligeiramente mais alta em energia em relação à estrutura de mínimo (0.03, 0.10 e $0.06 \mathrm{eV}$ para as moléculas ${ }^{\mathrm{tz}} \mathbf{A},{ }^{\mathrm{tz}} \mathbf{G}$ e ${ }^{\mathrm{tz}} \mathbf{I}$, respectivamente).

Interpolações lineares em coordenadas internadas (LIIC) são utilizadas no intuito de verificar a acessibilidade dessas cônicas a partir da região ${ }^{1}\left(\pi \pi^{*}\right)_{\min }$, principalmente para o grupo purina. Como é visto na Figura 5.13, o grupo pirimidínico não possui uma barreira entre o mínimo e a intersecção cônica, porém como mencionado acima, a estrutura ${ }^{1}\left(g s / \pi \pi^{*}\right)_{\mathrm{cl}}$ encontra-se em uma região energeticamente mais alta, impossibilitando o acesso à $\mathrm{Cl}$ e explicando o motivo desse grupo de moléculas ser fluorescente.

Com respeito ao grupo purina, a estrutura ${ }^{1}\left(g s / \pi \pi^{*}\right)$ CI poderia ser acessada a partir do mínimo depois de superar barreiras energéticas estimadas serem $0.25,0.92$ e $0.81 \mathrm{eV}$ para as moléculas ${ }^{\mathrm{tz}} \mathbf{A},{ }^{\mathrm{tz}} \mathbf{G}$ e ${ }^{\mathrm{tz}} \mathbf{I}$, respectivamente. Contudo, essas barreiras são energeticamente altas para serem vencidas, consequentemente, a energia extra do estado ${ }^{1}\left(\pi \pi^{*}\right)$ é lançada em forma de fluorescência a partir do mínimo desse estado. Comparando com o trabalho de Karsili e colaboradores para a molécula ${ }^{\mathrm{tz}} \mathbf{A}$ [222], eles encontraram uma estrutura ${ }^{1}\left(\pi \pi^{*}\right)_{\min }$ mais baixa em energia do que a cônica e nenhum barreira foi notada entre essas conformações. 

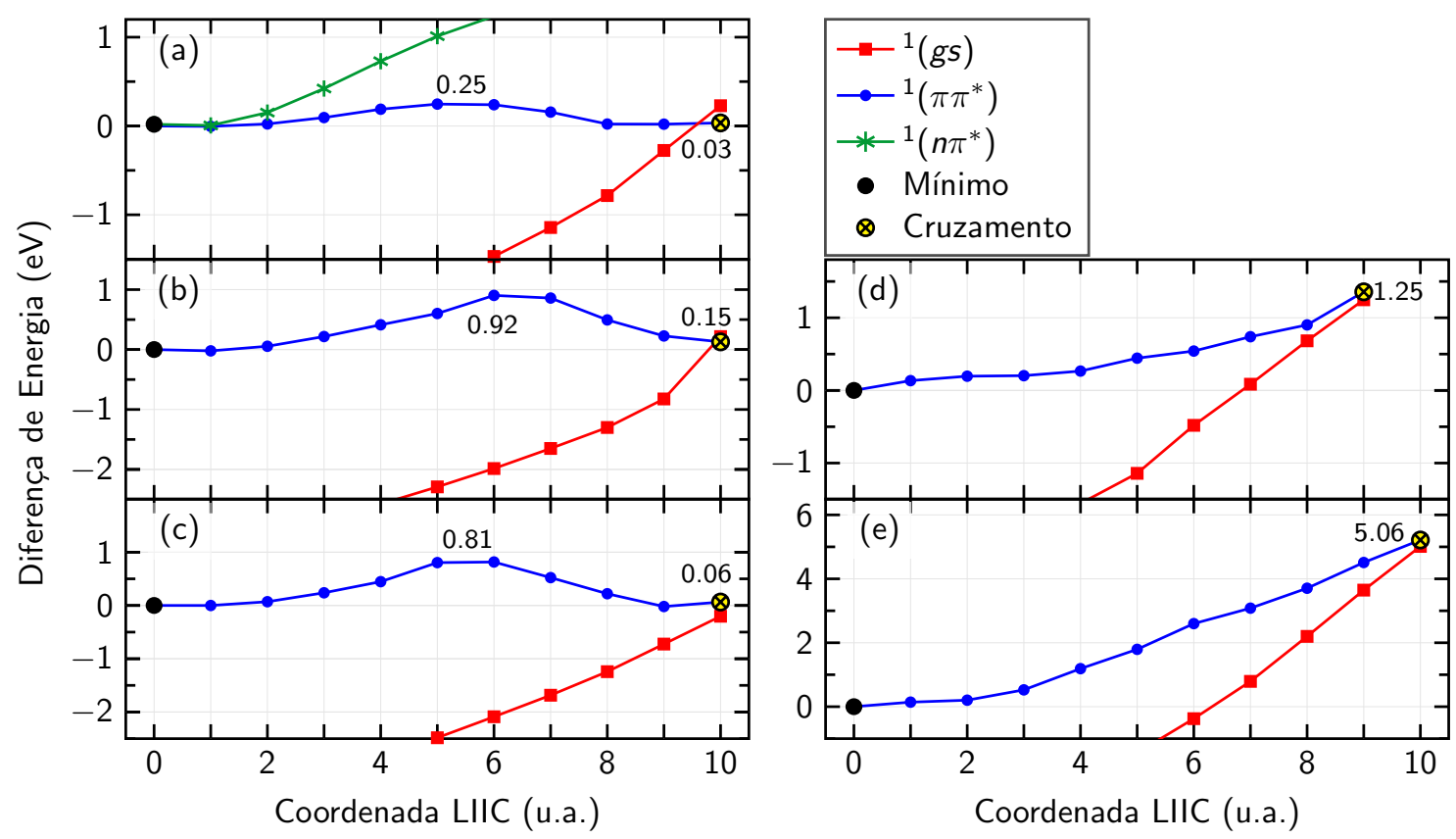

Figura 5.13 - Interpolações lineares em coordenadas internas ligando as estruturas ${ }^{1}\left(\pi \pi^{*}\right)_{\min }$ e ${ }^{1}\left(g s / \pi \pi^{*}\right)$ cl para as moléculas (a) ${ }^{\mathrm{tz}} \mathbf{A}$, (b) ${ }^{\mathrm{tz}} \mathbf{C}$, (c) ${ }^{\mathrm{tz}} \mathbf{G}$, (d) ${ }^{\mathrm{tz}} \mathbf{U}$ e (e) ${ }^{\mathrm{tz}} \mathbf{I}$. Em cada geometria gerada através da técnica LIIC é calculado as energias de excitação verticais no nível SS(X)-CASPT2 $(18,13) /$ cc-pVDZ.

Ciente das limitações da técnica LIIC, que compreende o fato das barreiras energéticas poderem ser superestimadas devido ao fato de não "caminharmos" no caminho de menor energia, resolvemos otimizar o respectivo estado de transição entre os pontos críticos para todas as moléculas purínicas no nível SA(2)-CASSCF/cc-pVDZ. Devido ao alto custo computacional não é viável a realização dessas otimizações no nível MS-CASPT2. Com isso em mente, é detectado menores barreiras energéticas para todas as moléculas $\left(0.18 \mathrm{eV}\right.$ para ${ }^{\mathrm{tz}} \mathbf{A}, 0.37 \mathrm{eV}$ para ${ }^{\mathrm{tz}} \mathbf{G} \mathrm{e}$ $0.68 \mathrm{eV}$ para ${ }^{\mathrm{tz}} \mathbf{I}$ ), embora ainda sejam barreiras consideravelmente altas para serem superadas. Dessa forma, acreditamos que essas moléculas também fluorescem em fase gasosa, apesar de não ter dados experimentais disponíveis. Uma recente investigação sobre a tienoguanina $\left({ }^{\text {th }} \mathbf{I}\right)$, uma análoga fluorescente das moléculas guanina e ${ }^{\text {tz }} \mathbf{G}$, nos níveis TD-DFT e CASSCF, mostraram um caminho de desativação similar ao reportado por nós para a molécula ${ }^{\text {tz }} \mathbf{G}$, com uma barreira energética $\sim 0.4 \mathrm{eV}$ [225].

Os efeitos de solvente também foram considerados no caminho fotoquímico descrito acima, empregando a metodologia ASEC-FEG para incluir a solvatação nos pontos selecionados ao longo do caminho fotoquímico, como por exemplo, nas estruturas de mínimos, barreiras e interseções cônicas. É importante frisar que os efeitos de solvente foram emulados congelando a geometria das intersecções cônicas otimizadas em fase gasosa. As diferenças de energia entre os valores computados em fase gasosa e solvente são mostrados na Tabela 5.9.

Em comparação com a fase gasosa, os efeitos de solvente deslocam a estrutura ${ }^{1}\left(g s / \pi \pi^{*}\right)_{\mathrm{Cl}}$ 
Tabela 5.9 - Barreiras energéticas (eV) computadas como a diferença de energia entre a geometria de mínimo do estado ${ }^{1}\left(\pi \pi^{*}\right)_{\min }$ e a estrutura correspondente ao máximo do LIIC (Barreira (LIIC)) e como a diferença de energia entre o estado de transição otimizado e o mínimo ${ }^{1}\left(\pi \pi^{*}\right)_{\min }$ (Barreira (TS)). A diferença de energia entre o mínimo e a interseção cônica $\left(E_{\min }-E_{C I}\right)$ para as fases gasosa e condensada (1,4-dioxano e água) também são reportadas. As energias de excitação vertical são computadas no nível SS(X)-CASPT2(18,13)/cc-pVDZ.

\begin{tabular}{|c|c|c|c|c|c|c|c|c|c|}
\hline \multirow{2}{*}{ Molécula } & \multicolumn{3}{|c|}{ Barreira (LIIC) } & \multicolumn{3}{|c|}{ Barreira (TS) } & \multicolumn{3}{|c|}{$E_{\min }-E_{C I}$} \\
\hline & $\overline{\text { Gas }}$ & Dioxano & Água & Gás & Dioxano & Água & Gas & Dioxano & Água \\
\hline${ }^{\mathrm{tz}} \mathbf{A}$ & 0.25 & 0.24 & 0.38 & 0.18 & 0.13 & 0.24 & -0.16 & 0.30 & 0.52 \\
\hline${ }^{\mathrm{tz}} \mathbf{C}$ & - & - & - & - & - & - & 1.25 & 1.36 & 1.48 \\
\hline${ }^{\mathrm{tz}} \mathbf{G}$ & 0.92 & 1.11 & 0.99 & 0.37 & 0.28 & 0.29 & -0.30 & 0.87 & 0.06 \\
\hline${ }^{\mathrm{tz}} \mathbf{C}$ & - & - & - & - & - & - & 5.06 & 5.20 & 5.82 \\
\hline tzI & 0.81 & 0.94 & 0.98 & 0.68 & 0.60 & 0.76 & -0.26 & 0.22 & 0.06 \\
\hline
\end{tabular}

para uma região ainda mais energética em relação ao mínimo para o grupo pirimidínico $\left({ }^{\mathrm{tz}} \mathbf{C}\right.$ $\left.\mathrm{e}^{\mathrm{tz}} \mathbf{U}\right)$, tornando ambas as moléculas mais propícias a emitir em solução. Esse deslocamento segue o aumento da polaridade do meio.

No caso das moléculas purínicas, a barreira em solução é computada de duas maneiras. A primeiras delas envolve a estrutura com maior energia fornecida pela LIIC. Considerando essa estrutura, a barreira energética sempre aumenta em solução. Em 1,4-dioxano, a maior variação em relação à fase gasosa é verificada para a molécula ${ }^{\text {tz }} \mathbf{G}(0.19 \mathrm{eV})$, seguida pela molécula ${ }^{\text {tz }}$ $(0.13 \mathrm{eV})$. Em solução aquosa, um aumento de $0.17 \mathrm{eV}$ na barreira energética é observado para a molécula ${ }^{\text {tz }} \mathbf{I}\left(0.07 \mathrm{eV}\right.$ para a molécula ${ }^{\mathrm{tz}} \mathbf{G}$ e $0.13 \mathrm{eV}$ para a molécula $\left.{ }^{\mathrm{tz}} \mathbf{A}\right)$. Esses resultados indicam que quanto mais polar é o solvente, maior é a probabilidade da molécula emitir.

A segunda abordagem é empregando a estrutura otimizada do estado de transição em fase gasosa. Como é visto na Tabela 5.9, não é possível observar nenhuma tendência sobre os efeitos de solventes. No entanto, o principal ponto a ser destacado é que ambas as abordagens ainda exibem uma barreira energética entre os pontos críticos em solução, sugerindo o motivo dos compostos purínicos serem emissivos em solução.

Ainda sobre as moléculas purínicas, como discorrido previamente, as estruturas ${ }^{1}\left(\pi \pi^{*}\right)_{\min }$ são ligeiramente mais estabilizadas do que as estruturas ${ }^{1}\left(g s / \pi \pi^{*}\right) \mathrm{Cl}$. Efeitos de solvente estabilizam ainda mais a região de mínimo. Por exemplo, a posição relativa entre as estruturas ${ }^{1}\left(\pi \pi^{*}\right)$ e ${ }^{1}\left(g s / \pi \pi^{*}\right)_{C l}$ aumenta $0.30 \mathrm{eV}$ em 1,4-dioxano e $0.52 \mathrm{eV}$ em água para a molécula ${ }^{\mathrm{tz}} \mathbf{A}$. Por outro lado, essa diferença aumenta para $0.87 \mathrm{eV}$ em 1,4-dioxano para a molécula ${ }^{\mathrm{tz}} \mathbf{G}$, mas em água, ambas as estruturas são colocadas muito perto em energia, separadas por apenas $0.06 \mathrm{eV}$.

Todos os resultados dessa seção podem ser sumarizados como: O caminho de desativação para todas as moléculas desse alfabeto são similares. Depois da absorção de luz, o estado ${ }^{1}\left(\pi \pi^{*}\right)$ 

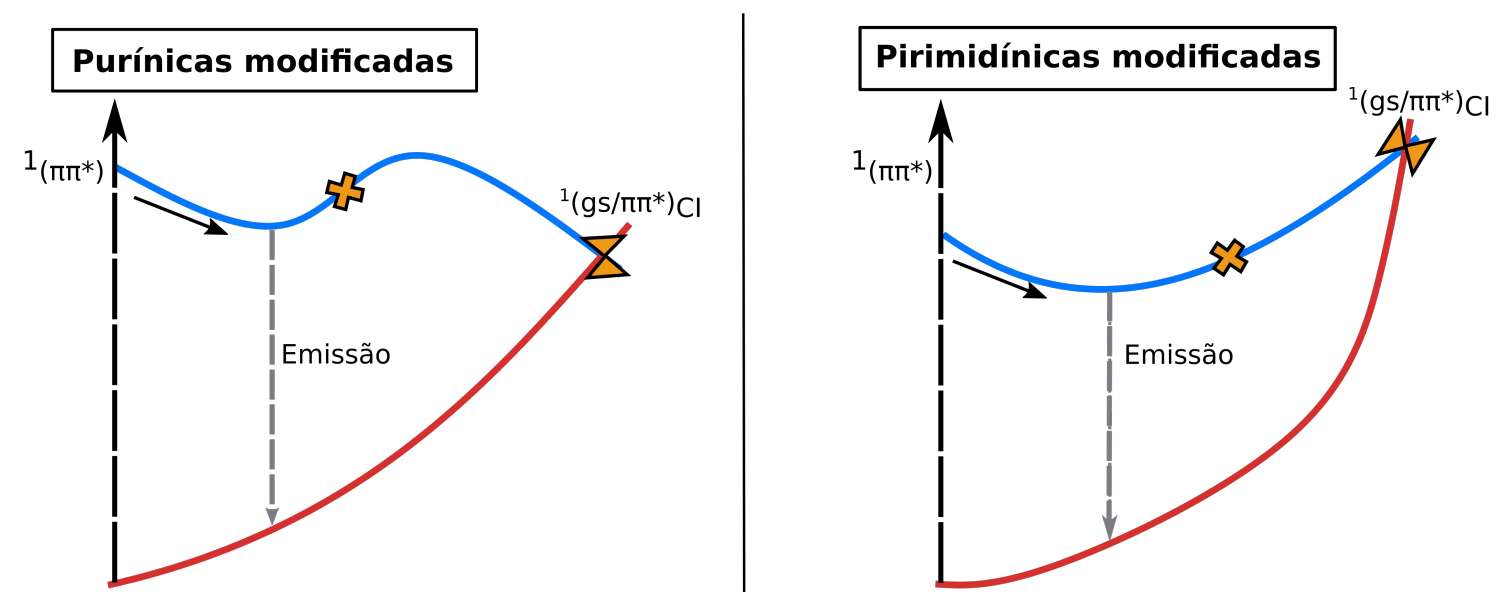

Figura 5.14 - Ilustração da fotofísica do novo alfabeto ribonucleosídeo fluorescente.

é populado e segue em direção a região de mínimo desse estado. A interseção cônica ${ }^{1}\left(g s / \pi \pi^{*}\right)_{\mathrm{Cl}}$ não pode ser alcançada devido a presença de uma alta barreira energética (compostos purínicos) ou essa estrutura está localizada em uma alta região energética (compostos pirimidínicos). A fluorescência no caso das moléculas pirimidínicas acontece pelo bloqueio da rotação da ligação $\mathrm{C}_{4}-\mathrm{C}_{5}$ e no caso das purínicas é, provavelmente, devido à um deslocamento para o vermelho na energia de absorção, que não permitiria que essas moléculas tenham a energia necessária para superar as barreiras energéticas e alcançar a região da $\mathrm{Cl}$. Portanto, o excesso de energia é lançada na região ${ }^{1}\left(\pi \pi^{*}\right)_{\min }$ como fluorescência. Efeitos de solvente não alteram o mecanismo, induzindo pequenas mudanças nas barreiras energéticas. Um esquema que sumariza os dois mecanismos é ilustrado na Figura 5.14. 


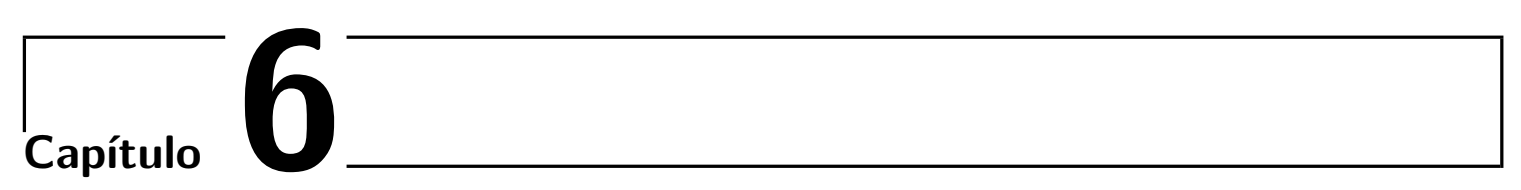

\section{Propriedades espectroscópicas da 2-aminopurina}

Nesse capítulo são investigadas as propriedades estruturais, eletrônicas e espectroscópicas da molécula 2-aminopurina (2AP) em fase gasosa e em cinco distintos solventes. Além disso, é obtido o valor de diferença de energia livre entre os dois tautômeros dessa molécula em etanol e em água.

\subsection{Introdução e motivação}

A molécula 2AP possui dois tautômeros, como pode ser visto na Figura 6.1. Essa molécula é um análogo emissivo bem conhecido da adenina (6-aminopurina) [213,226]. Enquanto a adenina apresenta um baixo rendimento quântico de fluorescência $\left(2.9 \times 10^{-4}-3.3 \times 10^{-4}\right)$, a 2AP exibe um alto rendimento quântico de 0.68 em solução aquosa, com um pico da banda de fluorescência em $3.70 \mathrm{eV}$ [227]. Existem diversos estudos teóricos dessa molécula em fase gasosa $[228,229]$. Em meios solvatados, os estudos teóricos são majoritariamente em solução aquosa $[27,226,230,231]$. Recentemente, Aboud-Zied publicou um trabalho experimental da $2 \mathrm{AP}$ medindo os espectros de absorção e fluorescência em diversos solventes, como também a influência nas propriedades espectroscópicas pela substituição do grupo amino por dimetilamino e dietilamino [232]. Além disso, Neely e colaboradores estimaram experimentalmente a concentração das espécies $7 \mathrm{H}$ e $9 \mathrm{H}$ da $2 \mathrm{AP}$ no estado excitado em água (40\% para o tautômero $7 \mathrm{H})$ e em etanol (20\% para o tautômero $7 \mathrm{H})$ [233]. Dessa maneira, a nossa intenção é fazer o estudo, do ponto de vista teórico, dos estados fundamental e excitados da 2AP em vários solventes de diversas polaridades e estimar o valor da diferença de energia livre entre os dois tautômeros da molécula $2 \mathrm{AP}$. 
<smiles>Nc1ncc2nc[nH]c2n1</smiles>

$9 \mathrm{H}$-aminopurina

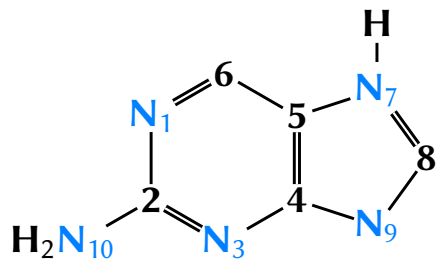

7H-aminopurina

Figura 6.1 - Estrutura química da molécula 9H-2-aminopurina (9H-2AP) e seu respectivo tautômero $7 \mathrm{H}$-2-aminopurina (7H-2AP).

\subsection{Detalhes computacionais}

A geometria molecular do estado fundamental da molécula 2AP foi otimizada no nível MP2/ANO-L-VDZP. Cálculo de frequências harmônicas revelaram nenhuma frequência imaginária, confirmando que essa geometria corresponde à um mínimo na hipersuperfície de energia potencial. A geometria do estado excitado mais baixo, que consiste de uma transição do tipo ${ }^{1}\left(\pi \pi^{*}\right)$ com uma intensidade alta, foi otimizada para ambos os tautômeros no nível MS(2)CASPT2 $(12,10) / A N O-L-V D Z P$ com um state-averaged de duas raízes (estado fundamental e o primeiro estado excitado). Esse estado excitado é derivado a partir do estado fundamental por uma excitação simples do orbital HOMO $\pi_{6}$ para o orbital LUMO $\pi_{1}^{*}$ (veja Figura 6.2). O espaço ativo empregado para otimização de geometria compreende todo o espaço $\pi$ (12 elétrons em 10 orbitais). Em todos os nossos cálculos, a correção IPEA [85] foi considerada nula e foi adotado um deslocamento imaginário [80] de 0.2 Hartree. Os cálculos das propriedades espectroscópicas foram realizadas no nível MS-CASPT2(18,13)/ANO-L-VDZP. O espaço ativo adotado para o cálculo de energias verticais é exibido na Figura 6.2.

A otimização de geometria em meio solvente foi realizada com o método ASEC-FEG $[165,166]$, com os mesmos critérios de convergência adotados para as moléculas mostradas no capítulo anterior. As simulações clássicas foram feitas com o método de Monte Carlo, com auxílio do programa DICE [171]. O protocolo adotado em cada passo de otimização consiste de uma termalização NVT de $8 \times 10^{4}$ ciclos de MC, seguidos de uma segunda termalização NPT de $12 \times 10^{4}$ ciclos de MC. A fase de produção foi realizada com um número total de $4 \times 10^{5}$ ciclos de MC. Baseado no critério da função de autocorrelação da energia [200], o intervalo de descorrelação utilizado foi de $2 \times 10^{3}$ ciclos de MC. O embedding eletrostático ASEC [160] foi composto de 200 configurações estatisticamente descorrelacionadas.

As simulações de MC atomísticas foram realizadas usando campos de forças empíricos com o potencial LJ mais Coulomb. Para a 2-aminopurina foram adotados os parâmetros LJ a partir do potencial OPLS [174] e cargas atômicas a partir do ajuste do potencial eletrostático (ESPF) [194]. Para os solventes foram empregados modelos específicos para 1,4-dioxano (DIO) [196], 


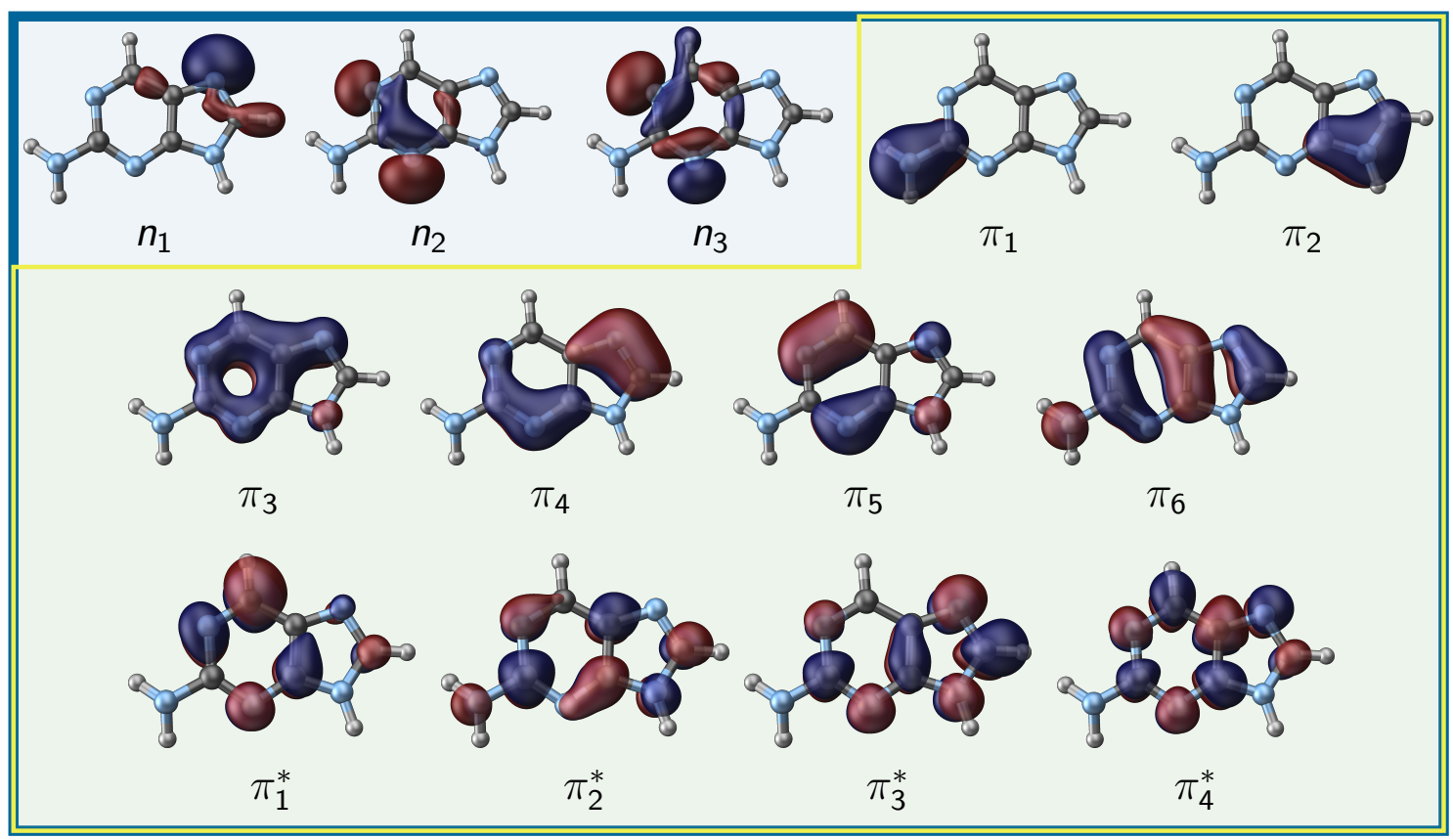

Figura 6.2 - Espaço ativo adotado para os cálculos das energias verticais da molécula 9H-2AP (fundo azul). O espaço contendo todos os orbitais $\pi$ (fundo amarelo) foi adotado para as otimizações de geometria do estado excitado mais baixo. Um espaço ativo similar para o tautômero $7 \mathrm{H}-2 \mathrm{AP}$ foi empregado.

acetonitrila (ACN) [234], etanol (ETH), metanol (MET) [235] e água (WAT) [195]. A caixa de simulação adotada garantiu uma camada mínima de solvatação de $12 \AA$. Dessa forma, o número de moléculas de solvente utilizadas foi 250 para 1,4-dioxano, 350 para acetonitrila e etanol, 500 para metanol e 1000 para água.

\subsubsection{Ciclo termodinâmico}

A diferença de energia livre em solução $\Delta G_{\text {sol }}(9 \mathrm{H} \rightarrow 7 \mathrm{H})$ entre os tautômeros foi estimada usando um hipotético ciclo termodinâmico [236], como ilustrado na Figura 6.3. Como a energia livre é uma função de estado, essa quantidade depende apenas dos pontos inicial e final. Logo, em um ciclo completo, a diferença de energia livre total é nula. Usando essa ideia para o ciclo da Figura 6.3, podemos encontrar uma expressão para o termo $\Delta G_{\text {sol }}(9 \mathrm{H} \rightarrow 7 \mathrm{H})$, que será dado por:

$$
\Delta G_{\text {sol }}(9 \mathrm{H} \rightarrow 7 \mathrm{H})=\Delta G_{\text {gas }}(9 \mathrm{H} \rightarrow 7 \mathrm{H})+\Delta \Delta G_{\text {solv }}
$$

sendo que,

$$
\begin{aligned}
\Delta G_{\text {gas }}(9 \mathrm{H} \rightarrow 7 \mathrm{H}) & =G_{\text {gas }}(7 H)-G_{\text {gas }}(9 H) \\
\Delta \Delta G_{\text {solv }} & =\Delta G_{\text {solv }}(7 H)-\Delta G_{\text {solv }}(9 H)
\end{aligned}
$$




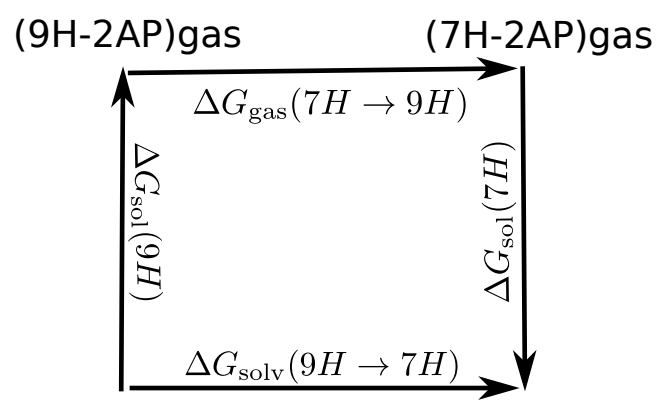

$(9 \mathrm{H}-2 \mathrm{AP})$ solv

(7H-2AP)solv

Figura 6.3 - Ciclo termodinâmico hipotético para obtenção da diferença de energia livre entre os dois tautômeros da molécula 2AP em solução.

Dessa forma, é necessário computar a diferença de energia livre em fase gasosa $\left(\Delta G_{\text {gas }}(9 \mathrm{H} \rightarrow 7 \mathrm{H})\right)$ e as respectivas energias livre de solvatação $\left(\Delta G_{\text {solv }}\right)$ da fase gasosa para o meio solvente.

\subsubsection{Energias livre de solvatação}

As energias livre de solvatação foram calculadas com o método de perturbação em energia livre (FEP) $[237,238]$, implementado nas simulação de MC. A título de comparação, as energias livre de solvatação no estado fundamental foram calculadas empregando o método PCM juntamente com o modelo United Atom for Hartree Fock (UAHF) no nível HF/6-31+G(d) [239]. O método SMD [141] também foi adotado no nível HF/6-31G devido à ser parametrizado para obter boas energias livre de solvatação.

A energia de solvatação foi obtida como o valor negativo da energia livre de aniquilação $\left(\Delta G_{\text {aniq }}\right)$, que é obtido através do processo de desaparecimento da molécula na solução [240]. Nesse processo, o estado inicial da simulação é um sistema composto de um soluto polarizável em solução e o estado final possui apenas a solução. Então, dois passos adicionais precisam ser efetuados para descrever o estado correto do soluto não-polarizado em fase gasosa na condição padrão (concentração de 1 molar). Em outras palavras, a energia de solvatação será expressa por:

$$
\Delta G_{\text {solv }}=-\Delta G_{\text {aniq }}+\Delta G_{\text {pol }}+\Delta G\left(P_{i} \rightarrow P_{f}\right)
$$

sendo que, $\Delta G_{\text {pol }}$ é a variação de energia livre devido à polarização do soluto saindo de fase gasosa para solução. $\Delta G\left(P_{i} \rightarrow P_{f}\right)$ é a diferença de energia livre vinda da variação da fase gasosa na condição padrão $\left(P_{i}=24.46 \mathrm{~atm}\right)$ para a condição de $1 \mathrm{~atm}$ na fase condensada. $O$ termo $\Delta G\left(P_{i} \rightarrow P_{f}\right)$ é constante, cujo valor é $-R T \ln (24.46)$ e pode ser derivado a partir de expressões da termodinâmica.

Uma boa aproximação é considerar apenas a parte da energia potencial na energia livre de polarização, ou seja, essa quantidade pode ser calculada via mecânica quântica. A energia livre 
de polarização pode ser calculada pela diferença da energia do soluto com a função de onda polarizada em solução $\left(\Psi_{\text {pol }}\right)$ e em vácuo $\left(\Psi_{0}\right)$, isto é:

$$
\Delta G_{\mathrm{pol}} \approx\left\langle\Psi_{\mathrm{pol}}\left|\mathcal{H}_{0}\right| \Psi_{\mathrm{pol}}\right\rangle-\left\langle\Psi_{0}\left|\mathcal{H}_{0}\right| \Psi_{0}\right\rangle
$$

visto que, $\mathcal{H}_{0}$ é o Hamiltoniano da molécula no vácuo. Dessa forma, a contribuição da interação soluto-solvente é apenas adicionada na função de onda.

Na técnica FEP é usado vários estados intermediários definidos a partir de um parâmetro de acoplamento $\lambda$ a fim de calcular a diferença de energia livre entre dois estados termodinâmicos. Dessa forma, o processo de aniquilação foi realizado em três etapas. A primeira delas consiste em levemente reduzir as cargas do soluto polarizado em solução para zero. A soma dessas contribuições corresponde ao negativo da parte eletrostática da energia livre de solvatação $\left(-\Delta G_{\text {ele }}\right)$. O segundo estágio envolve o desaparecimento do termo atrativo do potencial LJ, que condiz ao termo de van der Waals da energia livre de solvatação $\left(-\Delta G_{\mathrm{vdW}}\right)$. Por fim, a parte repulsiva do potencial LJ é removida, relacionando ao termo de cavitação da energia livre de solvatação $\left(-\Delta G_{\text {cav }}\right)$.

A interpolação linear do termo de van der Waals pode ser difícil de ser realizada pela razão de instabilidades numéricas. Isso se deve ao fato das forças repulsivas serem modeladas no caso do potencial LJ por um termo $r^{-12}$. Logo, para valores muitos pequenos de $\sigma$, podem conduzir para valores de $\Delta G$ bastante imprecisos. Para contornar esse problema, essa etapa de desaparecimento da interação de van der Waals é feita no último estágio.

Tendo em vista que otimizamos o soluto em solução, devemos considerar adicionalmente o termo de mudança estrutural. Levando em conta todas essas considerações, podemos expressar a energia livre de solvatação de uma dada espécie por:

$$
\Delta G_{\mathrm{solv}}=\Delta G_{\text {ele }}+\Delta G_{\mathrm{vdW}}+\Delta G_{\mathrm{cav}}+\Delta G_{\mathrm{pol}}+\Delta G_{\mathrm{est}}-R T \ln (24.46)
$$

A amostragem double-wide [240] foi empregada, ou seja, 1 simulação rende 2 incrementos na mudança de energia livre de Gibbs $(\Delta G)$, que corresponde a perturbamos simultaneamente para $\lambda_{i-1}$ e $\lambda_{i+1}$. A série de simulações de MC foi composta por um total de 11 simulações para fazer o soluto desaparecer lentamente a partir da solução em três processos: (i) 4 simulações com a amostragem double-wide para aniquilar o potencial coulombiano, (ii) 2 simulações com a amostragem double-wide para aniquilar o termo atrativo do potencial LJ e (iii) 5 simulações sem a amostragem double-wide para aniquilar o termo repulsivo do potencial LJ. 3 simulações independentes foram realizadas para obtenção das médias e dos desvios padrões. A energia livre de Gibbs dos tautômeros em fase gasosa foi calculada considerando a correção de ponto-zero na energia, que requer o cálculo da Hessiana. 


\subsection{Estrutura de mínimo dos estados fundamental e primeiro es- tado excitado}

A geometria do estado fundamental da molécula $9 \mathrm{H}-2 \mathrm{AP}$ possui uma estrutura plana, salvo os átomos de hidrogênio que ficam fora do plano molecular por $42^{\circ}$. Mesmo perfil é observado para o tautômero $7 \mathrm{H}-2 \mathrm{AP}$. Essas estruturas são condizentes com trabalhos teóricos anteriores [228].

Na Figura 6.4(a) são mostrados os parâmetros geométricos que sofreram mudanças perceptíveis com a inclusão do solvente para a molécula $9 \mathrm{H}-2 \mathrm{AP}$ no estado fundamental. As geometrias obtidas em DIO e em ACN são bem semelhantes à obtida em fase gasosa. Apenas a coordenada $\mathrm{N}_{7}-\mathrm{C}_{8}$ aumenta seu comprimento de acordo com a polaridade do meio. No caso das ligações $\mathrm{N}-\mathrm{H}$, o comprimento em ETH é ligeiramente maior do que em MET. A ligação $\mathrm{N}_{1}-\mathrm{C}_{2}$ apresenta um aumento de $0.008 \AA$ de gás para MET e WAT. Semelhante mudança é observada na ligação $N_{1}-C_{6}$ de gás para WAT, sendo que não foram notadas mudanças significativas para os demais solventes. $\mathrm{O}$ comprimento de ligação $\mathrm{N}_{7}-\mathrm{C}_{8}$ exibe uma elongação de 0.009 $\AA ̊$ de gás para ETH e MET. Já em WAT, esse acréscimo é de $0.013 \AA$. As ligações $\mathrm{N}-\mathrm{H}$ indicam estiramentos de gás para solvente polares próticos, no intervalo de $0.013-0.039 \AA$. Em contrapartida, a coordenada $\mathrm{C}_{8}-\mathrm{N}_{9}$ exibe uma redução em seu comprimento, com a maior mudança em MET e WAT $0.009 \AA$ A A ligação $\mathrm{C}_{2}-\mathrm{N}_{10}$ mostra uma diminuição de acordo com a polaridade do meio de GAS para MET (exceto em 1,4-dioxano), contudo em água, esse coordenada exibe comportamento oposto, com um aumento de $0.014 \AA$ em relação à fase gasosa.

O ângulo de piramidalização do grupo amino $(\alpha)$ não altera seu valor de fase gasosa para solventes polares apróticos (DIO e ACN). Para solventes polares próticos existe uma leve diminuição dessa coordenada para ETH e MET $\left(\sim 5^{\circ}\right)$. Já em água, é notado um aumento considerável de $10^{\circ}$. Esse aumento expressivo em água pode estar relacionado com às ligações de hidrogênio com a água. A 2AP também faz ligações de hidrogênio em ETH e MET, porém, na média, é bem menor em comparação com a água. Dessa forma, a mudança dessa coordenada pode estar diretamente relacionada com o número de ligações de hidrogênio que o grupo $\mathrm{NH}_{2}$ faz com o solvente.

Em fase gasosa, na região de $\mathrm{FC}$, o primeiro estado excitado $\left(S_{1}\right)$ corresponde a uma transição do tipo ${ }^{1}\left(\pi \pi^{*}\right)$, que deriva do fundamental pela substituição do orbital $\pi_{6}$ pelo $\pi_{1}^{*}$ (Figura 6.2). A força de oscilador associada à essa transição é bastante alta ( 0.1). 0 próximo estado excitado $\left(S_{2}\right)$, que está $0.31 \mathrm{eV}$ acima do $S_{1}$, é um estado escuro descrito por uma transição ${ }^{1}\left(n_{1} \pi_{1}^{*}\right)$. O estado $S_{3}$ é outro estado claro ${ }^{1}\left(\pi \pi^{*}\right)$, que é colocado $0.84 \mathrm{eV}$ acima do estado $S_{2}$. Esse estado eletrônico é descrito a partir do fundamental pela transição $\pi_{6} \rightarrow \pi_{2}^{*}$. Dessa forma, o estado $S_{1}$ é o mais provável de ser populado depois da excitação 

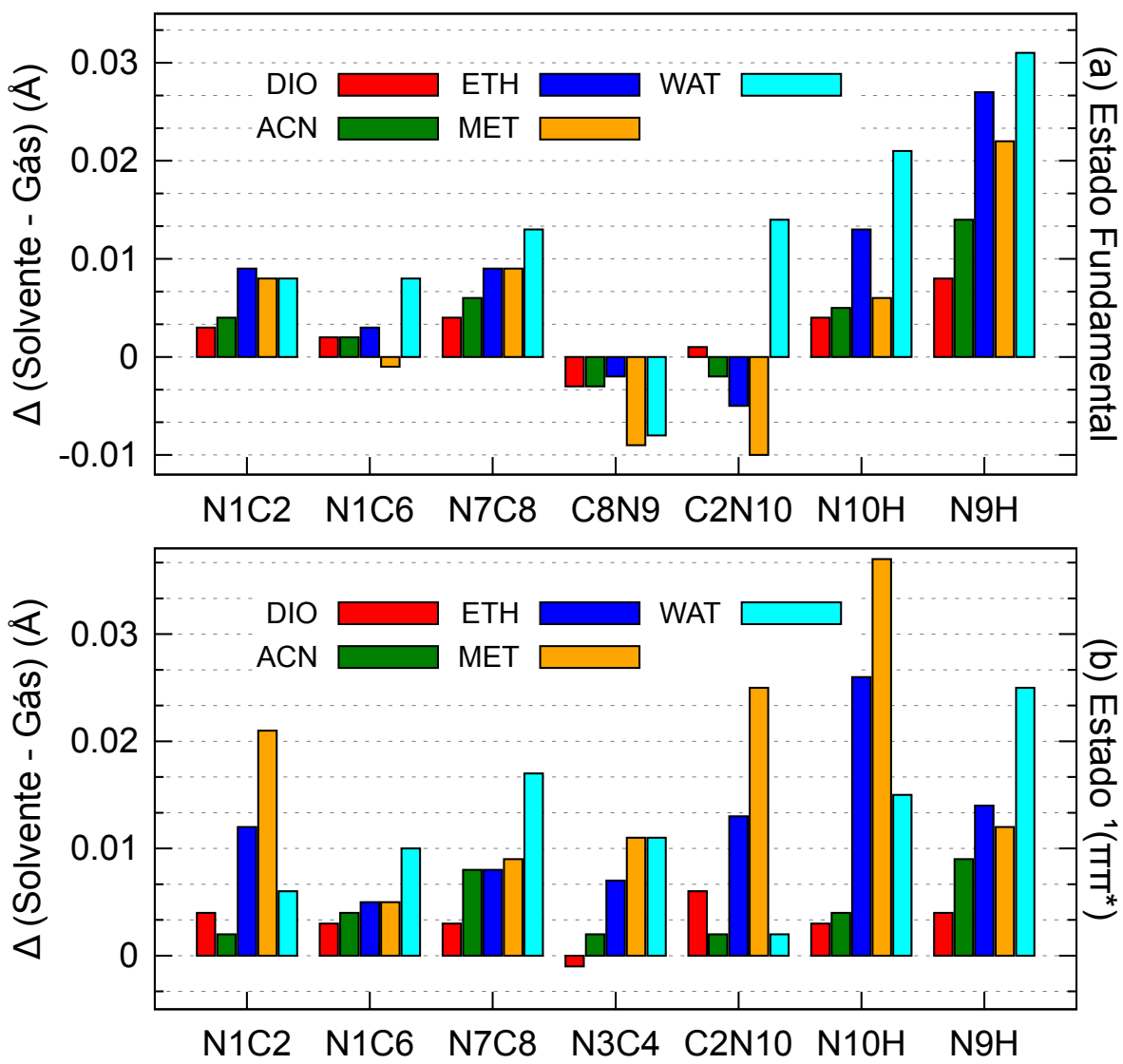

Figura 6.4 - Comprimentos de ligação $(\AA)$ para a molécula $9 \mathrm{H}$-aminopurina que foram mais susceptíveis a inclusão dos efeitos de solvente para o (a) estado fundamental e (b) primeiro estado excitado. A geometria no estado fundamental foi otimizada no nível MP2/ANO-L-VDZP, enquanto o método MS(2)-CASPT2(12,10)/ANO-L-VDZP foi empregado na otimização do primeiro estado ${ }^{1}\left(\pi \pi^{*}\right)$.

eletrônica, tendo em vista essa janela de excitação.

Tendo isso em vista, otimizamos em fase gasosa e em solvente apenas a estrutura do estado $S_{1}$. A geometria otimizada em fase gasosa é totalmente plana. Essa planarização do grupo amino pode estar associado ao fato do estado $S_{1}$ ser descrito pela transição ${ }^{1}\left(\pi_{6} \pi_{1}^{*}\right)$, e quando ocorre essa excitação, existe uma migração de densidade eletrônica do grupo amino para o restante da molécula. Em solvente, o ângulo $\alpha$ não segue uma tendência definida. Em ACN e WAT, o valor dessa coordenada se coincidem $\left(\sim 1^{\circ}\right)$ e são bem próximos do obtido em fase gasosa $\left(0^{\circ}\right)$. O ângulo de piramidalização possui maior valor em MET $\left(27^{\circ}\right)$, seguido por ETH $\left(19^{\circ}\right)$ e DIO $\left(18^{\circ}\right)$. Barbatti e Lischka utilizaram a ideia de microhidratação para levar em conta os efeitos da água para explicar o motivo da 2AP ser mais fluorescente em água. Nesse trabalho, os autores obtiveram uma geometria planar da 2AP quando otimizaram duas moléculas de água fazendo ligações de hidrogênio envolvendo o grupo amino [230].

Em termos dos comprimentos de ligação, apenas as coordenadas $N_{1}-C_{6}$ e $N_{7}-C_{8}$ aumentam 
com a polaridade do meio. Como ocorreu no estado fundamental, leves mudanças são observadas nos solventes polares apróticos (DIO e ACN), com o maior estiramento em relação à fase gasosa visto na ligação $\mathrm{N}_{9}-\mathrm{H}(0.009 \AA)$. Nas ligações $\mathrm{N}_{1}-\mathrm{C}_{2}, \mathrm{C}_{2}-\mathrm{N}_{10}$ e $\mathrm{N}_{10}-\mathrm{H}$, a maior influência do solvente é observada em metanol, sendo a alteração mais brusca de $0.037 \AA$ para o comprimento $\mathrm{N}_{10}-\mathrm{H}$. A ligação $\mathrm{N}_{9}-\mathrm{H}$ exibe o mesmo comportamento que no estado fundamental, sendo observado o maior aumento em água $(0.025 \AA)$. Já para a ligação $\mathrm{N}_{3}-\mathrm{C}_{4}$, tanto em MET quanto em WAT, é predito um mesmo valor de ligação, sendo $0.011 \AA$ maior em comparação com a fase gasosa.

\subsection{Estruturação do solvente e ligações de hidrogênios}

A Figura 6.5 exibe a $G_{\mathrm{MD}}(r)$ para a molécula 2-aminopurina nos respectivos mínimos dos estados fundamental e primeiro ${ }^{1}\left(\pi \pi^{*}\right)$ para os cinco solventes empregados. Como pode ser visto, essa função é idêntica em 1,4-dioxano para os dois estados eletrônicos, com uma nítida primeira camada de solvatação terminando em 4 Å. Até essa distância, a integração resulta em 15 moléculas de 1,4-dioxano. Uma segunda camada de solvatação também é observada, totalizando 60 moléculas de 1,4-dioxano até $8 \AA$. Em acetonitrila, existe uma boa concordância entre elas, mas o pico relacionado às ligações de hidrogênio $(\sim 2 \AA)$ é mais intenso no estado eletrônico ${ }^{1}\left(\pi \pi^{*}\right)$. Entretanto, o número de moléculas que formam a primeira e segunda camada de solvatação é exatamente o mesmo, isto é, as duas primeiras camadas de solvatação compreendem 18 e 75 moléculas de acetonitrila, respectivamente.
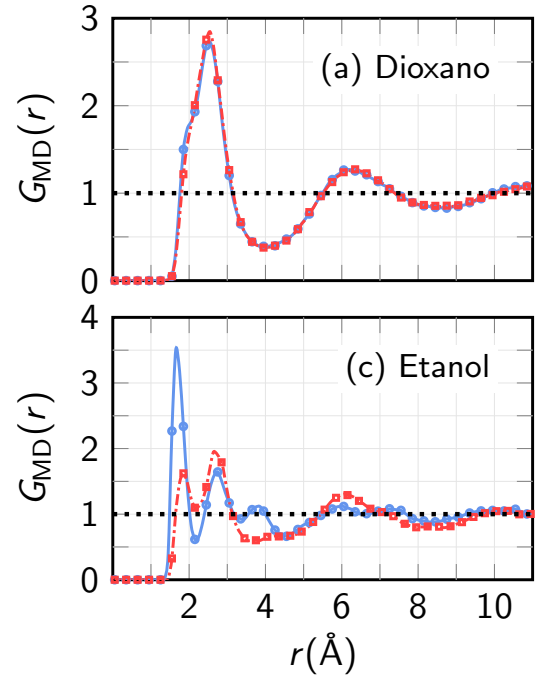
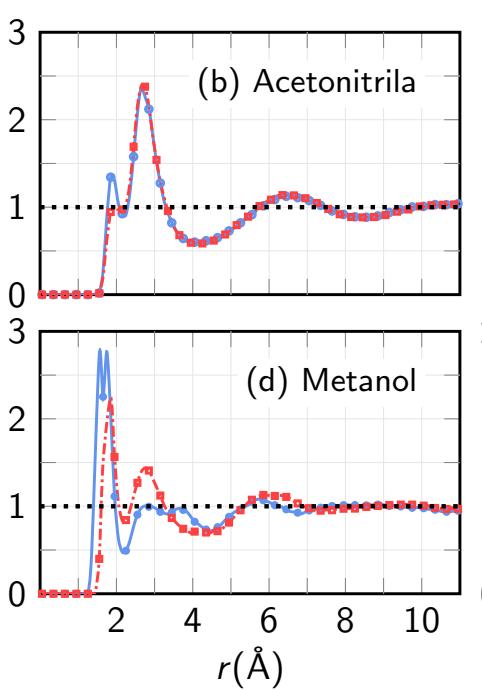
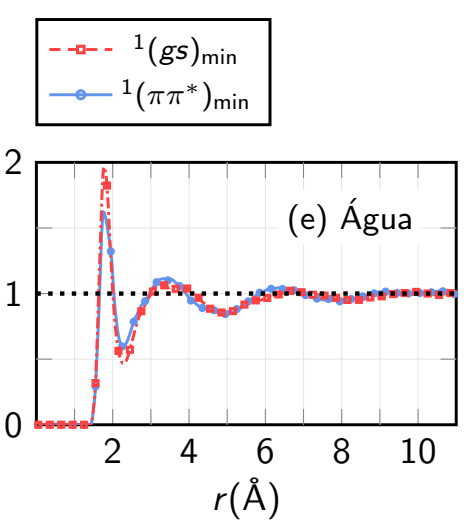

Figura 6.5 - Função distribuição de mínima distância para os estados fundamental e ${ }^{1}\left(\pi \pi^{*}\right)_{\min }$ para a 2-aminopurina em diversos solventes.

As principais distinções entre a $G_{\mathrm{MD}}(r)$ dos estados fundamental e primeiro ${ }^{1}\left(\pi \pi^{*}\right)$ são 
Tabela 6.1 - Estatística de ligação de hidrogênio por sítio e número médio total de ligações hidrogênio $(\langle L H\rangle)$ para os estados fundamental e ${ }^{1}\left(\pi \pi^{*}\right)$ em cinco solventes.

\begin{tabular}{ccccccc}
\hline Estado & & DIO & ACN & ETH & MET & WAT \\
\hline \multirow{1}{*}{$(g s)$} & $\mathrm{N}_{1} \cdots \mathrm{H}-\mathrm{O}$ & - & - & 0.93 & 0.79 & 1.58 \\
& $\mathrm{~N}_{3} \cdots \mathrm{H}-\mathrm{O}$ & - & - & 0.89 & 0.28 & 0.96 \\
& $\mathrm{~N}_{7} \cdots \mathrm{H}-\mathrm{O}$ & - & - & 1.38 & 1.48 & 2.07 \\
& $\mathrm{~N}_{9} \cdots \mathrm{H}-\mathrm{O}$ & - & - & 0.00 & 0.00 & 0.00 \\
& $\mathrm{~N}_{10} \cdots \mathrm{H}-\mathrm{O}$ & - & - & 0.02 & 0.04 & 1.00 \\
& $\mathrm{~N}_{10}-\mathrm{H}_{1} \cdots \mathrm{X}^{1}$ & 0.73 & 0.79 & 0.00 & 0.56 & 0.95 \\
& $\mathrm{~N}_{10}-\mathrm{H}_{2} \cdots \mathrm{X}$ & 0.68 & 0.80 & 1.00 & 0.81 & 0.99 \\
& $\mathrm{~N}_{9}-\mathrm{H} \cdots \mathrm{X}$ & 1.00 & 1.00 & 1.00 & 1.01 & 1.00 \\
\cline { 2 - 7 }${ }^{1}\left(\pi \pi^{*}\right)$ & $\langle L H\rangle$ & 2.41 & 2.59 & 5.22 & 4.97 & 8.55 \\
& $\mathrm{~N}_{1} \cdots \mathrm{H}-\mathrm{O}$ & - & - & 0.88 & 1.39 & 1.69 \\
& $\mathrm{~N}_{3} \cdots \mathrm{H}-\mathrm{O}$ & - & - & 0.25 & 0.04 & 1.71 \\
& $\mathrm{~N}_{7} \cdots \mathrm{H}-\mathrm{O}$ & - & - & 1.00 & 1.84 & 2.06 \\
& $\mathrm{~N}_{9} \cdots \mathrm{H}-\mathrm{O}$ & - & - & 0.00 & 0.00 & 0.00 \\
& $\mathrm{~N}_{10} \cdots \mathrm{H}-\mathrm{O}$ & - & - & 0.88 & 1.00 & 0.04 \\
& $\mathrm{~N}_{10}-\mathrm{H}_{1} \cdots \mathrm{X}$ & 0.91 & 0.94 & 1.00 & 1.00 & 0.94 \\
& $\mathrm{~N}_{10}-\mathrm{H}_{2} \cdots \mathrm{X}$ & 0.83 & 0.86 & 1.00 & 1.00 & 0.88 \\
& $\mathrm{~N}_{9}-\mathrm{H} \cdots \mathrm{X}$ & 1.00 & 0.99 & 0.99 & 0.99 & 1.00 \\
\cline { 2 - 6 } & $\langle L H\rangle$ & 2.72 & 2.79 & 6.00 & 7.26 & 8.32
\end{tabular}

${ }^{1} \mathrm{X}$ corresponde ao átomo de nitrogênio em ACN e ao átomo de oxigênio caso contrário.

observadas em etanol e metanol. Essas diferenças são perceptíveis nos picos relacionados respectivamente à microcamada de ligações de hidrogênio e a primeira camada de solvatação. Isso conduz para mudanças no número de moléculas de solvente contidas na primeira camada de solvatação, sendo que em ambos os meios há um maior número de moléculas de solvente no estado ${ }^{1}\left(\pi \pi^{*}\right)$. Além disso, analisando a $G_{\mathrm{MD}}(r)$ em etanol e metanol, vemos um surgimento de uma outra camada de solvatação no ${ }^{1}\left(\pi \pi^{*}\right)(\sim 4 \AA)$, que pode estar relacionada com alguma interação adicional que não é observada no estado fundamental. Por sua vez, em água, ambas as funções são bem semelhantes, com um ligeiro pico relativo às ligações de hidrogênio mais acentuado para o estado ${ }^{1}\left(\pi \pi^{*}\right)$. Essa leve mudança não altera o número de moléculas de água que formam a primeira camada de solvatação, cuja integração nesse pico resulta em 53 moléculas de água.

Uma última análise consiste em determinar o número de LH incluindo, além da distância associado ao primeiro mínimo da $g(r)$ entre os átomos aceitador e doador, critérios angulares e energéticos. Na Tabela 6.1 são apresentados os valores médios de LH para os estados fundamental e primeiro ${ }^{1}\left(\pi \pi^{*}\right)$ utilizando os seguintes critérios: $R_{\mathrm{NO}}=3.5 \AA, R_{\mathrm{NN}}=3.3 \AA \mathrm{e}$ $\theta=40^{\circ}$.

Nos solventes polares apróticos (1,4-dioxano e acetonitrila) existe um baixo número de LHs, 
que é menor do que 3 ligações de hidrogênios. Em ambos os solventes, o estado fundamental realiza em média um pouco menos de LH. Isso se deve, principalmente, ao grupo amino fazer menos LH no estado fundamental. Como existe uma migração de densidade eletrônica do grupo amino para o restante na molécula na excitação eletrônica para descrever o estado $S_{1}$, viabiliza que o nitrogênio $\mathrm{N}_{10}$ no estado excitado ${ }^{1}\left(\pi \pi^{*}\right)$ faça LH com o solvente. Já para os solventes polares próticos, o número de LHs é bem maior. Exceto em água, o maior número médio de LHs é visto no estado excitado ${ }^{1}\left(\pi \pi^{*}\right)$. Isso já era esperado, dado que o pico associado as LHs da $G_{\mathrm{MD}}(r)$ é mais pronunciado na estrutura ${ }^{1}\left(\pi \pi^{*}\right)$. A mesma ideia pode ser aplicada em água para explicar o motivo do estado fundamental possuir um maior número médio de $\mathrm{LH}$. No caso dos solventes etanol e metanol, o maior número de LHs no estado excitado ${ }^{1}\left(\pi \pi^{*}\right)$ é devido ao átomo de nitrogênio $\mathrm{N}_{3}$ e ao grupo amino realizarem, em média, mais LHs. Em água, o átomo de nitrogênio $N_{3}$ também faz mais $L H s$ no estado excitado ${ }^{1}\left(\pi \pi^{*}\right)$, porém o átomo de nitrogênio $\mathrm{N}_{10}$ efetua LHs apenas no estado fundamental. Essa não formação de LH acontece, provavelmente, em razão da geometria otimizada em água possuir um ângulo de piramidalização nulo. Dessa forma, o critério angular que é empregado para caracterizar uma LH não é atendido.

\subsection{Propriedades espectroscópicas}

A primeira propriedade espectroscópica computada é o espectro de absorção eletrônica. Todas as propriedades calculadas nessa seção foram calculadas utilizando a geometria otimizada para a molécula $9 \mathrm{H}-2 \mathrm{AP}$ em cada um dos solventes empregados. Na Tabela 6.2 é exibido o valor do pico do espectro de absorção obtido teoricamente nesse trabalho e comparado com outros trabalhos teóricos da literatura e também com dados experimentais. Como mencionado anteriormente, o primeiro estado excitado possui um caráter ${ }^{1}\left(\pi \pi^{*}\right)$ com uma alta força de oscilador $(\sim 0.1)$, seguido por uma transição ${ }^{1}\left(n \pi^{*}\right)$. Esse ordenamento energético em fase gasosa foi obtido previamente por Borin et al. no nível CASPT2//CASSCF [226] e por Seefeld et. al no nível MRCI//DFT [241]. Entretanto, Barbatti e Lischka, empregando o nível de teoria $A D C(2) /$ aug-cc-pVDZ, indicaram em seu trabalho que o primeiro estado excitado possui um caráter ${ }^{1}\left(n \pi^{*}\right)$ [230]. Existem vários trabalhos já propostos na literatura em outros níveis de cálculos, sendo que alguns deles predizem o $S_{1}$ como tendo um caráter majoritariamente ${ }^{1}\left(n \pi^{*}\right)$ e outros sugerem uma transição do tipo ${ }^{1}\left(\pi \pi^{*}\right)$. Ainda hoje não foi reportado nenhum dado experimental envolvendo a transição ${ }^{1}\left(n \pi^{*}\right)$, que poderia nos indicar qual seria o ordenamento energético correto. Todavia, vale salientar que esse nível de teoria é bastante acurado e, na maioria das vezes, resulta em uma correta ordem dos estados eletrônicos. Além do mais, descrevemos muito bem o pico do espectro de absorção eletrônico em fase gasosa (4.03 eV), que foi obtido experimentalmente pela técnica de jet-cooled (4.01 eV) [241].

Como podemos ver na Tabela 6.2, o desvio solvatocrômico de um solvente para outro 
Tabela 6.2 - Propriedades espectroscópicas (eV) calculadas em fase gasosa e em diversos meios solventes no nível de teoria MS(5)-CASPT2(18,13)/ANO-L-VDZP. As geometrias em solvente são as obtidas pelo procedimento de otimização de geometria ASEC-FEG. Dados experimentais [232] são incluídos para comparação.

\begin{tabular}{cccccccc}
\hline & & GAS & DIO & ACN & ETH & MET & WAT \\
\hline Absorção & Esse trabalho & 4.03 & 3.99 & 3.95 & 3.86 & 3.98 & 4.08 \\
& Borin et al. [226] & 4.07 & - & - & - & - & 4.02 \\
& Barbatti e Lischka [230] & 4.32 & - & - & - & - & 4.10 \\
& Experimental & 4.01 & 4.05 & 4.07 & 4.00 & 4.00 & 4.07 \\
Emissão & & & & & & & \\
& Esse trabalho & 3.39 & 3.26 & 3.37 & 3.24 & 3.27 & 3.20 \\
& $\quad$ Borin et al. & 3.45 & - & - & - & - & 3.35 \\
& Barbatti e Lischka & 2.99 & - & - & - & - & 3.23 \\
& Experimental & & 3.45 & 3.43 & 3.37 & 3.35 & 3.31 \\
Deslocamento & Esse trabalho & 0.64 & 0.73 & 0.58 & 0.62 & 0.71 & 0.88 \\
Stokes & Borin et al. & 0.62 & - & - & - & - & 0.67 \\
& Barbatti e Lischka & 1.33 & - & - & - & - & 0.87 \\
& Experimental & & 0.60 & 0.64 & 0.63 & 0.65 & 0.76 \\
\hline
\end{tabular}

é relativamente pequeno. Nossos resultados teóricos estão em bom acordo com os dados experimentais, com a maior diferença de $0.14 \mathrm{eV}$ obtida em etanol. Além disso, o valor de absorção concorda bem com trabalhos teóricos anteriores.

Outra propriedade calculada nesse trabalho foi a emissão eletrônica a partir do estado excitado $S_{1}{ }^{1}\left(\pi \pi^{*}\right)$ (veja Tabela 6.2). O resultado obtido em gás está em bom acordo com o valor experimental em 1,4-dioxano $(3.45 \mathrm{eV})$ e em ciclohexano (3.60 eV) [242]. Nossos resultados concordam bem com os previstos por Borin et al., com uma diferença menor que $0.1 \mathrm{eV}$. A principal diferença em relação à esse trabalho é a inclusão da correlação dinâmica na otimização de geometria. Curiosamente, os resultados obtidos por Barbatti e Lischka usando ADC(2)/aug-cc-pVDZ [230] estão bem fora dos obtidos nesse trabalho e com os reportados experimentalmente. A emissão em meio solvente é também bem descrita, com a maior discrepância menor do que $0.2 \mathrm{eV}$. A emissão experimentalmente diminui a energia com o aumento da polaridade do meio $(\mathrm{DIO} \rightarrow \mathrm{ACN} \rightarrow \mathrm{ETH} \rightarrow \mathrm{WAT})$. Excluindo o solvente 1,4-dioxano, conseguimos descrever satisfatoriamente a tendência experimental. Como discutido no capítulo anterior, pode ser que em solventes onde o fator eletrostático não seja dominante, como é o caso do solvente 1,4-dioxano, obrigatoriamente devemos adicionar os termos de dispersão e exchange. Comparando com os trabalhos teóricos em água, os nossos valores estão em conformidades com os resultados obtidos anteriormente.

Com as energias de absorção e emissão podemos estimar o deslocamento Stokes para a molécula 2AP (veja Figura 6.2). Como os nossos resultados para a absorção e emissão eletrônica se encontram em bom acordo com os dados experimentais, o deslocamento Stokes também foi 
uma propriedade espectroscópica bem descrita. Experimentalmente é observado um aumento expressivo de DIO $\rightarrow$ WAT de aproximadamente $0.16 \mathrm{eV}$. Nossos resultados teóricos apontam para um crescimento de $0.15 \mathrm{eV}$, que está em pleno acordo com o experimental. O desvio solvatocrômico no deslocamento Stokes de 1,4-dioxano para os outros solventes é pequeno e os resultados desse trabalho mostram essa mesma tendência. Em comparação com trabalhos teóricos, o deslocamento Stokes obtido nesse trabalho está em bom acordo com o obtido por Barbatti e Lischka [230]. Em contrapartida, os nossos resultados estão em torno de $0.2 \mathrm{eV}$ de diferença com o reportado por Borin e colaboradores. Nas nossas otimizações de geometria em solvente são apenas atualizados geometria e cargas atômicas do soluto, que poderia ser uma das razões para essa diferença. Além disso, vale enfatizar que no trabalho de Borin e colaboradores, a geometria do estado excitado ${ }^{1}\left(\pi \pi^{*}\right)$ não é otimizada em solução, utilizando a geometria do estado $S_{1}$ em fase gasosa no nível CASSCF/ANO-L-VDZP.

O último ponto é que alguns trabalhos experimentais recentes medem uma população de tripletos em acetonitrila, etanol e água $[243,244]$. De acordo com esses trabalhos, o estado excitado singleto ${ }^{1}\left(n \pi^{*}\right)$ seria a porta de entrada para a população dos estados tripletos. Tentamos explicar esse fenômeno baseado apenas no SOC e nas diferenças energéticas dos estados excitados. Uma conclusão mais precisa seria obtida otimizando os pontos de cruzamentos de energia. Olhando apenas para a diferença de energia entre os estados singletos e tripleto, presumimos que o caminho mais provável de popular o tripleto seria via $S_{1}\left(\pi \pi^{*}\right) \rightarrow T_{2}(n \pi)$. Em fase gasosa, a diferença entre esses estados eletrônicos é de $0.27 \mathrm{eV}$ com um SOC de 5.1 $\mathrm{cm}^{-1}$. A inclusão dos efeitos de solventes diminui essa diferença energética, ficando abaixo de $0.17 \mathrm{eV}$ para todos os solventes. Além disso, existe um leve aumento do SOC $\left(\sim 3 \mathrm{~cm}^{-1}\right)$. $\mathrm{O}$ caminho predito experimentalmente não seria viável, visto que o SOC associado com esse estado é muito baixo $\left(<2 \mathrm{~cm}^{-1}\right)$.

\subsection{Energia livre de solvatação}

As três contribuições para a energia livre de solvatação para os dois tautômeros da molécula 2AP foram calculadas usando simulações FEP-MC, como descrito em detalhes na seção de metodologia. Começando pelos resultados no estado fundamental, a Tabela 6.4 mostra os valores médios e os respectivos desvios padrões para as energias de solvatação em etanol e em água. Em conjunto são exibidos os resultados estimados com os modelos contínuos SMD e PCM/UAHF.

O termo eletrostático total da energia de solvatação em etanol foi obtido somando a parcela da polarização ao termo eletrostático, ou seja, $\Delta G_{\text {tot ele }}=\Delta G_{\text {ele }}+\Delta G_{\text {pol }}$. Em etanol obtemos o valor de $-14.9 \pm 0.8 \mathrm{kcal} / \mathrm{mol}$ para a molécula $9 \mathrm{H}-2 \mathrm{AP}$ e $-13.9 \pm 0.8 \mathrm{kcal} / \mathrm{mol}$ para o tautômero $7 \mathrm{H}-2 \mathrm{AP}$. Em solução aquosa, os valores para esse termo são relativamente 
maiores, em torno de $5 \mathrm{kcal} / \mathrm{mol}$. Comparando com os resultados via modelos PCM/UAHF e SMD em água, vemos que o modelo FEP-MC possui um $\Delta G_{\text {ele }}$ muito mais negativo. Isso significa que a metodologia ASEC-FEG polariza mais o soluto. Essa tendência já poderia ser esperada, visto que o modelo ASEC-FEG trata o solvente de forma atomística e considerada interações específicas, que são neglicenciadas nos modelos contínuos. Podemos verificar essa polarização olhando para o momento de dipolo em solução, que é muito maior com o modelo ASEC-FEG. Como esse modelo polariza mais o solvente, a energia livre de polarização também será bem maior do que nos outros métodos. Entretanto, a soma dos dois termos, que dá a energia livre de solvatação eletrostática total, resulta em um valor bastante similar em ambos os métodos aplicados. Já em etanol, acontece o oposto, com os termos $\Delta G_{\text {ele }}$ e $\Delta G_{\text {tot ele }}$ sendo mais negativos com os modelos contínuos. Ademais, o termo de polarização $\left(\Delta G_{\text {pol }}\right)$ com o FEP-MC concorda bem com os outros métodos. Em geral, os dois modelos contínuos empregados resultam em valores similares entre si em ambos os solventes tanto para o termo $\Delta G_{\text {ele }}$ quanto para a parte relacionada à polarização. Esses modelos foram parametrizados nesse nível de teoria para obtenção de energias livre de solvatação mais precisas, sendo testados em diversas moléculas e em diferentes solventes.

Analisando os resultados para o termo não-eletrostático $\Delta G_{\text {tot nao-ele, identificamos uma }}$ discrepância entre os modelos FEP-MC e contínuos. Os dois métodos QM possuem valores similares nos dois solventes. As maiores diferenças entre o FEP-MC e os modelos QM são observados no termo de cavitação, que pode diferir por mais de $10 \mathrm{kcal} / \mathrm{mol}$. Em água, o termo $\Delta G_{v d W}$ não acorda adequadamente, com diferenças da ordem de $7 \mathrm{kcal} / \mathrm{mol}$. Vale frisar que o modelo FEP-MC é altamente dependente do campo de força adotado e os parâmetros escolhidos para o potencial LJ não foram parametrizados para essa molécula. Além disso, no modelo ASEC-FEG existe apenas o refinamento da parte eletrostática, atualizando as cargas atômicas do soluto ao decorrer da simulação. Uma possível maneira de corrigir essa falha seria o refinamento dos parâmetros $\varepsilon$ e $\sigma$ ao decorrer do processo de otimização de geometria em solução.

Nossos resultados sugerem que é mais fácil solvatar a molécula $7 \mathrm{H}-2 \mathrm{AP}$ em água, visto que a energia livre de solvatação é mais negativa. Não podemos concluir isso em etanol, dado que a barra de erro contempla as duas estruturas. Um indício de qual estrutura é mais favorável a solvatação pode ser feita pela análise do momento de dipolo em fase gasosa e em solução. Para todos os ambientes, a molécula 7H-2AP apresenta sempre o menor momento de dipolo (veja Tabela 6.5). Esses argumentos são baseados no fato que em meios polares a contribuição eletrostática é dominante, facilitando a solvatação das moléculas que possuem o maior momento de dipolo. Analisando o valor relativo, vemos que a diferença da energia livre de solvatação entre os dois tautômeros é sempre menor com o método FEP-MC, com os modelos contínuos estimando um valor cerca $2.5 \mathrm{kcal} / \mathrm{mol}$ acima.

Nenhum dado experimental ou teórico na literatura foi encontrado para a energia de 
solvatação da molécula 2-aminopurina. Contudo, encontramos resultados teóricos de dinâmica molecular para o tautômero mais estável da molécula adenina, que se difere da molécula 2AP pela posição do grupo amino. Nesse trabalho é predito um energia livre de solvatação em torno de $16 \mathrm{kcal} / \mathrm{mol}$, porém os autores mencionam que o tempo de simulação foi curto para alcançar resultados convergidos para algumas perturbações termodinâmicas [245]. Mais recentemente, Jumbri e colaboradores estimaram um valor teórico de $-16.52 \pm 0.61 \mathrm{kcal} / \mathrm{mol}$ para a adenina embebida em solução aquosa utilizando o campo de força OPLS/BAR [246]. No mesmo trabalho foi obtido a energia livre de solvatação em alguns líquidos iônicos, sendo que os valores flutuam no intervalo energético entre $-22.51 \pm 0.43 \mathrm{e}-24.29 \pm 0.77 \mathrm{kcal} / \mathrm{mol}$. Todos esses resultados estão em boa concordância com os obtidos no nosso trabalho. Sabemos que a comparação não é totalmente justa, mas essa pequena modificação não deverá alterar drasticamente a energia livre de solvatação.

Esses resultados discutidos acima validam o campo de força adotado nesse trabalho para o cálculo da energia livre de solvatação. Nesse espírito, aplicamos o mesmo procedimento para o primeiro estado excitado ${ }^{1}\left(\pi \pi^{*}\right)$ (veja Tabela 6.5). Contudo, não exibimos nenhuma comparação com outros métodos, como feito para o estado fundamental. Uma maneira de se calcular as energias de solvatação para estados excitados empregando modelos contínuos seria a utilização da abordagem com TD-DFT e o método SMD, porém não efetuamos esse tipo de cálculo.

Como utilizamos os mesmos parâmetros LJ nos estados fundamental e ${ }^{1}\left(\pi \pi^{*}\right)$, as energias livre de solvatação envolvendo os termos não-eletrostático são semelhantes nos dois casos. $O$ termo de energia livre de solvatação associado à parte eletrostática é maior para a molécula $7 \mathrm{H}-2 \mathrm{AP}$, cerca de $7.9 \mathrm{kcal} / \mathrm{mol}$ em etanol e $11 \mathrm{kcal} / \mathrm{mol}$ em água. A inclusão do termo de polarização diminui essa diferença, principalmente em água. Da mesma forma observada no estado fundamental, a energia de solvatação é mais negativa para a molécula $7 \mathrm{H}-2 \mathrm{AP}$, com uma diferença relativa de $6.7 \pm 1.2 \mathrm{kcal} / \mathrm{mol}$ em etanol e $9.3 \pm 0.8 \mathrm{kcal} / \mathrm{mol}$. Isso leva a conclusão que é mais fácil solvatar o tautômero $7 \mathrm{H}-2 \mathrm{AP}$. Novamente, uma justificativa é devido ao dipolo no estado excitado ${ }^{1}\left(\pi \pi^{*}\right)$ da molécula $7 \mathrm{H}-2 \mathrm{AP}$ ser maior (veja Tabela 6.5). Em relação ao fundamental, a solvatação é mais vantajosa em etanol e menos em água.

Tabela 6.3 - Momento de Dipolo (Debye) dos dois tautômeros mais estáveis da 2AP obtido em diversos solventes para os dois primeiros estados eletrônicos.

\begin{tabular}{cccccccc}
\hline Tautômero & Estrutura & GAS & DIO & ACN & ETH & MET & WAT \\
\hline \multirow{2}{*}{$9 \mathrm{H}$} & $1(g s)_{\min }$ & 3.25 & $4.13 \pm 0.02$ & $4.72 \pm 0.04$ & $5.63 \pm 0.07$ & $5.85 \pm 0.06$ & $6.60 \pm 0.06$ \\
& $1\left(\pi \pi^{*}\right)_{\min }$ & 2.92 & $4.02 \pm 0.01$ & $4.44 \pm 0.04$ & $6.15 \pm 0.06$ & $7.30 \pm 0.06$ & $5.56 \pm 0.08$ \\
\multirow{2}{*}{$7 \mathrm{H}$} & $1(g s)_{\min }$ & 5.11 & $5.76 \pm 0.04$ & $6.59 \pm 0.05$ & $6.00 \pm 0.04$ & $7.32 \pm 0.06$ & $9.48 \pm 0.02$ \\
& $1\left(\pi \pi^{*}\right)_{\min }$ & 3.30 & - & $5.12 \pm 0.03$ & $7.30 \pm 0.03$ & $8.06 \pm 0.06$ & $7.80 \pm 0.02$ \\
\hline
\end{tabular}


Tabela 6.4 - Energias livre se solvatação $(\mathrm{kcal} / \mathrm{mol})$ no estado fundamental para os dois tautômeros da 2-aminopurina embebida em soluções de etanol e água usando a técnica FEP-MC. Entre parêntesis corresponde ao cálculo QM com HF/6-31+G(d)/PCM-UAHF e em colchetes ao valor obtido empregando o modelo contínuo SMD no nível HF/6-31G*.

\begin{tabular}{|c|c|c|c|c|c|c|}
\hline & \multicolumn{3}{|c|}{ Etanol } & \multicolumn{3}{|c|}{ Água } \\
\hline & $9 \mathrm{H}-2 \mathrm{AP}$ & $7 \mathrm{H}-2 \mathrm{AP}$ & Valor Relativo & $9 \mathrm{H}-2 \mathrm{AP}$ & $7 \mathrm{H}-2 \mathrm{AP}$ & Valor Relativo \\
\hline $\begin{array}{c}\Delta G_{\text {ele }} \\
\Delta G_{\text {pol }} \\
\Delta G_{\text {tot ele }}\end{array}$ & $\begin{array}{c}-16.5 \pm 0.8(-18.6)[-19.9] \\
1.6(2.3)[-2.6] \\
-14.9 \pm 0.8(-16.3)[-17.2]\end{array}$ & $\begin{array}{c}-17.4 \pm 0.8(-24.1)[-26.1] \\
3.5(4.1)[4.8] \\
-13.9 \pm 0.8(-20.0)[-21.3]\end{array}$ & $\begin{array}{c}0.9 \pm 1.1(5.5)[6.2] \\
-1.9(-1.8)[-2.2] \\
-1.0 \pm 1.1(3.7)[4.1]\end{array}$ & $\begin{array}{c}-32.5 \pm 0.3(-19.8)[-19.9] \\
13.4(2.5)[2.6] \\
-19.1 \pm 0.3(-17.3)[-17.2]\end{array}$ & $\begin{aligned}-38.5 & \pm 0.5(-25.8)[-27.7] \\
& 17.2(2.3)[5.3] \\
-21.3 & \pm 0.5(-21.2)[-22.4]\end{aligned}$ & $\begin{array}{c}6.0 \pm 0.6(-6.0)[-7.8] \\
-3.8(0.3)[-2.7] \\
2.2 \pm 0.6(3.9)[5.2]\end{array}$ \\
\hline $\begin{array}{c}\Delta G_{\mathrm{vdW}} \\
\Delta G_{\text {cav }} \\
\Delta G_{\text {tot nao-ele }}\end{array}$ & $\begin{array}{c}-15.1 \pm 0.1(-17.7) \\
5.0 \pm 0.3(16.1) \\
-10.1 \pm 0.3(1.6)[-2.0]\end{array}$ & $\begin{array}{c}-15.4 \pm 0.1(-17.7) \\
4.1 \pm 0.1(16.1) \\
-11.3 \pm 0.3(-1.6)[-2.0]\end{array}$ & $\begin{array}{c}0.3 \pm 0.4(0.0) \\
0.9 \pm 0.6(0.0) \\
1.2 \pm 0.5(0.0)[0.0]\end{array}$ & $\begin{array}{c}-13.1 \pm 0.1(-20.2) \\
9.4 \pm 0.4(21.1) \\
-3.7 \pm 0.4(1.0)[-2.0]\end{array}$ & $\begin{array}{c}-13.1 \pm 0.5(-20.2) \\
9.7 \pm 0.5(21.1) \\
-3.4 \pm 0.9(1.0)[-1.2]\end{array}$ & $\begin{array}{c}0.0 \pm 0.1(0.0) \\
-0.3 \pm 0.9(0.0) \\
-0.3 \pm 0.9(0.0)[-0.8]\end{array}$ \\
\hline $\begin{array}{c}\Delta G_{\text {est }} \\
\Delta G_{\text {solv }} \\
G_{\text {gas }}\end{array}$ & $\begin{array}{c}1.6 \\
-25.3 \pm 0.9(-17.9)[-19.2] \\
-293587.24\end{array}$ & $\begin{array}{c}0.7 \\
-26.4 \pm 0.9(-21.6)[-23.2] \\
-293583.34\end{array}$ & $\begin{array}{c}0.9 \\
1.2 \pm 1.3(3.7)[4.0] \\
-3.9\end{array}$ & $\begin{array}{c}2.2 \\
-22.5 \pm 0.5(-18.6)[-19.9] \\
-293584.98\end{array}$ & $\begin{array}{c}2.5 \\
-24.1 \pm 0.7(-20.3)[-23.6] \\
-293580.69\end{array}$ & $\begin{array}{c}-0.3 \\
1.6 \pm 0.9(4.0)[4.4] \\
-4.3\end{array}$ \\
\hline
\end{tabular}

Tabela 6.5 - Energias livre de solvatação $(\mathrm{kcal} / \mathrm{mol}$ ) computada empregando simulações FEP-MC para o primeiro estado excitado dos dois tautômeros da molécula 2-aminopurina em etanol e em água.

\begin{tabular}{|c|c|c|c|c|c|c|}
\hline & \multicolumn{3}{|c|}{ Etanol } & \multicolumn{3}{|c|}{ Água } \\
\hline & $9 \mathrm{H}-2 \mathrm{AP}$ & $7 \mathrm{H}-2 \mathrm{AP}$ & Valor Relativo & $9 \mathrm{H}-2 \mathrm{AP}$ & $7 \mathrm{H}-2 \mathrm{AP}$ & Valor Relativo \\
\hline$\Delta G_{\text {ele }}$ & $-14.9 \pm 0.4$ & $-22.8 \pm 0.8$ & $7.9 \pm 0.9$ & $-36.3 \pm 0.4$ & $-47.3 \pm 0.5$ & $11.0 \pm 0.5$ \\
\hline$\Delta G_{\mathrm{pol}}$ & 4.3 & 5.1 & -0.8 & 8.8 & 10.8 & -2.0 \\
\hline$\Delta G_{\text {tot ele }}$ & $-10.6 \pm 0.4$ & $-17.7 \pm 0.8$ & $7.1 \pm 0.9$ & $-27.5 \pm 0.4$ & $-36.5 \pm 0.5$ & $9.0 \pm 0.5$ \\
\hline$\Delta G_{\mathrm{vdW}}$ & $-15.2 \pm 0.4$ & $-14.9 \pm 0.4$ & $-0.3 \pm 0.6$ & $-13.0 \pm 0.1$ & $-13.1 \pm 0.1$ & $0.1 \pm 0.1$ \\
\hline$\Delta G_{\text {cav }}$ & $5.0 \pm 0.2$ & $4.8 \pm 0.2$ & $0.2 \pm 0.3$ & $9.3 \pm 0.2$ & $8.9 \pm 0.2$ & $0.4 \pm 0.3$ \\
\hline$\Delta G_{\text {tot nao-ele }}$ & $-10.2 \pm 0.4$ & $-10.1 \pm 0.4$ & $-0.1 \pm 0.6$ & $-3.7 \pm 0.2$ & $-4.2 \pm 0.2$ & $0.5 \pm 0.3$ \\
\hline$\Delta G_{\text {est }}$ & 6.9 & 7.2 & -0.3 & 6.1 & 6.3 & -0.2 \\
\hline$\Delta G_{\text {solv }}$ & $-15.8 \pm 0.6$ & $-22.5 \pm 1.0$ & $6.7 \pm 1.2$ & $-27.0 \pm 0.6$ & $-36.3 \pm 0.6$ & $9.3 \pm 0.8$ \\
\hline$G_{\text {gas }}$ & -292617.9 & -292608.9 & -9.0 & -292616.98 & -292606.40 & -10.6 \\
\hline
\end{tabular}




\subsection{Estabilidade energética}

Essa seção é dedicada a análise da estabilidade energética dos dois tautômeros da molécula 2AP em fase gasosa e em meio solvente (etanol e água). No estado fundamental em fase gasosa foi encontrado que o tautômero $9 \mathrm{H}-2 \mathrm{AP}$ é o mais estável por $3.9 \mathrm{kcal} / \mathrm{mol}$. Aplicando a equação (6.5) com os resultados da Tabela 6.5 foi possível determinar a estabilidade energética em etanol e em água. Em ambos os solventes, o tautômero 9H-2AP continua sendo o mais estável. Porém, há uma redução de estabilidade olhando para o valor absoluto. Nossos resultados indicam uma estabilidade de $2.8 \pm 1.3 \mathrm{kcal} / \mathrm{mol}$ em etanol e $2.7 \pm 0.9 \mathrm{kcal} / \mathrm{mol}$ em água.

No estado excitado podemos comparar com dados experimentais. De acordo com o experimento, existe uma população do $20 \%$ em etanol e $40 \%$ em solução aquosa para o tautômero menos estável [233]. Utilizando a relação de concentração entre espécies é possível estimar o valor da diferença de energia livre experimentalmente, $\Delta G=0.55 \mathrm{kcal} / \mathrm{mol}$ em água e $\Delta G=0.97 \mathrm{kcal} / \mathrm{mol}$. Como esses valores são pequenos, é um desafio do ponto de vista teórico conseguir capturar esse valor corretamente. Entretanto, os nossos valores teóricos utilizando simulações FEP-MC conseguem descrever razoavelmente esse valor e a tendência experimental.

Em fase gasosa, a diferença entre essas duas estruturas é da ordem de $2 \mathrm{kcal} / \mathrm{mol}$ a favor da estrutura 9H-2AP. Em solução de etanol, nossos resultados apontam uma estabilidade do tautômero $9 \mathrm{H}-2 \mathrm{AP}$ por $2.4 \pm 1.2 \mathrm{kcal} / \mathrm{mol}$. Em água existe uma diminuição da diferença de energia livre entre os dois tautômeros, seguindo a tendência experimental $(\Delta G=1.3 \pm 0.8 \mathrm{kcal} / \mathrm{mol})$. Olhando apenas para a média, vemos que existe uma boa concordância entre experimento e teoria, principalmente em água. 
capitul 7

\section{Desvendando a fotofísica da 6-selenoguanina}

Neste capítulo, apresentamos os resultados obtidos durante o estágio na Universidade de Viena, sob a supervisão da Professora Leticia González. O estudo é focado em cálculos estáticos e simulações de dinâmica não-adiabática em fase gasosa e em água de uma base modificada por átomo de selênio. O programa desenvolvido pelo grupo da Professora Leticia González é empregado na parte da dinâmica.

\subsection{Introdução e Motivação}

A estabilidade fotoquímica das bases canônicas é bastante sensível às mudanças químicas. Dentre a infinidade de novos compostos produzidos por essas simples modificações, apontamos os análogos tiobases, que vêm sendo amplamente estudados nos últimos anos. As moléculas dessa família diferem da sua respectiva nucleobase canônica pela substituição do átomo de oxigênio pelo átomo de enxofre. Descobertas experimentais revelam que essa simples modificação suprime a conversão interna para o estado fundamental e amplifica o rendimento quântico de formação de estados tripletos [41,42,247-252]. Em vista dessas verificações experimentais, um número substancial de trabalhos teóricos utilizando aproximações estáticas e/ou simulação de dinâmica não-adiabática têm sido realizados no intuito de entender como o estado tripleto de baixa energia poderia ser populado depois da absorção de luz UV [122,253-259]. Em termos de propriedades fotofísicas, as tiobases poderiam ser empregadas no campo da terapia fotodinâmica [31], atuando como fotosensibilizador. Esse tipo de composto pode também ser empregado em outras aplicações medicinais, tais como: fotoimunoterapia [32] e tratamentos de psoríase $[33,34]$, acne $[35,36]$ e herpes [37]. Para essas moléculas serem aplicadas no campo da PDT, um requerimento crucial é o alto rendimento de geração de oxigênio singleto $\left({ }^{1} \mathrm{O}_{2}\right)$. CrespoHernández e colegas reportaram experimentalmente que a molécula 6-tioguanina (6tGua) é uma possível candidata para PDT, visto que ela possui um rendimento de ${ }^{1} \mathrm{O}_{2}$ em torno de $21 \%$ [260]. Outras tio-bases são também consideradas como potenciais fotosensibilizadores, como 
por exemplo, as moléculas 2,4-ditiotimina [43], 6-tio-2-deoxyguanina [44] e 2,6-ditiopurina [45].

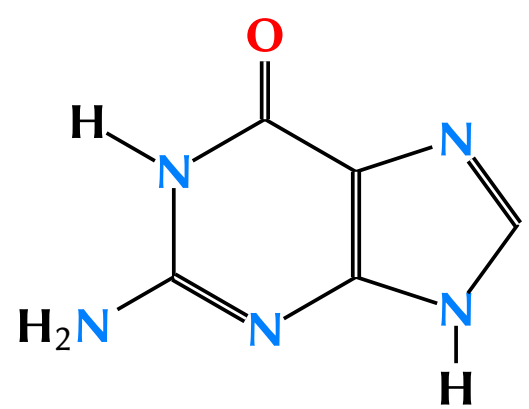

Guanina

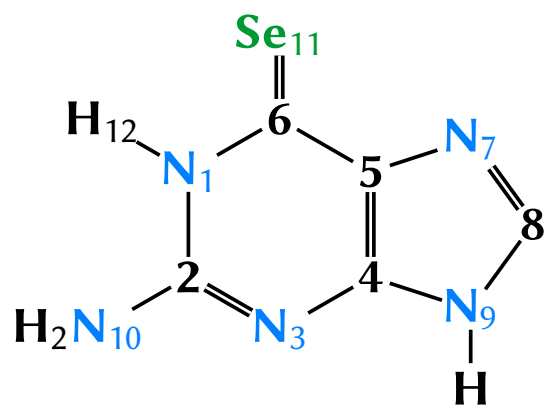

6-selenoguanina

Figura 7.1 - Estruturas esquemáticas e numeração para a guanina (lado esquerdo) e 6selenoguanina (lado direito).

Devido ao átomo de selênio pertencer à mesma família dos átomos de oxigênio e enxofre (família dos calcogênios), uma atenção experimental espontânea por nucleobases substituídas por selênio tem sido demonstrada ao longo do tempo [261-264]. Alguns trabalhos experimentais e teóricos apontam que esse tipo de substituição conduz para estruturas estáveis do RNA [265], DNA [266] e G-quadruplex [267]. Outra característica marcante é o deslocamento para o vermelho no espectro de absorção eletrônico em relação as respectivas tio-análogas [268-270].

Dentre essas modificações por átomo de selênio, destacamos a molécula 6-selenoguanina, que difere da nucleobase canônica guanina pela substituição do átomo de oxigênio do grupo carbonila na posição seis por um átomo de selênio (Figura 7.1). Recentemente, essa molécula foi estudada experimente com a técnica de espectroscopia de absorção transiente (TAS) [269]. Os resultados experimentais sugerem que depois da fotoexcitação por radiação UV, os estados tripletos da $6 \mathrm{SeGua}$ são populados mais rapidamente do que a análoga substituída por enxofre 6-tioguanina (130 fs e 350 fs, respectivamente). Não obstante, eles mediram um tempo de vida menor para os estados tripletos em comparação com a sua tio-análoga ( 1.7 ns e $1420 \mathrm{fs}$, respectivamente). Utilizando a 6tGua como modelo, neste mesmo artigo é postulado que o estado $S_{2}{ }^{1}\left(\pi \pi^{*}\right)$ fotoexcitado transfere a sua população para o estado $S_{1}{ }^{1}\left(n \pi^{*}\right)$ via intersecção cônica. O próximo evento fotoquímico é a transferência da população para os tripletos por meio de um cruzamento intersistemas com o $T_{2}{ }^{3}\left(n \pi^{*}\right)$ ou $T_{1}{ }^{3}\left(\pi \pi^{*}\right)$. Recentemente, cálculos estáticos em fase gasosa no nível de teoria MS-CASPT2 predizem dois factíveis caminhos de relaxação para popular o estado tripleto de mais baixa energia [271], indicando um ISC efetivo $S_{2} \rightarrow T_{2}$ e $S_{1} \rightarrow T_{1}$. Esses resultados com MS-CASPT2 estão em concordância com um trabalho anterior baseado em cálculos de acoplamento spin-orbíta (SOC) no nível DFT [272].

Nessa contribuição é apresentado os prováveis mecanismos de desativação dos estados excitados da molécula 6-selenoguanina, investigados pela otimização dos pontos críticos relevantes em dois níveis de teoria (ADC(2) e MS-CASPT2). Simulação de dinâmica de estados 
excitados dentro da aproximação SHARC (Surface Hopping with Arbitrary Coupling) é levando em consideração no intuito de responder as questões experimentais em aberto, que cálculos estáticos não podem ser aplicados. Os efeitos de solventes nos mecanismos de relaxação são também considerados nas nossas simulações de dinâmica não-adiabática

\subsection{Metodologia}

\subsubsection{Métodos de estrutura eletrônica e cálculos estáticos}

Os métodos de química quântica Multi-State Complete Active Space Second-Order Perturbation Theory (MS-CASPT2) [77, 78, 92, 273] e Algebraic Diagrammatic Construnction scheme for the polarization to the second order (ADC(2)) [274-276] aliado com o conjunto de funções base cc-pVDZ [189] são empregados para descrever os possíveis caminhos fotofísicos da molécula 6SeGua. Embora o método MS-CASPT2 esteja entre os melhores métodos para descrição de estados excitados, gradientes nucleares analíticos ainda não foram implementados eficientemente, inviabilizando seu uso em simulações de dinâmica de estados excitados. No intuito de superar esse problema, é utilizado o método $\operatorname{ADC}(2)$, que fornece uma eficiente implementação de gradientes nucleares analíticos e é capaz de reproduzir satisfatoriamente as mais relevantes regiões da hipersurperfície de energia potencial computada no nível MSCASPT2 $[277,278]$. Com o objetivo de validar o método $\operatorname{ADC}(2)$ nessa investigação, todas as otimizações de geometrias são realizadas em ambos os métodos de química quântica (ADC(2) e MS-CASPT2).

Alguns testes realizados incluindo efeitos relativísticos via o formalismo de Douglas-KrollHess [279] e o conjunto de bases atômica ANO-RCC-VDZP [280] revelam que o espectro de absorção eletrônico não altera significativamente em comparação com o valor estimado sem correção relativística e a com a base atômica cc-pVDZ (Anexo B). Baseado nesses resultados, o conjunto de funções bases cc-pVDZ é o mais factível, dado que demanda um tempo computacional menor do que empregando a base ANO-RCC.

Para os cálculos MS-CASPT2, o espaço ativo é selecionado baseado no número de ocupação médio, que nos permite excluir alguns orbitais $\pi$ e o lone-pair associado aos átomos de nitrogênios, cujo número de ocupação é próximo de dois. As integrais de dois elétrons foram computadas empregando a técnica RICD [281], que permite a aceleração dos cálculos. Diversas estruturas de mínimo em hipersurfícies de energia potencial de diferentes estados eletrônicos singletos e tripletos são otimizados numericamente no nível MS-CASPT2/cc-pVDZ, com um espaço ativo composto por nove orbitais $\pi, \pi^{*}$ mais o orbital $n$ localizado no átomo de selênio (CAS(12,10)). Em cada estrutura otimizada, as energias de excitação vertical são recalculadas acrescentando no espaço ativo de otimização os orbitais $\sigma$ e $\sigma^{*}$ situados na ligação $\mathrm{C}$-Se, 
resultando no espaço ativo CAS(14,12) (veja Figura 7.2). Um imaginary level shift [83] de 0.2 u.a é utilizado para lidar com problema de estados intrusos. Como sugerido na literatura [88], nenhuma correção IPEA [85] é adotada. Os cálculos MS-CASPT2 são realizados com a suíte OpenMolcas [282, 283].

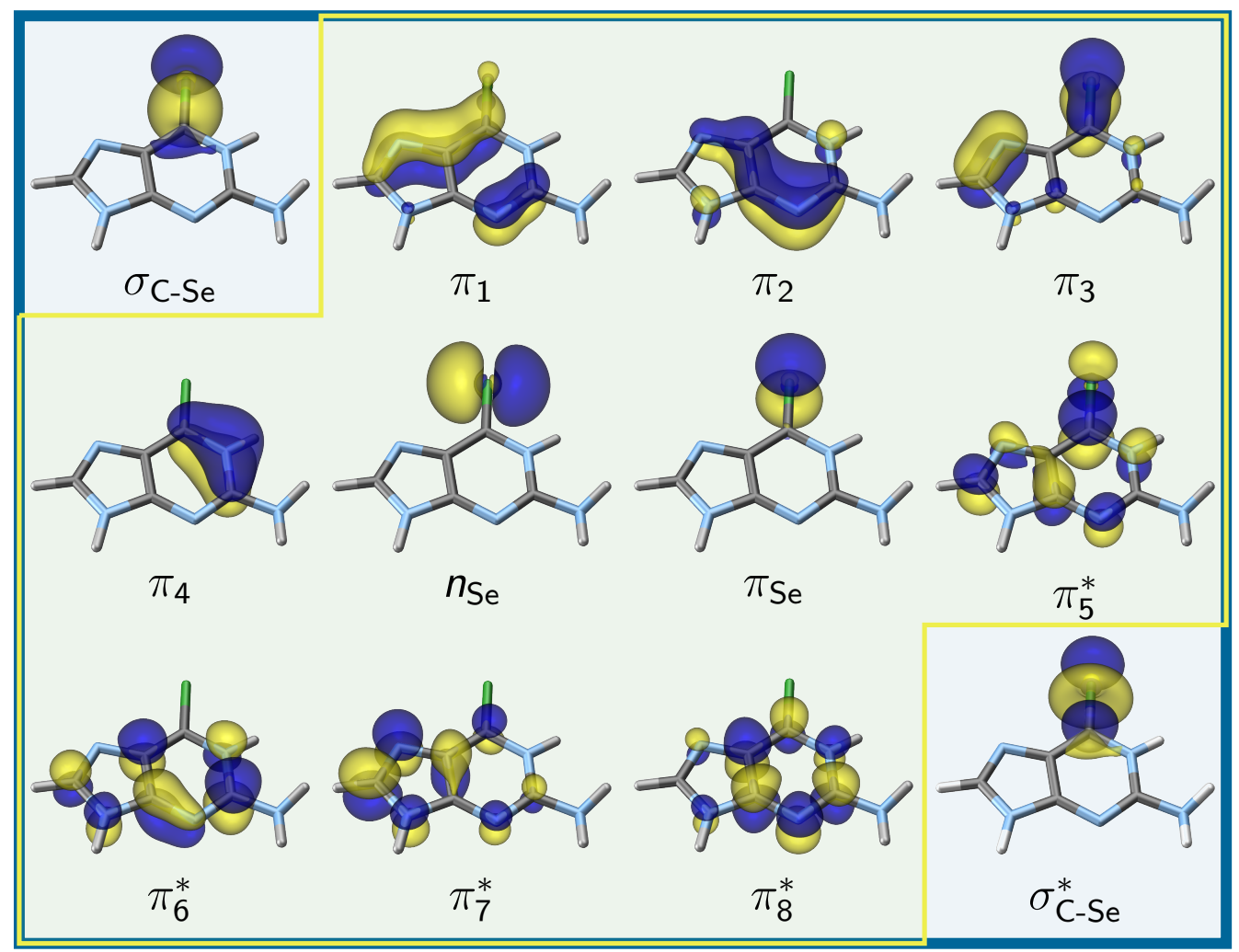

Figura 7.2 - Espaços ativos adotados durante os cálculos MS-CASPT2/cc-pVDZ. Os orbitais moleculares com fundo amarelo são utilizados para as otimizações de geometria (CAS $(12,10))$ e com fundo azul para os cálculos de energias de excitação verticais $(\operatorname{CAS}(14,12))$.

Como mencionado acima, a aplicabilidade do método $\mathrm{ADC}(2)$ para realização de dinâmica não-adiabática é validada repetindo todos os cálculos nesse nível de teoria e comparando os perfis energéticos e estruturais com os obtidos previamente calculados no nível MS-CASPT2. Portanto, as mais importantes estruturas de mínimo são reotimizados analiticamente através da aproximação resolution of identity no nível ADC(2)/cc-pVDZ, como implementando no software Turbomole 7.0 [284], que torna o procedimento muito mais rápido do que as otimizações numéricas no nível MS-CASPT2.

Além de mínimos, diversos pontos de cruzamento de energia mínima (MECPs) relacionados às intersecções cônicas $(\mathrm{Cl})$ ou cruzamento intersistemas entre estados singletos e tripletos (ISC) são encontrados nos níveis MS-CASPT2 e ADC(2). Nesses casos, as estruturas correspondem aos ISC's são otimizadas seguindo o algoritmo desenvolvido por Beapark, Robb e Schlegel [285] e as Cl's são otimizadas utilizando o procedimento de função penalidade proposto por Levine, 
Coe e Martínez [286]. As otimizações dos MECPs são realizadas através do otimizador externo do ORCA 4.0.1 [287] com os corretos gradientes nucleares. As estruturas mais relevantes são conectadas por interpolações lineares em coordenadas internas (LIIC) na finalidade de checar a existência de possíveis barreiras energéticas ao decorrer da varredura.

\subsubsection{Efeitos de solvente}

Os efeitos de solventes são incorporados por meio de uma dinâmica molecular clássica como implementado no programa AMBER18 [288]. As cargas atômicas do soluto são obtidas fitando o potencial eletrostático de acordo com o procedimento RESP (Restrained Electrostatic Potential) [289] no nível B3LYP/cc-pVDZ. Interações intramoleculares e intermoleculares do soluto (exceto os parâmetros associados com o átomo de selênio) são modelados através do campo AMBER generalizado (GAFF) [290,291]. Os parâmetros do campo de força para o átomo de selênio são retirados a partir da parametrização da molécula 2-selenouridina embebida em solução aquosa [292].

Como as versões recentes do programa de dinâmica não-adiabática não possui condições periódicas de contorno implementadas, a caixa de simulação deve ser grande o suficiente para evitar qualquer tipo de problema com efeitos de bordas. Com isso em mente, a molécula 6SeGua foi colocada em uma caixa de simulação octaédrica truncada de $12 \AA$ de aresta contendo 5406 moléculas de água representadas pelo modelo de água flexível (FWSPC) [293]. Nenhum tipo de restrição é aplicada e um passo temporal de 0.5 fs é adotado. Primeiramente, o sistema é minimizado mediante o algoritmo steepest descent, seguido por um estágio de aquecimento de 100 ps no ensemble NVT, escalonando a temperatura a partir de $0 \mathrm{~K}$ para $300 \mathrm{~K}$. Uma equilibração do sistema é feita por 1 ns no ensemble NPT em condições normais ( $T=300 \mathrm{~K}$ e $P=1$ bar) usando o termostato de Langevin. Finalmente, um estágio de produção é feito por $10 \mathrm{~ns}$, selecionando uma configuração a cada $20 \mathrm{ps}$.

Depois disso, decidimos rodar uma dinâmica QM/MM relativamente curta no estado fundamental em cada snapshot salvo durante a dinâmica molecular clássica. Essas dinâmicas QM/MM têm a proposta de amostrar adequadamente graus de liberdade relacionados aos comprimentos de ligação e ângulo, apesar dos ângulos torcionais não terem tempo suficiente para relaxar para seus respectivos mínimos. Contudo, acreditamos que a dinâmica molecular clássica descreve corretamente esses diedrais. Portanto, o impacto da escolha do campo de força é minimizado e um melhor ajuste das distâncias de ligação e ângulos são alcançados, principalmente os parâmetros associados com o átomo de selênio.

As simulações QM/MM são realizadas com o programa SHARC2.1 (Surface Hopping Including Arbitrary Couplings) [131-133], com a região QM descrita no nível ADC(2)/cc-pVDZ. A região $Q M$ abrange a molécula $6 \mathrm{SeGua,} \mathrm{enquanto} \mathrm{que} \mathrm{as} \mathrm{moléculas} \mathrm{de} \mathrm{água} \mathrm{permanecem}$ 


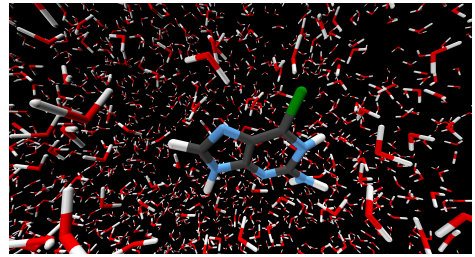

MM (Fundamental)

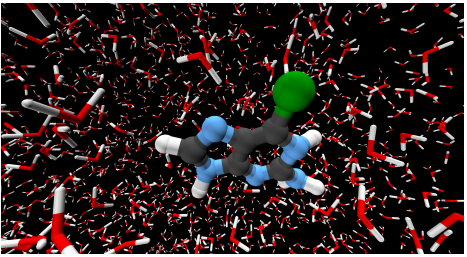

$\mathrm{QM} / \mathrm{MM}$ (Fundamental)

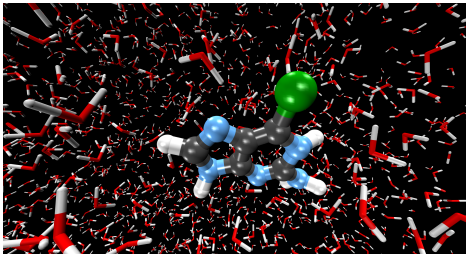

$\mathrm{QM} / \mathrm{MM}$ (Excitado)

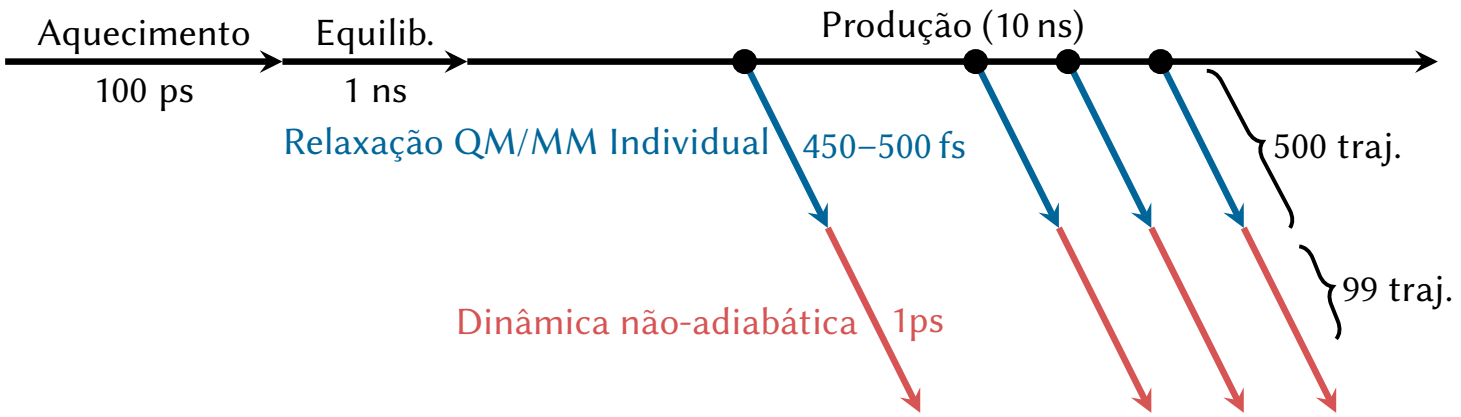

Figura 7.3 - Procedimento esquemático para geração das condições iniciais para a dinâmica de estados excitados. O primeiro passo consiste de uma dinâmica molecular clássica, na qual é salva um total de 500 snapshots no regime de produção. Em seguida, é realizado uma dinâmica $\mathrm{QM} / \mathrm{MM}$ para os estados fundamental e excitado. Condições iniciais para a dinâmica de estados excitados são selecionadas considerando uma janela de excitação.

sendo tratadas classicamente. As coordenadas e velocidades do sistema para cada configuração são transformadas no formato lido pelo programa SHARC, significando que as coordenadas dos átomos devem ser reescritas. Isso se deve ao programa AMBER propagar essas quantidades no tempo usando o algoritmo leapfrog, ou seja, as velocidades são atrasadas por um tempo de $\Delta t / 2$. Por sua vez, o programa SHARC evolui essas grandezas no tempo baseado no algoritmo velocity Verlet, isto é, as posições e velocidades são entregadas no mesmo tempo. Essa conversão de formato é discutida em detalhes no trabalho de Mai e colaboradores [294]. O tempo total da dinâmica $\mathrm{QM} / \mathrm{MM}$ é determinado randomicamente entre o intervalo de 450 e $500 \mathrm{fs}$, a fim de evitar qualquer tipo de bias devido ao movimento coerente de todas as trajetórias pela troca de um campo de força clássico para um esquema QM/MM. Na Figura 7.3 é ilustrado o procedimento adotado nesse trabalho.

\subsection{Dinâmica não-adiabática}

Simulações de dinâmica não-adiabática são realizadas com o método SHARC (Surface Hopping Including Arbitrary Couplings) [131-133], uma extensão da aproximação surface hopping proposta por Tully [120] incluindo outros tipos de acoplamentos, como por exemplo, cruzamento intersistemas e interação com laser. 
As condições iniciais para as simulações de dinâmica não-adiabática são obtidas pela amostragem de possíveis configurações do líquido a partir de simulações de dinâmica QM/MM. Ao todo são selecionadas 500 configurações e em cada uma delas são realizados cálculos de energias de excitação verticais e forças de oscilador para uma quantidade de 15 estados singletos e 14 estados tripletos no nível ADC(2)/cc-pVDZ. O espectro de absorção da 6SeGua em água é simulado a partir desses cálculos, utilizando uma soma sobre funções Gaussianas de largura $0.25 \mathrm{eV}$ centradas nas energias de excitação verticais com o peso proporcional à força de oscilador.

Os estados excitados iniciais são selecionados estocasticamente na janela de excitação $3.95-4.05 \mathrm{eV}$ (306 - $314 \mathrm{~nm}$, cobrindo o intervalo experimental proposto por Farell et al. [269]) baseado na força de oscilador [136], implicando que estados eletrônicos mais brilhantes são mais prováveis de serem acessados como estado inicial. Na tentativa de reduzir o custo computacional e evitar problemas de convergência de estados eletrônicos mais altos, apenas 3 estados singletos $\left(S_{0}, S_{1}\right.$ e $\left.S_{2}\right)$ e 3 estados tripletos $\left(T_{1}, T_{2}\right.$ e $\left.T_{3}\right)$ são considerados nas simulações de dinâmica não-adiabática. Por padrão, o programa SHARC propaga a dinâmica na representação diagonal, acarretando uma função de onda que é escrita como uma combinação linear de 12 estados (3 singletos e $3 \times 3$ tripletos), pois as componentes do spin na direção $z$ (autovalores: $-1,0 \mathrm{e}$ 1) são tratadas separadamente. Cada trajetória é propagada separadamente por $1 \mathrm{ps}$, com um passo de tempo nuclear de $0.5 \mathrm{fs}$. As funções de onda eletrônica são evoluídas no tempo usando o procedimento de diabatização local [110] com um passo temporal de 0.02 fs. Superposições da função de onda são empregadas para computar os acoplamentos não-adiabáticos como implementado no programa WFOVERLAP [109] e uma correção de decoerência [295] baseada na energia com um parâmetro de 0.1 u.a. é aplicada.

\subsection{Energias de excitação vertical}

As energias de excitação vertical estimadas para a molécula 6SeGua são apresentadas na Tabela 7.1 para diferentes níveis de teoria. Todos os métodos predizem um estado excitado mais baixo ${ }^{1}\left(n_{\mathrm{Se}} \pi_{5}^{*}\right)$, com valores similares obtidos nos níveis $\operatorname{ADC}(2)(2.76 \mathrm{eV}), \mathrm{MS}-\mathrm{CASPT} 2(14,12)$ $(2.76 \mathrm{eV})$ e MS-CASPT2(12,10) $(2.83 \mathrm{eV})$, enquanto que o método TD-B3LYP indica uma energia um pouco mais alta $(3.1 \mathrm{eV})$. Esse estado eletrônico deriva do estado fundamental por uma excitação eletrônica simples a partir do lone-pair localizado no átomo de selênio $\left(n_{\mathrm{Se}}\right)$ para o orbital anti-ligante $\pi_{5}^{*}$. Essa transição é similar ao estado ${ }^{1}\left(n_{\mathrm{Se}} \pi_{2}^{*}\right)$ obtida para a molécula 2-seleno-uracila (2SeUra) [268], embora é computada ser por volta de $0.5 \mathrm{eV}$ mais alta em energia no nível MS-CASPT2. Da mesma forma que na molécula 2SeUra, o estado

eletrônico $S_{1}{ }^{1}\left(n_{\mathrm{Se}} \pi_{5}^{*}\right)$ é considerado como um estado escuro e não possui contribuição para o espectro de absorção eletrônico. 
Tabela 7.1 - Energias de excitação vertical (eV) para a molécula 6SeGua calculadas nos métodos de química quântica MS(4,3)-CASPT2(12,10)/cc-pVDZ, MS(4,3)CASPT2 $(14,12) / c c-p V D Z$, and ADC(2)/cc-pVDZ. Em parênteses é reportado a força de oscilador correspondente à transição eletrônica.

\begin{tabular}{cccccc}
\hline Natureza & TD-B3LYP [272] & MS-CASPT2 $(12,10)$ & MS-CASPT2 $(14,12)$ & ADC(2) & Exp [269] \\
\hline $1\left(n_{S e} \pi_{5}^{*}\right)$ & $3.1(0.000)$ & $2.83(0.000)$ & $2.76(0.000)$ & $2.76(0.000)$ & \\
${ }^{1}\left(\pi_{S e} \pi_{5}^{*}\right)$ & $3.6(0.460)$ & $3.73(0.360)$ & $3.45(0.472)$ & $3.61(0.404)$ & 3.47 \\
${ }^{1}\left(\pi_{S e} \pi_{6}^{*}\right)$ & - & $4.64(0.047)$ & $4.34(0.054)$ & $4.64(0.042)$ & \\
${ }^{3}\left(\pi_{S e} \pi_{5}^{*}\right)$ & 2.5 & 2.46 & 2.43 & 2.55 & \\
${ }^{3}\left(n_{S e} \pi_{5}^{*}\right)$ & 2.9 & 2.74 & 2.67 & 2.63 & \\
\hline
\end{tabular}

O segundo estado excitado singleto na região de Franck-Condon é o estado $S_{2}{ }^{1}\left(\pi_{\mathrm{Se}} \pi_{5}^{*}\right)$, cujo valor previsto no nível MS-CASPT2 $(14,12)$ é $3.45 \mathrm{eV}$ em relação ao estado fundamental, em acordo com o dado experimental de $3.47 \mathrm{eV}$ medido por Farell e colegas [269]. Com o espaço ativo menor, o método MS-CASPT2 $(12,9)(3.73 \mathrm{eV})$ concorda bem com os outros métodos (ADC(2) (3.61 eV) e TD-B3LYP (3.60 eV)). Vemos aqui que a inclusão dos orbitais $\sigma$ e $\sigma^{*}$ no espaço ativo é de suma importância para obtenção de um bom acordo com o dado experimental, sendo uma possível razão o fato dessa transição eletrônica ser a partir do orbital $p_{z}$ do selênio para o restante da molécula. Em todos os casos, a correspondente transição $\pi_{\mathrm{Se}} \rightarrow \pi_{5}^{*}$ é associada com a maior força de oscilador $(f)$. Portanto, o estado $S_{2}{ }^{1}\left(\pi_{\mathrm{Se}} \pi_{5}^{*}\right)$ é considerado um estado claro. Novamente, o estado $S_{2}$ da molécula 2SeUra é também descrito por uma excitação eletrônica do tipo $\pi_{\mathrm{Se}} \rightarrow \pi^{*}$, sendo posicionada $3.98 \mathrm{eV}$ acima do estado fundamental e com a maior força de oscilador nesse intervalo de energia.

O próximo estado excitado singleto $\left(S_{3}\right)$, que possui uma função de onda representada por uma excitação simples $\pi_{\mathrm{Se}} \rightarrow \pi_{6}^{*}$ a partir do fundamental, é colocado em torno de $4.64 \mathrm{eV}$ acima do estado fundamental nos níveis MS-CASPT2(12,10) e ADC(2), e 4.34 eV no nível MS-CASPT2 $(14,12)$. Em todos os casos, a força de oscilador associado à essa transição é pequena $(\sim 0.05)$. Como esse estado está em uma região energeticamente mais alta e possui uma menor intensidade do que a transição eletrônica do estado fundamental para o $S_{2}$, a contribuição do estado $S_{3}$ para a primeira banda de absorção pode ser negligenciada. O estado correspondente à molécula $2 \mathrm{SeU}$ ra possui a mesma natureza eletrônica [268], e também é situado quase na mesma região energética em relação ao estado fundamental. Além disso, a intensidade dessa transição é fraca.

Como mostrado na Tabela 7.1 e discutido acima, os três estados excitados mais baixos da molécula 6SeGua são derivados com base no estado fundamental por excitações eletrônicas a partir dos orbitais no átomo de selênio. Estados excitados derivados com base em excitações delocalizadas nos átomos de nitrogênio ou no anel aparecem em uma região bem mais energética ( $4.9 \mathrm{eV})$ e, consequentemente, não participam dos eventos fotofísicos.

Na região de $\mathrm{FC}$, os dois estados excitados tripletos mais baixos são ${ }^{3}\left(\pi_{\mathrm{Se}} \pi_{5}^{*}\right)\left(T_{1}\right)$ e ${ }^{3}\left(n_{\mathrm{Se}} \pi_{5}^{*}\right)$ 
$\left(T_{2}\right)$. É importante salientar que todos os níveis de teoria indicam que os estados tripletos situam-se na mesma região energética $\left(T_{1}: 2.4-2.6 \mathrm{eV} ; T_{2}: 2.6-2.9 \mathrm{eV}\right)$. Os estados $T_{1}$ e $T_{2}$ são também excitações a partir dos orbitais do selênio. Como observado para os estados singletos, excitações a partir de outros orbitais surgem em regiões mais energéticas $(\sim 3.8 \mathrm{eV})$, que nos permite focar nos dois estados tripletos mais baixos. O mesmo padrão é observado para a molécula 2SeUra [268].

Nesse ponto é importante comparar a performance dos três níveis de teoria em descrever os estados excitados mais baixos da molécula 6SeGua. Como mostrado na Tabela 7.1, a ordem energética dos estados é a mesma. As energias relativas na região de FrankCondon estão em um razoável acordo: $\mathrm{O}$ estado $S_{2}$ é $\sim 0.9 \mathrm{eV}$ acima do estado $S_{1}$ com os métodos MS-CASPT2(12,10)/cc-pVDZ e ADC(2)/cc-pVDZ, sendo mais estabilizado no nível MS-CASPT2 $(14,12) / c c-p V D Z$. O estado $S_{3}$ é computado ser em volta de $0.9-1.0 \mathrm{eV}$ acima do estado $S_{2}$ nos três casos. O estado $T_{2}$ é colocado um pouco mais perto do estado $T_{1}(0.08 \mathrm{eV})$ no nível $\mathrm{ADC}(2) / \mathrm{cc}-\mathrm{pVDZ}$, enquanto que essa lacuna é maior no nível MS-CASPT2 $(0.28-0.24 \mathrm{eV})$. Dessa maneira, concluímos que os métodos ADC(2)/ccpVDZ e MS-CASPT2 $(12,10) / c c-p V D Z$ são suficientemente acurados em relação ao nível MS-CASPT2 $(14,10)$.

\subsection{Estruturas de mínimo e pontos de cruzamentos}

As otimizações dos pontos críticos, que englobam estruturas de mínimo e pontos de cruzamentos de energia mínima, são realizadas nos níveis MS-CASPT2(12,10) e ADC(2), com o auxílio do conjunto de funções base cc-pVDZ. Para os cálculos MS-CASPT2, um total de 4 singletos e 3 tripletos são considerados no procedimento de otimização de geometria. Como o programa OpenMOLCAS não lida com estados singletos e tripletos simultaneamente, um procedimento state-averaged para cada multiplicidade é efetuado separadamente. As estruturas otimizadas são ilustradas na Figura 7.4 e os parâmetros conformacionais mais relevantes e energias relativas são incluídas nas Tabelas 7.2 e 7.3. A classificação de Cremer-Pople $(Q$, amplitude) [220] e Boyens [221] é empregada para descrever as prováveis deformações do anel de seis membros, tais como: envelope (E), boat (B), screw-boat (S), twist-boat (T) e assim por diante. $\mathrm{O}$ índice nos símbolos representa qual átomo se move a partir do plane do anel.

A geometria do estado fundamental é praticamente planar em ambos os métodos, com os átomos de hidrogênio do grupo amino saindo fora do plano purina por $48^{\circ} \mathrm{em}$ ambos os níveis. A distância de ligação $C$-Se otimizada possui comprimento por volta de $1.82 \AA$, sendo mais estirada do que ligações típicas $\mathrm{C}=\mathrm{S}$ e $\mathrm{C}=\mathrm{O}$. Além disso, o valor estimado dessa ligação é similar ao computado anteriormente no nível MS-CASPT2 (1.821 $\AA$ ) [271] e mais curta do que a prevista com o método DFT (1.839 Å) [272]. 


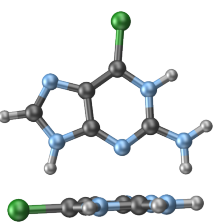

(a) planar

$\left(T_{2}\right)_{\min }^{\left(S_{0}\right)_{\min }}(\mathrm{ADC} 2)$

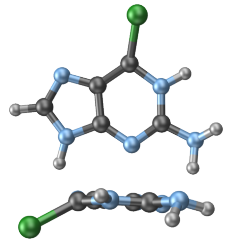

(b) $C_{6}$-pyramid

$\left(T_{1}\right)_{\min }(\mathrm{PT} 2)$

$\left(S_{2}\right)_{\min }$

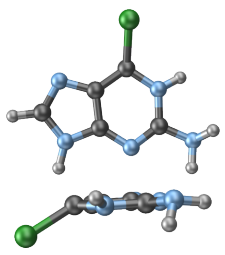

(c) $C_{6}, N_{1}$-pyramid

$\left(T_{2}\right)_{\min }(\mathrm{PT} 2)$

$\left(T_{1}\right)_{\min }(\mathrm{ADC} 2)$

$\left(T_{1} / T_{2}\right)_{\mathrm{Cl}}(\mathrm{ADC} 2)$ $\left(S_{1} / T_{2}\right)$ ISC

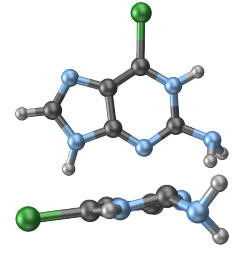

(c) $C_{2}$-envelope

$\left(S_{2} / S_{1}\right)_{\mathrm{Cl}}$

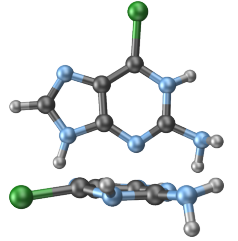

(d) $C_{6}, N_{1}$-pyramid

$\left(T_{1} / T 2\right)_{\mathrm{Cl}}(\mathrm{PT} 2)$

$\left(S_{1}\right)_{\min }$

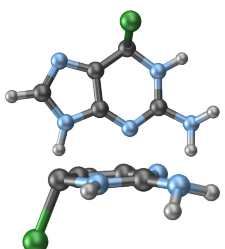

(e) $C_{6}$-perpendic $\left(S_{0} / T_{1}\right)$ ISC

Figura 7.4 - Estruturas de mínimo e cruzamentos de energia mínima em fase gasosa para a molécula 6SeGua computada nos níveis ADC(2)/cc-pVDZ e MS-CASPT2(12,10)/ccpVDZ. As geometrias são agrupadas de acordo com os parâmetros de Cremer-Pople e Boyens. Os índices ADC2 e PT2 indicam que um ponto crítico otimizado é rotulado em uma classificação de Boyens distinta pela mudança no nível de mecânica quântica.

Tabela 7.2 - Energias relativas $(\mathrm{eV})$ à estrutura do estado fundamental, comprimentos de ligações $(\AA)$, ângulo $\left(^{\circ}\right)$, parâmetros de Cremer-Pople [220] e classificação de Boyens [221] para os mínimos otimizados da molécula 6SeGua nos níveis MSCASPT2 $(12,10) /$ cc-pVDZ and ADC(2)/cc-pVDZ.

\begin{tabular}{|c|c|c|c|c|c|c|c|c|c|c|}
\hline \multirow{2}{*}{ Parâmetros } & \multicolumn{2}{|c|}{$\left(\mathrm{S}_{0}\right)_{\min }$} & \multicolumn{2}{|c|}{$\left(\mathrm{S}_{1}\right)_{\min }$} & \multicolumn{2}{|c|}{$\left(\mathrm{S}_{2}\right)_{\min }$} & \multicolumn{2}{|c|}{$\left(T_{1}\right)_{\min }$} & \multicolumn{2}{|c|}{$\left(T_{2}\right)_{\min }$} \\
\hline & PT2 & $\mathrm{ADC2}$ & PT2 & ADC2 & PT2 & $\mathrm{ADC} 2$ & PT2 & ADC2 & PT2 & ADC2 \\
\hline E & 0.0 & 0.0 & 2.45 & 2.50 & 3.03 & 2.95 & 2.25 & 2.30 & 2.38 & 2.44 \\
\hline$r\left(\mathrm{~N}_{1} \mathrm{C}_{2}\right)$ & 1.373 & 1.374 & 1.376 & 1.386 & 1.363 & 1.367 & 1.349 & 1.377 & 1.376 & 1.382 \\
\hline$r\left(\mathrm{C}_{2} \mathrm{~N}_{3}\right)$ & 1.319 & 1.319 & 1.327 & 1.310 & 1.332 & 1.326 & 1.343 & 1.316 & 1.319 & 1.315 \\
\hline$r\left(\mathrm{~N}_{3} \mathrm{C}_{4}\right)$ & 1.372 & 1.364 & 1.376 & 1.385 & 1.352 & 1.363 & 1.364 & 1.381 & 1.380 & 1.385 \\
\hline$r\left(\mathrm{C}_{4} \mathrm{C}_{5}\right)$ & 1.407 & 1.409 & 1.408 & 1.400 & 1.423 & 1.420 & 1.423 & 1.402 & 1.404 & 1.401 \\
\hline$r\left(\mathrm{C}_{5} \mathrm{C}_{6}\right)$ & 1.430 & 1.435 & 1.421 & 1.430 & 1.426 & 1.430 & 1.434 & 1.444 & 1.431 & 1.422 \\
\hline$r\left(\mathrm{~N}_{1} \mathrm{C}_{6}\right)$ & 1.416 & 1.405 & 1.432 & 1.430 & 1.409 & 1.420 & 1.442 & 1.433 & 1.429 & 1.428 \\
\hline$r\left(\mathrm{C}_{2} \mathrm{~N}_{10}\right)$ & 1.385 & 1.389 & 1.368 & 1.399 & 1.384 & 1.391 & 1.389 & 1.398 & 1.396 & 1.372 \\
\hline$r\left(\mathrm{C}_{2} \mathrm{Se}_{11}\right)$ & 1.820 & 1.793 & 1.922 & 1.914 & 2.073 & 1.997 & 1.920 & 1.911 & 1.932 & 1.906 \\
\hline$p\left(\mathrm{Se}_{11} \mathrm{C}_{2} \mathrm{~N}_{1} \mathrm{C}_{5}\right)$ & 1.0 & 0.5 & 27.3 & 24.2 & 49.2 & 42.2 & 37.7 & 34.0 & 31.8 & 0.0 \\
\hline$p\left(\mathrm{H}_{12} \mathrm{~N}_{1} \mathrm{C}_{2} \mathrm{C}_{6}\right)$ & 7.0 & 2.5 & 18.5 & 25.5 & 5.7 & 3.3 & 1.4 & 17.3 & 18.9 & 0.0 \\
\hline$Q$ & 0.00 & 0.00 & 0.09 & 0.06 & 0.02 & 0.06 & 0.07 & 0.04 & 0.04 & 0.00 \\
\hline Boyens & - & - & ${ }^{1} H_{6}$ & ${ }^{1} H_{6}$ & ${ }^{5} H_{6}$ & $E_{6}$ & $E_{6}$ & ${ }^{1} H_{6}$ & ${ }^{5} H_{6}$ & - \\
\hline
\end{tabular}

O primeiro estado excitado singleto $S_{1}{ }^{1}\left(n_{\mathrm{Se}} \pi_{5}^{*}\right)$ possui um mínimo localizado adiabaticamente $2.5 \mathrm{eV}$ acima da região de Frank-Condon. Nenhum cruzamento com outro estado eletrônico é detectado ao longo do procedimento de otimização. Em ambos os métodos, a estrutura otimizada é classificada no mesmo grupo de Boyens $\left({ }^{1} H_{6}\right)$, significando que as mudanças notáveis em relação à estrutura do estado fundamental são visíveis na piramidalização dos átomos de selênio (MS-CASPT2: $6.7^{\circ}$ e ADC(2): 24.2 ${ }^{\circ}$ ) e $\mathrm{H}_{12}$ (MS-CASPT2: $18.5^{\circ}$ e ADC(2): $25.5^{\circ}$ ). Ademais, uma elongação $\sim 0.1 \AA$ no comprimento de ligação $\mathrm{C}=$ Se é observada em relação à estrutura otimizada do estado fundamental. 
Tabela 7.3 - Energias relativas $(\mathrm{eV})$ à estrutura do estado fundamental, comprimentos de ligações $(\AA)$, ângulo $\left(^{\circ}\right)$, parâmetros de Cremer-Pople [220] e classificação de Boyens [221] para os pontos de cruzamento de energia mínima da molécula 6SeGua nos níveis MS-CASPT2(12,10)/cc-pVDZ and ADC(2)/cc-pVDZ.

\begin{tabular}{|c|c|c|c|c|c|c|c|c|}
\hline \multirow{2}{*}{ Parâmetros } & \multicolumn{2}{|c|}{$\left(\mathrm{S}_{1} / \mathrm{S}_{2}\right)_{\mathrm{CI}}$} & \multicolumn{2}{|c|}{$\left(\mathrm{S}_{1} / \mathrm{T}_{2}\right)_{\mathrm{ISC}}$} & \multicolumn{2}{|c|}{$\left(\mathrm{T}_{1} / \mathrm{T}_{2}\right)_{\mathrm{CI}}$} & \multicolumn{2}{|c|}{$\left(\mathrm{S}_{0} / \mathrm{T}_{1}\right)_{\mathrm{CI}}$} \\
\hline & PT2 & ADC2 & PT2 & ADC2 & PT2 & ADC2 & PT2 & ADC2 \\
\hline$E$ & 3.20 & 3.17 & 2.46 & 2.63 & 2.50 & 2.3 & 2.43 & 2.52 \\
\hline$r\left(\mathrm{~N}_{1} \mathrm{C}_{2}\right)$ & 1.442 & 1.433 & 1.386 & 1.392 & 1.383 & 1.368 & 1.348 & 1.363 \\
\hline$r\left(\mathrm{C}_{2} \mathrm{~N}_{3}\right)$ & 1.407 & 1.446 & 1.308 & 1.308 & 1.301 & 1.321 & 1.343 & 1.329 \\
\hline$r\left(\mathrm{~N}_{3} \mathrm{C}_{4}\right)$ & 1.303 & 1.290 & 1.388 & 1.387 & 1.381 & 1.375 & 1.348 & 1.365 \\
\hline$r\left(\mathrm{C}_{4} \mathrm{C}_{5}\right)$ & 1.449 & 1.488 & 1.398 & 1.399 & 1.393 & 1.409 & 1.432 & 1.418 \\
\hline$r\left(\mathrm{C}_{5} \mathrm{C}_{6}\right)$ & 1.380 & 1.372 & 1.431 & 1.427 & 1.421 & 1.443 & 1.465 & 1.468 \\
\hline$r\left(\mathrm{~N}_{1} \mathrm{C}_{6}\right)$ & 1.356 & 1.364 & 1.428 & 1.430 & 1.427 & 1.435 & 1.450 & 1.448 \\
\hline$r\left(\mathrm{C}_{2} \mathrm{~N}_{10}\right)$ & 1.427 & 1.429 & 1.398 & 1.399 & 1.413 & 1.397 & 1.376 & 1.390 \\
\hline$r\left(\mathrm{C}_{2} \mathrm{Se}_{11}\right)$ & 1.908 & 1.889 & 1.934 & 1.915 & 1.915 & 1.912 & 1.955 & 1.917 \\
\hline$p\left(\mathrm{Se}_{11} \mathrm{C}_{2} \mathrm{~N}_{1} \mathrm{C}_{5}\right)$ & 0.8 & 2.2 & 28.2 & 21.6 & 19.1 & 34.8 & 59.5 & 55.5 \\
\hline$p\left(\mathrm{H}_{12} \mathrm{~N}_{1} \mathrm{C}_{2} \mathrm{C}_{6}\right)$ & 11.7 & 3.4 & 22.6 & 29.4 & 32.5 & 9.6 & 0.4 & 2.3 \\
\hline $\mathrm{Q}[\AA]$ & 0.16 & 0.15 & 0.04 & 0.06 & 0.110 & 0.03 & 0.07 & 0.10 \\
\hline Boyens & ${ }^{2} E$ & ${ }^{2,5} B$ & ${ }^{1} H_{6}$ & ${ }^{1} \mathrm{H}_{6}$ & ${ }^{1} H_{6}$ & ${ }^{5} \mathrm{H}_{6}$ & $E_{6}$ & ${ }^{1} S_{6}$ \\
\hline
\end{tabular}

O mínimo do estado $S_{2}{ }^{1}\left(\pi_{\mathrm{Se}} \pi_{5}^{*}\right)$ é colocado adiabaticamente em torno de $3.0 \mathrm{eV}$ acima do estado fundamental em ambos os níveis de teoria. É importante mencionar que na região ${ }^{1}\left(\pi_{\mathrm{Se}} \pi_{5}^{*}\right)_{\min }$, o estado ${ }^{1}\left(\pi_{\mathrm{Se}} \pi_{5}^{*}\right)$ é ainda o estado excitado $S_{2}$. A diferença mais marcante é o estiramento da ligação $C=\operatorname{Se}(\sim 0.2 \AA)$ e a piramidalização do átomo de selênio por quase $50^{\circ}$ no nível MS-CASPT2 $\left(42^{\circ}\right.$ no nível ADC(2)). Apenas um mínimo é identificado na hipersuperfície de energia potencial do estado $S_{2}$, ao contrário da molécula 2SeUra, que é predito ter dois mínimos de acordo com o método MS-CASPT2.

A geometria molecular do mínimo do estado tripleto $T_{1}{ }^{3}\left(\pi_{\mathrm{Se}} \pi_{5}^{*}\right)$ exibe um anel de seis membros planar com uma larga piramidalização do átomo de selênio $\left(\sim 38^{\circ}\right)$. O método ADC(2) também resulta em um anel planar, mas com piramidalizações nos átomos de selênio $\left(\sim 34^{\circ}\right)$ e $\mathrm{H}_{12}\left(\sim 17^{\circ}\right)$. Em um estudo teórico recente da molécula 6tGua é reportado dois mínimos na hipersuperfície de energia potencial do estado $T_{1}$, que não é visto na molécula 6SeGua. A ausência desse segundo mínimo no estado excitado $T_{1}^{3}\left(\pi_{\mathrm{Se}} \pi_{5}^{*}\right)$ pode ser uma das razões para explicar o menor tempo de vida do estado tripleto em comparação ao que foi medido para a $6 \mathrm{tGua}$. A existência de um segundo mínimo no estado excitado $T_{1}$ da molécula 6tGua poderia ser responsável por prender a população no estado tripleto, consequentemente, amplificando o correspondente tempo de vida dos estados tripletos.

No nível MS-CASPT2/cc-pVDZ, o mínimo do estado $T_{2}{ }^{3}\left(n_{\mathrm{Se}} \pi_{5}^{*}\right)$ fica $0.65 \mathrm{eV}$ mais baixo em energia do que a estrutura ${ }^{1}\left(\pi_{\mathrm{Se}} \pi_{5}^{*}\right)$. Com o método $\mathrm{ADC}(2)$, é predito ser $0.51 \mathrm{eV}$ mais baixo em energia do que a estrutura ${ }^{1}\left(\pi_{\mathrm{Se}} \pi_{5}^{*}\right)$. A estrutura ${ }^{3}\left(n_{\mathrm{Se}} \pi_{5}^{*}\right)$ é caracterizada por um anel de seis membros planar, mas o átomo de selênio sai do plano em torno de $32^{\circ}$ no nível MS-CASPT2. A geometria otimizada no nível ADC(2), contudo, exibe uma conformação planar. 
Como será detalhado na próxima seção, a estrutura ${ }^{3}\left(n_{\mathrm{Se}} \pi_{5}^{*}\right)$ otimizada no nível $\mathrm{ADC}(2)$ não corresponde a um verdadeiro mínimo. Em relação à estrutura otimizada do estado fundamental, o comprimento de ligação $\mathrm{C}=\mathrm{Se}$ é por volta de $0.3 \AA$ maior.

Além de mínimos, os pontos de cruzamento de energias mínimas (MECP) crucias para explicar os possíveis canais fotofísicos são também otimizados em ambos os níveis de teoria. A busca por um MECP entre os estados $S_{1}$ e $S_{2}$ indica que na verdade essa estrutura corresponde à uma região com três estados degenerados, compreendendo os estados eletrônicos $S_{1}, S_{2}$ e $T_{2}$. Apesar disso, decidimos chamar essa estrutura de $\left(S_{1} / S_{2}\right)_{\mathrm{Cl}}$. É importante deixar claro que não procuramos por uma estrutura de degenerescência tripla. Em ambos os níveis de química quântica, a estrutura $\left(S_{1} / S_{2}\right)$ cl é assinalada como um envelope na posição $\mathrm{C}_{2}\left(E_{2}\right)$, com os átomos de hidrogênio do grupo amino quase perpendiculares ao plano molecular.

Uma intersecção cônica entre os dois estados tripletos mais baixos é também otimizada. Em ambos os níveis, a estrutura otimizada é descrita por uma piramidalização do átomo de selênio (MS-CASPT2: $19^{\circ}$ e $\mathrm{ADC}(2)$ : $35^{\circ}$ ). Dois cruzamentos intersistemas também foram otimizados, que consistem da intersecção entre os estados $S_{1}$ e $T_{2}\left(\left(S_{1} / T_{2}\right)\right.$ ISC $)$ e entre os estados fundamental e tripleto mais baixo $\left(\left(T_{1} / S_{0}\right)\right.$ ISC $)$. A estrutura $\left(S_{1} / T_{2}\right)$ ISC é semelhante à geometria do mínimo do $S_{1}$, enquanto que a estrutura $\left(T_{1} / S_{0}\right)$ ISC apresenta o maior ângulo de piramidalização entre todas as geometrias otimizadas.

\subsection{Caminhos de desativação fotofísicos}

Os eventos fotoquímicos relevantes são investigados inicialmente por meio de interpolações lineares em coordenadas internas (LIIC). No intuito de validar os resultados com o método ADC(2), a varredura com a aproximação LIIC é efetuada em ambos os níveis de cálculo.

A Figura 7.5 retrata a evolução dos estados eletrônicos $S_{0}, S_{1}, S_{2}, T_{1}$ e $T_{2}$ ao longo do caminho fotoquímico predito pela aproximação LIIC entre diferentes regiões da hipersuperfície de energia potencial de cada estado, computadas nos níveis de teoria ADC(2)/cc-pVDZ (painel (a)) e MS-CASPT2 $(14,12) / /$ MS-CASPT2 $(12,10) /$ cc-pVDZ (painel (b)). Para uma melhor discussão, os caminhos são divididos em três principais regiões: PATH I, PATH II e PATH III.

O PATH I (Figura 7.5) conecta as regiões de Franck-Condon (FC) e $S_{2}{ }^{1}\left(\pi_{\mathrm{Se}} \pi_{5}^{*}\right)$. Como é visto, o estado $S_{2}$ evolui a partir da região de $\mathrm{FC}$ em direção ao mínimo desse estado sem a presença de nenhuma barreira energética. Cálculos de caminho de menor energia (MEP) começando a partir do segundo estado eletrônico na região FC calculado no nível MS $(4,3)$ CASPT2(14,12)//SA(4)-CASSCF(12,10)/cc-pVDZ revelam o mesmo perfil como mostrado na Figura S1 (Anexo C). O próximo passo descrito pelo PATH I é o caminho a partir do $\left(S_{2}\right)_{\min }$ para a região $\left(S_{1} / S_{2}\right)_{\mathrm{Cl}}$, sendo que a barreira energética é estimada ser $0.41 \mathrm{eV}(11.7 \mathrm{kcal} / \mathrm{mol})$ no nível MS-CASPT2. O método ADC(2) prediz uma barreira energética mais alta (0.62 eV; 

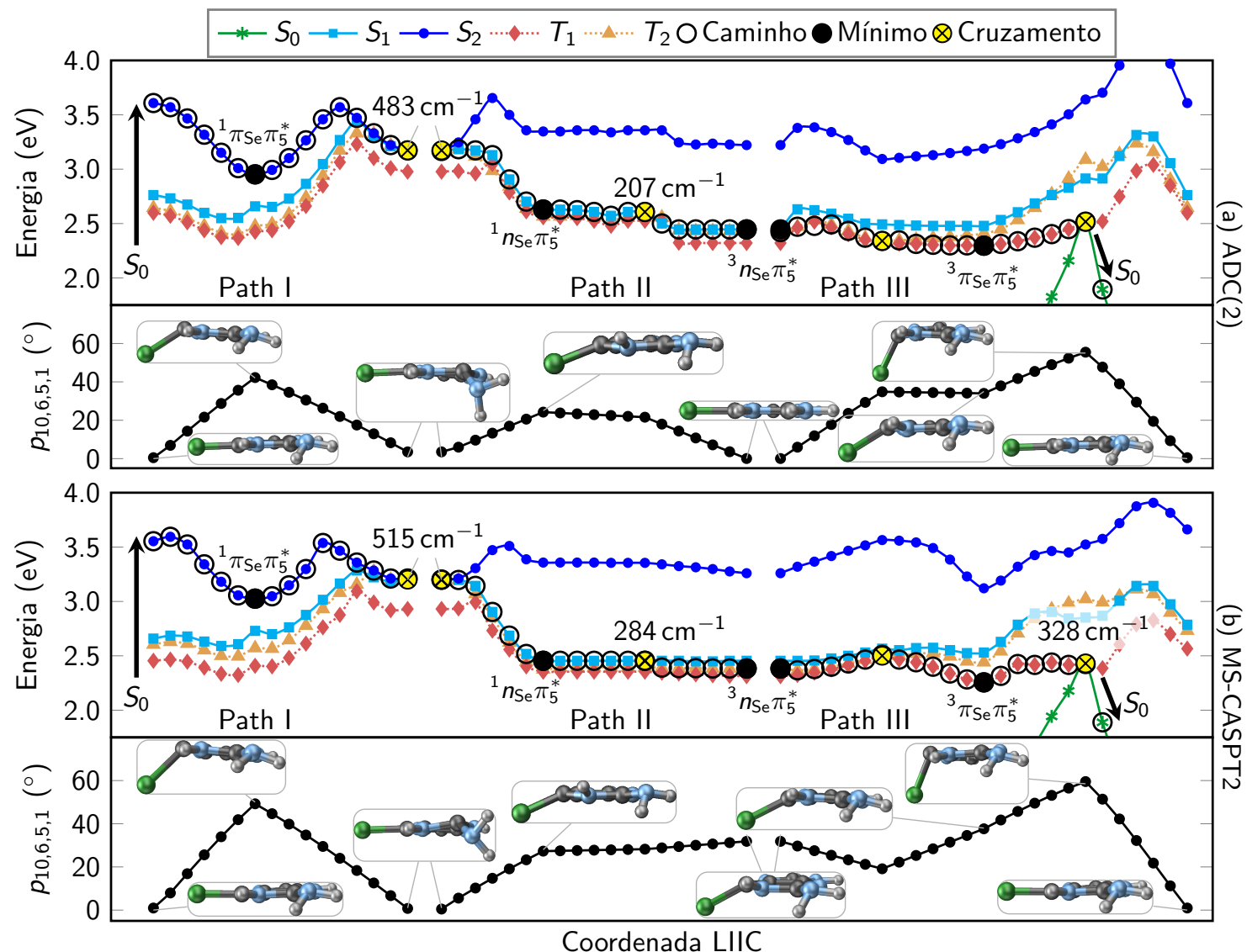

Figura 7.5 - Interpolações lineares em coordenadas internas conectando geometrias de mínimo e pontos de cruzamento de energia mínima computadas nos níveis (a) ADC(2)/ccpVDZ e (b)MS-CASPT2(14,12)//MS-CASPT2(12,10)/cc-pVDZ. Os caminhos de relaxação são indicados com círculos pretos abertos, mínimos com círculos pretos e pontos de cruzamento com $\mathrm{X}$. As setas pretas mostram a excitação vertical a partir da região de FC para o segunto estado excitado singleto. SOCs entre pontos de cruzamentos relacionado ao ISC são exibidos em $\mathrm{cm}^{-1}$.

$14.2 \mathrm{kcal} / \mathrm{mol}$ ). Em um trabalho recente, Cui e colaboradores estimaram uma barreira $\sim 10.2$ $\mathrm{kcal} / \mathrm{mol}$ utilizando o método MS-CASPT2 [271]. O acoplamento spin-orbita nessa geometria é extremamente alto (MS-CASPT2: $515 \mathrm{~cm}^{-1}$ e ADC(2): $483 \mathrm{~cm}^{-1}$ ). Nesse ponto, a população pode ser transferida para o estado $S_{1}$ através de uma intersecção cônica ou para o estado tripleto $T_{2}$ via cruzamento intersistemas singleto-tripleto. Embora a intersecção cônica seja um mecanismo de transferência de população mais eficiente, o canal fotoquímico provável pode ser determinado por meio de dinâmica não-adiabática, como será discutido nas próximas sessões.

O próximo passo fotoquímico, PATH II, conecta o ponto de degenerescência energética tripla $\left(\left(S_{1} / S_{2}\right)_{\mathrm{Cl}}\right)$ e a estrutura $\left(S_{1}\right)_{\text {min. }}$ Esse mínimo é alcançado a partir da região $\left(S_{1} / S_{2}\right)_{\mathrm{Cl}}$ dissipando uma energia de $0.75 \mathrm{eV}$ e $0.67 \mathrm{eV}$ com os métodos MS-CASPT2 e ADC(2), respectivamente. Na vizinhança desse mínimo, o estado tripleto pode ser facilmente acessado por um cruzamento entre os estados $S_{1}$ e $T_{2}\left(\left(S_{1} / T_{2}\right)\right.$ ISC $\left.)\right)$. Esse ponto de cruzamento está um 
pouco acima em energia em comparação com $\left(S_{1}\right)_{\min }(0.01 \mathrm{eV}$ com MS-CASPT2 e $0.13 \mathrm{eV}$ com $A D C(2))$. Ambos métodos predizem um menor SOC nessa região em relação ao ponto de cruzamento $\left(S_{1} / S_{2}\right) \mathrm{cl}\left(284 \mathrm{~cm}^{-1}\right.$ e $207 \mathrm{~cm}^{-1}$ com os métodos MS-CASPT2 e ADC(2), respectivamente). A partir dessa região, o sistema pode seguir em direção ao mínimo do estado $T_{2}$.

O último caminho (PATH III) começa na região $\left(T_{2}\right)_{\min }$ e o sistema pode seguir em direção à uma região de intersecção cônica com o estado $T_{1}$. É importante notar que o método MSCASPT2 coloca a intersecção cônica $\left(T_{1} / T_{2}\right)_{\mathrm{Cl}} 0.07 \mathrm{eV}$ adiabaticamente acima da estrutura $\left(T_{2}\right)_{\min }$, mas com o método $\mathrm{ADC}(2)$, essa $\mathrm{Cl}$ é $-0.08 \mathrm{eV}$ adiabaticamente abaixo da estrutura $\left(T_{2}\right)_{\min }$. Esse resultado pode ser entendido lembrando que a formulação do método ADC(2) é baseado em um único determinante de Slater, consequentemente, isso poderia conduzir para inconsistências nas regiões em que o caráter multiconfiguracional é significante. Por fim, o sistema segue para o mínimo do estado $T_{1}$ lançando uma energia de $0.03 \mathrm{eV}$ e $0.24 \mathrm{eV}$ com os método $A D C(2)$ e MS-CASPT2, respectivamente.

Com o passar do tempo, o sistema retorna para o estado fundamental via um cruzamento intersistema $\left(\left(\left(T_{1} / S_{0}\right)_{\text {ISC }}\right)\right)$. De acordo o método MS-CASPT2, esse ISC é localizado $0.17 \mathrm{eV}$ adiabaticamente acima do mínimo do estado $T_{1}$. O método $A D C(2)$ é bastante preciso para descrever esse ISC (0.27 eV acima da estrutura $\left.\left.\left(T_{1}\right)_{\min }\right)\right)$, mesmo os SOCs entre o $S_{0}$ e o estados tripletos não estarem disponíveis na versão atual do programa Turbomole. Contudo, um preciso $S_{0} / T_{1}$ não é sempre garantido, como mostrado em um recente trabalho da molécula 2SeUra [268]. O SOC nessa região é menor do que na região $\left(S_{1} / S_{2}\right)_{\mathrm{Cl}}$, embora ainda seja considerado alto $\left(328 \mathrm{~cm}^{-1}\right)$.

\subsection{Simulação do espectro de absorção eletrônico}

As condições iniciais para a simulação de dinâmica não-adiabática são obtidas por meio da amostragem de 500 snapshots baseados em uma dinâmica QM/MM no estado fundamental da molécula $6 \mathrm{SeGua} \mathrm{embebida} \mathrm{em} \mathrm{água,} \mathrm{sendo} \mathrm{que} \mathrm{as} \mathrm{moléculas} \mathrm{de} \mathrm{água} \mathrm{são} \mathrm{tratadas} \mathrm{classicamente}$ (veja Metodologia). O primeiro passo é a simulação do espectro de absorção da 6SeGua em água, cujo perfil é apresentado na Figura 7.6. Esse espectro de absorção é simulado a partir de cálculos de energias de excitação vertical considerando 15 estados singletos no nível ADC(2)/cc-pVDZ.

$\mathrm{O}$ espectro de absorção simulado exibe uma banda no intervalo a partir de $3.01-4.14 \mathrm{eV}$ $(300-400 \mathrm{~nm})$, com um pico em $3.59 \mathrm{eV}(345 \mathrm{~nm})$. A contribuição para essa banda é vinda por intermédio dos estados excitados singletos $S_{1}$ e $S_{2}$, apesar do estado $S_{2}$ possuir maior intensidade. O estado $S_{1}{ }^{1}\left(n_{\mathrm{Se}} \pi_{5}^{*}\right)$ é assinalado como um estado escuro em fase gasosa. Em água, contudo, algumas configurações salvas pela dinâmica QM/MM colocam o estado eletrônico ${ }^{1} \pi_{\mathrm{Se}} \pi_{5}^{*}$ como o primeiro estado excitado pela razão de utilizarmos aqui a representação 


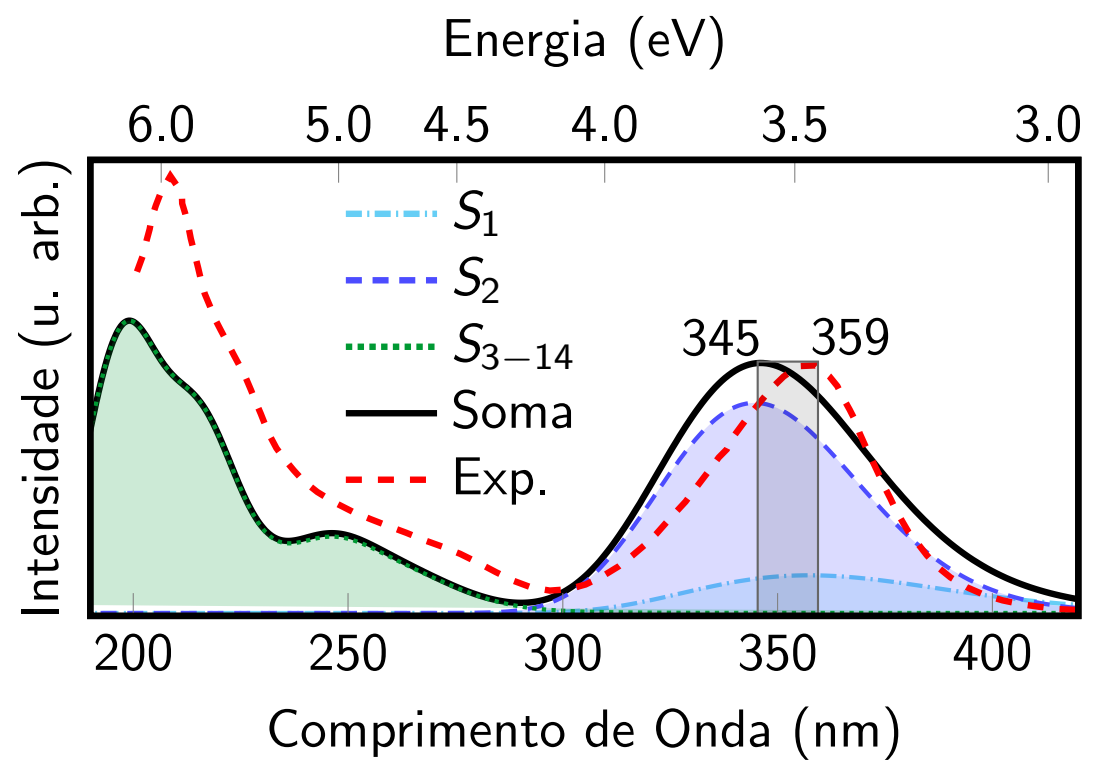

Figura 7.6 - Espectro de absorção eletrônico da molécula 6SeGua embebida em água baseado na amostragem de 500 configurações advindas de uma dinâmica QM/MM no estado fundamental. Em cada snapshot, um total de 15 estados singletos são considerados no nível ADC(2)/cc-pVDZ. A região em cinza denota a janela de excitação $(3.95-4.05 \mathrm{eV} ; 345-359 \mathrm{~nm})$ para seleção das condições iniciais para os cálculos de dinâmica não-adiabática.

adiabática. Em comprimentos de onda mais curtos, estados excitados de mais alta energia contribuem para o espectro de absorção e uma segunda banda com pico em 197 nm, com um "ombro" em torno de $250 \mathrm{~nm}$, é observado.

Em relação ao dado experimental, os picos simulados estão em bom acordo com os valores reportados, com a maior diferença de $12 \mathrm{~nm}$. O espectro de absorção simulado exibe - alargamento da primeira banda de absorção como previsto experimentalmente, porém a segunda banda apresenta um intensidade consideravelmente menor. Todavia, a forma dos espectros simulado e teórico se ajustam adequadamente.

As condições iniciais para os cálculos de dinâmica não-adiabática são escolhidas na janela de excitação mostrada na Figura 7.6. Esse intervalo cobre a energia de excitação experimental, que incluem os estados $S_{0}, S_{1}$ e $S_{2}$. Portanto, outras transições eletrônicas correspondentes à estados eletrônicos com mais altas energias são negligenciados.

\subsection{Dinâmica não-adiabática}

Seguindo o procedimento descrito na seção anterior, 136 condições iniciais são geradas, com 20 delas começando a partir do estado $S_{1}$ e 116 a partir do estado $S_{2}$. De todas essas 
condições iniciais, 100 trajetórias são propagadas por 1 ps (15 começando a partir do estado $S_{1}$ e 85 começando do estado $S_{2}$ ) e uma delas foi descartada devido às instabilidades numéricas.

A Figura 7.7a exibe a evolução da população eletrônica da molécula 6SeGua em água considerando um ensemble de 99 trajetórias. A evolução temporal é computada adotando estados adiabáticos $\left(S_{0}, S_{1}, S_{2}, T_{1}, T_{2}\right.$ e $\left.T_{3}\right)$. Desde que a molécula é sujeita a movimentos significantes, a natureza da função de onda dos estados adiabáticos não é constante necessariamente, ou seja, os estados adiabáticos não são identificados com caráter eletrônico puro $\left(\left(n \pi^{*}\right)\right.$ ou $\left.\left(\pi \pi^{*}\right)\right)$. Na fase gasosa, o estado $S_{2}$ corresponde principalmente à um estado ${ }^{1}\left(\pi_{\mathrm{Se}} \pi_{5}^{*}\right)$ e o estado $S_{1}$ para um estado eletrônico ${ }^{1}\left(n_{\mathrm{Se}} \pi_{5}^{*}\right)$. Para os estados tripletos, devido a mistura da natureza eletrônica, a correspondência não é clara. Em solução aquosa, a combinação dos caráteres eletrônicos ${ }^{1}\left(n_{\mathrm{Se}} \pi_{5}^{*}\right)$ e ${ }^{1}\left(\pi_{\mathrm{Se}} \pi_{5}^{*}\right)$ nos estados $S_{1}$ e $S_{2}$ torna a análise mais problemática. Portanto, decidimos analisar os resultados empregando a representação adiabática.

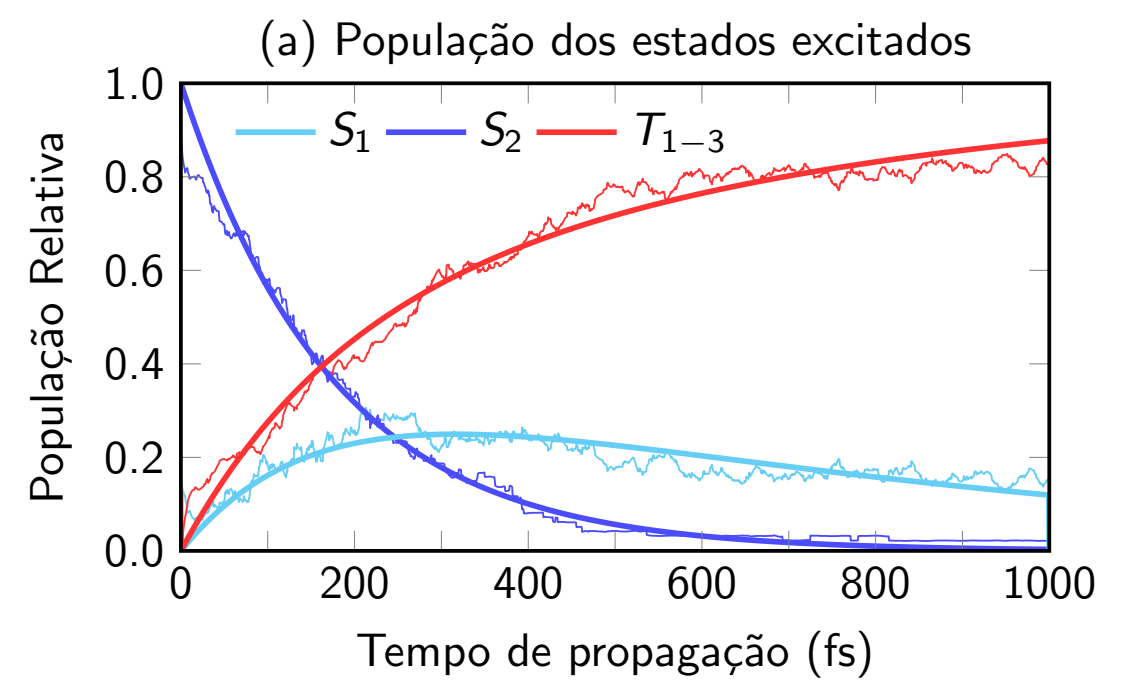

(b) Transferência Líquida

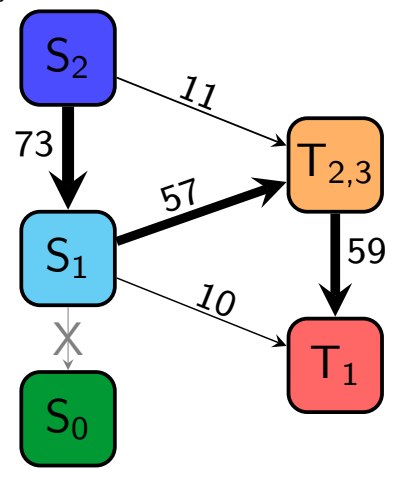

(c) Constantes Temporais (fs)

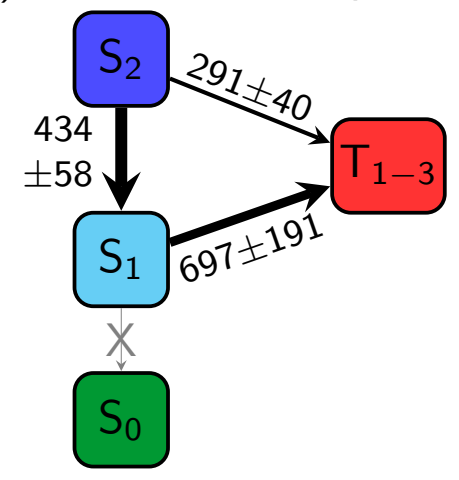

Figura 7.7 - (a) Evolução temporal da população dos estados de excitados para um ensemble compreendo 99 trajetórias. Os painéis (b) e (c) refletem o número de hops líquidos e o ajuste das constantes temporais, respectivamente

Como pode ser visto na Figura $7.7 a, 85 \%$ da população eletrônica inicialmente está no 
estado $S_{2}$, enquanto o restante da população permanece no estado $S_{1}$. Depois de $400 \mathrm{fs}$, a população do estado $S_{2}$ cai abruptamente para menos do que $10 \%$. Por outro lado, no mesmo intervalo de tempo, os estados $S_{1}$ e tripletos (indexando os três estados tripletos mais baixos em um único índice $T_{1-3}$ ) aumentam para $25 \%$ e $68 \%$, respectivamente. É importante notar que a população do estado $S_{1}$ cresce inicialmente até 300 fs e depois decresce sistematicamente. Baseado nesse comportamento, o estado $S_{1}$ pode ser considerado um estado intermediário. Simultaneamente, a população dos estados tripletos cresce rapidamente e no final da simulação essa população é acima de $80 \%$.

A transferência de população líquida entre os estados adiabáticos é apresentada na Figura 7.7b. A taxa de hops em uma direção e no caminho oposto não necessariamente deve ser igual e essas diferenças indicam quantas trajetórias permanecem em um estado particular no final da simulação. De acordo com os nossos resultados, o caminho de relaxação preferencial é claramente identificado como $S_{2} \rightarrow S_{1} \rightarrow T_{2} \rightarrow T_{1}$, sendo que os estados $T_{2}$ e $T_{3}$ são agrupados em um único índice $\left(T_{2,3}\right)$. Contudo, apenas um hop líquido para o estado $T_{3}$ é observado. O caminho direto $S_{2} \rightarrow T_{2}$ é verificado em apenas $13 \%$ das trajetórias e nenhuma transferência de população para o estado fundamental é observado durante a escala de tempo da simulação. Esse caminho de desativação dominante está em acordo com o que foi descrito por Martínez-Fernandez et al. para a molécula 6tGua, baseado em simulações de dinâmica não-adiabática semiempírica [296]. Todavia, a constante de tempo reportada por eles condizente ao evento de ISC é muito menor do que o previsto experimentalmente.

As constantes temporais são obtidas com a ajuda de um modelo cinético, que é detalhado nas referências $[122,297]$. O ajuste de cada curva é plotada na Figura 7.7 a junto com os valores da população extraídos da simulação de dinâmica não-adiabática. As constantes temporais e o respectivo erro, que é estimado com o método bootstrapping [121], são apresentados na Figura 7.7c. Nossos resultados sugerem três constantes temporais: (i) 434 fs para $S_{2} \rightarrow S_{1}$, (ii) 291 fs para $S_{2} \rightarrow T$ e (iii) 697 fs para $S_{1} \rightarrow T$. Logo, o tempo médio corresponde ao ISC é considerado ser $500 \mathrm{fs}$, cujo valor encontra-se na mesma ordem de magnitude computada para a molécula 2SeUra (450fs) por intermédio de simulações de dinâmica não-adiabática [268]. Entretanto, esse valor estimado para o ISC é muito maior do que o medido experimentalmente $(130 \pm 50 \mathrm{fs})[269]$.

No intuito de investigar a origem da discrepância entre a constante de tempo relacionado ao ISC obtida experimentalmente e teoricamente, resolvemos simular o espectro de absorção transiente (TAS) utilizando os dados das trajetórias. A escolha de simular esse espectro é devido ao fato dessas constantes de tempo experimentais serem extraídas a partir desse observável. Para simular esse espectro, tempos específicos e snapshots associados são selecionados, sendo realizados cálculos de energias de excitação vertical no nível ADC(2)/cc-pVDZ para um total de 15 singletos e 14 tripletos em cada configuração. Vale salientar que é preciso transformar tanto as energias quanto as forças de oscilador para a representação diagonal, visto que a 
dinâmica é propagada no tempo nessa representação.

O espectro TAS experimental é reportado para seis tempos (Figura 7.8a) na escala de femtosegundos. Nesse espectro é possível perceber um pico bem definido em $490 \mathrm{~nm}$ e o surgimento de uma cauda em $675 \mathrm{~nm}$ para escalas de tempo maior. O nosso espectro TAS simulado (Figura 7.8b) reproduz razoavelmente o perfil experimental, embora o pico esteja um pouco deslocado e a intensidade é mais baixa para tempo mais longos. O espectro TAS simulado da $6 \mathrm{SeGua} \mathrm{em} \mathrm{água} \mathrm{pode} \mathrm{ser} \mathrm{sumarizado} \mathrm{como} \mathrm{a} \mathrm{contribuição} \mathrm{de} \mathrm{duas} \mathrm{regiões}$ energéticas (Figura 7.8c), com a região de menor energia $\sim 2 \mathrm{eV}$ (low energy) fornecendo uma alta intensidade até 200 fs. A integração desse espectro (Figura 7.8d) considerando duas regiões de absorção transiente rendem duas constantes de tempo $\left(\tau_{1}=131 \mathrm{fs}\right.$ e $\left.\tau_{2}=88 \mathrm{fs}\right)$. Ambas as constantes de tempo estão em bom acordo com o observado experimentalmente $(130 \pm 50 \mathrm{fs})[269]$.

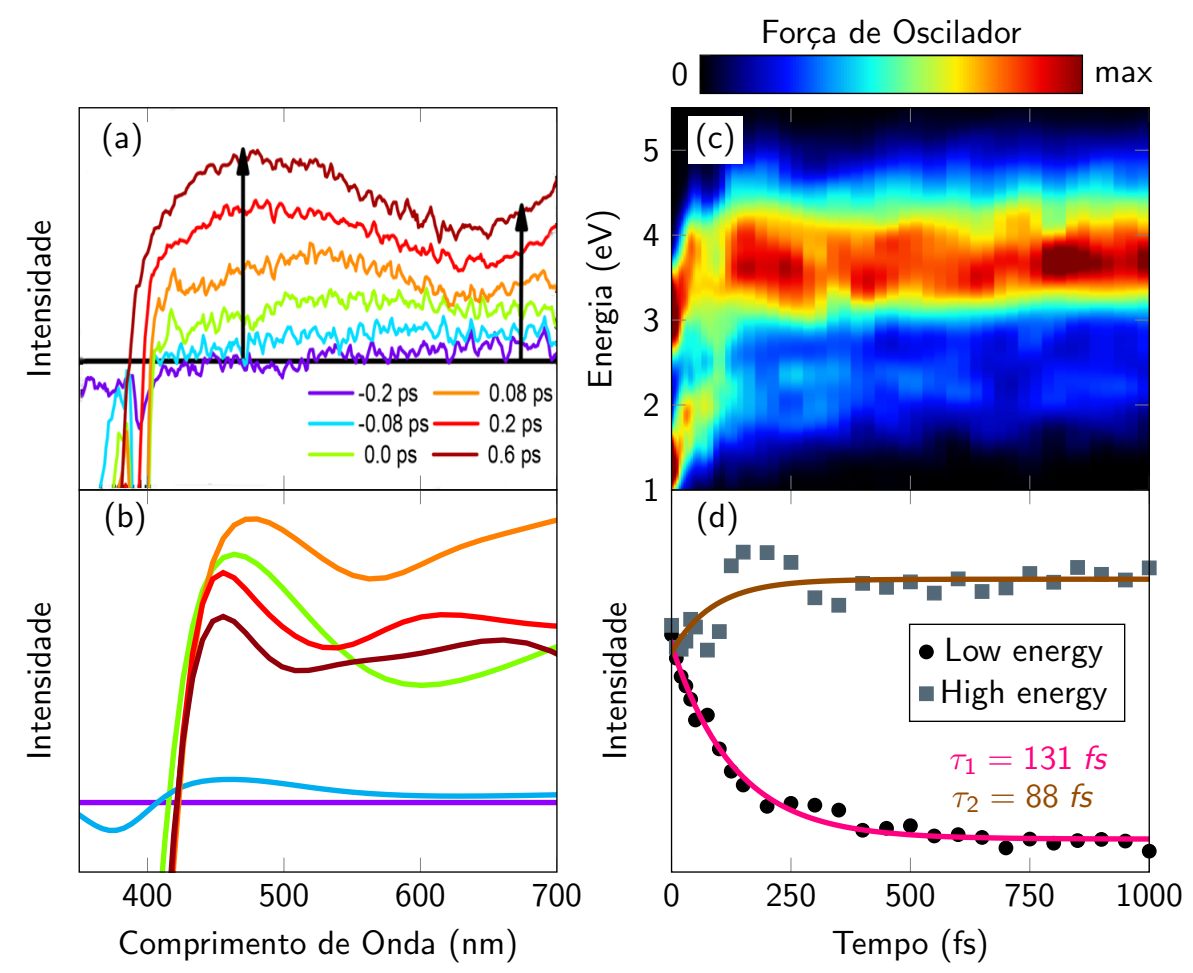

Figura 7.8 - (a) Espectro de absorção transiente experimental [269], (b) espectro de absorção transiente simulado para específicos tempos, (c) evolução temporal do espectro de absorção transiente e (d) integração do espectro de aborção transiente juntamente com o respectivo ajuste exponencial.

A evolução da transferência de carga é também investigada analisando a matriz densidade de primeira-ordem, como implementado no programa Theodore $[111,298]$. Dois fragmentos são utilizados para realização dessa análise, sendo um deles compreendo apenas o átomo de selênio e o segundo fragmento consiste dos átomos remanescentes da molécula. Na Figura 7.9 são mostrados as populações de buracos deixados no átomo de selênio ao decorrer do tempo 
(Se $\rightarrow$ Remainder) e de elétrons que chegam no átomo de selênio (Remainder $\rightarrow \mathrm{Se}$ ) derivados a partir de um ensemble de 99 trajetórias. As constantes de tempos são obtidas segundo um ajuste biexponencial.

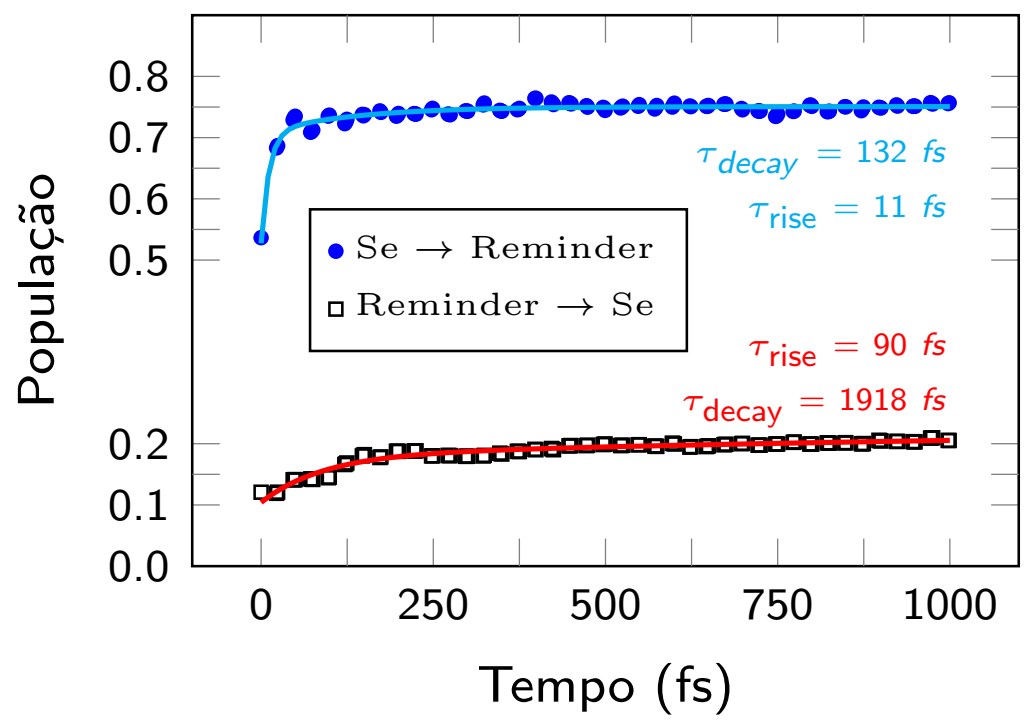

Figura 7.9 - População média de elétrons (buracos) deixando (chegando) no átomo de selênio oriunda de um ensemble de 99 trajetórias. As constantes temporais são ajustadas empregando um ajuste biexponencial.

Como pode ser visto na Figura 7.9, depois da excitação eletrônica há uma migração ultra-rápida de elétrons do átomo de selênio para o restante da molécula ( $\tau_{\text {rise }}=11 \mathrm{fs}$ ). O fluxo de elétrons a partir do átomo de selênio é estabilizado por volta de 130 fs, que, curiosamente, é a mesma escala de tempo observada para o processo de ISC. Entretanto, os elétrons podem retornar para o átomo de selênio em dois intervalos de tempo. Uma primeira onda de elétrons chega rapidamente no átomo de selênio ( $\tau_{\text {rise }}=90 \mathrm{fs}$ ), enquanto em torno de 2 ps é alcançado uma equilibração completa, que pode estar relacionada à reorganização do solvente ao redor do soluto.

A reorganização das cargas atômicas depois da absorção de radiação UV pode afetar o arranjo das moléculas de solvente em torno do soluto, sendo a função distribuição radial de pares $g(r)$ um bom parâmetro para analisar esses efeitos. A $g(r)$ é diretamente relacionada ao número de coordenação e a integração sobre os picos dessa função resulta na informação sobre o fator de estrutura, que pode ser comparado com dados experimentais. A Figura 7.10 exibe a $g(r)$ entre os átomos de selênio e hidrogênio das moléculas de água. No estado fundamental, essa função possui um pico bem definido em $2.5 \AA$, indicando a formação de uma ligação de hidrogênio. Uma segunda camada é também verificada, terminando em $6 \AA$. Depois disso, não é possível perceber uma outra camada de solvatação pela razão da $g(r)$ ficar perto de um, implicando que essa função assemelha-se a distribuição de um gás ideal [299]. 


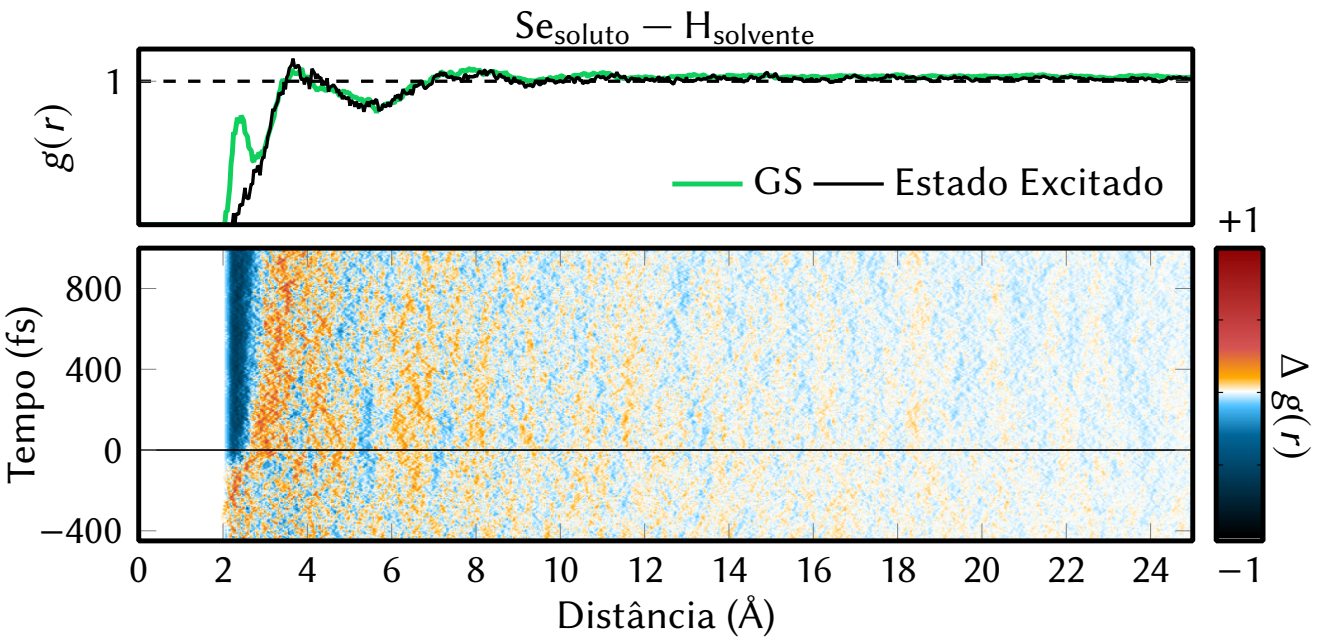

Figura 7.10 - (a) Função de distribuição radial de pares $(g(r))$ entre $\mathrm{Se}_{\text {soluto }}-\mathrm{H}_{\text {solvente }}$ no estado fundamental (linha verde) e estado excitado (linha preta). Para o estado excitado, uma média sobre 99 trajetórias é considerado. (b) Evolução temporal da $g(r)$ levando em conta todas as trajetórias. A diferença na $g(r)(\Delta g(r))$ é obtida usando como referência o valor médio da $g(r)$ no estado fundamental. Tempos negativos correspondem ao estado fundamental e tempos positivos para o estado excitado.

Para o estado excitado, não é observado nenhum pico no intervalo de $2-3 \AA$, assim, assinalando que a ligação de hidrogênio descrita acima é rompida depois da molécula $6 \mathrm{SeGua}$ absorver luz UV. Isso é esperado, porque existe uma realocação da carga eletrônica da molécula, com uma porção dos elétrons migrando a partir do átomo de selênio em direção ao restante da molécula. Portanto, não é vantajoso manter essa ligação de hidrogênio soluto-solvente. Nessa região, as moléculas de água preferem fazer ligações de hidrogênio com elas mesmo ao invés de ligar com o átomo de selênio. Para distância mais longas, a $g(r)$ dos estados fundamental e excitado exibem o mesmo perfil.

\subsection{Evolução temporal dos parâmetros estruturais e modos vibra- cionais}

Uma outra importante característica extraída da dinâmica é a evolução temporal de comprimentos de ligações, ângulos e outros parâmetros geométricos. Como pode ser visto na Figura 7.11a, a ligação $C=$ Se possui uma distância média em torno de $1.82 \AA$ no estado fundamental (tempo negativo). Depois da excitação eletrônica, essa ligação é elongada para $\sim 2.0 \AA$. Baseado nas estruturas otimizadas, essa distância de ligação pode estar relacionada com o estado $S_{2}$ no intervalo de $0-100$ fs. Por volta de 400 fs, essa ligação estabiliza. Como as estruturas otimizadas dos estados $S_{1}, T_{2}$ e $T_{1}$ possuem similar valores para essa coordenada, 
não é possível determinar quando o estado $T_{1}$ é acessado.

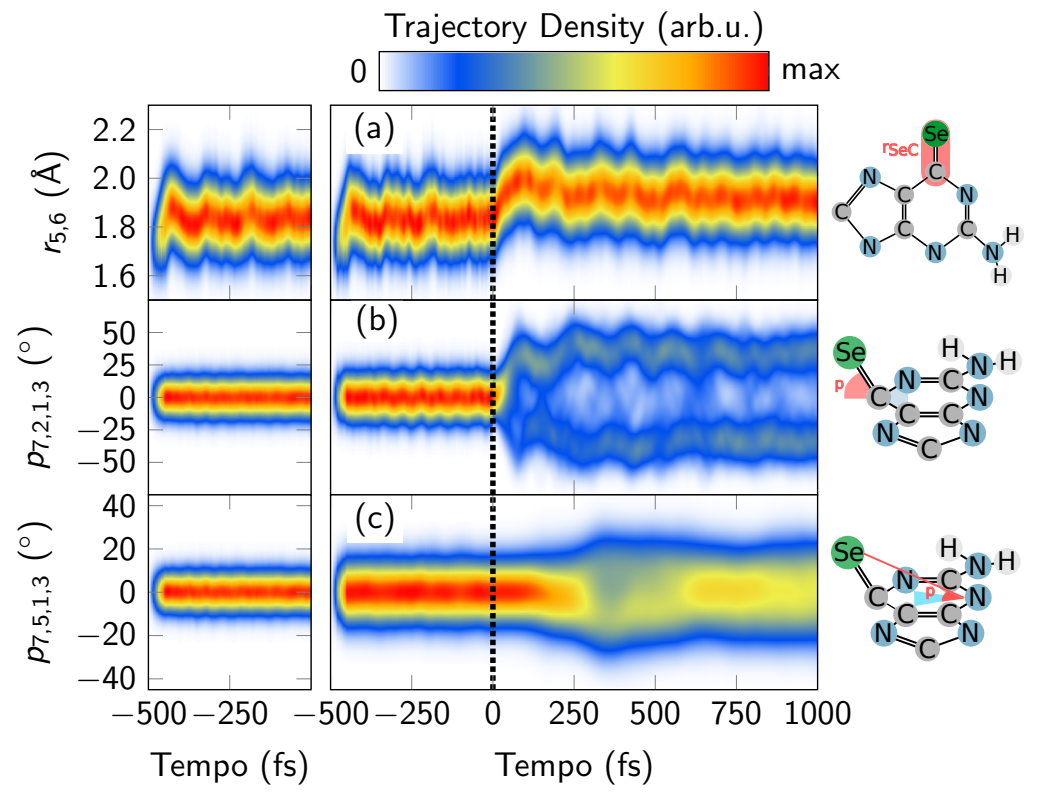

Figura 7.11 - Evolução temporal da (a) comprimento de ligação $C=S e$, ângulo de piramidalização (b) $p_{11,6,1,5}$ e (c) $p_{11,3,1,5}$ a partir de um ensemble de 99 trajetórias. Os painéis do lado esquerdo mostram a evolução temporal das mesmas coordenadas consideradas todas as 500 trajetórias propagadas no estado fundamental por meio de simulações de dinâmica QM/MM.

Na Figura 7.11b ilustra o ângulo de piramidalização do átomo de selênio ao decorrer do tempo. Essa coordenada tem um valor médio de $0^{\circ}$ no estado fundamental, que encontra-se em acordo com a geometria otimizada. A piramidalização ocorre depois de poucos femtosegundos, com a maioria das trajetórias possuindo um valor em torno de $40^{\circ}$ dentro de 100 fs. Esse ângulo está em acordo com o que foi observado para a estrutura otimizada do estado $S_{2}$ $\left(42^{\circ}\right)$. Perto dos $200 \mathrm{fs}$, a maioria das trajetórias indicam uma piramidalização menor do que $10^{\circ}$, que poderia ser associada com a estrutura de mínimo do estado $T_{2}\left(0^{\circ}\right)$. Depois disso, a piramidalização aumenta rapidamente como um valor médio de $35^{\circ}$, que pode ser correlacionada com a estrutura de mínimo do estado $T_{1}\left(35^{\circ}\right)$.

O último painel da Figura 7.11c exibe outra definição da piramidalização do átomo de selênio, removendo o átomo $C_{6}$ do plano molecular. Essa medida fornece o deslocamento fora do plano do átomo de selênio, sem considerar o átomo $C_{6}$. Por conseguinte, o movimento fora do plano do átomo de selênio é um processo lento, que leva em torno de 300 fs para estabilizar. Logo, a rápida piramidalização é claramente devido ao movimento do átomo $\mathrm{C}_{6}$ para fora do plano. Isso é esperado, visto que o átomo de selênio possui uma massa atômica maior do que o átomo de carbono. Um comportamento análogo foi observado anteriormente para a molécula 2SeUra [268].

Além da evolução temporal dos parâmetros estruturais, podemos analisar como os modos 
vibracionais evoluem ao decorrer do tempo. Essa análise é bastante útil para selecionar os principais DOF's da molécula, podendo ser empregados como o conjunto de parâmetros iniciais para uma dinâmica quântica. A ideia aqui é apenas ilustrar como é a propagação de alguns modos da 6SeGua, como pode ser visto na Figura 7.12.

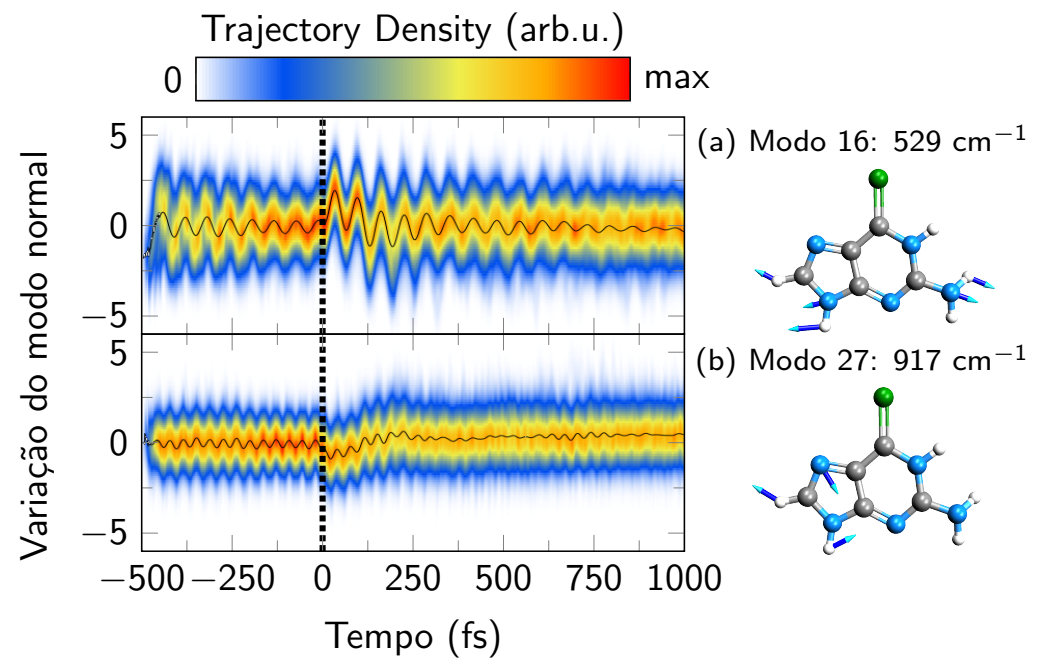

Figura 7.12 - Evolução temporal de alguns modos vibracionais da 6SeGua no estados fundamental (tempo negativo) e excitados (tempo positivo). A linha em preto representa a média sobre um ensemble de 99 trajetórias. $O$ valor da frequência na região de FC é também reportada.

A Figura 7.12a mostra a evolução do modo $Q_{16}$, cuja frequência na região de $\mathrm{FC}$ é de 529 $\mathrm{cm}^{-1}$ e é majoritariamente descrito pelos estiramentos do grupo amino, do átomo de nitrogênio $\mathrm{N}_{9}$ e de alguns átomos de hidrogênio. Esse modo apresenta uma deslocamento uniforme no estado fundamental, mas quando ocorre a excitação eletrônica, são necessários por volta de 250 fs para a estabilização. Isso indica que essa instabilização acontece depois do evento do ISC, que se sucede 100 fs antes. Outro modo que sofre mudança depois da excitação eletrônica é o $Q_{27}$, que envolve os estiramentos de alguns átomos de hidrogênios e do átomo de nitrogênio $\mathrm{N}_{7}$. Como pode ser visto na $7.12 \mathrm{~b}$, esse modo vibra com menos intensidade do que o modo anterior. Como verificado para o modo $Q_{16}$, a total estabilização depois da excitação eletrônica também se verifica em torno de 250 fs, porém a desestabilização não é tão abrupta.

\subsection{Tempo de vida do estado tripleto}

A última pergunta em aberto está associada com o curto tempo de vida do estado tripleto da $6 \mathrm{SeGua}$, que é medido ser 835 mais rápido do que o medido para a 6tGua em solução aquosa [269]. Como é inviável realizar simulações de dinâmica não-adiabática tão longas, decidimos seguir outra estratégia. Nesse propósito, otimizamos as estruturas do estado $T_{1}$ e do 
cruzamento intersistemas $\left(T_{1} / S_{0}\right)$ ISC para ambas as moléculas no nível MS-CASPT2 $(12,10) /$ ccpVDZ em fase gasosa e em água (modelo PCM). Essas estruturas foram conectadas por meio de interpolações lineares.

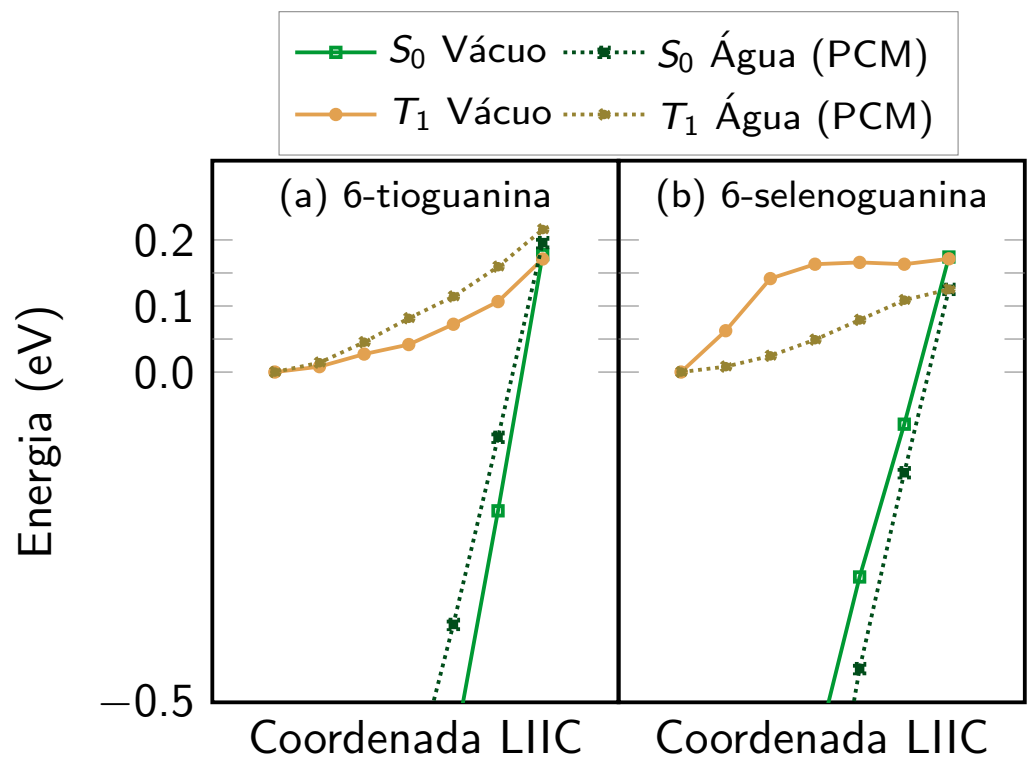

Figura 7.13 - Interpolações lineares em coordenadas internas ligando as estruturas $\left(T_{1}\right)_{\min }$ e $\left(T_{1} / S_{0}\right)$ ISC para (a) 6-tioguanina e (b) 6-selenoguanina em fase gasosa e em água. O modelo PCM é introduzido para levar em conta os efeitos de solvente. Em cada estrutura gerada a partir da varredura LIIC é seguida por cálculos de energias de excitação vertical no nível MS-CASPT2(14,12)/cc-pVDZ.

Como pode ser percebido na Figura 7.13, a barreira energética em fase gasosa é a mesma para ambas as espécies $(0.17 \mathrm{eV})$. Entretanto, em relação ao valor da fase gasosa, a barreira energética em água aumenta $0.05 \mathrm{eV}$ para a molécula $6 \mathrm{tGua}(0.22 \mathrm{eV})$ e diminui pela mesma quantidade para a molécula $6 \mathrm{SeGua}(0.12 \mathrm{eV})$. Levando isso em conta, podemos concluir que o caminho de retorno para o estado fundamental é mais difícil para a molécula 6tGua e, consequentemente, a população eletrônica ficaria presa por mais tempo no estado tripleto da 6 tGua do que na $6 \operatorname{SeGua.~Aliado~a~isso,~cálculos~no~nível~} \operatorname{CASSCF}(12,10) / A N O-S$ indicam a presença de dois mínimos na hipersuperfície de energia potencial do estado $T_{1}$ da 6tGua [300], que poderia também aumentar o tempo de vida dos estados tripletos. Em contrapartida, é encontrado apenas um mínimo nessa hypersuperfície de energia potencial para a 6SeGua.

Resumindo, concluímos que o curto tempo de vida do estado tripleto medido para a 6SeGua em relação ao estimado para sua tio-análoga é devido à ausência de um segundo mínimo na superfície do estado $T_{1}$ e também a uma menor barreira energética no caminho fotofísico a partir da estrutura $\left(T_{1}\right)_{\min }$ em direção ao ISC com o estado fundamental. Dessa forma, mesmo a 6SeGua possuindo uma taxa rápida de geração de estados tripletos, essa molécula não poderia ser aplicada como um fotosensibilizador Type II, mas seria um melhor candidata 
para reações Type I, como destacado por Crespo-Hernández et al. no estudo experimental da 6-selenoguanina [269]. 


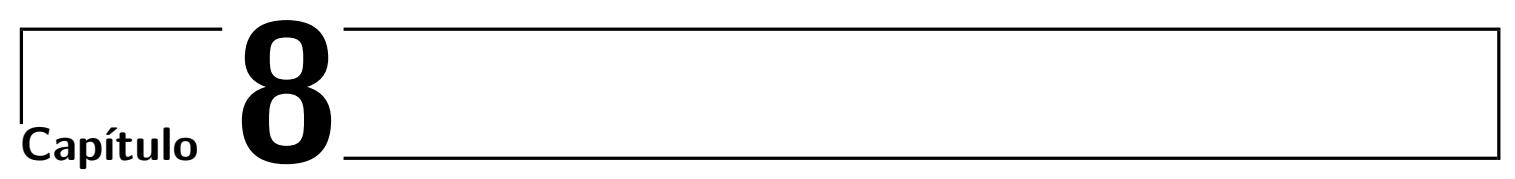

\section{Considerações Finais e Perspectivas}

Nesse trabalho foram estudados os efeitos de solvente em espectroscopia eletrônica de absorção e emissão em moléculas modificas do DNA/RNA. Além disso, foram explicados os principais mecanismos de relaxação fotofísicas empregando métodos de química bastante acurados. Os efeitos de solvente foram incluídos com o modelo PCM e/ou abordagens QM/MM.

O primeiro sistema estudado foi um promissor alfabeto ribonucleosídeo fluorescente, constituído de cinco moléculas $\left({ }^{\mathrm{tz}} \mathbf{A},{ }^{\mathrm{tz}} \mathbf{C},{ }^{\mathrm{tz}} \mathbf{G},{ }^{\mathrm{tz}} \mathbf{U}\right.$ e $\left.{ }^{\mathrm{tz}} \mathbf{I}\right)$. As propriedades espectroscópicas em ambos os solventes (1,4-dioxano e água) foram bem descritas com a metodologia ASEC-FEG. Pelos nossos resultados, o modelo PCM não possui um padrão definido, pois dependendo da molécula, esse método pode descrever bem ou exibir erros consideráveis em relação aos dados experimentais. As cinco moléculas estudadas puderam ser agrupadas em dois grupos. Ambas as moléculas fluorescem a partir do estado claro ${ }^{1}(\pi \pi)$, porém a explicação do motivo de serem fluorescentes depende do grupo. No caso das moléculas pirimidinas $\left({ }^{\mathrm{tz}} \mathbf{C} \mathrm{e}^{\mathrm{tz}} \mathbf{U}\right)$, a fluorescência acontece porque a cônica ${ }^{1}(g s / \pi \pi)_{\mathrm{Cl}}$ se encontra em uma região bastante energética. Por sua vez, a cônica ${ }^{1}(g s / \pi \pi)_{\mathrm{Cl}}$ está na mesma região energética que a estrutura ${ }^{1}(\pi \pi)_{\min }$ para as moléculas purinas $\left({ }^{\mathrm{tz}} \mathbf{A},{ }^{\mathrm{tz}} \mathbf{G}\right.$ e $\left.{ }^{\mathrm{tz}} \mathbf{I}\right)$, mas existe uma considerável barreira energética separando essas estruturas.

O segundo sistema estuda foi a conhecida 2-aminopurina. Essa molécula foi investigada em solventes de diversas polaridades. A metodologia ASEC-FEG prediz bons resultados para as propriedades espectroscópicas (absorção, emissão e deslocamentos Stokes) dessa molécula em todos os solventes empregados. A maioria dos trabalhos teóricos calculam essas propriedades apenas em fase gasosa e água. Nossos resultados para o deslocamento Stokes de 1,4-dioxano para água fica em melhor concordância com os obtidos previamente. Analisando o SOC e a diferença energética entre os estados singletos e tripletos, predizemos que poderia haver uma transferência de população do estado $S_{1}{ }^{1}\left(\pi \pi^{*}\right)$ para o estado $T_{2}{ }^{3}\left(n \pi^{*}\right)$, porém não encontramos de fato o cruzamento intersistemas. Isso foi fundamentado na diferença energética entre esses estados, que diminui em solvente, além de existir um leve aumento do SOC 
$\left(\sim 3 \mathrm{~cm}^{-1}\right)$. Recentes resultados experimentais estimam que o estado ${ }^{1}\left(n \pi^{*}\right)$ seria a porta de entrada para o estado tripleto, porém o SOC associado é muito pequeno $\left(\sim 1 \mathrm{~cm}^{-1}\right)$. Uma parte final do trabalho foi tentar obter a diferença de energia livre entre os dois tautômeros da $2 \mathrm{AP}$ em etanol e água usando a técnica FEP-MC. A diferença experimentalmente é muito pequena, mas conseguimos capturar razoavelmente a tendência experimental.

O último sistema investigado foi uma substituição simples da guanina que conduz para um alto rendimento de estados tripletos. Esse sistema foi investigado usando aproximações estáticas e dinâmicas. Nesse sistema concluímos que depois que o sistema é fotoexcitado, o estado $S_{2}$ relaxa rapidamente para o $S_{1}$. Depois disso, a população é transferida para o estado tripleto $T_{2}$ via cruzamento intersistemas, e, finalmente, acessa o estado $T_{1}$. Esse caminho de relaxação é análogo ao obtido previamente para a 6-tioguanina. Duas constantes temporais foram extraídas a partir da simulação do espectro de absorção transiente e que estão dentro do intervalo experimental. $\mathrm{O}$ estado tripleto da $6 \mathrm{SeGua}$ possui um menor tempo de vida em relação à sua análoga tiobase, sendo que pode ser atribuído a falta de um segundo mínimo na PES do estado $T_{1}$, além da energia de ativação ser menor do que na 6-tioguanina.

Esses trabalhos mostram a importância dos estudos de bases modificadas no DNA/RNA. As moléculas estudadas aqui são tratadas separadamente e são bem distintas do que é encontrado in vivo. Dessa forma, uma perspectiva futura, é a inserção desse tipo de molécula no DNA/RNA do ponto de vista teórico. Esse passo é necessário para uma descrição ainda mais realística do sistema. Já começamos a fazer algo nessa linha com a molécula 6-selenoguanina, escolhendo duas regiões QM no DNA. Esse trabalho é uma colaboração com o prof. Ganglong Cui (Beijing Normal University), que foi firmada no período que estive em Viena.

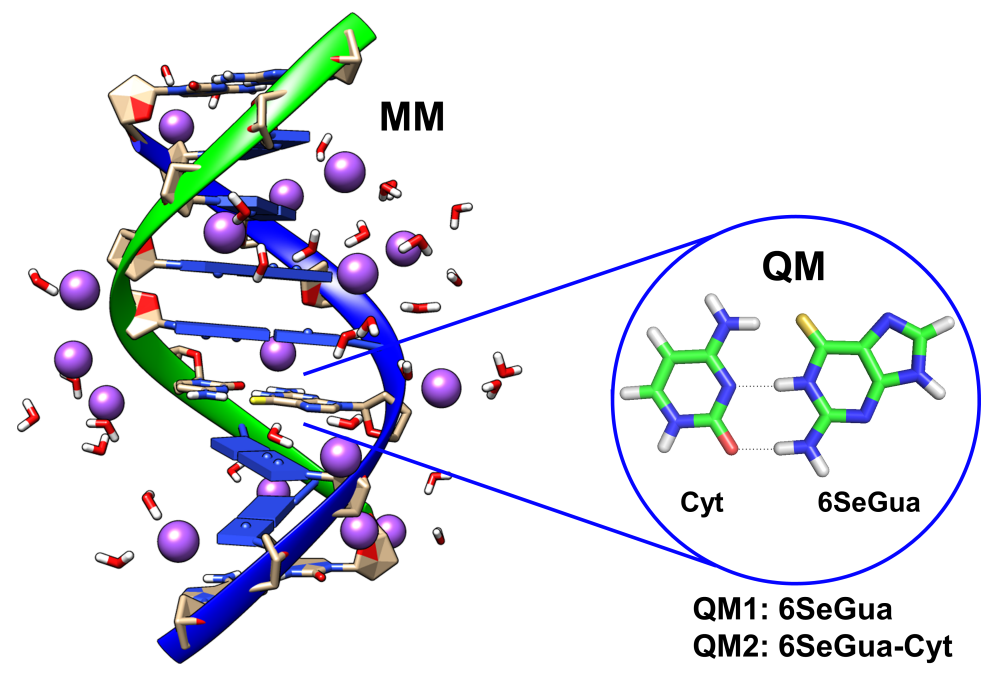

Figura 8.1 - Ilustração das partes QM e MM utilizadas na inserção da molécula 6-selenoguanina no DNA. Duas regiões QM estão sendo consideradas. A primeira delas compreende apenas a $6 \mathrm{SeG}$ e a outra inclui o respectivo par de base (citosina). 


\section{Referências}

1 TURRO, N.; RAMAMURTHY, V.; RAMAMURTHY, V.; SCAIANO, J. Principles of Molecular Photochemistry: An Introduction. University Science Books, 2009.

2 KLESSINGER, M.; MICHL, J. Excited States and Photochemistry of Organic Molecules. VCH, 1995.

3 DOMCKE, W.; YARKONY, D. Conical Intersections: Theory, Computation and Experiment. World Scientific, 2011.

4 EL-SAYED, M. Spin-orbit Coupling and the Radiationless Processes in Nitrogen Heterocyclics. J. Chem. Phys., v. 38, n. 12, p. 2834-2838, 1963.

5 BERNARDI FERNANDO; OLIVUCCI, M. R. M. A. Potential Energy Surface Crossings in Organic Photochemistry. Chem. Soc. Rev., v. 25, p. 321-328, 1996.

6 MAI, S.; GONZáLEZ, L. Molecular Photochemistry: Recent Developments in Theory. Angew. Chem. Int. Edit., v. 59, n. 39, p. 16832-16846, 2020.

7 SAGAN, C. Ultraviolet Selection Pressure on the Earliest Organisms. Journal of theoretical biology, v. 39, n. 1, p. 195-200, 1973.

8 VRIES, M. S. de; HOBZA, P. Gas-phase Spectroscopy of Biomolecular Building Blocks. Annu. Rev. Phys. Chem., v. 58, p. 585-612, 2007.

9 JIANG, Y.; RABBI, M.; KIM, M.; KE, C.; LEE, W.; CLARK, R. L.; MIECZKOWSKI, P. A.; MARSZALEK, P. E. UVA Generates Pyrimidine Dimers in DNA Directly. Biophys. J., v. 96, n. 3, p. 1151-1158, 2009.

10 GRUIJL, F. R. de; KRANEN, H. J. van; MULLENDERS, L. H. UV-induced DNA Damage, Repair, Mutations and Oncogenic Pathways in Skin Cancer. J. Photoch. Photobio. B, v. 63, n. 1, p. 19-27, 2001.

11 POVEDA, A. M.; CLECH, M. L.; PASERO, P. Transcription and Replication. Transcription, v. 1, n. 2, p. 99-102, 2010.

12 CRESPO-HERNÁNDEZ, C. E.; COHEN, B.; HARE, P. M.; KOHLER, B. Ultrafast ExcitedState Dynamics in Nucleic Acids. Chem. Rev., v. 104, n. 4, p. 1977-2020, 2004.

13 TUNA, D.; SOBOLEWSKI, A. L.; DOMCKE, W. Mechanisms of Ultrafast Excited-State Deactivation in Adenosine. J. Phys. Chem. A, v. 118, n. 1, p. 122-127, 2014. 
14 GIUSSANI, A.; SEGARRA-MARTÍ, J.; ROCA-SANJUÁN; MERCHÁN, M. Excitation of nucleobases from a computational perspective I: Reaction Paths. In: BARBATTI, M.; BORIN, A. C.; ULRICH, S. (Ed.). Photoinduced Phenomena in Nucleic Acids I - Nucleobases in the Gas Phase and in Solvents. Cham: Springer International Publishing, 2015. v. 355, p. 57-97.

15 MAI, S.; RICHTER, M.; MARQUETAND, P.; GONZÁLEZ, L. Excitation of Nucleobases from a Computational Perspective II: Dynamics. In: BARBATTI, M.; BORIN, A. C.; ULRICH, S. (Ed.). Photoinduced Phenomena in Nucleic Acids I - Nucleobases in the Gas Phase and in Solvents. Cham: Springer International Publishing, 2015. v. 355, p. 99-153.

16 DAHM, R. Friedrich Miescher and the Discovery of DNA. Dev. Biol., v. 278, n. 2, p. 274-288, 2005.

17 WATSON, J. D.; CRICK, F. H. et al. A Structure for Deoxyribose Nucleic Acid. Nature, v. 171, n. 4356, p. $737-738,1953$.

18 GEHRING, K.; LEROY, J.-L.; GUÉRON, M. A Tetrameric DNA Structure with Protonated Cytosine-Cytosine Base Pairs. Nature, v. 363, n. 6429, p. 561-565, 1993.

19 BIFFI, G.; TANNAHILL, D.; MCCAFFERTY, J.; BALASUBRAMANIAN, S. Quantitative Visualization of DNA G-quadruplex Structures in Human Cells. Nat. Chem., v. 5, n. 3, p. 182, 2013.

20 LAKOWICZ, J. R. Principles of Fluorescence Spectroscopy. New York: Springer, 2006.

21 HELL, S. W. Toward Fluorescence Nanoscopy. Nat. Biotech., v. 21, n. 11, p. 1347-1355, 2003.

22 KRUEGER, A. T.; KOOL, E. T. Redesigning the Architecture of the Base Pair: Toward Biochemical and Biological Function of New Genetic Sets. Chem. \& Biol., v. 16, n. 3, p. 242-248, 2009.

23 SINKELDAM, R. W.; GRECO, N. J.; TOR, Y. Fluorescent Analogs of Biomolecular Building Blocks: Design, Properties, and Applications. Chemical Reviews, v. 110, n. 5, p. 2579-2619, 2010.

24 XIE, Y.; TAM, V. K.; TOR, Y. The Interactions of Small Molecules with DNA and RNA. In: MAYER, G. (Ed.). The Chemical Biology of Nucleic Acids. [S.I.]: John Wiley \& Sons, Ltd, 2010. p. 115-140.

25 HIRAO, I. Unnatural Base Pair Systems for DNA/RNA-based Biotechnology. Curr. Opi. Chem. Bio., v. 10, n. 6, p. 622-627, 2006.

26 NORDLUND, T. M.; ANDERSSON, S.; NILSSON, L.; RIGLER, R.; GRÄSLUND, A.; MCLAUGHLIN, L. Structure and Dynamics of a Fluorescent DNA Oligomer Containing the EcoRI Recognition Sequence: Fluorescence, Molecular Dynamics, and NMR Studies. Biochemistry, v. 28, n. 23, p. 9095-9103, 1989.

27 LUDWIG, V.; AMARAL, M. S.; COSTA, Z. M.; BORIN, A. C.; CANUTO, S.; SERRANOANDRÉS, L. 2-Aminopurine Non-radiative Decay and Emission in Aqueous Solution: A Theoretical Study. Chem. Phys. Lett., v. 463, n. 1-3, p. 201-205, 2008. 
28 GAIED, N. B.; GLASSER, N.; RAMALANJAONA, N.; BELTZ, H.; WOLFF, P.; MARQUET, R.; BURGER, A.; MELY, Y. 8-Vinyl-deoxyadenosine, An Alternative Fluorescent Nucleoside Analog to 2-deoxyribosyl-2-aminopurine with Improved Properties. Nuc. Acids Res., v. 33, n. 3, p. 1031-1039, 2005.

29 NADLER, A.; STROHMEIER, J.; DIEDERICHSEN, U. 8-Vinyl-2-deoxyguanosine as a Fluorescent 2-deoxyguanosine Mimic for Investigating DNA Hybridization and Topology. Angew. Chem. Int. Edit., v. 50, n. 23, p. 5392-5396, 2011.

30 AHMED, I. A.; ACHARYYA, A.; ENG, C. M.; RODGERS, J. M.; DEGRADO, W. F.; JO, H.; GAI, F. 4-Cyanoindole-2-deoxyribonucleoside as a Dual Fluorescence and Infrared Probe of DNA Structure and Dynamics. Molecules, v. 24, n. 3, p. 602, 2019.

31 BROWN, S. B.; BROWN, E. A.; WALKER, I. The Present and Future Role of Photodynamic Therapy in Cancer Treatment. Lancet. Oncol., v. 8, n. 5, p. 497-508, 2004.

32 ROSA, L. P.; SILVA, F. C. da. Antimicrobial Photodynamic Therapy: A New Therapeutic Option to Combat Infections. J. Med. Microbiol., v. 3, n. 4, p. 1-7, 2014.

33 GU, X.; NYLANDER, E.; COATES, P. J.; NYLAN, K. Oxidation Reduction is a Key Process for Successful Treatment of Psoriasis by Narrow-band UVB Phototherapy. Acta Derm-Venereol., v. 95, n. 2, p. 140-146, 2015.

34 CHOI, Y. M.; ADELZADEH, L.; WU, J. J. Photodynamic Therapy for Psoriasis. J. Dermatol. Treat., v. 26, n. 3, p. 202-207, 2015.

35 DARLENSKI, R.; FLUHR, J. W. Photodynamic Therapy in Dermatology: Past, Present, and Future. J. Biomed. Opt., v. 18, n. 6, p. 061208, 2012.

36 KIM, M.; JUNG, H. Y.; PARK, H. J. Topical PDT in the Treatment of Benign Skin Diseases: Principles and New Applications. Int. J. Mol. Sci., v. 16, n. 10, p. 23259-23278, 2015.

37 MAROTTI, J.; ARANHA, A. C. C.; EDUARDO, C. D. P.; RIBEIRO, M. S. Photodynamic Therapy Can Be Effective as a Treatment for Herpes Simplex Labialis. Photomed. Laser Surg., v. 27, n. 2, p. 357-363, 2009.

38 SCHWEITZER, C.; SCHMIDT, R. Physical Mechanisms of Generation and Deactivation of Singlet Oxygen. Chem. Rev., v. 103, n. 5, p. 1685-1758, 2003.

39 YANO, S.; HIROHARA, S.; OBATA, M.; HAGIYA, Y.; OGURA, S. I.; IKEDA, A.; KATAOKA, H.; TANAKA, M.; JOH, T. Current States and Future Views in Photodynamic Therapy. J. Photoch. Photobio. C, v. 12, n. 1, p. 46-67, 2011.

40 FOOTE, C. S. Definition of Type I and Type II Photosensitized Oxidation. Photochem. Photobio., v. 54, n. 5, p. 659-659, 1991.

41 ASHWOOD, B.; POLLUM, M.; CRESPO-HERNÁNDEZ, C. E. Photochemical and Photodynamical Properties of Sulfur-Substituted Nucleic Acid Bases. Photochem. Photobiol., v. 95, p. 33-58, 2019.

42 REICHARDT, C.; GUO, C.; CRESPO-HERNÁNDEZ, C. E. Excited-State Dynamics in 6-Thioguanosine from the Femtosecond to Microsecond Time Scale. J. Phys. Chem. B, v. 115, p. $3263-3270,2011$. 
43 POLLUM, M.; JOCKUSCH, S.; CRESPO-HERNÁNDEZ, C. E. 2,4-Dithiothymine as a Potent UVA Chemotherapeutic Agent. J. Am. Chem. Soc., v. 136, p. 17930-17933, 2014.

44 POLLUM, M.; ORTIZ-RODRÍGUEZ, L. A.; JOCKUSCH, S.; CRESPO-HERNÁNDEZ, C. E. The Triplet State of 6-thio-2'-deoxyguanosine: Intrinsic Properties and Reactivity Toward Molecular Oxygen. Photochem. Photobiol., v. 92, p. 286-292, 2016.

45 POLLUM, M.; LAM, M.; JOCKUSCH, S.; CRESPO-HERNÁNDEZ, C. E. Dithionated Nucleobases as Effective Photodynamic Agents Against Human Epidermoid Carcinoma Cells. ChemMedChem, v. 13, n. 10, p. 1044-1050, 2018.

46 VIANNA, J. D. M.; FAZZIO, A.; CANUTO, S. Teoria Quântica de Moléculas e Sólidos. [S.I.]: Livraria da Física, 2004. 330 p.

47 BAER, M. Beyond Born-Oppenheimer: Electronic Nonadiabatic Coupling Terms and Conical Intersections. [S.I.]: Wiley-Interscience, 2006. 234 p.

48 KOPPEL, H.; DOMCKE, W.; CEDERBAUM, S. Multimode Molecular Dynamics Beyond the Born-Oppenheimer Approximation. In: PRIGOGINE, I.; STUART, A. R. (Ed.). Advances in Chem. Phys. [S.I.]: Wiley-Blackwell, 2007. v. 57, p. 59-246.

49 SZABO, A.; OSTLUND, N. S. Modern Quantum Chemistry. [S.I.]: Dover, Mineola, 1996. 480 p.

50 ROOTHAAN, C. C. J. New Developments in Molecular Orbital Theory. Rev. Mod. Phys., v. 23, p. 69-89, 1951.

51 MULLIKEN, R. S. Spectroscopy, Molecular Orbitals, and Chemical Bonding. Science, v. 157, n. 3784, p. 13-24, 1967.

52 LÖWDIN, P.-O. Correlation Problem in Many-Electron Quantum Mechanics I. Review of Different Approaches and Discussion of Some Current Ideas. Advances in Chem. Phys., p. 207-322, 1958.

53 LINDGREN, I. The Rayleigh-Schrodinger Perturbation and the Linked-diagram Theorem for a Multi-configurational Model Space. Journal of Physics B: Atomic and Mol. Phys., IOP Publishing, v. 7, n. 18, p. 2441, 1974.

54 MØLLER, C.; PLESSET, M. S. Note on an Approximation Treatment for Many-electron Systems. Phys. Rev., v. 46, n. 7, p. 618, 1934.

55 BRUECKNER, K. Many-body Problem for Strongly Interacting Particles. II. Linked Cluster Expansion. Phys. Rev., v. 100, n. 1, p. 36, 1955.

56 BRANDOW, B. H. Linked-cluster Expansions for the Nuclear Many-body Problem. Rev. Mod. Phy., v. 39, n. 4, p. 771, 1967.

57 GOLDSTONE, J. Derivation of the Brueckner Many-body Theory. Proceedings of the Royal Society of London. Series A. Mathematical and Physical Sciences, v. 239, n. 1217, p. 267-279, 1957.

58 CHRISTIANSEN, O.; OLSEN, J.; JØRGENSEN, P.; KOCH, H.; MALMQVIST, P.-Å. On the Inherent Divergence in the Møller-Plesset Series. The Neon Atom a Test Case. Chem. Phys. Lett., v. 261, n. 3, p. 369-378, 1996. 
59 HEAD-GORDON, M.; RICO, R. J.; OUMI, M.; LEE, T. J. A Doubles Correction to Electronic Excited States from Configuration Interaction in the Space of Single Substitutions. Chem. Phys. Lett., v. 219, n. 1-2, p. 21-29, 1994.

60 COESTER, F. Bound States of a Many-particle System. Nucl. Phys., v. 7, p. 421-424, 1958.

61 PALDUS, J.; ČÍŽEK, J.; SHAVITT, I. Correlation Problems in Atomic and Molecular Systems. IV. Extended Coupled-Pair Many-Electron Theory and Its Application to the BH3 Molecule. Phys. Rev. A, v. 5, n. 1, p. 50, 1972.

62 HELGAKER, T.; JORGENSEN, P.; OLSEN, J. Molecular Electronic-Structure Theory. 1. ed. [S.I.]: Wiley, 2000. 944 p.

63 CHRISTIANSEN, O.; KOCH, H.; JØRGENSEN, P. The Second-order Approximate Coupled Cluster Singles and Doubles Model CC2. Chem. Phys. Lett., v. 243, n. 5-6, p. 409-418, 1995.

$64 \mathrm{KOCH}, \mathrm{H}$.; CHRISTIANSEN, O.; JORGENSEN, P.; MERÁS, A. M. Sanchez de; HELGAKER, T. The CC3 model: An Iterative Coupled Cluster Approach Including Connected Triples. J. Chem. Phys., v. 106, n. 5, p. 1808-1818, 1997.

65 SCUSERIA, G. E.; JANSSEN, C. L.; III, H. F. S. An Efficient Reformulation of the Closedshell Coupled Cluster Single and Double Excitation (CCSD) Equations. J. Chem. Phys., v. 89, n. 12 , p. $7382-7387,1988$.

66 III, G. D. P.; BARTLETT, R. J. A Full Coupled-cluster Singles and Doubles Model: The Inclusion of Disconnected Triples. J. Chem. Phys., v. 76, n. 4, p. 1910-1918, 1982.

67 SHEPARD, R. The Multiconfiguration Self-Consistent Field Method. In: LAWLEY, K. P. (Ed.). Advances in Chemical Physics. [S.I.]: John Wiley \& Sons, Ltd, 1987. p. 63-200.

68 ROOS, B. O. The Complete Active Space Self-Consistent Field Method and its Applications in Electronic Structure Calculations. Adv. Chem. Phys., v. 69, p. 399-445, 1987.

69 MERCHÁN, M.; SERRANO-ANDRÉS, L. II - Ab Initio Methods for Excited States. In: OLIVUCCI, M. (Ed.). Computational Photochemistry. [S.I.]: Elsevier, 2005. v. 16, p. 35-91.

70 OLSEN, J.; ROOS, B. O.; JO/RGENSEN, P.; JENSEN, H. J. A. Determinant Based Configuration Interaction Algorithms for Complete and Restricted Configuration Interaction Spaces. J. Chem. Phys., v. 89, n. 4, p. 2185-2192, 1988.

71 SIEGBAhN, P. E.; ALMLÖF, J.; HEIBERG, A.; ROOS, B. O. The Complete Active Space SCF (CASSCF) Method in a Newton-Raphson Formulation with Application to the HNO Molecule. J. Chem. Phys., v. 74, n. 4, p. 2384-2396, 1981.

72 ROOS, B. O.; TAYLOR, P. R.; SIGBAHN, P. E. A Complete Active Space SCF Method (CASSCF) Using a Density Matrix Formulated Super-Cl Approach. Chem. Phys., v. 48, n. 2, p. $157-173,1980$.

73 GREIN, F.; CHANG, T. Multiconfiguration Wavefunctions Obtained by Application of the Generalized Brillouin Theorem. Chem. Phys. Lett., v. 12, n. 1, p. 44-48, 1971. 
74 SIEGBAHN, P.; HEIBERG, A.; ROOS, B.; LEVY, B. A Comparison of the Super-Cl and the Newton-Raphson Scheme in the Complete Active Space SCF Method. Phys. Scrip., v. 21, n. 3-4, p. 323, 1980.

75 AQUILANTE, F.; AUTSCHBACH, J.; CARLSON, R. K.; CHIBOTARU, L. F.; DELCEY, M. G.; VICO, L. D.; GALVÁN, I. F.; FERRÉ, N.; FRUTOS, L. M.; GAGLIARDI, L. et al. Molcas 8: New Capabilities for Multiconfigurational Quantum Chemical Calculations Across the Periodic Table. J. Comput. Chem., v. 37, n. 5, p. 506-541, 2016.

76 WERNER, H.-J.; MEYER, W. A Quadratically Convergent MCSCF Method for the Simultaneous Optimization of Several States. The Journal of Chem. Phys., v. 74, n. 10, p. 5794-5801, 1981.

77 ANDERSSON, K.; MALMQVIST, P.-Å.; ROOS, B. O. Second-order Perturbation Theory with a Complete Active Space Self-consistent Field Reference Function. J. Chem. Phys., v. 96, n. 2, p. 1218-1226, 1992.

78 ANDERSSON, K.; MALMQVIST, P.-Å.; ROOS, B. O.; SADLEJ, A. J.; WOLINSKI, K. Second-Order Perturbation Theory with a CASSCF Reference Function. J. Phys. Chem., v. 94, p. 5483-5488, 1990.

79 ANDERSSON, K.; ROOS, B. O. Multiconfigurational Second-order Perturbation Theory. In: YARKONY, D. R. (Ed.). Modern Electronic Structure Theory. [S.I.]: World Scientific Publishing, 1995. p. 55-109.

80 ROOS, B. O.; ANDERSSON, K.; FÜLSCHER, M. P.; SERRANO-ANDRÉS, L.; PIERLOOT, K.; MERCHÁN, M.; MOLINA, V. Applications of Level Shift Corrected Perturbation Theory in Electronic Spectroscopy. J. Mol. Struct., v. 388, p. 257-276, 1996.

81 ROOS, B. O. Multiconfigurational Quantum Chemistry for Ground and Excited States. In: SHUKLA, M.; LESZCZYNSKI, J. (Ed.). Induced Molecular Phenomena in Nucleic Acids: A Comprehensive Theoretical and Experimental Analysis. Chichester: Springer, 2008. p. 125-156.

82 BORIN, A. C. Métodos ab initio Multiconfiguracionais. In: MORGON, N.; COUTINHO, K. (Ed.). Métodos de Química Teórica e Modelagem Molecular. São Paulo: Livraria da Física, 2007. p. 171-207.

83 FORSBERG, N.; MALMQVIST, P.-Å. Multiconfiguration Perturbation Theory with Imaginary Level Shift. Chem. Phys. Lett., v. 274, p. 196-204, 1997.

84 PULAY, P. A Perspective on the CASPT2 Method. Int. J. Quantum Chem., v. 111, n. 13, p. 3273-3279, 2011.

85 GHIGO, G.; ROOS, B. O.; MALMQVIST, P.-Å. A Modified Definition of the Zeroth-Order Hamiltonian in Multiconfigurational Perturbation Theory (CASPT2). Chem. Phys. Lett., v. 396, p. 142-149, 2004.

86 KEPENEKIAN, M.; ROBERT, V.; GUENNIC, B. L. What Zeroth-order Hamiltonian for CASPT2 Adiabatic Energetics of Fe(II)N6 architectures? J. Chem. Phys., v. 131, n. 11, p. 114702, 2009. 
87 DAKU, L. M. L.; AQUILANTE, F.; ROBINSON, T. W.; HAUSER, A. Accurate Spinstate Energetics of Transition Metal Complexes. 1. CCSD (T), CASPT2, and DFT study of $[\mathrm{M}(\mathrm{NCH}) 6] 2+(\mathrm{M}=\mathrm{Fe}, \mathrm{Co})$. J. Chem. Theor. Comput., v. 8, n. 11, p. 4216-4231, 2012.

88 ZOBEL, J. P.; NOGUEIRA, J. J.; GONZÁLEZ, L. The IPEA Dilemma in CASPT2. Chem. Sci., v. 8, p. 1482-1499, 2017.

89 ANGELI, C.; CIMIRAGLIA, R.; MALRIEU, J.-P. N-electron Valence State Perturbation Theory: A Spinless Formulation and an Efficient Implementation of the Strongly Contracted and of the Partially Contracted Variants. J. Chem. Phys., v. 117, n. 20, p. 9138-9153, 2002.

90 NAKANO, H.; UCHIYAMA, R.; HIRAO, K. Quasi-degenerate Perturbation Theory with General Multiconfiguration Self-consistent Field Reference Functions. J. Comput. Chem., v. 23, n. 12 , p. $1166-1175,2002$.

91 Wiebeler, C.; BORIN, V.; ARAúJO, A. V. Sanchez de; SCHAPIRO, I.; BORIN, A. C. Excitation Energies of Canonical Nucleobases Computed by Multiconfigurational Perturbation Theories. Photochemistry and photobiology, v. 93, n. 3, p. 888-902, 2017.

92 FINLEY, J.; MALMQVIST, P.-Å.; ROOS, B. O.; SERRANO-ANDRÉS, L. The Multi-State CASPT2 Method. Chem. Phys. Lett., v. 288, n. 2-4, p. 299-306, 1998.

93 SHIOZAKI, T.; GYŐRFFY, W.; CELANI, P.; WERNER, H.-J. Extended Multi-state Complete Active Space Second-order Perturbation Theory: Energy and Nuclear Gradients. Int. J. Quantum Chem., v. 135, p. 081106, 2011.

94 VERYAZOV, V.; MALMQVIST, P. Å.; ROOS, B. O. How to Select Active Space for Multiconfigurational Quantum Chemistry? Int. J. Quantum Chem., v. 111, n. 13, p. 33293338, 2011.

95 MALMQVIST, P. Å.; RENDELL, A.; ROOS, B. O. The Restricted Active Space SelfConsistent-Field Method, Implemented with a Split Graph Unitary Group Approach. Journal of Physical Chemistry, v. 94, n. 14, p. 5477-5482, 1990.

96 MA, D.; MANNI, G. L.; GAGLIARDI, L. The Generalized Active Space Concept in Multiconfigurational Self-consistent Field Methods. J. Chem. Phys., v. 135, n. 4, p. 044128, 2011.

97 KOSLOFF, R. Propagation Methods for Quantum Molecular Dynamics. Annu. Rev. Phys. Chem., v. 45, n. 1, p. 145-178, 1994.

98 BECK, M. H.; JÄCKLE, A.; WORTH, G. A.; MEYER, H.-D. The Multiconfiguration Time-dependent Hartree (MCTDH) Method: A Highly Efficient Algorithm for Propagating Wavepackets. Phys. Rep., v. 324, n. 1, p. 1-105, 2000.

99 WANG, H.; THOSS, M. Multilayer Formulation of the Multiconfiguration Time-Dependent Hartree Theory. J. Chem. Phys., v. 119, n. 3, p. 1289-1299, 2003.

100 WORTH, G.; ROBB, M.; BURGHARDT, I. A Novel Algorithm for Non-Adiabatic Direct Dynamics using Variational Gaussian Wavepackets. Faraday Discuss., v. 127, p. 307-323, 2004. 
101 MAKHOV, D. V.; SYMONDS, C.; FERNANDEZ-ALBERTI, S.; SHALASHILIN, D. V. $A b$ initio Quantum Direct Dynamics Simulations of Ultrafast Photochemistry with Multiconfigurational Ehrenfest Approach. Chem. Phys., v. 493, p. 200-218, 2017.

102 CURCHOD, B. F.; MARTÍNEZ, T. J. Ab initio Nonadiabatic Quantum Molecular Dynamics. Chem. Rev., v. 118, n. 7, p. 3305-3336, 2018.

103 CRESPO-OTERO, R.; BARBATTI, M. Recent Advances and Perspectives on Nonadiabatic Mixed Quantum-Classical Dynamics. Chem. Rev., v. 118, n. 15, p. 7026-7068, 2018.

104 TULLY, J. C.; PRESTON, R. K. Trajectory Surface Hopping Approach to Nonadiabatic Molecular Collisions: The Reaction of $\mathrm{H}+$ with D2. J. Chem. Phys., v. 55, n. 2, p. 562-572, 1971.

105 SUBOTNIK, J. E.; OUYANG, W.; LANDRY, B. R. Can we Derive Tully's Surface Hopping Algorithm from the Semiclassical Quantum Liouville Equation? Almost, But Only With Decoherence. J. Chem. Phys., v. 139, n. 21, p. 214107, 2013.

106 KAPRAL, R. Surface Hopping from the Perspective of Quantum-classical Liouville Dynamics. Chem. Phys., v. 481, p. 77-83, 2016.

107 VERLET, L. Computer "Experiments"on Classical Fluids. I. Thermodynamical Properties of Lennard-Jones Molecules. Phys. Rev., v. 159, p. 98-103, 1967.

108 PITTNER, J.; LISCHKA, H.; BARBATTI, M. Optimization of Mixed Quantum-classical Dynamics: Time-derivative Coupling Terms and Selected Couplings. Chem. Phys., v. 356, n. 1, p. 147-152, 2009.

109 PLASSER, F.; RUCKENBAUER, M.; MAI, S.; OPPEL, M.; MARQUETAND, P.; GONZÁLEZ, L. Efficient and Flexible Computation of Many-electron Wave Function Overlaps. J. Chem. Theory. Comput., v. 12, n. 3, p. 1207-1219, 2016.

110 GRANUCCI, G.; PERSICO, M.; TONIOLO, A. Direct Semiclassical Simulation of Photochemical Processes with Semiempirical Wave Functions. J. Chem. Phys., v. 114, p. 1060810615, 2001.

111 PLASSER, F.; LISCHKA, H. Analysis of Excitonic and Charge Transfer Interactions from Quantum Chemical Calculations. J. Chem. Theory. Comput., v. 8, n. 8, p. 2777-2789, 2012.

112 GRANUCCI, G.; PERSICO, M.; ZOCCANTE, A. Including Quantum Decoherence in Surface Hopping. J. Chem. Phys., v. 133, n. 13, p. 134111, 2010.

113 ZHU, C.; NANGIA, S.; JASPER, A. W.; TRUHLAR, D. G. Coherent Switching with Decay of Mixing: An Improved Treatment of Electronic Coherence for Non-Born-Oppenheimer Trajectories. J. Chem. Phys., v. 121, n. 16, p. 7658-7670, 2004.

114 SUBOTNIK, J. E.; SHENVI, N. A New Approach to Decoherence and Momentum Rescaling in the Surface Hopping Algorithm. J. Chem. Phys., v. 134, n. 2, p. 024105, 2011.

115 JAIN, A.; ALGUIRE, E.; SUBOTNIK, J. E. An Efficient, Augmented Surface Hopping Algorithm that Includes Decoherence for Use in Large-scale Simulations. J. Chem. Theor. Comput., v. 12, n. 11, p. 5256-5268, 2016. 
116 PREZHDO, O. V.; ROSSKY, P. J. Evaluation of Quantum Transition Rates from Quantumclassical Molecular Dynamics Simulations. J. Chem. Phys., v. 107, n. 15, p. 5863-5878, 1997.

117 ISHIDA, T.; NANBU, S.; NAKAMURA, H. Clarification of Nonadiabatic Chemical Dynamics by the Zhu-Nakamura Theory of Nonadiabatic Transition: From Triatomic Systems to Reactions in Solutions. Int. Rev. Phys. Chem., v. 36, n. 2, p. 229-285, 2017.

118 BARBATTI, M.; RUCKENBAUER, M.; PLASSER, F.; PITTNER, J.; GRANUCCI, G.; PERSICO, M.; LISCHKA, H. Newton-X: A Surface Hopping Program for Nonadiabatic Molecular Dynamics. Wiley Interdiscip. Rev. Comput. Mol. Sci., v. 4, n. 1, p. 26-33, 2014.

119 DU, L.; LAN, Z. An On-the-fly Surface Hopping Program Jade for Nonadiabatic Molecular Dynamics of Polyatomic Systems: Implementation and Applications. J. Chem. Theor. Comput., v. 11, n. 4, p. 1360-1374, 2015.

120 TULLY, J. C. Molecular dynamics with Electronic Transitions. J. Chem. Phys., v. 93, p. 1061-1071, 1990.

121 NANGIA, S.; JASPER, A. W.; MILLER, T. F.; TRUHLAR, D. G. Army Ants Algorithm for Rare Event Sampling of Delocalized Nonadiabatic Transitions by Trajectory Surface Hopping and the Estimation of Sampling Errors by the Bootstrap Method. J. Chem. Phys., v. 120, n. 8, p. 3586-3597, 2004.

122 MAI, S.; MARQUETAND, P.; GONZÁLEZ, L. Intersystem Crossing Pathways in the Noncanonical Nucleobase 2-Thiouracil: A Time-Dependent Picture. J. Phys. Chem. Lett., v. 7 , n. 11, p. 1978-1983, 2016.

123 TAPAVICZA, E.; TAVERNELLI, I.; ROTHLISBERGER, U. Trajectory surface hopping within linear response time-dependent density-functional theory. Phys. Rev. Lett., v. 98, p. 023001, 2007.

124 PECHUKAS, P. Time-dependent Semiclassical Scattering Theory. II. Atomic Collisions. Phys. Rev., v. 181, n. 1, p. 174-185, 1969.

125 HERMAN, M. F. Nonadiabatic Semiclassical Scattering. I. Analysis of Generalized Surface Hopping Procedures. J. Chem. Phys., v. 81, n. 2, p. 754-763, 1984.

126 BREIT, G. Dirac's equation and the spin-spin interactions of two electrons. Physical Review, v. 39, n. 4, p. 616-624, 1932.

127 HESS, B. A.; MARIAN, C. M.; WAHLGREN, U.; GROPEN, O. A Mean-field Spin-orbit Method Applicable to Correlated Wavefunctions. Chem. Phys. Lett., v. 251, n. 5-6, p. 365-371, 1996.

128 HERMAN, M. F. Choosing a Good Representation of the Quantum State Wave Functions for Semiclassical Surface Hopping Calculations. J. Chem. Phys., v. 111, n. 23, p. 10427-10435, 1999.

129 MAI, S.; MARQUETAND, P.; GONZÁLEZ, L. A General Method to Describe Intersystem Crossing Dynamics in Trajectory Surface Hopping. Int. J. Quantum Chem., v. 115, n. 18, p. 1215-1231, 2015. 
130 FIEDLSCHUSTER, T.; HANDT, J.; GROSS, E.; SCHMIDT, R. Surface Hopping in Laser-driven Molecular Dynamics. Phys. Rev. A, v. 95, n. 6, p. 063424, 2017.

131 MAI, S.; RICHTER, M.; HEINDL, M.; MENGER, M. F. S. J.; ATKINS, A.; RUCKENBAUER, M.; PLASSER, F.; IBELE, L. M.; KROPF, S.; OPPEL, M.; MARQUETAND, P.; GONZÁLEZ, L. SHARC2.1: Surface Hopping Including Arbitrary Couplings - Program Package for Non-Adiabatic Dynamics. 2019. Sharc-md.org.

132 RICHTER, M.; MARQUETAND, P.; GONZÁLEZ-VÁZQUEZ, J.; SOLA, I.; GONZÁLEZ, L. SHARC: ab initio Molecular Dynamics with Surface Hopping in the Adiabatic Representation Including Arbitrary Couplings. J. Chem. Theory Comput., v. 7, p. 1253-1258, 2011.

133 MAI, S.; MARQUETAND, P.; GONZÁLEZ, L. Nonadiabatic Dynamics: The SHARC Approach. WIREs Comput. Mol. Sci., v. 8, p. e1370, 2018.

134 VALLET, V.; MARON, L.; TEICHTEIL, C.; FLAMENT, J.-P. A Two-step Uncontracted Determinantal Effective Hamiltonian-based SO-Cl Method. Journal Chem. Phys., v. 113, n. 4, p. 1391-1402, 2000.

135 BARBATTI, M.; SEN, K. Effects of Different Initial Condition Samplings on Photodynamics and Spectrum of Pyrrole. Int. J. Quantum Chem., v. 116, n. 10, p. 762-771, 2016.

136 BARBATTI, M.; GRANUCCI, G.; PERSICO, M.; RUCKENBAUER, M.; VAZDAR, M.; ECKERT-MAKSIć, M.; LISCHKA, H. The On-the-fly Surface-Hopping Program System Newton$\mathrm{X}$ : Application to ab initio Simulation of the Nonadiabatic Photodynamics of Benchmark Systems. J. Photoch. Photobio. A, v. 190, p. 228-240, 2007.

137 GEORG, H. C.; CANUTO, S. Métodos Híbridos para Modelagem do Ambiente Molecular. In: MORGON, N.; COUTINHO, K. (Ed.). Métodos de Química Teórica e Modelagem Molecular. São Paulo: Livraria da Física, 2007. p. 453-488.

138 MENNUCI, B.; CAMMI, R. Continuum Solvation Models in Chemical Physics. New York: Wiley, 2007.

139 MIERTUS, S.; SCROCCO, E.; TOMASI, J. Electrostatic Interaction of a Solute with a Continuum. A Direct Utilization of ab initio Molecular Potentials for the Prevision of Solvent Effects. Chem. Phys., v. 55, n. 1, p. 117-129, 1981.

140 KLAMT, A.; SCHÜÜRMANN, G. COSMO: A New Approach to Dielectric Screening in Solvents with Explicit Expressions for the Screening Energy and its Gradient. J. Chem. Soc., n. 5, p. 799-805, 1993.

141 MARENICH, A. V.; CRAMER, C. J.; TRUHLAR, D. G. Universal Solvation Model Based on Solute Electron Density and on a Continuum Model of the Solvent Defined by the Bulk Dielectric Constant and Atomic Surface Tensions. J. Phys. B, v. 113, n. 18, p. 6378-6396, 2009.

142 CONSTANCIEL, R. Theoretical Basis of the Empirical Reaction Field Approximations Through Continuum Model. Theor. Chim. Acta, v. 69, n. 5-6, p. 505-523, 1986.

143 TAPIA, O.; GOSCINSKI, O. Self-consistent Reaction Field Theory of Solvent Effects. Mol. Phys., v. 29, n. 6, p. 1653-1661, 1975. 
144 MCCREERY, J. H.; CHRISTOFFERSEN, R. E.; HALL, G. G. The Development of Quantum Mechanical Solvent Effect Models. Macroscopic Electrostatic Contributions. J. Am. Chem. Soc., v. 98, n. 23, p. 7191-7197, 1976.

145 RIVAIL, J.-L.; RINALDI, D. A Quantum Chemical Approach to Dielectric Solvent Effects in Molecular Liquids. Chem. Phys., v. 18, n. 1-2, p. 233-242, 1976.

146 ONSAGER, L. Electric Moments of Molecules in Liquids. J. Am. Chem. Soc., v. 58, n. 8, p. 1486-1493, 1936.

147 KIRKWOOD, J. G. Theory of Solutions of Molecules Containing Widely Separated Charges With Special Application to Zwitterions. J. Chem. Phys., v. 2, n. 7, p. 351-361, 1934.

148 SCALMANI, G.; FRISCH, M. J. Continuous surface charge polarizable continuum models of solvation. i. general formalism. J. Chem. Phys., v. 132, n. 11, p. 114110, 2010.

149 CAR, R.; PARRINELLO, M. Unified Approach for Molecular Dynamics and DensityFunctional Theory. Phys. Rev. Lett., v. 55, n. 22, p. 2471, 1985.

150 MARX, D.; HUTTER, J. A b initio Molecular Dynamics: Basic Theory and Advanced Methods. [S.I.]: Cambridge University Press, 2009.

151 MORIARTY, N. W.; KARLSTRÖM, G. Electronic Polarization of a Water Molecule in Water. A Combined Quantum Chemical and Statistical Mechanical Treatment. J. Phys. Chem., v. 100, n. 45, p. 17791-17796, 1996.

152 FRENKEL, D.; SMIT, B. Understanding Molecular Simulation: From Algorithms to Applications. [S.I.]: Elsevier, 2001. v. 1.

153 ALLEN, M. P.; TILDESLEY, D. J. Computer Simulation of Liquids. [S.I.]: Oxford university press, 2017.

154 WARSHEL, A.; LEVITT, M. Theoretical Studies of Enzymic Reactions: Dielectric, Electrostatic and Steric Stabilization of the Carbonium Ion in the Reaction of Lysozyme. J. Mol. Biol, v. 103, n. 2, p. 227-249, 1976.

155 SINGH, U. C.; KOLLMAN, P. A. A Combined ab initio Quantum Mechanical and Molecular Mechanical Method for Carrying Out Simulations on Complex Molecular Systems: Applications to the $\mathrm{CH} 3 \mathrm{Cl}+\mathrm{Cl}$ - Exchange Reaction and Gas Phase Protonation of Polyethers. J. Comput. Chem., v. 7, n. 6, p. 718-730, 1986.

156 FIELD, M. J.; BASH, P. A.; KARPLUS, M. A Combined Quantum Mechanical and Molecular Mechanical Potential for Molecular Dynamics Simulations. J. Comput. Chem., v. 11, n. 6, p. 700-733, 1990.

157 REUTER, N.; DEJAEGERE, A.; MAIGRET, B.; KARPLUS, M. Frontier Conds in QM/MM Methods: A Comparison of Different Approaches. J. Phys. Chem. A, v. 104, n. 8, p. 17201735, 2000.

158 SENN, H. M.; THIEL, W. QM/MM Methods for Biomolecular Systems. Angew. Chem. Int. Edit., v. 48, n. 7, p. 1198-1229, 2009. 
159 COUTINHO, K.; RIVELINO, R.; GEORG, H. C.; CANUTO, S. The Sequential QM/MM Method and Its Applications to Solvent Effects in Electronic and Structural Properties of Solutes. In: CANUTO, S. (Ed.). Solvation Effects on Molecules and Biomolecules: Computational Methods and Applications. Dordrecht: Springer Netherlands, 2008. p. 159-189.

160 COUTINHO, K.; GEORG, H.; FONSECA, T.; LUDWIG, V.; CANUTO, S. An Efficient Statistically Converged Average Configuration for Solvent Effects. Chem. Phys. Lett., v. 437, n. 1-3, p. 148-152, 2007.

161 SANCHEZ, M. L.; AGUILAR, M.; VALLE, F. Olivares del. Study of Solvent Effects by means of Averaged Solvent Electrostatic Potentials obtained from Molecular Dynamics Data. J. Comput. Chem., v. 18, n. 3, p. 313-322, 1997.

162 MORALES, J. L. A Numerical Study of Limited Memory BFGS Methods. Appl. Math. Lett., v. 15, n. 4, p. 481-487, 2002.

163 OKUYAMA-YOSHIDA, N.; NAGAOKA, M.; YAMABE, T. Transition-State Optimization on Free Energy Surface: Toward Solution Chemical Reaction Ergodography. Int. J. Quantum Chem., v. 70, n. 1, p. 95-103, 1998.

164 NAGAOKA, M. Structure Optimization of Solute Molecules via Free Energy Gradient Method. Kor. Chem. Soc., v. 24, p. 805-808, 2003.

165 GEORG, H. C.; CANUTO, S. Electronic Properties of Water in Liquid Environment. A Sequential QM/MM Study Using the Free Energy Gradient Method. J. Phys. B, v. 116, n. 36, p. 11247-11254, 2012.

166 FRANCO, L. R.; BRANDÃO, I.; FONSECA, T. L.; GEORG, H. C. Elucidating the Structure of Merocyanine Dyes with the ASEC-FEG Method. Phenol Blue in Solution. J. Chem. Phys., v. 145, n. 19, p. 194301, 2016.

167 MeTROPOlIS, N.; ULAM, S. The Monte Carlo Method. J. Am. Stat. Assoc., v. 44, n. 247, p. 335-341, 1949.

168 METROPOLIS, N.; ROSENBLUTH, A. W.; ROSENBLUTH, M. N.; TELLER, A. H.; TELLER, E. Equation of State Calculations by Fast Computing Machines. J. Chem. Phys., v. 21, n. 6, p. 1087-1092, 1953.

169 LANDAU, D. P.; BINDER, K. A Guide to Monte Carlo Simulations in Statistical Physics. Cambridge: University Press, 2013.

170 SALINAS, S. R. Introdução a Física Estatística. São Paulo: Edusp, 1997.

171 CEZAR, H. M.; CANUTO, S.; COUTINHO, K. DICE: A Monte Carlo Code for Molecular Simulation Including the Configurational Bias Monte Carlo Method. J. Chem. Inf. Model., v. 60, n. 7, p. 3472-3488, 2020.

172 SIEPMANN, J. I.; FRENKEL, D. Configurational Bias Monte Carlo: A New Sampling Scheme for Flexible Chains. Mol. Phys., v. 75, n. 1, p. 59-70, 1992.

173 HÜNENBERGER, P. H. Thermostat Algorithms for Molecular Dynamics Simulations. In: HOLM, C. D.; KREMER, K. P. D. (Ed.). Advanced Computer Simulation: Approaches for Soft Matter Sciences I. Berlin, Heidelberg: Springer Berlin Heidelberg, 2005. p. 105-149. 
174 JORGENSEN, W. L.; TIRADO-RIVES, J. The OPLS Optimized Potentials for Liquid Simulations: Potential Functions for Proteins, Energy Minimizations for Crystals of Cyclic Peptides and Crambin. J. Am. Chem. Soc., v. 110, n. 6, p. 1657-1666, 1988.

175 JORGENSEN, W. L.; CHANDRASEKHAR, J.; MADURA, J. D.; IMPEY, R. W.; KLEIN, M. L. Comparison of Simple Potential Functions for Simulating Liquid Water. J. Chem. Phys., v. 79 , n. 2, p. 926-935, 1983.

176 MAHONEY, M. W.; JORGENSEN, W. L. A Five-site Model for Liquid Water and the Reproduction of the Density Anomaly by Rigid, Nonpolarizable Potential Functions. J. Chem. Phys., v. 112, n. 20, p. 8910-8922, 2000.

177 LENNARD-JONES, J. E. The Equation of State of Gases and Critical Phenomena. Physica, v. 4, n. 10, p. 941-956, 1937.

178 GOOD, R. J.; HOPE, C. J. New Combining Rule for Intermolecular Distances in Intermolecular Potential Functions. J. Chem. Phys., v. 53, n. 2, p. 540-543, 1970.

179 CHATFIELD, C. The Analysis of Time Series. An Introduction. 6th. ed. [S.I.]: CRC Press, 2004.

180 COUTINHO, K. Modelo discreto de solvente. Solvatocromismo no espectro de absorção molecular. 1997. Tese (Doutorado) — Instituto de Fisica, Universidade de Sao Paulo, 1997.

181 GEORG, H. C.; COUTINHO, K.; CANUTO, S. Solvent Effects on the UV-visible Absorption Spectrum of Benzophenone in Water: A Combined Monte Carlo Quantum Mechanics Study Including Solute Polarization. J. Chem. Phys., v. 126, n. 3, p. 034507, 2007.

182 SHIN, D.; SINKELDAM, R. W.; TOR, Y. Emissive RNA Alphabet. J. Am. Chem. Soc., v. 133, n. 38, p. 14912-14915, 2011.

183 ROVIRA, A. R.; FIN, A.; TOR, Y. Chemical Mutagenesis of an Emissive RNA Alphabet. J. Am. Chem. Soc., v. 137, n. 46, p. 14602-14605, 2015.

184 SAMANTA, P. K.; MANNA, A. K.; PATI, S. K. Thieno Analogues of RNA Nucleosides: A Detailed Theoretical Study. J. Phys. B, v. 116, n. 26, p. 7618-7626, 2012.

185 GEDIK, M.; BROWN, A. Computational study of the excited state properties of modified \{RNA\} nucleobases. J. Photochem. Photobiol. A, v. 259, p. 25-32, 2013.

186 CHAWLA, M.; POATER, A.; OLIVA, R.; CAVALLO, L. Structural and Energetic Characterization of the Emissive RNA Alphabet Based on the Isothiazolo[4,3-d]pyrimidine Heterocycle Core. Phys. Chem. Chem. Phys., v. 18, n. 27, p. 18045-18053, 2016.

187 CHAWLA, M.; POATER, A.; BESALÚ-SALA, P.; KALRA, K.; OLIVA, R.; CAVALLO, L. Theoretical Characterization of Sulfur-to-Selenium Substitution in an Emissive RNA Alphabet: Impact on H-bonding Potential and Photophysical Properties. Phys. Chem. Chem. Phys., v. 20, n. 11 , p. $7676-7685,2018$.

188 ROVIRA, A. R.; FIN, A.; TOR, Y. Expanding a Fluorescent RNA Alphabet: Synthesis, Photophysics and Utility of Isothiazole-Derived Purine Nucleoside Surrogates. Chem. Sci., v. 8, n. 4, p. 2983-2993, 2017. 
189 DUNNING, T. H. Gaussian Basis Sets for Use in Correlated Molecular Calculations. I. The Atoms Boron Through Neon and Hydrogen. J. Chem. Phys., v. 90, n. 2, p. 1007-1023, 1989.

190 VICO, L. D.; OLIVUCCI, M.; LINDH, R. New General Tools for Constrained Geometry Optimizations. J. Chem. Theor. Comput., v. 1, n. 5, p. 1029-1037, 2005.

191 Metropolis, N.; ROSEnBluTH, A. W.; ROSENBlUTH, M. N.; TELLER, A. H.; TELLER, E. Equation of State Calculations by Fast Computing Machines. J. Chem. Phys., v. 21, n. 6, p. 1087-1092, 1953.

192 JORGENSEN, W. L.; MAXWELL, D. S.; TIRADO-RIVES, J. Development and Testing of the OPLS All-Atom Force Field on Conformational Energetics and Properties of Organic Liquids. J. Am. Chem. Soc., v. 118, n. 45, p. 11225-11236, 1996.

193 BRENEMAN, C. M.; WIBERG, K. B. Determining Atom-Centered Monopoles from Molecular Electrostatic Potentials. The Need for High Sampling Density in Formamide Conformational Analysis. J. Comput. Chem., v. 11, n. 3, p. 361-373, 1990.

194 FERRÉ, N.; ÁNGYÁN, J. G. Approximate Electrostatic Interaction Operator for QM/MM Calculations. Chem. Phys. Lett., v. 356, n. 3-4, p. 331-339, 2002.

195 BERENDSEN, H. J. C.; GRIGERA, J. R.; STRAATSMA, T. P. The Missing Term in Effective Pair Potentials. J. Phys. Chem., v. 91, n. 24, p. 6269-6271, 1987.

196 LUHMER, M.; REISSE, J. Molecular Dynamics Simulation Study of the NMR Relaxation of Xenon-131 Dissolved in 1,3-Dioxane and 1,4-Dioxane. J. Magn. Reson., v. 115, n. 2, p. 197-205, 1995.

197 ZHANG, L.; KONG, X.; WANG, M.; ZHENG, M. Photophysical Properties of the Isomorphic Emissive RNA Nucleobase Analogues and Effect of Water Solution, Ribose, and Base Pairing: A Theoretical Study. Int. J. Quantum Chem., v. 117, n. 13, p. e25377, 2017.

198 SWIATLA-WOJCIK, D. Evaluation of the Criteria of Hydrogen Bonding in Highly Associated Liquids. Chem. Phys., v. 342, n. 1-3, p. 260-266, 2007.

199 MEZEI, M.; BEVERIDGE, D. L. Theoretical Studies of Hydrogen Bonding in Liquid Water and Dilute Aqueous Solutions. J. Chem. Phys., v. 74, n. 1, p. 622-632, 1981.

200 COUTINHO, K.; CANUTO, S. The Sequential Monte Carlo-Quantum Mechanics Methodology. Application to the Solvent Effects in the Stokes Shift of Acetone in Water. J. Mol. Struct., v. 632, n. 1-3, p. 235-246, 2003.

201 BASCH, H.; GARMER, D.; JASIEN, P.; KRAUSS, M.; STEVENS, W. Electrical Properties of nucleic Acid Bases. Chem. Phys. Lett., v. 163, n. 6, p. 514-522, 1989.

202 DEVOE, H.; TINOCO, I. The Stability of Helical Polynucleotides: Base contributions. J. Mol. Bio., v. 4, n. 6, p. 500-517, 1962.

203 BROWN, R. B.; GODFREY, P. D.; NAUGHTON, D.; PIERLOT, A. P. Sequence-selective Hydrolysis of Duplex DNA by an Oligonucleotide-directed Nuclease. J. Am. Chem. Soc., v. 110, p. $514,1989$. 
204 GAO, J.; XIA, X. A Priori Evaluation of Aqueous Polarization Effects Through Monte Carlo QM-MM Simulations. Science, v. 258, n. 5082, p. 631-635, 1992.

205 LUDWIG, V.; COSTA, Z. M. da; AMARAL, M. S. do; BORIN, A. C.; CANUTO, S.; SERRANO-ANDRÉS, L. Photophysics and Photostability of Adenine in Aqueous Solution: A Theoretical Study. Chem. Phys. Lett., v. 492, n. 1, p. 164-169, 2010.

206 LUDWIG, V.; COUTINHO, K.; CANUTO, S. A Monte Carlo-Quantum Mechanics Study of the Lowest $n-\pi^{*}$ and $\pi-\pi^{*}$ States of Uracil in Water. Phys. Chem. Chem. Phys., v. 9, p. 4907-4912, 2007.

207 SERRANO-ANDRÉS, L.; MERCHÁN, M. Quantum Chemistry of the Excited state: 2005 Overview. J. Mol. Struct., v. 729, n. 1-2, p. 99-108, 2005.

208 GEORG, H. C.; COUTINHO, K.; CANUTO, S. Converged Electronic Polarization of Acetone in Liquid Water and the Role in the $n \rightarrow \pi^{*}$ Transition. Chem. Phys. Lett., v. 429, n. 1-3, p. 119-123, 2006.

209 BISTAFA, C.; CANUTO, S. Solvent Effects on the Two Lowest-Lying Singlet Excited States of 5-fluorouracil. Theor. Chem. Acc., v. 132, n. 1, p. 1299, 2013.

210 GESTER, R. M.; GEORG, H. C.; FONSECA, T. L.; PROVASI, P. F.; CANUTO, S. A Simple Analysis of the Influence of the Solvent-Induced Electronic Polarization on the $15 \mathrm{~N}$ Magnetic Shielding of Pyridine in Water. Theor. Chem. Acc., v. 131, n. 5, p. 1220, 2012.

211 OROZCO-GONZALEZ, Y.; BISTAFA, C.; CANUTO, S. Solvent Effect on the Stokes Shift and on the Nonfluorescent Decay of the Daidzein Molecular System. J. Phys. Chem. A, v. 117, n. 21, p. 4404-4411, 2013.

212 KISTLER, K. A.; MATSIKA, S. Quantum Mechanical Studies of the Photophysics of DNA and RNA Bases. In: YORK, D. M.; LEE, T.-S. (Ed.). Multi-scale Quantum Models for Biocatalysis: Modern Techniques and Applications. Dordrecht: Springer Netherlands, 2009. p. 285-339.

213 SERRANO-ANDRES, L.; MERCHAN, M.; BORIN, A. C. Adenine and 2-aminopurine: Paradigms of Modern Theoretical Photochemistry. Proc. Nat. Aca. Sci., v. 103, n. 23, p. 8691-8696, 2006.

214 SERRANO-ANDRÉS, L.; MERCHÁN, M.; BORIN, A. C. A Three-State Model for the Photophysics of Adenine. Chem. Eur. J., v. 12, n. 25, p. 6559-6571, 2006.

215 MERCHÁN, M.; SERRANO-ANDRÉS, L. Ultrafast Internal Conversion of Excited Cytosine via the Lowest $\pi \pi^{*}$ Electronic Singlet State. J. Am. Chem. Soc., v. 125, n. 27, p. 8108-8109, 2003.

216 MERCHAN, M.; GONZALEZ-LUQUE, R.; CLIMENT, T.; SERRANO-ANDRES, L.; RODRÍGUEZ, E.; REGUERO, M.; PELAEZ, D. Unified Model for the Ultrafast Decay of Pyrimidine Nucleobases. J. Phys. B, v. 110, n. 51, p. 26471-26476, 2006.

217 SERRANO-ANDRES, L.; MERCHAN, M.; BORIN, A. C. A Three-State Model for the Photophysics of Guanine. J. Am. Chem. Soc., v. 130, n. 8, p. 2473-2484, 2008.

218 MATSIKA, S. Radiationless Decay of Excited States of Uracil Through Conical Intersections. J. Phys. Chem. A, v. 108, n. 37, p. 7584-7590, 2004. 
219 GUO, X.; LAN, Z.; CAO, Z. Ab initio Insight into Ultrafast Nonadiabatic Decay of Hypoxanthine: Keto-N7H and Keto-N9H Tautomers. Phys. Chem. Chem. Phys., v. 15, n. 26, p. 10777-10782, 2013.

220 CREMER, D. t.; POPLE, J. General Definition of Ring Puckering Coordinates. J. Am. Chem. Soc., v. 97, n. 6, p. 1354-1358, 1975.

221 BOEYENS, J. C. The Conformation of Six-Membered Rings. J. Crystal Mol. Struct., v. 8, n. 6, p. 317-320, 1978.

222 KARSILI, T. N.; THODIKA, M.; NGUYEN, L.; MATSIKA, S. The Origin of Fluorescence in DNA Thio-analogues. Chem. Phys., v. 515, p. 434-440, 2018.

223 BARBATTI, M.; LISCHKA, H. Nonadiabatic Deactivation of 9H-Adenine: A Comprehensive Picture Based on Mixed Quantum-Classical Dynamics. J. Am. Chem. Soc., v. 130, n. 21, p. 6831-6839, 2008.

224 BARBATTI, M.; BORIN, A. C.; ULRICH, S. Photoinduced Processes in Nucleic Acids. In: BARBATTI, M.; BORIN, A. C.; ULRICH, S. (Ed.). Photoinduced Phenomena in Nucleic Acids I - Nucleobases in the Gas Phase and in Solvents. Cham: Springer International Publishing, 2015. v. 355, p. 1-32.

225 MARTINEZ-FERNANDEZ, L.; GAVVALA, K.; SHARMA, R.; DIDIER, P.; RICHERT, L.; MARTI, J. S.; MORI, M.; MELY, Y.; IMPROTA, R. Excited-State Dynamics of Thienoguanosine, an Isomorphic Highly Fluorescent Analogue of Guanosine. Chem. Eur. J., v. 25, n. 30, p. 7375-7386, 2019.

226 BORIN, A. C.; SERRANO-ANDRÉS, L.; LUDWIG, V.; COUTINHO, K.; CANUTO, S. Theoretical Electronic Spectra of 2-aminopurine in Vapor and in Water. Int. J. Quantum Chem., v. 106, n. 13, p. 2564-2577, 2006.

227 PAL, S. K.; PEON, J.; ZEWAIL, A. H. Ultrafast Decay and Hydration Dynamics of DNA Bases and Mimics. Chem. Phys. Lett., v. 363, n. 1-2, p. 57-63, 2002.

228 HE, R.-X.; DUAN, X.-H.; LI, X.-Y. Theoretical Investigation of Spectral Properties and Tautomerization Mechanism of 2-aminopurine. Phys. Chem. Chem. Phys., v. 8, n. 5, p. 587-591, 2006.

229 RACHOFSKY, E. L.; ROSS, J. A.; KRAUSS, M.; OSMAN, R. CASSCF Investigation of Electronic Excited States of 2-aminopurine. J. Phys. Chem. A, ACS Publications, v. 105, n. 1, p. 190-197, 2001.

230 BARBATTI, M.; LISCHKA, H. Why Water Makes 2-aminopurine Fluorescent? Phys. Chem. Chem. Phys., v. 17, n. 23, p. 15452-15459, 2015.

231 JEAN, J. M.; HALL, K. B. Theoretical Study of the Excited State Properties and Transitions of 2-aminopurine in the Gas phase and in Solution. J. Phys. Chem. A, ACS Publications, v. 104, n. 9, p. 1930-1937, 2000.

232 ABOU-ZIED, O. K. Effect of NH2 Rotation on the Fluorescence of 2-aminopurine in Solution. J. Photochem. Photobiol. A, v. 261, p. 1-6, 2013. 
233 NEELY, R. K.; MAGENNIS, S. W.; DRYDEN, D. T.; JONES, A. C. Evidence of Tautomerism in 2-aminopurine from Fluorescence Lifetime Measurements. J. Phys. Chem. B, v. 108, n. 45 , p. $17606-17610,2004$.

234 BÖHM, H.; MCDONALD, I.; MADDEN, P. An Effective Pair Potential for Liquid Acetonitrile. Mol. Phys., v. 49, n. 2, p. 347-360, 1983.

235 JORGENSEN, W. L. Optimized Intermolecular Potential Functions for Liquid Alcohols. J. Phys. Chem., v. 90, n. 7, p. 1276-1284, 1986.

236 PLIEGO, J.; JOSEFREDO, R. Thermodynamic Cycles and the Calculation of pKa. Chem. Phys. Lett., v. 367, n. 1-2, p. 145-149, 2003.

237 JORGENSEN, W. L.; THOMAS, L. L. Perspective on Free-Energy Perturbation Calculations for Chemical Equilibria. J. Chem. Theor. Comput., v. 4, n. 6, p. 869-876, 2008.

238 JORGENSEN, W. L.; RAVIMOHAN, C. Monte carlo simulation of differences in free energies of hydration. J. Chem. Phys., v. 83, n. 6, p. 3050-3054, 1985.

239 BARONE, V.; COSSI, M.; TOMASI, J. A New Definition of Cavities for the Computation of Solvation Free Energies by the Polarizable Continuum Model. J. Chem. Phys., v. 107, n. 8, p. 3210-3221, 1997.

240 JORGENSEN, W. L.; BUCKNER, J. K.; BOUDON, S.; TIRADO-RIVES, J. Efficient Computation of Absolute Free Energies of Binding by Computer Simulations. Application to the Methane Dimer in Water. J. Chem. Phys., v. 89, n. 6, p. 3742-3746, 1988.

241 SEEFELD, K. A.; PLÜTZER, C.; LÖWENICH, D.; HÄBER, T.; LINDER, R.; KLEINERMANNS, K.; TATCHEN, J.; MARIAN, C. M. Tautomers and Electronic States of Jet-cooled 2-aminopurine Investigated by Double Resonance Spectroscopy and Theory. Phys. Chem. Chem. Phys., v. 7, n. 16, p. 3021-3026, 2005.

242 MCCULlOUGH, A. K.; DODSON, M.; SCHÄRER, O. D.; LLOYD, R. S. The Role of Base Flipping in Damage Recognition and Catalysis by T4 Endonuclease V. J. Bio. Chem., v. 272 , n. 43 , p. $27210-27217,1997$.

243 REICHARDT, C.; WEN, C.; VOGT, R. A.; CRESPO-HERNÁNDEZ, C. E. Role of Intersystem Crossing in the Fluorescence Quenching of 2-aminopurine 2-deoxyriboside in Solution. Photochem. Photobio. Sci., v. 12, n. 8, p. 1341-1350, 2013.

244 BÖHNKE, H.; RÖTTGER, K.; INGLE, R. A.; MARROUX, H. J.; BOHNSACK, M.; ORR-EWING, A. J.; TEMPS, F. Efficient Intersystem Crossing in 2-aminopurine Riboside Probed by Femtosecond Time-resolved Transient Vibrational Absorption Spectroscopy. Phys. Chem. Chem. Phys., v. 20, n. 30, p. 20033-20042, 2018.

245 MILlER, J. L.; KOLLMAN, P. A. Solvation Free Energies of the Nucleic Acid Bases. J. Phys. Chem., v. 100, n. 20, p. 8587-8594, 1996.

246 JUMBRI, K.; MICAELO, N. M.; RAHMAN, M. B. A. Solvation Dree energies of Nucleic Acid Bases in lonic Liquids. Mol. Sim., v. 43, n. 1, p. 19-27, 2017.

247 HARADA, Y.; OKABE, C.; KOBAYASHI, T.; SUZUKI, T.; ICHIMURA, T.; NISHI, N.; $\mathrm{XU}$, Y.-Z. Ultrafast Intersystem Crossing of 4-Thiothymidine in Aqueous Solution. J. Phys. Chem. Lett., v. 1, p. 480-484, 2010. 
248 HARADA, Y.; SUZUKI, T.; ICHIMURA, T.; XU, Y.-Z. Triplet Formation of 4Thiothymidine and Its Photosensitization to Oxygen Studied by Time-Resolved Thermal Lensing Technique. J. Phys. Chem. B, v. 111, p. 5518-5524, 2007.

249 MAI, S.; POLLUM, M.; MARTÍNEZ-FERNÁNDEZ, L.; DUNN, N.; MARQUETAND, P.; CORRAL, I.; CRESPO-HERNÁNDEZ, C. E.; GONZÁLEZ, L. The Origin of Efficient Triplet State Population in Sulfur-Substituted Nucleobases. Nat. Commun., v. 7, p. 13077, 2016.

250 MOHAMADZADE, A.; BAI, S. M.; BARBATTI, M.; ULLRICH, S. Intersystem Crossing Dynamics in Singly Substituted Thiouracil Studied by Time-Resolved Photoelectron Spectroscopy: Micro-Environmental Effects due to Sulfur Position. Chem. Phys., v. 515, p. 572-579, 2018.

251 KURAMOCHI, H.; KOBAYASHI, T.; SUZUKI, T.; ICHIMURA, T. Excited-State Dynamics of 6-Aza-2-Thiothymine and 2-Thiothymine: Highly Efficient Intersystem Crossing and Singlet Oxygen Photosensitization. J. Phys. Chem. B, v. 114, p. 8782-8789, 2010.

252 POLLUM, M.; CRESPO-HERNÁNDEZ, C. E. Communication: The Dark Singlet State as a Doorway State in the Ultrafast and Efficient Intersystem Crossing Dynamics in 2-Thiothymine and 2-Thiouracil. J. Chem. Phys., v. 140, p. 071101, 2014.

253 BAI, S.; BARBATTI, M. On the Decay of the Triplet State of Thionucleobases. Phys. Chem. Chem. Phys., v. 19, n. 20, p. 12674-12682, 2017.

254 CUI, G. L.; THIEL, W. Intersystem Crossing Enables 4-Thiothymidine to Act as a Photosensitizer in Photodynamic Therapy: An Ab Initio QM/MM Study. J. Phys. Chem. Lett., v. 5, p. 2682-2687, 2014.

255 CUI, G. L.; FANG, W.-H. State-Specific Heavy-Atom Effect on Intersystem Crossing Processes in 2-Thiothymine: A Potential Photodynamic Therapy Photosensitizer. J. Chem. Phys., v. 138, p. 044315, 2013.

256 GOBBO, J. P.; BORIN, A. C. 2-Thiouracil Deactivation Pathways and Triplet States Population. Comput. Theor. Chem., v. 1040-1041, p. 195-201, 2014.

257 GOBBO, J. P.; BORIN, A. C. On the Population of Triplet Excited States of 6-Aza-2Thiothymine. J. Phys. Chem. A, v. 117, p. 5589-5596, 2013.

258 YU, H.; SANCHEZ-RODRIGUEZ, J. A.; POLLUM, M.; CRESPO-HERNÁNDEZ, C. E.; MAI, S.; MARQUETAND, P.; GONZÁLEZ, L.; ULLRICH, S. Internal Conversion and Intersystem Crossing Pathways in UV Excited, Isolated Uracils and Their Implications in Prebiotic Chemistry. Phys. Chem. Chem. Phys., v. 18, p. 20168-20176, 2016.

259 MAI, S.; MARQUETAND, P.; GONZÁLEZ, L. A Static Picture of the Relaxation and Intersystem Crossing Mechanisms of Photoexcited 2-Thiouracil. J. Phys. Chem. A, v. 119, p. 9524-9533, 2015.

260 ASHWOOD, B.; JOCKUSCH, S.; CRESPO-HERNÁNDEZ, C. E. Excited-State Dynamics of the Thiopurine Prodrug 6-Thioguanine: Can N9-Glycosylation Affect Its Phototoxic Activity? Molecules, v. 22, n. 3, p. 379, 2017.

261 CATON-WILLIAMS, J.; HUANG, Z. Biochemistry of Selenium-Derivatized Naturally Occurring and Unnatural Nucleic Acids. Chem. Biodivers., v. 5, p. 396-407, 2008. 
262 CATON-WILLIAMS, J.; HUANG, Z. Synthesis and DNA-Polymerase Incorporation of Colored 4-Selenothymidine Triphosphate for Polymerase Recognition and DNA Visualization. Angew. Chem. Int. Ed., v. 120, p. 1747-1749, 2008.

263 MAUTNER, H. G.; CHU, S.-H.; JAFFE, J. J.; SARTORELLI, A. C. The Synthesis and Antineoplastic Properties of Selenoguanine, Selenocytosine and Related Compounds. J. Med. Chem., v. 6, n. 1, p. 36-39, 1963.

264 ABOUL-ENEIN, H. Y.; AWAD, A. A.; AL-ANDIS, N. M. Synthesis and the Antiperoxidase Activity of Seleno analogues of the Antithyroid Drug Propylthiouracil. J. Enzym. Inhib., v. 7, n. 2, p. 147-150, 1993.

265 SALON, J.; GAN, J.; ABDUR, R.; LIU, H.; HUANG, Z. Synthesis of 6-Se-guanosine RNAs for Structural Study. Org. Lett., v. 15, n. 15, p. 3934-3937, 2013.

266 HASSAN, A. E.; SHENG, J.; ZHANG, W.; HUANG, Z. High Fidelity of Base Pairing by 2-selenothymidine in DNA. J. Am. Chem. Soc., v. 132, n. 7, p. 2120-2121, 2010.

267 FAUSTINO, I.; CURUTCHET, C.; LUQUE, F. J.; OROZCO, M. The DNA-forming Properties of 6-selenoguanine. Phys. Chem. Chem. Phys., v. 16, n. 3, p. 1101-1110, 2014

268 MAI, S.; WOLF, A.-P.; GONZÁLEZ, L. Curious Case of 2-Selenouracil: Efficient Population of Triplet States and Yet Photostable. J. Chem. Theory. Comput., v. 15, n. 6, p. 3730-3742, 2019.

269 FARRELL, K. M.; BRISTER, M. M.; PITTELKOW, M.; SøLLING, T. I.; CRESPOHERNÁNDEZ, C. E. Heavy-Atom-Substituted Nucleobases in Photodynamic Applications: Substitution of Sulfur with Selenium in 6-Thioguanine Induces a Remarkable Increase in the Rate of Triplet Decay in 6-Selenoguanine. J. Am. Chem. Soc., v. 140, p. 11214-11218, 2018.

270 MANAE, M. A.; HAZRA, A. Interplay Between Conjugation and Size-driven Delocalization Leads to Characteristic Properties of Substituted Thymines. J. Phys. Chem. A, v. 121, n. 42, p. 8147-8153, 2017.

271 FANG, Y.-G.; PENG, Q.; FANG, Q.; FANG, W.; CUI, G. MS-CASPT2 Studies on the Photophysics of Selenium-Substituted Guanine Nucleobase. ACS Omega, v. 4, n. 6, p. 9769-9777, 2019.

272 PIRILLO, J.; MAZZONE, G.; RUSSO, N.; BERTINI, L. Photophysical Properties of S, Se and Te-Substituted Deoxyguanosines: Insight into Their Ability To Act as Chemotherapeutic Agents. J. Chem. Inf. Model, v. 57, n. 2, p. 234-242, 2017.

273 AQUILANTE, F.; MALMQVIST, P.-Å.; PEDERSEN, T. B.; GHOSH, A.; ROOS, B. O. Cholesky Decomposition-based Multiconfiguration Second-Order Perturbation Theory (CDCASPT2): Application to the Spin-state Energetics of Colll(diiminato)(NPh). J. Chem. Theor. Comput., v. 4, n. 5, p. 694-702, 2008.

274 SCHIRMER, J. Beyond the Random-Phase Approximation: A New Approximation Scheme for the Polarization Propagator. Phys. Rev. A, v. 26, p. 2395-2416, 1982.

275 TROFIMOV, A.; SCHIRMER, J. An Efficient Polarization Propagator Approach to Valence Electron Excitation Spectra. J. Phys. B, v. 28, n. 12, p. 2299, 1995. 
276 DREUW, A.; WORMIT, M. The Algebraic Diagrammatic Construction Scheme for the Polarization Propagator for the Calculation of Excited States. Wiley Interdiscip. Rev. Comput. Mol. Sci., v. 5, n. 1, p. 82-95, 2015.

277 BUDZÁK, S.; SCALMANI, G.; JACQUEMIN, D. Accurate Excited-state Geometries: A CASPT2 and Coupled-cluster Reference Database for Small Molecules. J. Chem. Theor. Comput., v. 13, n. 12, p. 6237-6252, 2017.

278 VETTA, M. D.; GONZÁLEZ, L.; CORRAL, I. The Role of Electronic Triplet States and High-Lying Singlet States in the Deactivation Mechanism of the Parent BODIPY: An ADC(2) and CASPT2 Study. ChemPhotoChem, v. 3, n. 9, p. 727-738, 2019.

279 PENG, D.; REIHER, M. Exact Decoupling of the Relativistic Fock Operator. Theor. Chem. Acc., v. 131, n. 1, p. 1081, 2012.

280 WIDMARK, P.-O.; MALMQVIST, P.-Å.; ROOS, B. O. Density Matrix Averaged Atomic Natural Orbital (ANO) Basis Sets for Correlated Molecular Wave Functions. Theor. Chim. Acta, v. 77, n. 5, p. 291-306, 1990.

281 AQUILANTE, F.; LINDH, R.; PEDERSEN, T. B. Unbiased Auxiliary Basis Sets for Accurate Two-electron Integral Approximations. J. Chem. Phys., v. 127, n. 11, p. 114107, 2007.

282 GALVÁN, F. et al. OpenMolcas: From Source Code to Insight. J. Chem. Theory. Comput., v. 15, p. 5925-5964, 2019.

283 AQUILANTE, F. et al. Modern Quantum Chemistry with [Open]Molcas. J. Chem. Phys., v. 152, n. 21, p. 214117, 2020.

284 BALASUBRAMANI, S. G. et al. TURBOMOLE: Modular Program Suite for ab initio Quantum-chemical and Condensed-matter Simulations. J. Chem. Phys., v. 152, n. 18, p. 184107, 2020.

285 BEARPARK, M. J.; ROBB, M. A.; SCHLEGEL, H. B. A Direct Method for the Location of the Lowest Energy Point on a Potential Surface Crossing. Chem. Phys. Lett., v. 223, p. 269-274, 1994.

286 LEVINE, B. G.; COE, J. D.; MARTÍNEZ, T. J. Optimizing Conical Intersections without Derivative Coupling Cectors: Application to Multistate Multireference Second-order Perturbation Theory (MS-CASPT2). J. Phys. B, v. 112, n. 2, p. 405-413, 2008.

287 NEESE, F. The ORCA Program System. Wiley Interdiscip. Rev. Comput. Mol. Sci., v. 2, p. 73-78, 2012.

288 CASE, D. et al. AMBER2018. 2018. University of California, San Francisco.

289 BAYLY, C. I.; CIEPLAK, P.; CORNELL, W.; KOLLMAN, P. A. A Well-behaved Electrostatic Potential Based Method using Charge Restraints for Deriving Atomic Charges: The RESP Model. J. Phys. Chem. Lett., v. 97, p. 10269-10280, 1993.

290 PéREZ, A.; MARCHáN, I.; SVOZIL, D.; SPONER, J.; CHEATHAM, T. E.; LAUGHTON, C. A.; OROZCO, M. Refinement of the AMBER Force Field for Nucleic Acids: Improving the Description of $\alpha / \gamma$ Conformers. Biophys. J., v. 92, p. 3817-3829, 2007. 
291 WANG, J.; WOLF, R. M.; CALDWELL, J. W.; KOLLMAN, P. A.; CASE, D. A. Development and Testing of a General Amber Force Field. J. Comput. Chem., v. 26, p. 114-114, 2005.

292 CHRISTOFFERSON, A.; ZHAO, L.; SUN, H.; HUANG, Z.; HUANG, N. Theoretical Studies of the Base Pair Fidelity of Selenium-Modified DNA. J. Phys. Chem. B, v. 115, p. 10041-10048, 2011.

293 WU, Y.; TEPPER, H. L.; VOTH, G. A. Flexible Simple Point-charge Water Model with Improved Liquid-state Properties. J. Chem. Phys., v. 124, p. 024503, 2006.

294 MAI, S.; GATTUSO, H.; MONARI, A.; GONZÁLEZ, L. Novel Molecular-Dynamics-Based Protocols for Phase Space Sampling in Complex Systems. Front. Chem., v. 6, p. 495, 2018.

295 GRANUCCI, G.; PERSICO, M. Critical Appraisal of the Fewest Switches Algorithm for Surface Hopping. J. Chem. Phys., v. 126, n. 13, p. 134114, 2007.

296 MARTÍNEZ-FERNÁNDEZ, L.; CORRAL, I.; GRANUCCI, G.; PERSICO, M. Competing Ultrafast Intersystem Crossing and Internal Conversion: A Time Resolved Picture for the Deactivation of 6-thioguanine. Chem. Sci., v. 5, n. 4, p. 1336-1347, 2014.

297 MARAZZI, M.; MAI, S.; ROCA-SANJUÁAN, D.; DELCEY, M. G.; LINDH, R.; GONZÁLEZ, L.; MONARI, A. Benzophenone Ultrafast Triplet Population: Revisiting the Kinetic Model by Surface-Hopping Dynamics. J. Phys. Chem. Lett., v. 7, n. 4, p. 622-626, 2016.

298 PLASSER, F. TheoDORE: A Toolbox for a Detailed and Automated Analysis of Electronic Excited State Computations. The Journal of Chem. Phys., v. 152, n. 8, p. 084108, 2020.

299 MCQUARRIE, D. A. Statistical Mechanics. New York: HarperCollins Publishing, Inc., 1976. (Harper's Chemistry Series).

300 MARTÍNEZ-FERNÁNDEZ, L.; GONZÁLEZ, L.; CORRAL, I. An ab initio Mechanism for Efficient Population of Triplet States in Cytotoxic Sulfur Substituted DNA bases: The Case of 6-thioguanine. ChemComm, v. 48, n. 15, p. 2134-2136, 2012. 

Apêndices 



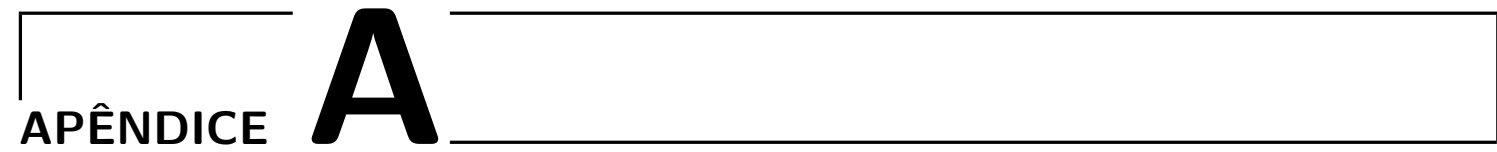

\section{Espaço ativo utilizado no método CASSCF e CASPT2 para o alfabeto ribonucleosídeo fluorescente}
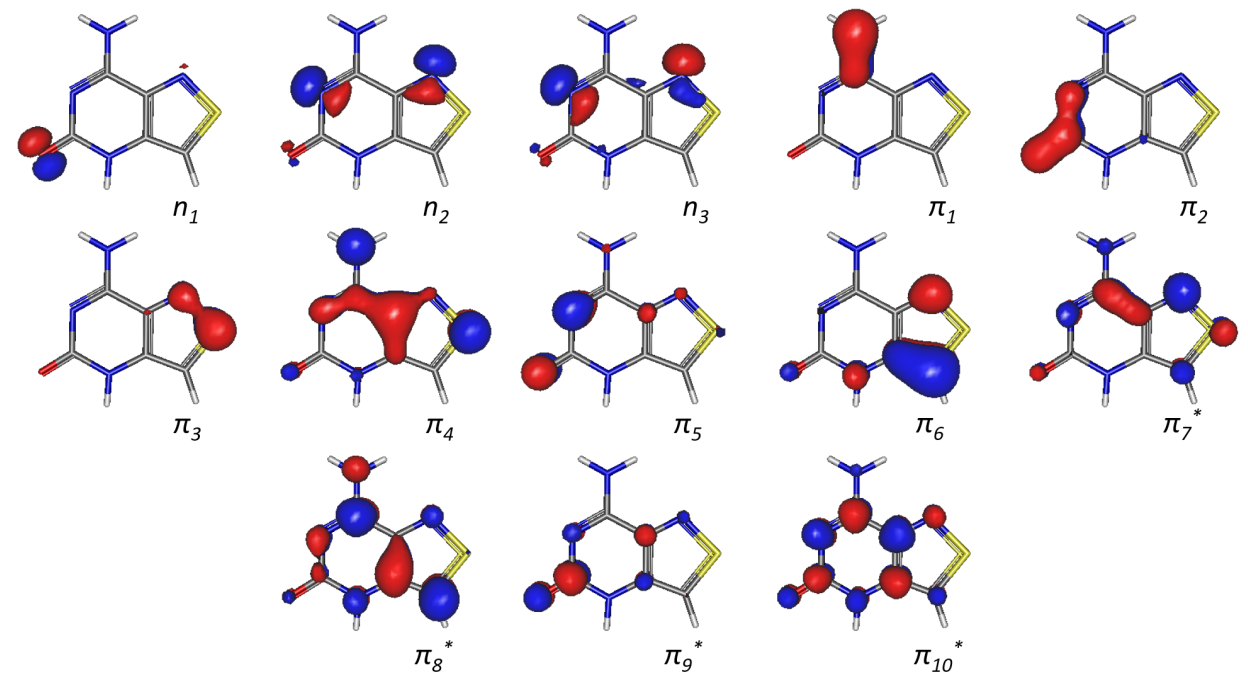

Figura A.1 - Espaço ativo para a molécula ${ }^{\text {tz }} \mathbf{G}$ com 3 orbitais $n$ e 10 orbitais $\pi$, contendo 18 elétrons calculado no nível SA(8)-CASSCF/cc-pVDZ. 

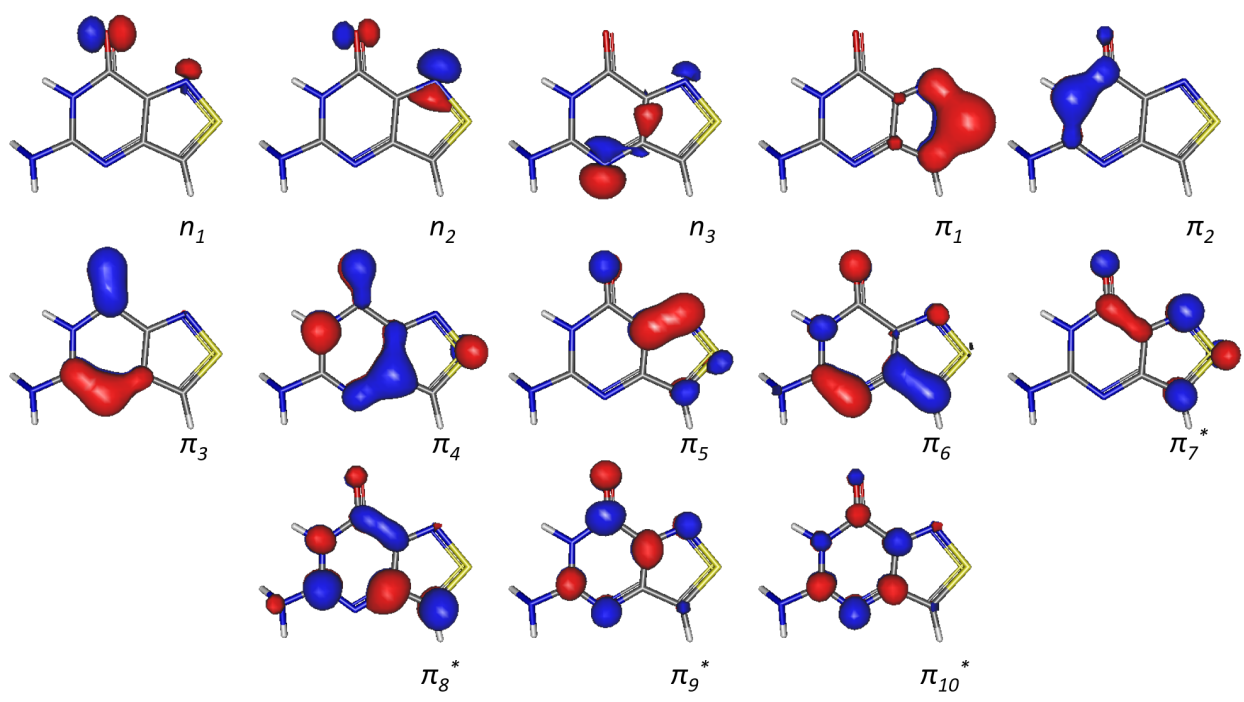

Figura A.2 - Espaço ativo para a molécula ${ }^{\text {tz }} \mathbf{G}$ com 3 orbitais $n$ e 10 orbitais $\pi$, contendo 18 elétrons calculado no nível SA(8)-CASSCF/cc-pVDZ.
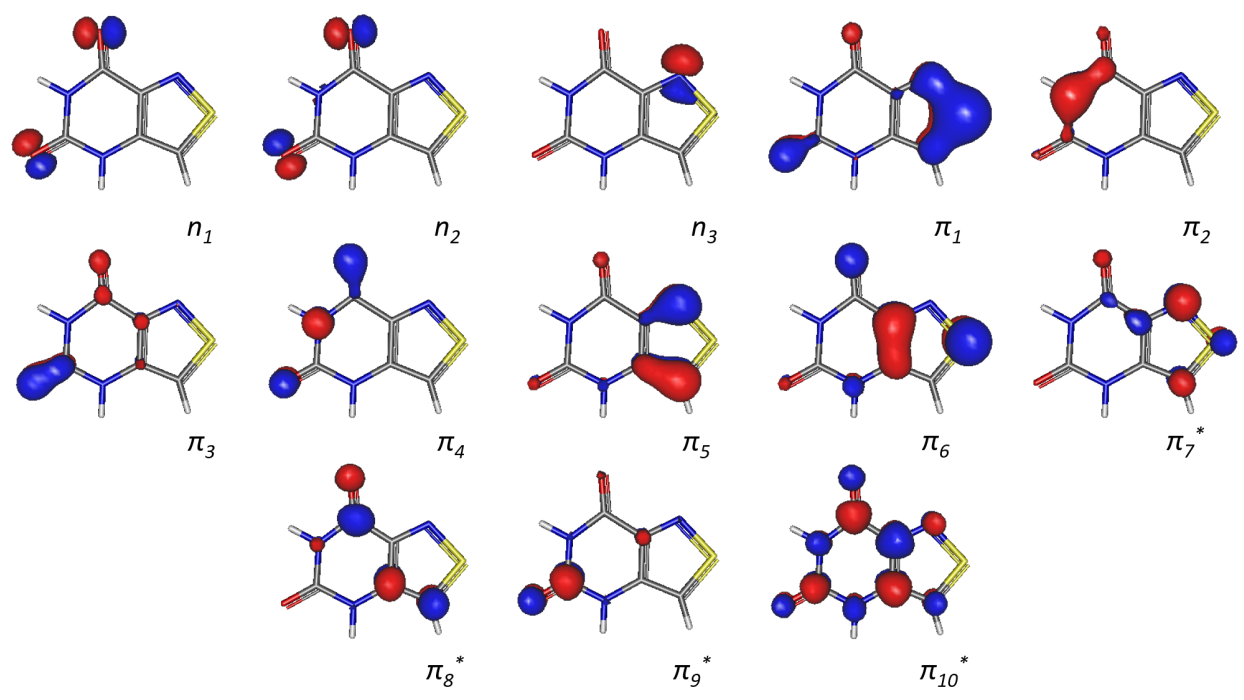

Figura A.3 - Espaço ativo para a molécula ${ }^{\text {tz }} \mathbf{U}$ com 3 orbitais $n$ e 10 orbitais $\pi$, contendo 18 elétrons calculado no nível SA(8)-CASSCF/cc-pVDZ. 

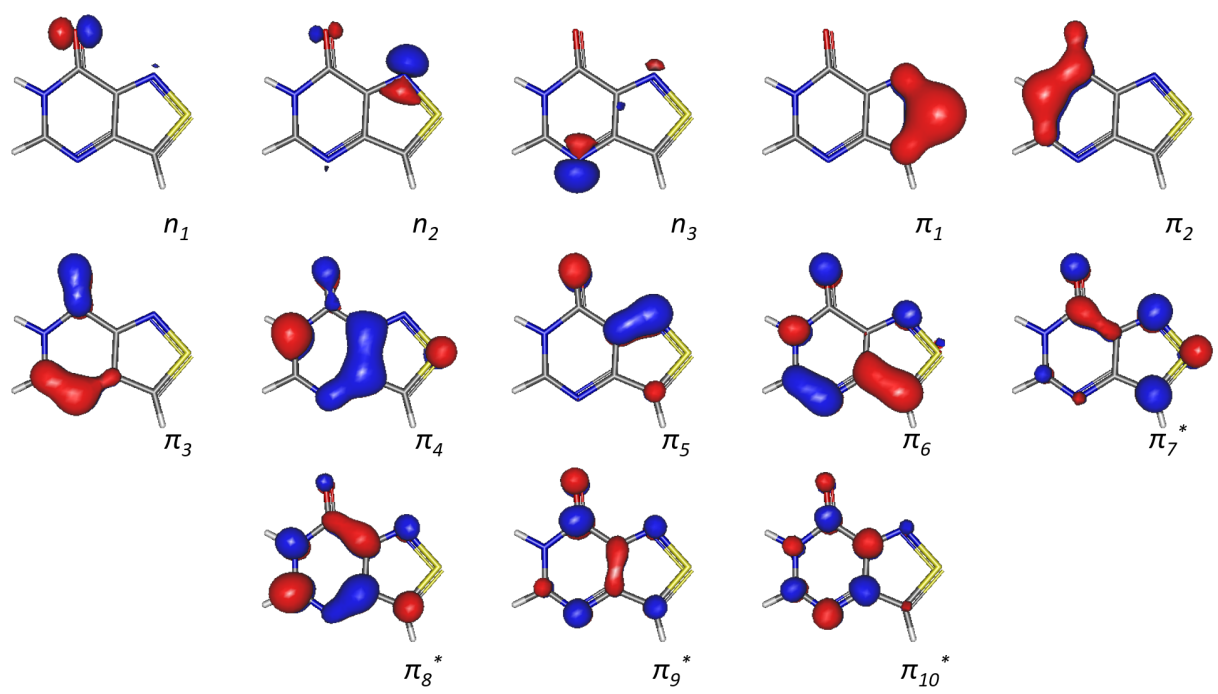

Figura A.4 - Espaço ativo para a molécula ${ }^{\text {tz }} \mathbf{I}$ com 3 orbitais $n$ e 10 orbitais $\pi$, contendo 18 elétrons calculado no nível SA(8)-CASSCF/cc-pVDZ. 

${ }_{\text {Aefnoce }}$ B

\section{Comparação entre as bases atômicas cc-pVDZ e ANO-RCC-VDZP para a molécula 6-selenoguanina}

Tabela B.1 - Comprimentos de ligação $(\AA)$ para o estado fundamental em fase gasosa computada no nível MP2 empregando duas bases diferentes. Os efeitos relativísticos via formalismo de Douglas-Kroll-Hess são incluídos no cálculo com a base ANORCC-VDZP.

\begin{tabular}{ccc}
\hline Comprimento de Ligação & cc-pVDZ & ANO-RCC-VDZP \\
\hline$r\left(\mathrm{~N}_{1} \mathrm{C}_{2}\right)$ & 1.371 & 1.375 \\
$r\left(\mathrm{C}_{2} \mathrm{~N}_{3}\right)$ & 1.315 & 1.322 \\
$r\left(\mathrm{~N}_{3} \mathrm{C}_{4}\right)$ & 1.356 & 1.362 \\
$r\left(\mathrm{C}_{4} \mathrm{C}_{5}\right)$ & 1.403 & 1.410 \\
$r\left(\mathrm{C}_{5} \mathrm{C}_{6}\right)$ & 1.424 & 1.432 \\
$r\left(\mathrm{~N}_{1} \mathrm{C}_{6}\right)$ & 1.404 & 1.406 \\
$r\left(\mathrm{C}_{2} \mathrm{~N}_{10}\right)$ & 1.364 & 1.365 \\
$r\left(\mathrm{C}_{2} \mathrm{Se}_{11}\right)$ & 1.801 & 1.799 \\
\hline
\end{tabular}

Tabela B.2 - Energias de excitação vertical da 6-selenoguanina computada no nível MS(4,3)CASPT2 $(14,10)$ utilizando duas bases atômicas diferentes. Os efeitos relativísticos via formalismo de Douglas-Kroll-Hess são incluídos no cálculo com a base ANORCC-VDZP. Esses cálculos foram realizados utilizando a estrutura do estado fundamental otimizada no nível MP2/ANO-RCC-VDZP.

\begin{tabular}{lccllc}
\hline \multirow{2}{*}{ Natureza } & \multicolumn{2}{c}{ cc-pVDZ } & & \multicolumn{2}{c}{ ANO-RCC-VDZP } \\
\cline { 2 - 3 } \cline { 5 - 6 } & $\Delta E$ & $f$ & & $\Delta E$ & $f$ \\
\hline${ }^{1}\left(n_{S e} \pi_{5}^{*}\right)$ & 2.76 & & & 2.76 & \\
${ }^{1}\left(\pi_{S e} \pi_{5}^{*}\right)$ & 3.45 & 0.472 & & 3.38 & 0.343 \\
${ }^{1}\left(\pi_{S e} \pi_{6}^{*}\right)$ & 4.34 & 0.054 & & 4.63 & 0.044 \\
${ }^{3}\left(\pi_{S e} \pi_{5}^{*}\right)$ & 2.43 & & & 2.46 & \\
${ }^{3}\left(n_{S e} \pi_{5}^{*}\right)$ & 2.66 & & & 2.70 & \\
${ }^{3}\left(\pi_{S e} \pi_{6}^{*}\right)$ & 3.85 & & 3.88 & \\
\hline
\end{tabular}





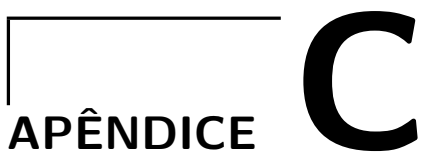

\section{Caminho de menor energia para a 6-selenoguanina}

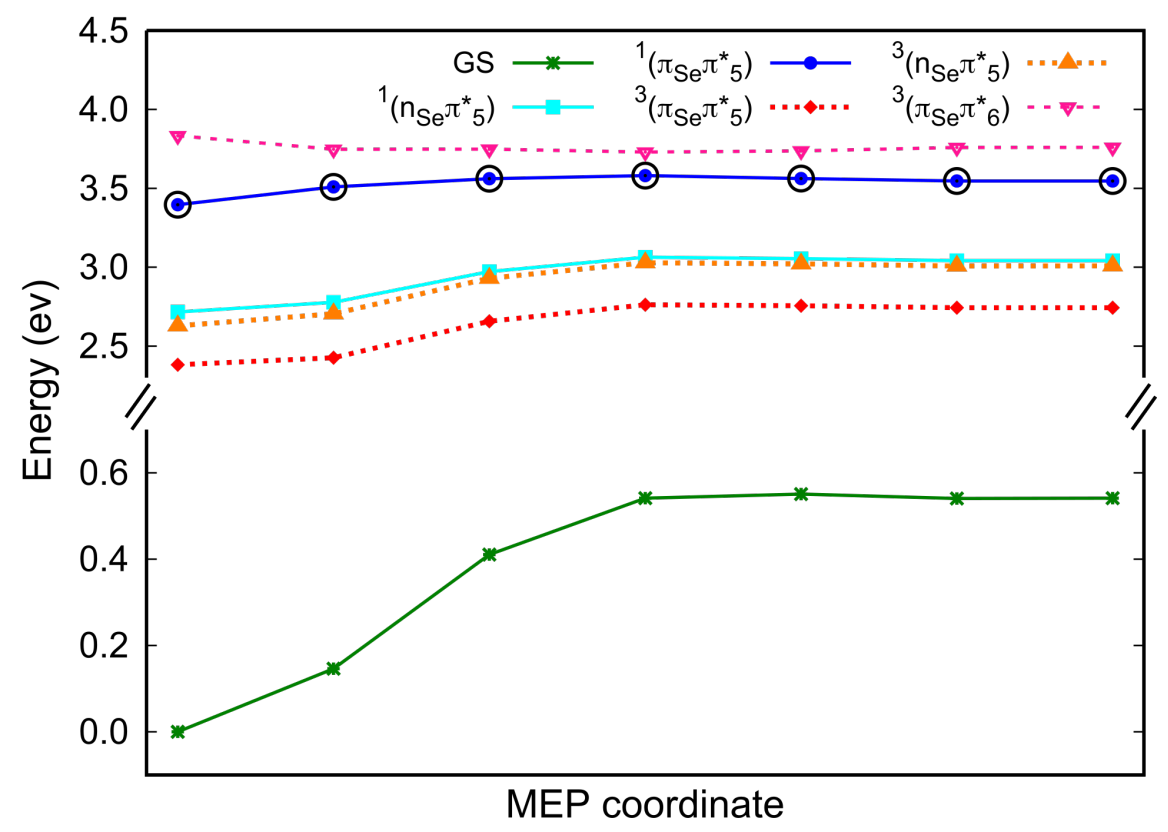

Figura C.1 - Caminho de menor energia (MEP) a partir da região de $\mathrm{FC}$ em direção à estrutura ${ }^{1}\left(\pi_{\mathrm{Se}} \pi_{8}^{*}\right)_{\text {min }}$ para a 6 SeGua calculada no nível SA(4)-CASSCF $(12,10) /$ cc-pVDZ. Em cada estrutura gerada do MEP foi seguida por um cálculo vertical no nível MS(4,3)-CASPT2(14,12)/cc-pVDZ. 

Anexos 



\section{ANEXO}

\section{Publicações em que o texto foi baseado}

1. Valverde, D.; Araújo, A. V.; Borin, A. C.; Canuto, S. Electronic Structure and Absorption Spectra od Fluorescent Nucleoside Analogues. Phys. Chem. Chem. Phys. 19, 29354 (2017).

2. Valverde, D.; Araújo, A. V.; Canuto, S; Borin, A. C. Photophysics of Emissive ${ }^{t z} C$ [Isothiazolo-Cytidine] and ${ }^{t z} U$ [Isothiazolo-Uridine] Pyrimidine Analogues. ChemPhotoChem 3, 916 (2019).

3. Araújo, A. V.; Valverde, D.; Canuto, S; Borin, A. C. Solvation Structures and Deactivation Pathways of Luminescent Isothiazole-Derived Nucleobases: ${ }^{t z} \mathbf{A},{ }^{t z} \mathbf{G}$, and ${ }^{t z} \mathbf{I}$. $J$. Phys. Chem. A 124, 6834 (2020).

4. Fang, Y-G; Valverde, D.; Mai, S.; Canuto, S.; Borin, A. C.; Cui. G.; González, L. Excited-State Properties and Relaxation Pathways of Selenium-Substituted Guanine Nucleobase in Aqueous Solution and DNA Duplex. (Submetido).

5. Valverde, D.; Mai, S.; Canuto, S.; Borin, A. C.; González, L. Nonadiabatic Dinamics Simulations of 6-Selenoguanine in Water. (Em preparação).

6. Valverde, D.; Borin, A. C., Canuto, S. Spectroscopic Properties of 2-Aminopurine in Aprotic and Protic Solvents (Em preparação). 



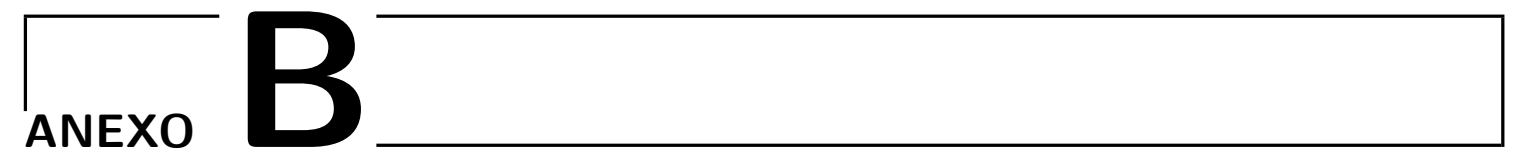

\section{Outras publicações durante o doutorado}

1. Valverde, D.; Ludwig, Z. M.; da Costa, C. R.; Ludwig, V.; Georg, H. C. Zwitterionization of Glycine in Water Environment: Stabilization Mechanism and NMR Spectral Signatures. J. Chem. Phys. 148, 024305 (2018).

2. Ludwig, V.; Ludwig, Z. M.; Valverde, D.; Georg, H. C.; Canuto, S. Free Energy Gradient for Understanding the Stability and Properties of Neutral and Charged L-alanine Molecule in Water. J. Mol. Liq. 319, 114109 (2020).

3. Valverde, D.; Mai, S.; Araújo, A. V.; Canuto, S.; González, L.; Borin, A. C. On the Population of Triplet States of 2-Seleno-Thymine. (Em preparação).

4. Valverde, D.; Castro, H. C.; Canuto. S. Free Energy Gradient for Solvent Effects on Energy Hypersurface. The Reaction $\mathrm{Cl}^{-} \cdots \mathrm{CH}_{3}-\mathrm{Br} \rightarrow \mathrm{Cl}-\mathrm{CH}_{3} \cdots \mathrm{Br}^{-}$. (Em preparação). 



\section{Participações em Eventos}

1. Reunião Anual do NAP-FCx 2018. Photophysics and Photostabilization of a Fluorescent RNA Alphabet. Atibaia, Brasil - 2018. (Encontro)

2. XLIV Congress of Theoretical Chemists of Latin Expression. Free Energy Gradient for Solvent Dffects on Energy Hypersurface. The Reaction $\mathrm{Cl}^{-}{ }^{-} \mathrm{CH}_{3}-\mathrm{Br} \rightarrow \mathrm{Cl}-$ $\mathrm{CH}_{3} \cdots \mathrm{Br}^{-}$. Chile, Santiago, 2018. (Congresso)

3. $10^{\text {th }}$ International Meeting on Photodynamics and Related Aspects. Solvent Effects on the Electronic Structure and Spectroscopic Properties of an Expanded Fluorescent RNA Alphabet. Cartagena, Colômbia - 2018. (Congresso)

4. Encontro de Outono da Sociedade Brasileira de Física. Spectroscopic Properties of 2-Aminopurine in Aprotic and Protic Solvents. Foz do Iguaçu, Brasil - 2018. (Encontro)

5. XIX Simpósio Brasileiro de Química Teórica. Theoretical Investigation of the Emission Spectra and Stokes Shift of Modified Canonical Nucleobases in Gas Phase, 1,4-Dioxane and Water. Águas de Lindóia, Brasil - 2017. (Simpósio)

6. XL Encontro Nacional de Física da Matéria Condensada. Computational ab initio Multiconfigurational study of the Spectroscopic Properties of modified RNA nucleobases in Soluion. Armação de Búzios, Brasil - 2017. (Encontro) Esse trabalho ganhou uma menção honrosa.

7. XV Escola Brasileira de Estrutura Eletrônica. Computational Study of the Photochemical of Modified RNA nucleobases in Medium using Free Energy Gradient and ab initio Multiconfigurational Method. São Bernado do Campo, Brasil - 2016. (Escola) 